\title{
Fatty acid metabolism in the metabolic syndrome : effects of dietary fat quantity and quality
}

Citation for published version (APA):

van Hees, A. M. J. (2011). Fatty acid metabolism in the metabolic syndrome : effects of dietary fat quantity and quality. [Doctoral Thesis, Maastricht University]. Universitaire Pers Maastricht. https://doi.org/10.26481/dis.20111111ah

Document status and date:

Published: 01/01/2011

DOI:

10.26481/dis.20111111ah

Document Version:

Publisher's PDF, also known as Version of record

\section{Please check the document version of this publication:}

- A submitted manuscript is the version of the article upon submission and before peer-review. There can be important differences between the submitted version and the official published version of record. People interested in the research are advised to contact the author for the final version of the publication, or visit the DOI to the publisher's website.

- The final author version and the galley proof are versions of the publication after peer review.

- The final published version features the final layout of the paper including the volume, issue and page numbers.

Link to publication

\footnotetext{
General rights rights.

- You may freely distribute the URL identifying the publication in the public portal. please follow below link for the End User Agreement:

www.umlib.nl/taverne-license

Take down policy

If you believe that this document breaches copyright please contact us at:

repository@maastrichtuniversity.nl

providing details and we will investigate your claim.
}

Copyright and moral rights for the publications made accessible in the public portal are retained by the authors and/or other copyright owners and it is a condition of accessing publications that users recognise and abide by the legal requirements associated with these

- Users may download and print one copy of any publication from the public portal for the purpose of private study or research.

- You may not further distribute the material or use it for any profit-making activity or commercial gain

If the publication is distributed under the terms of Article $25 \mathrm{fa}$ of the Dutch Copyright Act, indicated by the "Taverne" license above, 


\title{
Fatty acid metabolism in the metabolic syndrome
}

\author{
Effects of dietary fat quantity and quality
}




\section{iftín}

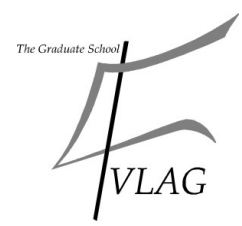

The study presented in this thesis was performed within NUTRIM School for Nutrition, Toxicology and Metabolism which participates in the Graduate School VLAG (Food Technology, Agrobiotechnology, Nutrition and Health Sciences), accredited by the Royal Netherlands Academy of Arts and Sciences.

Cover design: $\quad$ Wouter Eijgelaar and Anneke van Hees

Layout: $\quad$ Anneke van Hees

Printed by: Datawyse / Universitaire Pers Maastricht

(C) Copyright Anneke van Hees, Maastricht 2011

Universitaire Pers Maastricht

ISBN 9789461590886 


\title{
Fatty acid metabolism in the metabolic syndrome \\ Effects of dietary fat quantity and quality
}

\author{
PROEFSCHRIFT \\ ter verkrijging van de graad van doctor \\ aan de Universiteit Maastricht, \\ op gezag van de Rector Magnificus, \\ Prof. mr. G.P.M.F. Mols, \\ volgens het besluit van het College van Decanen, \\ in het openbaar te verdedigen \\ op vrijdag 11 november 2011 om 14.00 uur
}

door

Anna Maria Johanna van Hees

geboren te Boxmeer op 6 oktober 1981

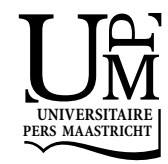




\section{Promotores}

Prof. dr. Ellen E. Blaak

Prof. dr. Wim H.M. Saris

\section{Beoordelingscommissie}

Prof. dr. Patrick A.J. Schrauwen (voorzitter)

Dr. Bas Havekes

Prof. dr. Martine Laville (Centre Hospitalier Lyon Sud, Pierre Bénite, France)

Dr. Marco R. Mensink (Wageningen University)

Prof. dr. Ger J. van der Vusse

The research described in this thesis was mainly performed as part of the LIPGENE project, an European Union Sixth Framework Integrated Programme funded by the European Community (FOOD-CT-2003-505944).

Financial support by the Netherlands Association for the Study of Obesity (NASO) for the publication of this thesis is gratefully acknowledged.

Additional support granted by Nutricia Advanced Medical Nutrition, Danone Research - Centre for Specialised Nutrition is gratefully appreciated. 


\section{Contents}

\section{Chapter 1}

General introduction

\section{Chapter 2}

Determinants of diet-induced changes in insulin sensitivity among subjects

with the metabolic syndrome: the Lipgene study

\section{Chapter 3}

Skeletal muscle fatty acid handling in insulin resistant men

\section{Chapter 4}

Effects of dietary fat modification on skeletal muscle fatty acid handling in the metabolic syndrome

\section{Chapter 5}

Adipose triglyceride lipase and hormone-sensitive lipase protein expression in subcutaneous adipose tissue are decreased after an isoenergetic low-fat high-complex carbohydrate diet in the metabolic syndrome

\section{Chapter 6}

Fasting and postprandial remnant-like particle cholesterol concentrations in obese participants are associated with plasma triglycerides, insulin resistance, and body fat distribution

\section{Chapter 7}

General discussion

Summary

Samenvatting

Dankwoord 



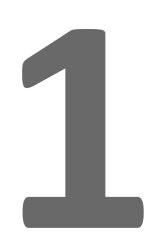

General introduction 
The metabolic syndrome (MetS) represents a clustering of risk factors for the development of type 2 diabetes and cardiovascular disease (1). During the last two decades the number of people with the MetS worldwide is increasing rapidly together with the global epidemic of obesity and type 2 diabetes mellitus $(1,2)$. According to the latest estimates from the World Health Organization (WHO), by 2015 approximately 2.3 billion adults will have overweight and 700 million will have obesity (3), and the number of people worldwide suffering from diabetes is estimated to increase from about 171 million in 2000 to about 366 million in 2030 (4). Moreover, cardiovascular disease is the number one cause for death worldwide (representing $30 \%$ of all deaths), and it is estimated that by 2030 almost 24 million people will die from cardiovascular disease (5). Taken together, these data highlight the need to examine the pathophysiology of the MetS.

Among various definitions and descriptions of the MetS, the condition is mainly characterised by central obesity, hyperglycaemia, insulin resistance, increased plasma triglycerides and/or decreased plasma high-density lipoprotein (HDL)cholesterol (i.e. dyslipidaemia) and hypertension. These metabolic disturbances are all interrelated and have shown to cluster more frequently than only by chance (6). Insulin resistance and central obesity have each been considered to be the primary factors underlying the MetS, although the underlying biological mechanisms are complex and not fully understood (7). Disturbances in fatty acid metabolism play an important role in the MetS. An expanded adipose tissue mass or an impaired buffering capacity of the adipose tissue may result in an increased supply of lipids (i.e. lipid overflow) to non-adipose tissues such as skeletal muscle and liver, resulting in excessive fat uptake and storage $(8,9)$. Ectopic fat disposition, in particular the accumulation of lipid metabolites, can reduce insulin action in skeletal muscle by interfering with insulin signalling and inducing inflammatory pathways (10-12). Skeletal muscle is the most abundant insulin-sensitive tissue, comprising up to $40 \%$ of total body mass and being responsible for almost $80 \%$ of insulinstimulated glucose disposal (13), indicating the importance of skeletal muscle fatty acid metabolism in the development of the MetS.

Both genetic as well as environmental factors like a high-fat diet and a sedentary lifestyle play a role in the aetiology of the MetS and it has been shown that diet and lifestyle interventions can be at least as effective as pharmacological approaches in the prevention of the type 2 diabetes mellitus (14). In view of dietary recommendations for preventing or treating type 2 diabetes mellitus and the MetS, there is a general consensus that the saturated fat content of the diet has to be reduced, preferably to below $10 \%$ of total daily energy intake $(15,16)$. A key question, however, remains whether saturated fat should be replaced by carbohydrates or unsaturated fat. Reducing the intake of saturated fat may improve lipid metabolism and insulin action in the MetS, possibly through effects on lipid 
overflow from the adipose tissue and effects on skeletal muscle fatty acid handling, which will be investigated in the current thesis.

The first part of this introductory chapter will provide a brief background on the Mets, describing the history, the use of different definitions and their appropriateness, and the aetiology. The second part will describe fatty acid metabolism in the healthy state and the role of disturbances in fatty acid metabolism in the development of obesity, insulin resistance and the MetS, with a primary focus on the role of impairments in skeletal muscle metabolism. The role of dietary fat in the treatment and/or prevention of the MetS will be described in the third part. Finally, an overview of the studies described in this thesis will be provided.

\section{THE METABOLIC SYNDROME}

The MetS is a heterogeneous condition that is characterised by a clustering of risk factors for cardiovascular disease and type 2 diabetes, including central (abdominal) obesity, hyperglycaemia, hyperinsulinaemia, insulin resistance, dyslipidaemia and hypertension $(1,17)$. In addition, several other manifestations may be present that are not included in the definitions of the MetS, such as chronic low-grade inflammation, a pro-thrombotic state, hyperuricaemia, endothelial dysfunction and disturbances in the pituitary-adrenal axis (17). There is no doubt that lifestyle factors such as cigarette smoking, physical inactivity and an atherogenic diet are related to several components of the MetS (1).

\section{History}

A clustering of metabolic abnormalities in cardiovascular disease was already described in 1923 by the Swedish physician Kylin as the 'hypertensionhyperglycaemia-hyperuricaemia syndrome' (18) and in 1947, upper body obesity was recognised as a potential underlying risk factor for these metabolic abnormalities (19). However, it is only 2 decades ago that the clustering of cardiovascular risk factors gained more attention when Reaven introduced the concept of 'Syndrome X' during his Banting lecture in 1988 (20). Syndrome X was described as a combination of insulin resistance, hyperinsulinaemia, hyperglycaemia, dyslipidaemia and arterial hypertension. Thereafter, many terms have been used to describe the condition, such as the insulin resistance syndrome, the metabolic syndrome, the deadly quartet, the pluri-metabolic syndrome and the dysmetabolic syndrome. Nowadays the term 'metabolic syndrome' is most commonly used in literature. 

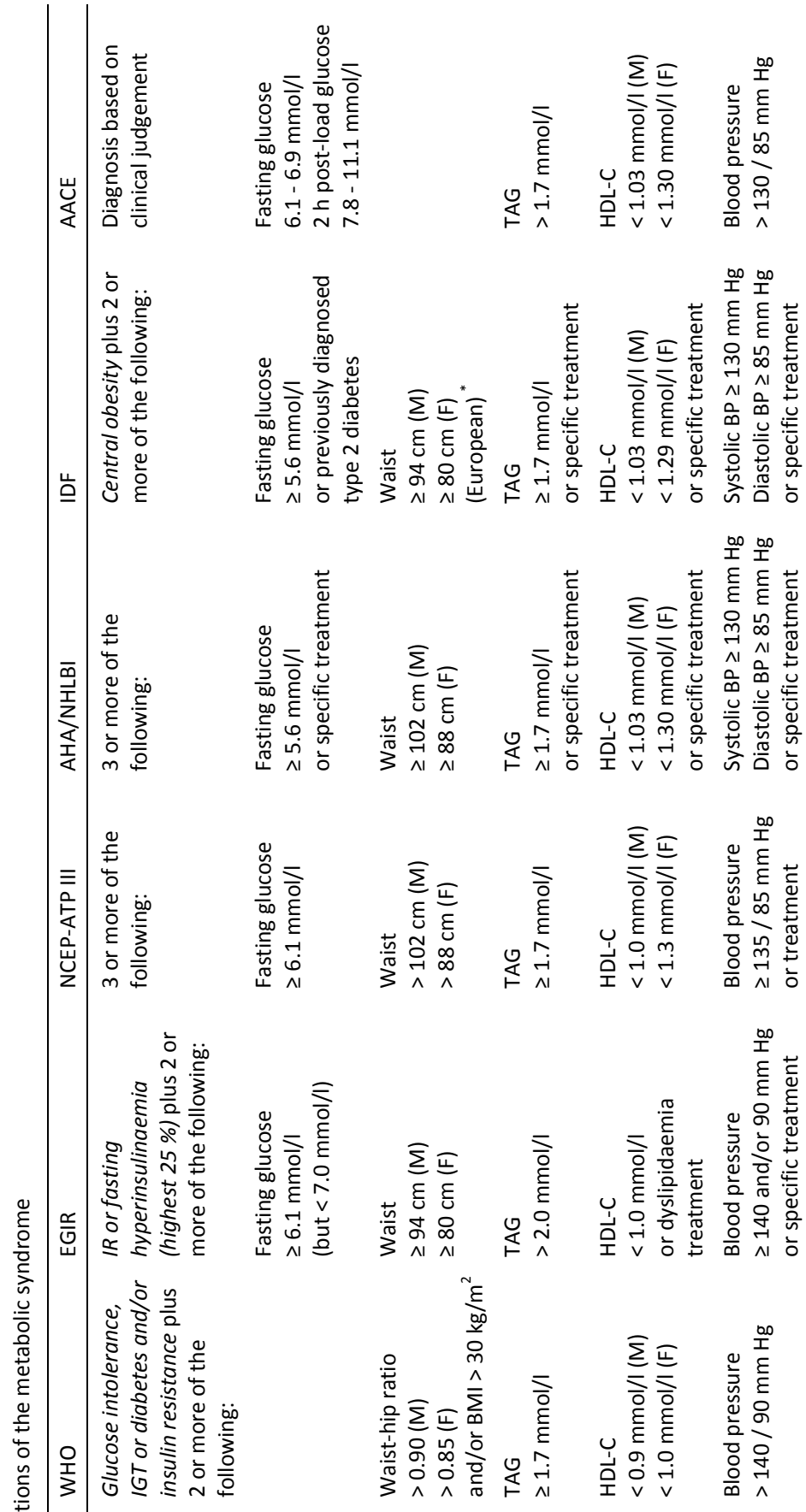

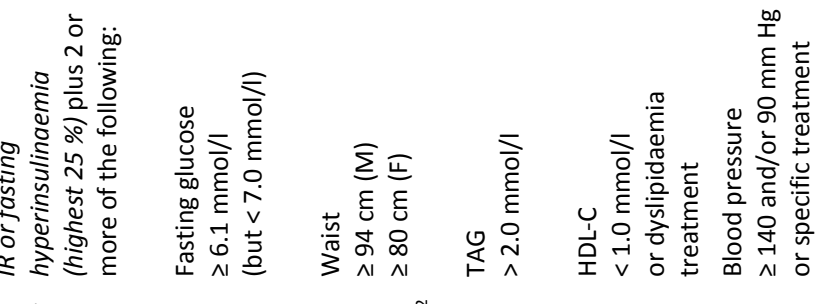

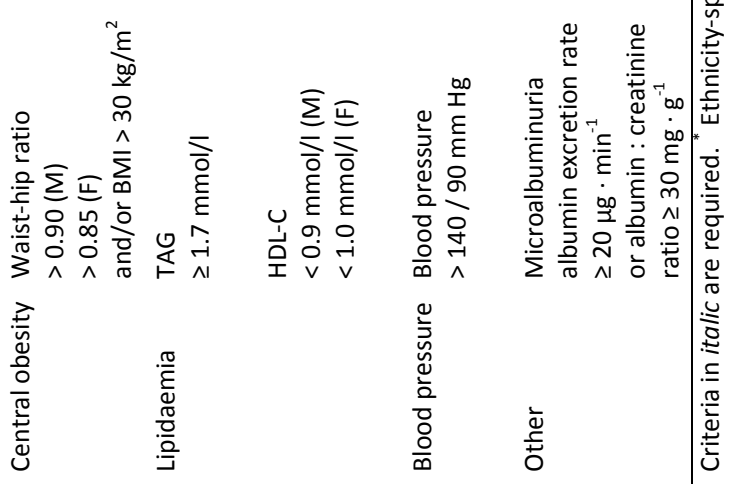




\section{Definitions}

Although the MetS was accepted as a concept, there was no general definition available and different cut-off values and characteristics were used in literature to describe the syndrome. The first attempt to develop an international definition of the MetS was made by the WHO in 1998, and currently there are at least 5 definitions from different organisations and expert groups (Table 1.1) $(21,22)$ : the WHO in 1998 (revised in 1999) (23); the European Group for Study of Insulin resistance (EGIR) in 1999 (24); and the National Cholesterol Education Program Adult Treatment Expert Panel III (NCEP-ATP III) in 2001 (25,26). The most recent definitions are developed in 2005 by the International Diabetes Federation (IDF) Consensus Panel $(17,27)$ and the American Heart Association/National Heart, Lung, and Blood Institute (AHA/NHLBI) (28,29). Furthermore, the American Association of Clinical Endocrinologists (AACE) released a position statement on the insulin resistance syndrome, rather than a precise definition, allowing the diagnosis to rely on clinical judgement (30). In addition, Lemieux et al introduced the concept of 'hypertriglyceridaemic waist', an inexpensive tool to identify men characterised by the MetS and at high risk for cardiovascular disease (31).

The original description of the MetS was based on the pathophysiology of insulin resistance (20), and this concept was also used in the definitions of the WHO, the EGIR and in the position statement of the AACE. In the new IDF definition $(17,27)$, both insulin resistance and central obesity are acknowledged as important causative factors in the pathogenesis of the MetS. Moreover, ethnic-specific thresholds for waist circumference are described in this IDF definition, making it suitable for global application.

\section{Clinical use and predictability}

The MetS is a widely used concept in research and clinical practice nowadays, but the added value of defining the MetS and issues about the pathophysiology of the syndrome remain subject of debate (32). In a joint statement by the American Diabetes Association and the European Association for the Study of Diabetes in 2005 it was concluded that "Until much needed research is completed, clinicians should evaluate and treat all cardiovascular disease risk factors without regard to whether a patient meets the criteria for diagnosis of the metabolic syndrome." (32), and this statement is shared with others $(33,34)$. Major criticism include that 1$)$ there are many definitions with different cut-off points or even different components; 2) the underlying pathophysiology is unclear; 3) the predictability for cardiovascular disease and type 2 diabetes does not have added value above the already known risk factors $(21,32,35)$. However, in general it has been shown that the MetS is associated with an approximately 2-fold increased risk for developing cardiovascular disease and a 5-fold increased risk for incident type 2 diabetes (36). 
Although the definition of the MetS is difficult to develop and research is needed to define the pathophysiology of the syndrome, there are benefits in diagnosing the syndrome. Diagnosis is helpful in initiating awareness of health risk, thereby stimulating lifestyle modification and weight loss $(21,36,37)$. Moreover, the concept of the MetS stimulated the research for underlying mechanisms of diabetes and cardiovascular disease, and has drawn attention to the fact that patients diagnosed with diabetes, hypertension or dyslipidaemia should be investigated (and treated) for other abnormalities as well (21).

\section{Aetiology}

The aetiology of the MetS is complex and not fully understood, as reflected by the difficulties in reaching consensus about one general definition of the MetS. The metabolic disturbances characterising the MetS are all interrelated and have been shown to cluster more frequently than only by chance (6), indicating that there may not be one common denominator. Currently, however, central obesity and/or (skeletal muscle) insulin resistance are considered to be the primary factors underlying the MetS. The role of both obesity and insulin resistance in the aetiology of the MetS will be described in more detail in the next chapters.

\section{FAT METABOLISM}

Adipose tissue, skeletal muscle and the liver are the major organs involved in substrate metabolism and research over the past decades revealed the presence of a strong inter-organ relationship in substrate metabolism. Therefore, functional disturbances in either of these organs can theoretically cause or contribute to the development of insulin resistance and dyslipidaemia as seen in the MetS $(8,9)$.

\section{Inter-organ relationships in substrate metabolism in the MetS}

The adipose tissue is an important organ in lipid metabolism by buffering (in particular) the postprandial dietary fatty acids from the circulation and preventing an excessive supply of lipids to non-adipose tissues such as skeletal muscle, liver, heart and pancreas. An increased supply of lipids (i.e. lipid overflow) into the circulation due to excess dietary intake is associated with many aspects of the MetS such as insulin resistance, atherosclerosis and hepatic steatosis (38), leading to the hypothesis that the adipose tissue plays a central role in the development of insulin resistance and the MetS (Figure 1.1). During conditions of chronic excessive energy intake (in particular by means of dietary fat) and/or a sedentary lifestyle, the adipose tissue mass increases and its buffering capacity becomes limited, leading to 
increased circulating free fatty acid (FFA) concentrations. An increased supply of lipids to non-adipose tissues may result in lipid accumulation in these tissues when the uptake of fatty acids exceeds the capacity to oxidise fat. This ectopic fat accumulation, in particular in skeletal muscle, liver and pancreas, is associated with the development of insulin resistance and/or impaired insulin secretion in these tissues. More specifically, increased intramyocellular lipid accumulation is associated with disturbances in insulin signalling and impaired glucose transporter 4 (GLUT-4) mediated glucose uptake, whereas hepatic lipid accumulation results in impaired insulin clearance from the circulation and decreased suppression of endogenous glucose production, together resulting in increased circulating glucose concentrations and hyperinsulinaemia. In addition, lipid overflow towards the liver stimulates the endogenous formation and secretion of triacylglycerol (TAG), leading to increased concentrations of very low-density lipoprotein (VLDL)-TAG into the circulation. This contributes to dyslipidaemia in the MetS by increasing total circulating TAG concentrations and decreasing HDL-cholesterol concentrations via the exchange of TAG for cholesterol (39). In addition, skeletal muscle insulin resistance may promote dyslipidaemia by diverting carbohydrates away from muscle glycogen storage towards increased hepatic glucose clearance and subsequent de novo lipogenesis (7). Ectopic fat disposition in the pancreas may result in decreased glucose-stimulated insulin secretion by the beta-cell, but this effect may require a long period before manifestation since obesity and insulin resistance are most often associated with increased rather than decreased insulin concentrations in the early development of type 2 diabetes mellitus (40).

The increased adipose tissue mass and higher plasma FFA and glucose concentrations are associated with an increased inflammatory response of the adipose tissue and an altered production of adipokines. This can further enhance lipid overflow and induce insulin resistance via modulation of skeletal muscle lipid metabolism or via direct interference with insulin signalling.

Not only an increased supply of lipids to the skeletal muscle, but also impairments in the regulation of fatty acid uptake, storage and/or oxidation can create a dysbalance in fatty acid metabolism and induce skeletal muscle insulin resistance. Therefore, intrinsic disturbances in skeletal muscle fatty acid handling are considered to play a central role in the pathogenesis of the MetS and type 2 diabetes as well, which will be described in more detail in the next chapter. In short, these intrinsic disturbances include a metabolic inflexibility to switch between fat and glucose oxidation under different metabolic conditions $(41,42)$ and decreased muscle oxidative capacity, partly related to reduced mitochondrial content and/or function $(12,43)$.

For a better understanding of these complex inter-organ relationships in substrate metabolism and their relationship with obesity, insulin resistance and the MetS, the next paragraphs will describe in more detail the role of adipose tissue function in 


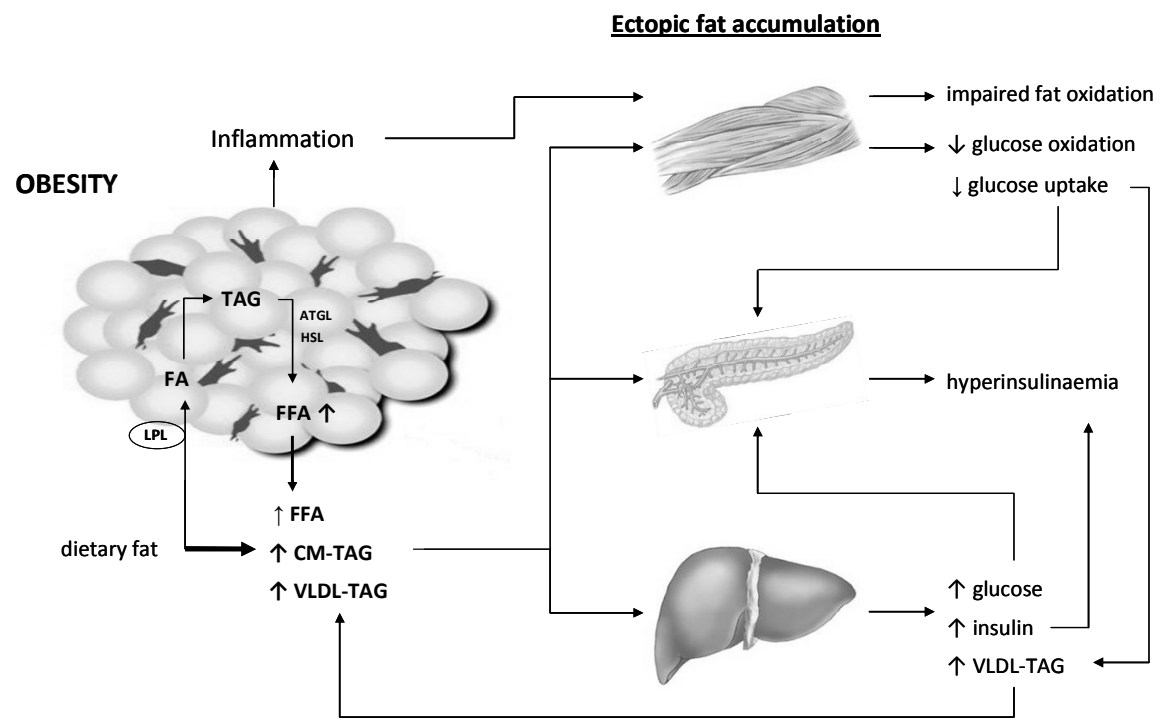

Figure 1.1 Lipid overflow from an expanded adipose tissue mass and/or intrinsic disturbances in substrate metabolism in skeletal muscle, pancreas and liver creates a dysbalance between fatty acid uptake and oxidation and subsequent ectopic fat accumulation, which is associated with insulin resistance and impaired insulin secretion. An increased supply of FFA to the liver stimulates the production and secretion of VLDL-TAG, thereby contributing to hyperlipidaemia. Skeletal muscle insulin resistance not only promotes hyperglycaemia, but may also further enhance hepatic steatosis and VLDLTAG output by diverting glucose away from muscle glycogen storage towards increased hepatic glucose clearance and de novo lipogenesis. These processes will further enhance plasma lipid and glucose concentrations and create a vicious circle. Moreover, enlarged and relatively hypoperfused adipocytes may produce and secrete inflammatory adipokines into the circulation that can interfere with fatty acid metabolism in skeletal muscle. (adapted from Goossens, GH. Physiol Behav 2008;94:206:18).

whole body fatty acid metabolism and the possible consequences of dysfunctional adipose tissue, as well as the role of hepatic lipid metabolism in the development of insulin resistance and the MetS. The relationship between skeletal muscle substrate metabolism, insulin resistance and the MetS will be described in more detail in the next chapter.

\section{Adipose tissue function and dysfunction}

The vast majority of TAG in the body is stored in the adipose tissue (>95\%), with only smaller amounts available in other tissues like skeletal muscle and liver.

\section{Lipid buffering capacity of adipose tissue}

The adipose tissue is a dynamic tissue with an important role in regulating plasma lipid concentrations, both during fasting and in the postprandial period after meal consumption (9). The adipose tissue exerts its lipid buffering capacity mainly in the postprandial period by suppressing the release of FFA into the circulation, increasing 
the clearance of circulating TAG and suppressing the endogenous production and secretion of TAG (9).

The major source of FFA in the circulation is the adipose tissue, which mobilises fatty acids via a catabolic process named endogenous lipolysis. In human adipose tissue, the regulation of lipolysis depends on the balance between lipolytic hormones (catecholamines) and anti-lipolytic hormones (insulin). Upon stimulation, adipose triglyceride lipase (ATGL) is the main enzyme responsible for the hydrolysis of TAG into diacylglycerol (DAG), whereas hormone-sensitive lipase (HSL) is mainly responsible for the subsequent hydrolysis of DAG into monoacylglycerol. Monoacylglycerol lipase then completes the last step of TAG hydrolysis by converting monoacylglycerol into glycerol. During each step of the process, one fatty acid is liberated that can either be released into the circulation, or be used for re-esterification back to TAG. It has been shown that ATGL and HSL are responsible for over $95 \%$ of total TAG hydrolysis in mice (44), but also co-factors like the lipid droplet-covering proteins perilipin (PLIN1) and comparative gene identification 58 (CGI-58) may play a critical role in the regulation of these lipolytic enzymes $(38,45,46)$. Regulation of the lipolytic pathway in adipose tissue is complex and multifactorial (for excellent reviews see $(38,45,46)$ ).

Lipoprotein lipase (LPL), on the other hand, is the rate-limiting enzyme hydrolysing circulating TAG and is thus responsible for extracellular lipolysis and the clearance of circulating dietary TAG (chylomicron-TAG) and VLDL-TAG from the circulation. LPL is bound to the luminal side of the capillary endothelium and its regulation is tissuespecific; in adipose tissue the major activator of LPL activity is insulin (47). The resulting fatty acids from extracellular lipolysis can be transported into the adipose tissue and used for re-esterification to TAG, but a significant proportion of these fatty acids can also spillover into the circulation and enter the plasma FFA pool (48). This process of fatty acid trapping in the adipose tissue has shown to be dependent on the concentration gradient of fatty acids across the membrane of the adipocyte and on stimulation of the re-esterification pathway $(9,48,49)$. As a result of high enzyme activity of ATGL and HSL in the fasting state, the intracellular fatty acid concentrations rise and the concentration gradient will not be in favour of fatty acid uptake, resulting in decreased uptake of LPL-derived fatty acids. In this respect, it has been shown recently that in healthy men, the spillover fraction of VLDL-TAG was approximately $70 \%$ in the fasting state (50). The opposite occurs in the postprandial state, when endogenous lipolysis is suppressed by insulin and the reesterification pathway is stimulated (9). The concentration gradient is then in favour of fatty acid uptake, and a much larger proportion of liberated fatty acids is taken up by the adipose tissue $(49,51)$. In healthy men, the spillover of fatty acids derived from chylomicrons has shown to be variable with a minimum of $20 \%$ spillover, whereas the spillover of fatty acids derived from VLDL was approximately zero in the postprandial state (50). 
Adipose tissue dysfunction and insulin resistance; two hypotheses

Two main hypotheses describe the possible link between dysfunctional adipose tissue and whole body insulin resistance; the lipid overflow hypothesis and the endocrine hypothesis.

\section{1) The lipid overflow hypothesis}

The lipid overflow hypothesis describes the relationship between dysfunctional adipose tissue (i.e. reduced buffering capacity), increased lipid accumulation in nonadipose tissues and the development of insulin resistance in these tissues (Figure 1.1). As described above, the adipose tissue has a crucial part in regulating plasma lipid concentrations, especially in the postprandial state, and the buffering capacity of adipose tissue refers to its ability to suppress the release of fatty acids into the circulation and to increase the clearance of circulating chylomicron- and VLDL-TAG (9). During periods of chronic excessive energy intake, adipocytes become overloaded with TAG and the adipose tissue will expand to accommodate extra fatty acids. Failure of the adipose tissue to differentiate new adipocytes upon increased demand for fatty acid storage results in enlargement of existing adipocytes, that are less sensitive to the action of insulin and are associated with impairments in buffering capacity (52).

The buffering of fatty acids is mainly regulated by insulin-mediated inhibition of endogenous lipolysis and by LPL-activating effects of insulin at the site of adipose tissue. Therefore, it has been argued that resistance to the effects of insulin in the adipose tissue may largely explain the increased flux of FFA in the circulation that is often observed in insulin resistant conditions. Indeed, insulin-mediated suppression of fatty acid release has shown to be blunted in obesity, impaired glucose tolerance and type 2 diabetes (53-55), and also TAG clearance was found to be impaired in obesity, insulin resistance and type 2 diabetes, due to reduced stimulating effects of insulin on LPL-activity $(53,56-58)$. Moreover, there are indications that the process of fatty acid trapping in the adipose tissue is less efficient during hyperinsulinaemia in obese type 2 diabetes patients compared to non-obese healthy controls (51), resulting in impaired reduction of fatty acid spillover in the postprandial period.

In contrast, other studies show that hyperinsulinaemia in obesity and insulin resistance is inversely related to HSL and ATGL expression in adipose tissue and to whole-body FFA rate of appearance when values are expressed per unit fat mass (59-61), suggesting decreased lipolysis in the obese insulin resistant state. These findings implicate that the increased lipid flux that is often observed in obesity may be largely explained by a mass effect of expanding adipose tissue and that hyperinsulinaemia in obesity occurs (partly) as a compensation to prevent further increase in plasma lipid concentrations and worsening of the insulin resistant state $(59,60,62)$. 
Additional research is needed on the regulation of fatty acid buffering in the adipose tissue and the effects of insulin on endogenous lipolysis, both under healthy conditions and in different stages of insulin resistance.

\section{2) The endocrine hypothesis}

Obesity, insulin resistance and the MetS are often characterised by a state of chronic low-grade inflammation $(1,63)$, which appears to be initiated mainly in the adipose tissue. Recent years of research have shown that the adipose tissue is not only a lipid buffering organ, but also actively secretes a variety of signal molecules (adipokines) like cytokines, chemokines and hormones, that can act locally (autocrine and/or paracrine) or can be secreted into the circulation (endocrine) to signal to other tissues and modulate their metabolism (64). As the adipose tissue expands during the progression to obesity, adipocytes become enlarged and relatively hypoperfused (65), both characteristics being related to the development of adipose tissue dysfunction and eliciting an inflammatory response. Inflammation may induce insulin resistance via modulation of skeletal muscle lipid metabolism and/or via direct interference with insulin signalling, leading to the endocrine hypothesis stating that obesity promotes the development of insulin resistance by altering the production of adipokines. This paragraph will briefly describe recent insights in the relationship between dysfunctional adipokine secretion, skeletal muscle fatty acid metabolism and insulin resistance.

Among the various adipokines that are characterised over the last years, some have the potential to increase insulin sensitivity (adiponectin, leptin) whereas other can impair insulin sensitivity (tumor necrosis factor- $\alpha$ (TNF- $\alpha$ )) or have less unambiguous effects (resistin, interleukin (IL)-6). Adiponectin and leptin may stimulate skeletal muscle fat oxidation and decrease intramyocellular lipid accumulation in isolated rodent and human muscle, which has been hypothesised to explain, in large part, their insulin-sensitising effects (66). Plasma levels of adiponectin are decreased in human obesity, insulin resistance and type 2 diabetes $(67,68)$ and are inversely associated with visceral fat mass (69). Administration of adiponectin stimulates skeletal muscle fatty acid oxidation and glucose uptake in $\mathrm{C} 2 \mathrm{C} 12$ myotubes and rat muscle strips $(70,71)$ and mitochondrial biogenesis in human myotubes (72). In conjunction with decreased plasma concentrations of adiponectin, decreased adiponectin sensitivity may also be present (66), as studies using human muscle strips and myotubes have demonstrated an impaired ability of adiponectin to stimulate fatty acid oxidation in obese and type 2 diabetic individuals $(73,74)$. However, underlying mechanisms for these observations are far from clear and need further investigation.

Leptin plays an important role in the regulation of body weight control by centrally controlling food intake and energy expenditure, but it also interferes with peripheral tissues such as skeletal muscle. Leptin affects lipid metabolism in skeletal 
muscle by partitioning fatty acids towards oxidation and away from storage after intravenous leptin injection in rats or treatment of isolated mouse muscle $(75,76)$, enhancing intramyocellular TAG (IMTG) hydrolysis at rest and during contraction and increasing fatty acid oxidation during contraction in isolated rat muscle after in vivo treatment with leptin (77). These processes all contribute to the prevention of excessive lipid accumulation. Moreover, leptin stimulates glucose uptake and oxidation in rat muscle $(78,79)$. Despite the insulin-sensitising effects of leptin, obese and insulin resistant conditions are associated with increased plasma leptin levels (80-82), indicating a state of central and peripheral leptin resistance. Indeed, leptin stimulates fatty acid oxidation in isolated skeletal muscle of lean, but not obese individuals (83).

Pro-inflammatory adipo(cyto)kines may directly interfere with insulin signalling in skeletal muscle, but may also contribute to the development of insulin resistance via effects on fatty acid metabolism and the promotion of ectopic fat accumulation (84). Plasma levels of TNF- $\alpha$ are increased in the obese insulin resistant state, most likely due to increased expression levels of TNF- $\alpha$ in human and rodent adipose tissue and skeletal muscle (85-87). TNF- $\alpha$ impairs GLUT-4 translocation and glucose uptake in skeletal muscle, although findings are inconsistent $(84,88)$. The possible effects of TNF- $\alpha$ on skeletal muscle fatty acid metabolism are largely unknown. One study in isolated rat soleus muscle reported no effects of TNF- $\alpha$ on skeletal muscle fatty acid uptake, oxidation and IMTG accumulation, but an increase in fatty acid esterification into the DAG pool (89). IL-6 is produced by human adipose tissue and skeletal muscle and its plasma concentrations are elevated in the obese insulin resistant state $(86,90,91)$, but the relationship of IL-6 with insulin resistance is controversial (90). Acute increases in plasma IL-6 concentrations do not impair glucose uptake in healthy subjects (92) and increased IL-6 production by skeletal muscle during exercise may enhance glucose production and disposal (93). On the other hand, IL-6 may inhibit adipocyte differentiation and increase plasma FFA levels via increased lipolysis in human $(94,95)$ and blunt the insulin-mediated suppression of fat oxidation in isolated rat soleus muscle (89).

Controversy exists about the role of resistin in the pathogenesis of insulin resistance. Some studies in human report a positive link between plasma resistin levels and insulin resistance (96), whereas others report no link or only a weak link $(97,98)$. Resistin may impair glucose uptake in isolated rat skeletal muscle $(99)$, but the role of resistin in skeletal muscle substrate metabolism and the pathogenesis of insulin resistance is far from clear and needs further investigation.

Given the above, disturbances in adipokine production and secretion may contribute to the pathogenesis of insulin resistance, at least partly via modulation of skeletal muscle substrate metabolism, but underlying mechanisms explaining this relationship are complex and poorly understood. Moreover, adipokines are 
generally studied in isolation, whereas the interaction amongst adipokines is least as important and requires more attention in future research (84).

\section{Hepatic fatty acid metabolism}

The majority of TAG in the circulation is transported in VLDL and chylomicrons (together called the TAG-rich lipoproteins). The liver produces VLDL particles containing TAG, free cholesterol, esterified cholesterol, phospholipids, protein and one molecule of apolipoprotein B (ApoB100), whereas chylomicrons are synthesised exclusively in the intestine to transport dietary fat into the circulation and contain one molecule of ApoB48 instead of ApoB100 (100). The fatty acids that are used for VLDL synthesis originate from several endogenous sources, being mainly the circulating FFA pool, lipoprotein remnants that are cleared by the liver, intracellular lipids and de novo lipogenesis $(101,102)$. The total flux of lipids to the liver is an important determinant of hepatic VLDL production and secretion, and can be suppressed by insulin (102-104). In the MetS, it is likely that an increased flux of lipids to the liver as a result of dysfunctional adipose tissue may both stimulate hepatic fat accumulation, associated with hepatic insulin resistance and increase the production of VLDL. Hepatic insulin resistance may further increase circulating VLDLTAG concentrations due to diminished insulin-mediated suppression of VLDL production by the liver (105). Together, this may result in overproduction and secretion of VLDL-TAG into the circulation and contribute to dyslipidaemia in the MetS. Moreover, as VLDL- and chylomicron-TAG compete for the same clearance mechanism, increased VLDL-TAG in the fasting state may result in delayed clearance of TAG-rich lipoproteins in the postprandial state, thereby worsening the hypertriglyceridaemic state. Of interest, it has been shown that circulating levels of lipoprotein remnants are increased in visceral obesity, insulin resistance and type 2 diabetes (106-108), which can be largely explained by impaired hepatic clearance of these particles $(108,109)$.

\section{SKELETAL MUSCLE FATTY ACID METABOLISM}

Carbohydrates and fatty acids are the two main substrates in the body available for energy. Under resting conditions and during low-intensity exercise, fatty acids derived from the adipose tissue are the predominant fuel used by skeletal muscle and glucose is saved for glucose-dependent organs such as the brain. After meal ingestion, glucose becomes the major fuel for energy and fatty acids are stored as TAG, mainly in adipose tissue. The ability of skeletal muscle to increase fat oxidation upon increased fatty acid availability and to switch between fat and glucose oxidation under different conditions, such as the fasting-to-fed state or exercise, has 
been termed metabolic flexibility. Disturbances in metabolic flexibility are thought to play an important role in the development of skeletal muscle insulin resistance $(41,42)$.

This chapter describes skeletal muscle fatty acid metabolism in the healthy state and how disturbances in skeletal muscle fatty acid metabolism are thought to play an important role in the aetiology of insulin resistance and the MetS.

\section{Transport of fatty acids}

Fatty acids are not soluble in water and have to be transported through the circulation bound to albumin (called FFA or non-esterified fatty acids), or esterified as a component of TAG, phospholipids and esterified cholesterol. Although esterified fatty acids in VLDL and chylomicrons comprise the largest part of total fatty acids in the circulation (>90\%), the high plasma turnover of FFA has the potential to supply large amounts of energy to tissues (47).

\section{Uptake of fatty acids by skeletal muscle}

The fatty acids that are liberated after LPL-mediated lipolysis and those from the plasma FFA pool can be taken up in skeletal muscle via passive diffusion, depending on the concentration gradient over the muscle membrane, and via membraneassociated carrier proteins such as fatty acid translocase protein (FAT/CD36), plasma membrane bound fatty acid binding protein (FABPpm) and a family of fatty acid transport proteins (FATP1-6) $(110,111)$. Of these transporter proteins, CD36 has been the best characterised (47). Studies in mice have shown that CD36 deficiency significantly impairs fatty acid uptake, whereas CD36 over-expression in muscle was associated with reduced plasma FFA and TAG concentrations $(112,113)$. In human it has been demonstrated that muscle CD36 protein expression is upregulated during insulin-stimulated conditions (114).

The contribution of TAG-derived fatty acids to skeletal muscle fatty acid uptake and oxidation is not fully understood, but is thought to be at least equally important as plasma FFA $(115,116)$. In the postprandial state, both VLDL and chylomicrons are present in the circulation and these particles compete for LPL-mediated hydrolysis in the capillary bed of skeletal muscle. Despite the observation that VLDL make a large contribution to circulating TAG, even in the postprandial phase $(117,118)$, it has been shown repeatedly that LPL prefers chylomicron above VLDL for hydrolysis of TAG (119-121). The uptake of TAG-derived fatty acids after hydrolysis is thought to be highly efficient in skeletal muscle when compared to adipose tissue $(53,115,120)$, and this could be explained by a concentration gradient across the muscle membrane which is highly in favour of fatty acid uptake. However, others suggest that there is also release (spillover) of TAG-derived fatty acids into the 
plasma FFA pool across skeletal muscle $(121,122)$ and that these fatty acids mix with the plasma FFA pool to compete for cellular uptake (116).

\section{Fatty acid partitioning within the skeletal muscle}

The fatty acids that enter the cell bind to cytosolic fatty acid binding protein (FABPC) for transport through the cytoplasm (110) and can either be partitioned towards oxidation in the mitochondria or towards storage in intracellular lipid fractions.

\section{Fat oxidation}

The first step in the oxidative pathway is the activation of fatty acids to fatty acylCoA by the enzyme acyl-CoA synthetase and the uptake of fatty acyl-CoA in the mitochondrion. This uptake is regulated by the carnitine palmitoyl transferase (CPT) system, in which CPT-1 is responsible for the transport over the outer mitochondrial membrane, and acylcarnitine translocase and CPT-II for the transport over the inner mitochondrial membrane. CPT-1 is the rate-limiting step in the uptake of long-chain fatty acids in mitochondria and therefore an important site for regulating fatty acid oxidation (123). CPT-1 can be suppressed by cytosolic malonyl-CoA concentrations, which are increased by acetyl-CoA carboxylase under the influence of citrate and degraded by malonyl-CoA decarboxylase. Recently, it has been shown that the fatty acid transporter FAT/CD36 is also present on the mitochondrial membrane, both in rat and human muscle cells, and that it substantially contributes to fatty acid oxidation in conjunction with CPT-1 (124-126). Very recently, comparable results have been obtained for the fatty acid transporter FATP1 in a rat muscle cell line (126).

Inside the mitochondrial matrix, fatty acyl-CoA is stepwise degraded into acetylCoAs in a process called beta-oxidation. Next, acetyl-CoA enters the tricarboxylic acid cycle (TCA-cycle) in which citrate is formed in a first step, followed by complete oxidation of acetyl-CoA. The biochemical energy released during beta-oxidation and in the TCA-cycle is transferred to hydrogen atoms bound to nicotinamide- and flavin adenine dinucleotide ( $N A D+/ F A D)$, and transferred to the respiratory chain where it is eventually used for the formation of adenosine triphosphate (ATP).

\section{Fat storage}

Skeletal muscle can store small amounts of fat, either extramyocellular in adipocytes dispersed between muscle fibres, or intracellular in lipid droplets that are most often localised nearby the mitochondria. The synthesis of TAG in the myocyte involves the activity of several glycerol-3-phosphates (GPAT1-4), lipin and diacylglycerol acyltransferases (DGAT1-2) (127). The amount of TAG being stored partly depends on the oxidative capacity of the muscle. Type I oxidative muscle fibres, that mainly use fatty acids as a fuel, generally contain higher amounts of 
IMTG than type IIb glycolytic fibres, which mainly oxidise glucose. In agreement, the expression of the lipolytic enzyme HSL is also higher in muscle that predominantly contain type 1 fibres (128). Although the hydrolysis of IMTG in skeletal muscle is regulated somewhat differently than in adipose tissue, the same enzymes may be involved (46). HSL protein expression has been demonstrated in human muscle a few years ago (129), whereas protein expression of ATGL in human skeletal muscle lipolysis has only recently been demonstrated (130). In addition, lipid droplet associated proteins such as PLIN1 and adipose differentiation related protein (ADRP or adipophilin) are also found to be expressed in skeletal muscle, although protein expression levels of PLIN1 were very low $(131,132)$. ADRP, on the other hand, is highly expressed in skeletal muscle and might be involved in the organisation of lipid droplets and the regulation of HSL binding to the lipid droplet $(132,133)$.

\section{Other functions of intramyocellular fatty acids}

Intermediates of intramyocellular TAG metabolism, such as fatty acyl-CoA, DAG, ceramides and phospholipids, can function as second messengers, modulate gene expression or be incorporated in the muscle membrane. Studies in rodents show that the quality of fatty acids (saturated, monounsaturated and $n-3$ and $n-6$ polyunsaturated) can influence insulin action due to effects on fatty acid incorporation into different lipid fractions, altered substrate oxidation and/or modulation of phospholipids in the muscle membrane (134-137). In addition, several human in vivo studies have shown that insulin sensitivity is associated with skeletal muscle phospholipid fatty acid composition (138-141). More specifically, the level of $n-3$ polyunsaturated fatty acids in skeletal muscle phospholipids is positively associated with insulin sensitivity (139-141), and it has been shown that both saturated and $n-3$ polyunsaturated fatty acids in the muscle membrane are independent predictors of insulin resistance (139).

\section{Skeletal muscle fatty acid metabolism, insulin resistance and the metabolic syndrome}

Insulin resistance and central obesity are often considered to be the central features of the MetS, but their contribution to the pathogenesis of the syndrome is not fully understood. Because skeletal muscle is the most abundant insulin-sensitive tissue, comprising up to $40 \%$ of total body mass and responsible for almost $80 \%$ of insulinstimulated glucose disposal (13), it can be considered to be a major tissue in the aetiology of insulin resistance and the MetS, making it important to study the role of skeletal muscle substrate metabolism in this context.

Several factors have been suggested to contribute to the development of skeletal muscle insulin resistance, including disturbances in fatty acid metabolism. A dysbalance between fatty acid uptake and fatty acid oxidation, in which the uptake 
exceeds the capacity to oxidise fat, is associated with the accumulation of IMTG. Although IMTG have been linked to insulin resistance in earlier studies, recent evidence suggests that intermediates of IMTG metabolism (lipid metabolites) are more closely linked to insulin resistance $(10,11)$. Increased muscle fat accumulation may be caused by intrinsic disturbances in the regulation of fatty acid uptake and/or oxidation, but may also be the consequence of an increased supply of lipids to the skeletal muscle (for the latter, see 'Adipose tissue function and dysfunction').

This paragraph describes potential mechanism explaining the relationship between intrinsic disturbances in skeletal muscle fatty acid handling (uptake, oxidation and storage) and insulin resistance.

\section{The glucose-fatty acid cycle}

The classic studies of Sir Randle and colleagues suggested that increased fat oxidation leads to reduced glucose oxidation and this mechanism is known as the Randle cycle or the glucose-fatty acid cycle (142). In this hypothesis, increased FFA availability is coupled to increased FFA oxidation. High rates of fat oxidation in the mitochondria result in accumulation of acetyl-CoA and citrate that respectively inhibit pyruvate dehydrogenase (PDH) and phosphofructokinase. As a result, glucose-6-phosphate concentrations increase and inhibit hexokinase, eventually resulting in reduced glucose uptake and oxidation (142). Several studies confirm that elevated plasma FFA concentrations rapidly inhibit glucose oxidation, but without a concomitant acute reduction in insulin-stimulated glucose uptake $(143,144)$. In fact, the onset of skeletal muscle insulin resistance was delayed by approximately 2-4 hours after FFA infusion (143-145) and was found to be accompanied by IMTG accumulation (145). In addition, it was found that FFA decrease glucose-6-phosphate levels in human skeletal muscle, suggesting that FFA primarily inhibit glucose transport and/or phosphorylation (146).

Complementary to the Randle cycle, it was demonstrated that increased glucose concentrations may inhibit fatty acid oxidation via increased intracellular malonylCoA concentrations and subsequent inhibition of CPT-1 (147), thereby confirming that the balance of glucose and fatty acid oxidation is a coordinated process.

\section{Accumulation of intramyocellular lipids and lipid metabolites}

Accumulation of IMTG has been associated with skeletal muscle insulin resistance in humans (148-150), and is already present in young lean offspring of type 2 diabetic parents (151). Both high-fat diets and acute intravenous FFA infusions result in increased IMTG stores and concomitant development of insulin resistance $(135,145,152-154)$, highlighting an important role of lipid oversupply in fatty acidinduced insulin resistance.

Evidence is increasing, however, that IMTG accumulation is not the direct cause of insulin resistance. Instead, IMTG may accumulate to protect the skeletal muscle 
from the deleterious actions of lipid metabolites / intermediates such as DAG, ceramide and long-chain fatty acyl-CoAs (127), which can interfere with insulinmediated glucose uptake in skeletal muscle $(10,11,155)$. Other evidence against a direct role of IMTG in insulin resistance originates from the observation that skeletal muscle of trained athletes is characterised by a high insulin sensitivity despite increased IMTG concentrations (156). This metabolic paradox may be explained by a higher muscle oxidative capacity in the trained athletes (156), in addition to the observation that a larger proportion of the intramyocellular lipids droplets is in direct contact with the mitochondria after exercise training intervention (157). On the contrary, increasing IMTG levels have been associated with decreasing oxidative capacity in obese and type 2 diabetic individuals (158). A higher turnover of IMTG in athletes may prevent the accumulation of lipid metabolites that can interfere with insulin signalling $(127,159)$.

\section{Impaired regulation of skeletal muscle fatty acid uptake and oxidation}

Metabolic flexibility is an important characteristic of the skeletal muscle. The dynamic process of adjusting lipid oxidation to fatty acid uptake and IMTG turnover may prevent the muscle from excess lipid storage, whereas disturbances in this process may result in the accumulation of lipids and lipid metabolites (42).

During fasting conditions fatty acids normally are the predominant substrate for oxidation, whereas the uptake and oxidation is suppressed in the postprandial phase at the expense of glucose. Skeletal muscle fat oxidation has shown to be impaired during fasting in obese subjects $(41,160)$, visceral obese women $(161)$ and subjects with type 2 diabetes mellitus $(162,163)$, and also during exercise in type 2 diabetes (164) and beta-adrenergic stimulation in obesity (160). Moreover, it has been shown that men with impaired glucose tolerance already display the same defects in postabsorptive fatty acid utilisation as type 2 diabetic patients, indicating that these defects may be a primary factor in the development of type 2 diabetes (165). This finding is emphasised by the observations that weight loss in type 2 diabetic patients did not result in increased basal plasma-derived fatty acid oxidation, despite considerable improvements in insulin sensitivity (166), and that reliance upon fatty acid oxidation during fasting was also not improved after substantial weight loss in obese subjects (41). Also, extremely obese women and women that were previously extremely obese showed similar impairments in plasma-derived fatty acid oxidation during fasting, indicating the presence of a possible genetic predisposition for massive weight gain (167). However, it should be noted that plasma-derived fatty acid oxidation during fasting not only reflects fat oxidation in skeletal muscle, but also in the liver. Moreover, other studies reported improvements in fasting fat oxidation after weight loss in men with impaired glucose tolerance (168) and after weight loss combined with exercise in obese subjects (169). In the latter, insulin sensitivity was improved 3-fold higher in 
subjects receiving a combination of weight loss and exercise intervention compared to weight loss or exercise alone, which was proposed to be mediated via changes in skeletal muscle fatty acid metabolism (169). Impairments in postprandial fat oxidation possibly play a larger role in fatty acid-induced insulin resistance and IMTG accumulation, also since people in developed countries are in a postprandial state for the largest part of the day. It has been observed that insulin-mediated suppression of fatty acid uptake and oxidation is impaired in leg muscle of type 2 diabetic patients and obese subjects, and that improvements can be achieved by weight loss $(41,162,169)$. Also in obese men with impaired glucose tolerance an impaired capacity to switch between carbohydrate and fat oxidation was observed, which improved after weight loss (168).

The above-described studies provide no conclusive evidence on the relative importance of impairments in fasting and postprandial skeletal muscle fat oxidation in obesity and type 2 diabetes. Moreover, disturbances in skeletal muscle fatty acid uptake may occur in parallel or independently from impairments in muscle fat oxidation and affect metabolic flexibility (42). In this context, a growing body of evidence suggest that alterations in membrane fatty acid transporters are associated with impaired fat utilisation, insulin resistance and type 2 diabetes, although findings are not unambiguous. Skeletal muscle FAT/CD36 expression has shown to be regulated acutely by insulin in vivo, and was positively related to insulin resistance (114). In addition, earlier studies by Bonen et al showed that the transport rate of long-chain fatty acids into skeletal muscle was increased in muscle strips of obese and type 2 diabetic subjects, being associated with an increased sarcolemmal FAT/CD36 content and increased IMTG stores (170). Recent discoveries of FAT/CD36 in the regulation of mitochondrial fat oxidation suggest that impairments in the expression of this fatty acid transporter may also be directly associated with impairments in fat oxidation (125), but this requires further investigation. On the other hand, a reduced capacity of fatty acid uptake across forearm and leg muscle during fasting has been observed in type 2 diabetic patients and visceral obese women compared to lean controls $(161,163)$. Furthermore, Blaak et al observed a decreased content of FABPc and a concomitant decrease in fatty acid uptake in muscle of type 2 diabetic patients (163).

In view of the apparent role of oxidative metabolism in fatty acid-induced insulin resistance, research has been focused on mitochondrial function in skeletal muscle. Indeed, mitochondrial dysfunction and reduced ATP-synthesis rate have been associated with IMTG accumulation and insulin resistance in obesity, type 2 diabetes and offspring of type 2 diabetic parents $(171,172)$. Impairments in mitochondrial oxidative capacity may be the result of decreased mitochondrial density and impairments in the transport of fatty acids into the mitochondria, but also of intrinsic disturbances of enzyme activities in the processes of beta-oxidation, oxidative phosphorylation and the electron transport chain $(43,173)$. 
To conclude, the dynamic process of metabolic flexibility comprises a close interplay between fatty acid supply, uptake, oxidation and storage in skeletal muscle. Disturbances in skeletal muscle fatty acid handling are thought to play a crucial role in the development of insulin resistance and intramyocellular lipid accumulation, thereby contributing to the pathogenesis of the MetS and type 2 diabetes. However, additional research is needed to support and elucidate this hypothesis.

\section{NUTRITION AND THE METABOLIC SYNDROME}

Diet and lifestyle interventions can be at least as effective as pharmacological approaches in the prevention of type 2 diabetes and the MetS (14). Most dietary interventions are aimed at reducing caloric intake and manipulating macronutrient composition (i.e. carbohydrate, fat and protein), dietary fat quality, glycaemic index and glycaemic load, fibre and vitamin intake and alcohol consumption. The ideal diet for individuals with the MetS should be one with a favourable effect on each of the different components of the condition (174). Because (central) obesity and insulin resistance are considered to be the primary factors underlying the MetS, dietary intervention should be primarily focused on weight reduction and improvements of the insulin resistant state. Caloric restriction and increased physical activity promote weight loss and subsequent improvements in all abnormalities clustering in the MetS, including insulin sensitivity (175). In addition, insulin sensitivity is also affected by the quality of dietary fat, independently of its effects on weight reduction $(175,176)$. However, despite the fact that there is increasing evidence for an association between dietary fat and obesity, type 2 diabetes and the MetS, the optimal amount and type of dietary fat has not been fully elucidated (177).

It would go beyond the scope of this introduction to discuss all possible diet and lifestyle interventions in the prevention and treatment of the MetS. Therefore, the next two paragraphs are focused on the association between dietary fat intake, insulin resistance and skeletal muscle substrate metabolism.

\section{Dietary fat quantity or quality?}

Although it is well-known that weight reduction is a powerful tool for treating or preventing the components of the MetS, more research is needed on the effects of dietary fat quantity and composition on insulin sensitivity and the development of the MetS (175). Dietary intervention, aimed at reducing the intake of saturated fat, may improve lipid metabolism and insulin action in the MetS, possibly through effects on body weight, lipid overflow from the adipose tissue and skeletal muscle fatty acid handling. It remains an issue of debate, however, whether saturated fat 
should be replaced by carbohydrates or unsaturated fat. Replacement of fat by carbohydrates has shown to be beneficial in promoting weight loss and lowering low-density lipoprotein (LDL)-cholesterol concentrations, thereby reducing the risk for cardiovascular disease and type 2 diabetes in subjects with the MetS. But on the other hand, these diets are also associated with a reduction in HDL-cholesterol concentrations and, at least initially, increased TAG concentrations (178-180), and may therefore worsen dyslipidaemia in subjects with the MetS. Contrary to low-fat diets, low-carbohydrate diets are associated with improvements in both TAG and HDL-cholesterol concentrations, but also with increased LDL-cholesterol and total cholesterol concentrations and the risk of excess calorie intake (181).

A well-controlled human study on the effects of dietary fat quality and quantity on insulin sensitivity is the KANWU study (182). In this study, substitution of dietary saturated fatty acids (SFA) for monounsaturated fatty acids (MUFA) resulted in impaired insulin sensitivity in healthy subjects, although the beneficial effects of the MUFA-enriched diet on insulin sensitivity were only observed in subjects with a habitual low dietary fat intake (<37 energy\%) (182). A well-controlled crossover study in type 2 diabetics and (non-)obese people without diabetes showed that insulin sensitivity increased and LDL-cholesterol concentrations decreased following a diet rich in polyunsaturated fatty acids (PUFA) compared to an isoenergetic SFArich diet (183). Both studies confirm that SFA-rich diets decrease insulin sensitivity, but give no decisive answer to the question whether positive effects of the MUFAand PUFA-rich diet were achieved due to lowering of SFA or specifically increasing MUFA or PUFA in the diet $(182,183)$.

\section{Dietary fat and skeletal muscle fatty acid metabolism}

The fatty acid composition of the diet is known to influence the fatty acid profile of skeletal muscle lipids and thereby may play an important role in the development of skeletal muscle insulin resistance and type 2 diabetes (184). So far, however, only little information is available on the relationship between dietary fat quantity and quality and skeletal muscle fatty acid handling in vivo.

Recently, the short-term effects of a high-carbohydrate versus a high-fat diet on tissue-specific fatty acid metabolism were investigated in healthy volunteers. Compared to a high-fat diet, a high-carbohydrate diet resulted in decreased fatty acid oxidation in both muscle and liver and altered the partitioning of fatty acids towards storage in these tissues (185). Studies in rodents and human cell lines show that the quality of fatty acids (SFA, MUFA, $n-3$ and $n-6$ PUFA) can influence insulin action in skeletal muscle due to effects on fatty acid incorporation into different lipid fractions, substrate oxidation and/or modulation of phospholipids in the muscle membrane (134-137). There are indications that SFA accumulate preferentially as DAG, thereby potentially interfering with insulin signalling, whereas 
unsaturated fatty acids are more readily converted into TAG $(134,186)$. In addition, replacing dietary SFA by unsaturated fatty acids may favour fat oxidation above storage (186), as unsaturated fatty acids are generally more readily oxidised. This intracellular partitioning of unsaturated fatty acids towards either oxidation or rapid incorporation into IMTG stores may prevent excessive accumulation of lipid intermediates that can interfere with insulin signalling. Also, the fatty acid profile of phospholipids in the muscle membrane is associated with insulin sensitivity. Unsaturated fatty acids, in particular long-chain $n-3$ fatty acids, increase membrane fluidity and have been associated with improved insulin action (137). Moreover, highly unsaturated fatty acids can also affect intramyocellular lipogenesis and fatty acid oxidation, acting as agonists of transcription factors such as members of the peroxisome proliferator-activated receptor family (PPARs) and sterol regulatory element-binding protein-1c (SREBP-1c).

Dietary fatty acids may also influence skeletal muscle fatty acid handling indirectly via effects on other tissues such as liver and adipose tissue. Both dietary fat quantity and quality may modulate endogenous lipolysis and reduce lipid overflow, thereby regulating the flux of fatty acids to skeletal muscle during fasting and postprandial conditions. A MUFA-rich diet, for instance, has been shown to increase TAG hydrolase activity in adipose tissue of type 2 diabetic patients when compared to an isoenergetic high saturated fat diet (187). Dietary PUFA can stimulate adipocyte differentiation and increase lipolytic gene expression via agonising effects on PPARY and concomitantly decrease lipogenesis through inhibition of SREBP-1c (188-190). Moreover, inhibiting effects of long-chain $n-3$ PUFA on SREBP-1c in the liver result in decreased hepatic VLDL production and secretion (191). Together, these effects may improve adipose tissue function and reduce lipid overflow from both adipose tissue and liver towards skeletal muscle. Furthermore, dietary fatty acids may contribute to attenuation the inflammatory response via a better adipose tissue function, thereby improving skeletal muscle fatty acid metabolism and increasing insulin sensitivity (see 'Adipose tissue function and dysfunction') (192). 


\section{OUTLINE OF THE THESIS}

Dietary intervention, aimed at reducing the intake of saturated fat, may improve lipid metabolism and insulin sensitivity in the MetS, possibly through effects on lipid overflow from the adipose tissue and skeletal muscle fatty acid handling. This thesis describes research performed as part of the LIPGENE human dietary intervention study; a 12-week parallel, randomised, controlled, European multicentre study designed to investigate the effects of dietary fat modification on insulin sensitivity and various risk factors of the MetS. In this study, 486 men and women with the MetS (NCEP-ATP III) were included and randomised to one of four isoenergetic intervention diets differing in fat quantity and quality. Several factors may determine the individual responsiveness to the dietary intervention. In chapter $\mathbf{2}$ we investigated the possible determinants of diet-induced changes in insulin sensitivity and insulin resistance among all subjects participating in the LIPGENE human dietary intervention study. To gain more insight in the metabolic mechanisms underlying the effects of dietary fat modification on whole body insulin sensitivity and other risk factors in the MetS, skeletal muscle and adipose tissue fatty acid metabolism were investigated in a subcohort of men and women in the LIPGENE study. The contribution of dietary fat (chylomicron-TAG) vs. endogenous fat (FFA and VLDLTAG) to in vivo skeletal muscle fatty acid metabolism in insulin resistant men is investigated in chapter $\mathbf{3}$ by using a recently developed dual stable isotope tracer technique in combination with arteriovenous measurements across the forearm muscle. In view of the apparent role of lipid intermediates in skeletal muscle insulin resistance, intramuscular partitioning of fatty acids into different lipid fractions (TAG, DAG, phospholipids and FFA) and the transcriptional regulation of skeletal muscle fatty acid metabolism are discussed in chapter 3 as well. In chapter 4 we investigated the effects of dietary fat modification on in vivo skeletal muscle fatty acid metabolism in men with the MetS. By means of the same dual stable isotope tracer technique in combination with arteriovenous measurements across the forearm muscle we investigated the effects of the LIPGENE dietary intervention on fasting and postprandial skeletal muscle fatty acid handling (uptake and oxidation). Impairments in the regulation of adipose tissue lipolysis can largely contribute to lipid overflow into the circulation. In chapter 5 we investigated whether dietary fat modification could affect mRNA and protein expression levels of lipolytic enzymes (ATGL and HSL) in subcutaneous adipose tissue of men and women with the MetS, in addition to the effects on whole body rate of appearance of fatty acids into the circulation. Obesity, insulin resistance, hypertension and disturbances in postprandial lipid metabolism are strongly linked to an atherogenic lipoprotein phenotype (193) and these factors are all described in the MetS. Increased concentrations of lipoprotein remnants, and in particular their cholesterol content, are considered to be highly atherogenic and may underlie the increased risk for 
cardiovascular disease in the MetS. Remnant-like particles derive from TAG-rich lipoproteins (VLDL and chylomicrons) and are normally cleared from the circulation by the liver. Concentrations in plasma may rise due to disturbances in fatty acid handling of adipose tissue, skeletal muscle and liver and may be influenced by weight loss and dietary fat modification. Results of a part of the European multicentre study NUGENOB investigating determinants of fasting and postprandial remnant-like particle cholesterol concentrations in lean and obese subjects are described in chapter 6 , in addition to the effects of a 10-week hypoenergetic low-fat of high-fat diet on remnant-like particle cholesterol concentrations in the obese subjects. In chapter 7 the main findings from the studies described in this thesis are integrated and discussed in a broader perspective and implications for future research are provided. 


\section{References}

1. Eckel RH, Grundy SM, Zimmet PZ. The metabolic syndrome. Lancet 2005;365(9468):1415-28.

2. Zimmet $P$, Alberti KG, Shaw J. Global and societal implications of the diabetes epidemic. Nature 2001;414(6865):782-7.

3. World Health Organization. Fact sheet $N^{\circ} 311$ : Obesity and overweight. 2006. http://www.who.int/mediacentre/factsheets/fs311/en/index.html.

4. Wild S, Roglic G, Green A, Sicree R, King H. Global prevalence of diabetes: estimates for the year 2000 and projections for 2030. Diabetes Care 2004;27(5):1047-53.

5. World Health Organization. Fact Sheet $\mathrm{N}^{\circ} 317$ : Cardiovascular diseases (CVDs). 2009. http://www.who.int/mediacentre/factsheets/fs317/en/index.html.

6. Ferrannini E, Haffner SM, Mitchell BD, Stern MP. Hyperinsulinaemia: the key feature of a cardiovascular and metabolic syndrome. Diabetologia 1991;34(6):416-22.

7. Petersen KF, Dufour S, Savage DB, Bilz S, Solomon G, Yonemitsu S, et al. The role of skeletal muscle insulin resistance in the pathogenesis of the metabolic syndrome. Proc Natl Acad Sci U S A 2007;104(31):12587-94.

8. Blaak EE. Basic disturbances in skeletal muscle fatty acid metabolism in obesity and type 2 diabetes mellitus. Proc Nutr Soc 2004;63(2):323-30.

9. Frayn KN. Adipose tissue as a buffer for daily lipid flux. Diabetologia 2002;45(9):1201-10.

10. Corcoran MP, Lamon-Fava S, Fielding RA. Skeletal muscle lipid deposition and insulin resistance: effect of dietary fatty acids and exercise. Am J Clin Nutr 2007;85(3):662-77.

11. Schmitz-Peiffer $\mathrm{C}$. Signalling aspects of insulin resistance in skeletal muscle: mechanisms induced by lipid oversupply. Cell Signal 2000;12(9-10):583-94.

12. Schrauwen $P$, Hesselink MK. Oxidative capacity, lipotoxicity, and mitochondrial damage in type 2 diabetes. Diabetes 2004;53(6):1412-7.

13. DeFronzo RA, Jacot E, Jequier E, Maeder E, Wahren J, Felber JP. The effect of insulin on the disposal of intravenous glucose. Results from indirect calorimetry and hepatic and femoral venous catheterization. Diabetes 1981;30(12):1000-7.

14. Gillies CL, Abrams KR, Lambert PC, Cooper NJ, Sutton AJ, Hsu RT, et al. Pharmacological and lifestyle interventions to prevent or delay type 2 diabetes in people with impaired glucose tolerance: systematic review and meta-analysis. Bmj 2007;334(7588):299.

15. Mann JI, De Leeuw I, Hermansen K, Karamanos B, Karlstrom B, Katsilambros N, et al. Evidencebased nutritional approaches to the treatment and prevention of diabetes mellitus. Nutr Metab Cardiovasc Dis 2004;14(6):373-94.

16. Riccardi G, Rivellese AA. Dietary treatment of the metabolic syndrome--the optimal diet. Br J Nutr 2000;83 Suppl 1(S143-8.

17. Alberti KG, Zimmet P, Shaw J. Metabolic syndrome--a new world-wide definition. A Consensus Statement from the International Diabetes Federation. Diabet Med 2006;23(5):469-80.

18. Kylin E. Studies of the hypertension-hyperglycaemia-hyperuricemia syndrome (Studien ueber das Hypertonie-Hyperglykamie-Hyperurikamiesyndrom). Zentralblatt fuer Innere Medizin 1923;44(10527.

19. Vague J. La differenciation sexuelle; facteur determinant des formes de l'obesite. Presse Med 1947;55(30):339-40.

20. Reaven GM. Banting lecture 1988. Role of insulin resistance in human disease. Diabetes 1988;37(12):1595-607.

21. Balkau B, Valensi P, Eschwege E, Slama G. A review of the metabolic syndrome. Diabetes Metab 2007;33(6):405-13.

22. Ryden L, Standl E, Bartnik M, Van den Berghe G, Betteridge J, de Boer MJ, et al. Guidelines on diabetes, pre-diabetes, and cardiovascular diseases: executive summary. The Task Force on Diabetes and Cardiovascular Diseases of the European Society of Cardiology (ESC) and of the European Association for the Study of Diabetes (EASD). Eur Heart J 2007;28(1):88-136. 
23. Alberti KG, Zimmet PZ. Definition, diagnosis and classification of diabetes mellitus and its complications. Part 1: diagnosis and classification of diabetes mellitus provisional report of a WHO consultation. Diabet Med 1998;15(7):539-53.

24. Balkau B, Charles MA. Comment on the provisional report from the WHO consultation. European Group for the Study of Insulin Resistance (EGIR). Diabet Med 1999;16(5):442-3.

25. Executive Summary of The Third Report of The National Cholesterol Education Program (NCEP) Expert Panel on Detection, Evaluation, And Treatment of High Blood Cholesterol In Adults (Adult Treatment Panel III). Jama 2001;285(19):2486-97.

26. Third Report of the National Cholesterol Education Program (NCEP) Expert Panel on Detection, Evaluation, and Treatment of High Blood Cholesterol in Adults (Adult Treatment Panel III) final report. Circulation, 2002:3143-421.

27. Alberti KG, Zimmet $P$, Shaw J. The metabolic syndrome--a new worldwide definition. Lancet 2005;366(9491):1059-62.

28. Grundy SM, Cleeman JI, Daniels SR, Donato KA, Eckel RH, Franklin BA, et al. Diagnosis and management of the metabolic syndrome: an American Heart Association/National Heart, Lung, and Blood Institute Scientific Statement. Circulation 2005;112(17):2735-52.

29. Grundy SM, Cleeman JI, Daniels SR, Donato KA, Eckel RH, Franklin BA, et al. Diagnosis and management of the metabolic syndrome. An American Heart Association/National Heart, Lung, and Blood Institute Scientific Statement. Executive summary. Cardiol Rev 2005;13(6):322-7.

30. Einhorn D, Reaven GM, Cobin RH, Ford E, Ganda OP, Handelsman Y, et al. American College of Endocrinology position statement on the insulin resistance syndrome. Endocr Pract 2003;9(3):23752.

31. Lemieux I, Pascot A, Couillard C, Lamarche B, Tchernof A, Almeras N, et al. Hypertriglyceridemic waist: A marker of the atherogenic metabolic triad (hyperinsulinemia; hyperapolipoprotein B; small, dense LDL) in men? Circulation 2000;102(2):179-84.

32. Kahn R, Buse J, Ferrannini E, Stern M. The metabolic syndrome: time for a critical appraisal: joint statement from the American Diabetes Association and the European Association for the Study of Diabetes. Diabetes Care 2005;28(9):2289-304.

33. Reaven GM. The metabolic syndrome: is this diagnosis necessary? Am J Clin Nutr 2006;83(6):123747.

34. Gale EA. The myth of the metabolic syndrome. Diabetologia 2005;48(9):1679-83.

35. Yudkin JS. Insulin resistance and the metabolic syndrome--or the pitfalls of epidemiology. Diabetologia 2007;50(8):1576-86.

36. Cornier MA, Dabelea D, Hernandez TL, Lindstrom RC, Steig AJ, Stob NR, et al. The metabolic syndrome. Endocr Rev 2008;29(7):777-822.

37. Reaven GM. The metabolic syndrome: requiescat in pace. Clin Chem 2005;51(6):931-8.

38. Watt MJ, Steinberg GR. Regulation and function of triacylglycerol lipases in cellular metabolism. Biochem J 2008;414(3):313-25.

39. Vrolix R, van Meijl LE, Mensink RP. The metabolic syndrome in relation with the glycemic index and the glycemic load. Physiol Behav 2008;94(2):293-9.

40. van Herpen NA, Schrauwen-Hinderling VB. Lipid accumulation in non-adipose tissue and lipotoxicity. Physiol Behav 2008;94(2):231-41.

41. Kelley DE, Goodpaster B, Wing RR, Simoneau JA. Skeletal muscle fatty acid metabolism in association with insulin resistance, obesity, and weight loss. Am J Physiol 1999;277(6 Pt 1):E113041.

42. Corpeleijn E, Saris WH, Blaak EE. Metabolic flexibility in the development of insulin resistance and type 2 diabetes: effects of lifestyle. Obes Rev 2009;10(2):178-93.

43. Holloway GP, Bonen A, Spriet LL. Regulation of skeletal muscle mitochondrial fatty acid metabolism in lean and obese individuals. Am J Clin Nutr 2009;89(1):455S-62S. 
44. Schweiger M, Schreiber R, Haemmerle G, Lass A, Fledelius C, Jacobsen P, et al. Adipose triglyceride lipase and hormone-sensitive lipase are the major enzymes in adipose tissue triacylglycerol catabolism. J Biol Chem 2006;281(52):40236-41.

45. Zechner R, Kienesberger PC, Haemmerle G, Zimmermann R, Lass A. Adipose triglyceride lipase and the lipolytic catabolism of cellular fat stores. J Lipid Res 2009;50(1):3-21.

46. Jocken JW, Blaak EE. Catecholamine-induced lipolysis in adipose tissue and skeletal muscle in obesity. Physiol Behav 2008;94(2):219-30.

47. Goldberg IJ, Eckel RH, Abumrad NA. Regulation of fatty acid uptake into tissues: lipoprotein lipaseand CD36-mediated pathways. J Lipid Res 2009;50 Suppl(S86-90.

48. Frayn KN, Coppack SW, Fielding BA, Humphreys SM. Coordinated regulation of hormone-sensitive lipase and lipoprotein lipase in human adipose tissue in vivo: implications for the control of fat storage and fat mobilization. Adv Enzyme Regul 1995;35(163-78.

49. Frayn KN, Shadid S, Hamlani R, Humphreys SM, Clark ML, Fielding BA, et al. Regulation of fatty acid movement in human adipose tissue in the postabsorptive-to-postprandial transition. Am J Physiol 1994;266(3 Pt 1):E308-17.

50. Ruge T, Hodson L, Cheeseman J, Dennis AL, Fielding BA, Humphreys SM, et al. Fasted to fed trafficking of Fatty acids in human adipose tissue reveals a novel regulatory step for enhanced fat storage. J Clin Endocrinol Metab 2009;94(5):1781-8.

51. Riemens SC, Sluiter WJ, Dullaart RP. Enhanced escape of non-esterified fatty acids from tissue uptake: its role in impaired insulin-induced lowering of total rate of appearance in obesity and Type II diabetes mellitus. Diabetologia 2000;43(4):416-26.

52. Danforth E, Jr. Failure of adipocyte differentiation causes type II diabetes mellitus? Nat Genet 2000;26(1):13.

53. Coppack SW, Evans RD, Fisher RM, Frayn KN, Gibbons GF, Humphreys SM, et al. Adipose tissue metabolism in obesity: lipase action in vivo before and after a mixed meal. Metabolism 1992;41(3):264-72.

54. Laws A, Hoen HM, Selby JV, Saad MF, Haffner SM, Howard BV. Differences in insulin suppression of free fatty acid levels by gender and glucose tolerance status. Relation to plasma triglyceride and apolipoprotein B concentrations. Insulin Resistance Atherosclerosis Study (IRAS) Investigators. Arterioscler Thromb Vasc Biol 1997;17(1):64-71.

55. Groop LC, Bonadonna RC, DelPrato S, Ratheiser K, Zyck K, Ferrannini E, et al. Glucose and free fatty acid metabolism in non-insulin-dependent diabetes mellitus. Evidence for multiple sites of insulin resistance. J Clin Invest 1989;84(1):205-13.

56. Potts JL, Coppack SW, Fisher RM, Humphreys SM, Gibbons GF, Frayn KN. Impaired postprandial clearance of triacylglycerol-rich lipoproteins in adipose tissue in obese subjects. Am J Physiol 1995;268(4 Pt 1):E588-94.

57. Panarotto D, Remillard P, Bouffard L, Maheux P. Insulin resistance affects the regulation of lipoprotein lipase in the postprandial period and in an adipose tissue-specific manner. Eur J Clin Invest 2002;32(2):84-92.

58. Annuzzi G, Giacco R, Patti L, Di Marino L, De Natale C, Costabile G, et al. Postprandial chylomicrons and adipose tissue lipoprotein lipase are altered in type 2 diabetes independently of obesity and whole-body insulin resistance. Nutr Metab Cardiovasc Dis 2008;18(8):531-8.

59. Jocken JW, Langin D, Smit E, Saris WH, Valle C, Hul GB, et al. Adipose triglyceride lipase and hormone-sensitive lipase protein expression is decreased in the obese insulin-resistant state. J Clin Endocrinol Metab 2007;92(6):2292-9.

60. Bickerton AS, Roberts R, Fielding BA, Tornqvist H, Blaak EE, Wagenmakers AJ, et al. Adipose tissue fatty acid metabolism in insulin-resistant men. Diabetologia 2008;51(8):1466-74.

61. Groop LC, Bonadonna RC, Simonson DC, Petrides AS, Shank M, DeFronzo RA. Effect of insulin on oxidative and nonoxidative pathways of free fatty acid metabolism in human obesity. Am J Physiol 1992;263(1 Pt 1):E79-84. 
62. Lewis GF, Carpentier A, Adeli K, Giacca A. Disordered fat storage and mobilization in the pathogenesis of insulin resistance and type 2 diabetes. Endocr Rev 2002;23(2):201-29.

63. Fernandez-Real JM, Ricart W. Insulin resistance and chronic cardiovascular inflammatory syndrome. Endocr Rev 2003;24(3):278-301.

64. Goossens $\mathrm{GH}$. The role of adipose tissue dysfunction in the pathogenesis of obesity-related insulin resistance. Physiol Behav 2008;94(2):206-18.

65. Schenk S, Saberi M, Olefsky JM. Insulin sensitivity: modulation by nutrients and inflammation. J Clin Invest 2008;118(9):2992-3002.

66. Dyck DJ. Adipokines as regulators of muscle metabolism and insulin sensitivity. Appl Physiol Nutr Metab 2009;34(3):396-402.

67. Hotta K, Funahashi T, Arita Y, Takahashi M, Matsuda M, Okamoto Y, et al. Plasma concentrations of a novel, adipose-specific protein, adiponectin, in type 2 diabetic patients. Arterioscler Thromb Vasc Biol 2000;20(6):1595-9.

68. Weyer C, Funahashi T, Tanaka S, Hotta K, Matsuzawa Y, Pratley RE, et al. Hypoadiponectinemia in obesity and type 2 diabetes: close association with insulin resistance and hyperinsulinemia. J Clin Endocrinol Metab 2001;86(5):1930-5.

69. Cote M, Mauriege P, Bergeron J, Almeras N, Tremblay A, Lemieux I, et al. Adiponectinemia in visceral obesity: impact on glucose tolerance and plasma lipoprotein and lipid levels in men. J Clin Endocrinol Metab 2005;90(3):1434-9.

70. Yamauchi T, Kamon J, Minokoshi Y, Ito Y, Waki H, Uchida S, et al. Adiponectin stimulates glucose utilization and fatty-acid oxidation by activating AMP-activated protein kinase. Nat Med 2002;8(11):1288-95.

71. Tomas E, Tsao TS, Saha AK, Murrey HE, Zhang Cc C, Itani SI, et al. Enhanced muscle fat oxidation and glucose transport by ACRP30 globular domain: acetyl-CoA carboxylase inhibition and AMP-activated protein kinase activation. Proc Natl Acad Sci U S A 2002;99(25):16309-13.

72. Civitarese AE, Ukropcova B, Carling S, Hulver M, DeFronzo RA, Mandarino L, et al. Role of adiponectin in human skeletal muscle bioenergetics. Cell Metab 2006;4(1):75-87.

73. Bruce CR, Mertz VA, Heigenhauser GJ, Dyck DJ. The stimulatory effect of globular adiponectin on insulin-stimulated glucose uptake and fatty acid oxidation is impaired in skeletal muscle from obese subjects. Diabetes 2005;54(11):3154-60.

74. Chen MB, McAinch AJ, Macaulay SL, Castelli LA, O'Brien P E, Dixon JB, et al. Impaired activation of AMP-kinase and fatty acid oxidation by globular adiponectin in cultured human skeletal muscle of obese type 2 diabetics. J Clin Endocrinol Metab 2005;90(6):3665-72.

75. Wein S, Ukropec J, Gasperikova D, Klimes I, Sebokova E. Concerted action of leptin in regulation of fatty acid oxidation in skeletal muscle and liver. Exp Clin Endocrinol Diabetes 2007;115(4):244-51.

76. Muoio DM, Dohm GL, Fiedorek FT, Jr., Tapscott EB, Coleman RA. Leptin directly alters lipid partitioning in skeletal muscle. Diabetes 1997;46(8):1360-3.

77. Steinberg GR, Bonen A, Dyck DJ. Fatty acid oxidation and triacylglycerol hydrolysis are enhanced after chronic leptin treatment in rats. Am J Physiol Endocrinol Metab 2002;282(3):E593-600.

78. Yaspelkis BB, 3rd, Ansari L, Ramey EL, Holland GJ, Loy SF. Chronic leptin administration increases insulin-stimulated skeletal muscle glucose uptake and transport. Metabolism 1999;48(5):671-6.

79. Ceddia RB, William WN, Jr., Curi R. Comparing effects of leptin and insulin on glucose metabolism in skeletal muscle: evidence for an effect of leptin on glucose uptake and decarboxylation. Int J Obes Relat Metab Disord 1999;23(1):75-82.

80. Maffei M, Halaas J, Ravussin E, Pratley RE, Lee GH, Zhang Y, et al. Leptin levels in human and rodent: measurement of plasma leptin and ob RNA in obese and weight-reduced subjects. Nat Med 1995;1(11):1155-61.

81. Considine RV, Sinha MK, Heiman ML, Kriauciunas A, Stephens TW, Nyce MR, et al. Serum immunoreactive-leptin concentrations in normal-weight and obese humans. N Engl J Med 1996;334(5):292-5. 
82. Segal KR, Landt M, Klein S. Relationship between insulin sensitivity and plasma leptin concentration in lean and obese men. Diabetes 1996;45(7):988-91.

83. Steinberg GR, Parolin ML, Heigenhauser GJ, Dyck DJ. Leptin increases FA oxidation in lean but not obese human skeletal muscle: evidence of peripheral leptin resistance. Am J Physiol Endocrinol Metab 2002;283(1):E187-92.

84. Dyck DJ, Heigenhauser GJ, Bruce CR. The role of adipokines as regulators of skeletal muscle fatty acid metabolism and insulin sensitivity. Acta Physiol (Oxf) 2006;186(1):5-16.

85. Hotamisligil GS, Shargill NS, Spiegelman BM. Adipose expression of tumor necrosis factor-alpha: direct role in obesity-linked insulin resistance. Science 1993;259(5091):87-91.

86. Kern PA, Ranganathan S, Li C, Wood L, Ranganathan G. Adipose tissue tumor necrosis factor and interleukin-6 expression in human obesity and insulin resistance. Am J Physiol Endocrinol Metab 2001;280(5):E745-51.

87. Saghizadeh M, Ong JM, Garvey WT, Henry RR, Kern PA. The expression of TNF alpha by human muscle. Relationship to insulin resistance. J Clin Invest 1996;97(4):1111-6.

88. Sell H, Eckel J, Dietze-Schroeder D. Pathways leading to muscle insulin resistance--the muscle--fat connection. Arch Physiol Biochem 2006;112(2):105-13.

89. Bruce CR, Dyck DJ. Cytokine regulation of skeletal muscle fatty acid metabolism: effect of interleukin-6 and tumor necrosis factor-alpha. Am J Physiol Endocrinol Metab 2004;287(4):E61621.

90. Carey AL, Febbraio MA. Interleukin-6 and insulin sensitivity: friend or foe? Diabetologia 2004;47(7):1135-42.

91. Keller P, Keller C, Carey AL, Jauffred S, Fischer CP, Steensberg A, et al. Interleukin-6 production by contracting human skeletal muscle: autocrine regulation by IL-6. Biochem Biophys Res Commun 2003;310(2):550-4.

92. Steensberg A, Fischer $C P$, Sacchetti $M$, Keller C, Osada T, Schjerling $P$, et al. Acute interleukin-6 administration does not impair muscle glucose uptake or whole-body glucose disposal in healthy humans. J Physiol 2003;548(Pt 2):631-8.

93. Febbraio MA, Hiscock N, Sacchetti M, Fischer CP, Pedersen BK. Interleukin-6 is a novel factor mediating glucose homeostasis during skeletal muscle contraction. Diabetes 2004;53(7):1643-8.

94. Sopasakis VR, Sandqvist M, Gustafson B, Hammarstedt A, Schmelz M, Yang X, et al. High local concentrations and effects on differentiation implicate interleukin- 6 as a paracrine regulator. Obes Res 2004;12(3):454-60.

95. van Hall G, Steensberg A, Sacchetti M, Fischer C, Keller C, Schjerling P, et al. Interleukin-6 stimulates lipolysis and fat oxidation in humans. J Clin Endocrinol Metab 2003;88(7):3005-10.

96. Steppan CM, Bailey ST, Bhat S, Brown EJ, Banerjee RR, Wright CM, et al. The hormone resistin links obesity to diabetes. Nature 2001;409(6818):307-12.

97. Heilbronn LK, Rood J, Janderova L, Albu JB, Kelley DE, Ravussin E, et al. Relationship between serum resistin concentrations and insulin resistance in nonobese, obese, and obese diabetic subjects. J Clin Endocrinol Metab 2004;89(4):1844-8.

98. Lee JH, Chan JL, Yiannakouris N, Kontogianni M, Estrada E, Seip R, et al. Circulating resistin levels are not associated with obesity or insulin resistance in humans and are not regulated by fasting or leptin administration: cross-sectional and interventional studies in normal, insulin-resistant, and diabetic subjects. J Clin Endocrinol Metab 2003;88(10):4848-56.

99. Pravenec M, Kazdova L, Landa V, Zidek V, Mlejnek P, Jansa P, et al. Transgenic and recombinant resistin impair skeletal muscle glucose metabolism in the spontaneously hypertensive rat. J Biol Chem 2003;278(46):45209-15.

100. Zilversmit DB. Atherogenic nature of triglycerides, postprandial lipidemia, and triglyceride-rich remnant lipoproteins. Clin Chem 1995;41(1):153-8.

101. Barrows BR, Parks EJ. Contributions of different fatty acid sources to very low-density lipoproteintriacylglycerol in the fasted and fed states. J Clin Endocrinol Metab 2006;91(4):1446-52. 
102. Lewis GF. Fatty acid regulation of very low density lipoprotein production. Curr Opin Lipidol 1997;8(3):146-53.

103. Taskinen MR. Diabetic dyslipidaemia: from basic research to clinical practice. Diabetologia 2003;46(6):733-49.

104. Gill JM, Brown JC, Bedford D, Wright DM, Cooney J, Hughes DA, et al. Hepatic production of VLDL1 but not VLDL2 is related to insulin resistance in normoglycaemic middle-aged subjects. Atherosclerosis 2004;176(1):49-56.

105. Malmstrom R, Packard CJ, Caslake M, Bedford D, Stewart P, Yki-Jarvinen H, et al. Defective regulation of triglyceride metabolism by insulin in the liver in NIDDM. Diabetologia 1997;40(4):45462.

106. Abbasi F, McLaughlin T, Lamendola C, Yeni-Komshian H, Tanaka A, Wang $T$, et al. Fasting remnant lipoprotein cholesterol and triglyceride concentrations are elevated in nondiabetic, insulinresistant, female volunteers. J Clin Endocrinol Metab 1999;84(11):3903-6.

107. Watanabe N, Taniguchi T, Taketoh H, Kitagawa Y, Namura H, Yoneda N, et al. Elevated remnant-like lipoprotein particles in impaired glucose tolerance and type 2 diabetic patients. Diabetes Care 1999;22(1):152-6.

108. Chan DC, Watts GF, Barrett PH, Mamo JC, Redgrave TG. Markers of triglyceride-rich lipoprotein remnant metabolism in visceral obesity. Clin Chem 2002;48(2):278-83.

109. Williams KJ, Chen K. Recent insights into factors affecting remnant lipoprotein uptake. Curr Opin Lipidol 2010;21(3):218-28.

110. Glatz JF, Bonen A, Luiken JJ. Exercise and insulin increase muscle fatty acid uptake by recruiting putative fatty acid transporters to the sarcolemma. Curr Opin Clin Nutr Metab Care 2002;5(4):36570.

111. Abumrad N, Coburn C, Ibrahimi A. Membrane proteins implicated in long-chain fatty acid uptake by mammalian cells: CD36, FATP and FABPm. Biochim Biophys Acta 1999;1441(1):4-13.

112. Coburn CT, Knapp FF, Jr., Febbraio M, Beets AL, Silverstein RL, Abumrad NA. Defective uptake and utilization of long chain fatty acids in muscle and adipose tissues of CD36 knockout mice. J Biol Chem 2000;275(42):32523-9.

113. Ibrahimi A, Bonen A, Blinn WD, Hajri T, Li X, Zhong K, et al. Muscle-specific overexpression of FAT/CD36 enhances fatty acid oxidation by contracting muscle, reduces plasma triglycerides and fatty acids, and increases plasma glucose and insulin. J Biol Chem 1999;274(38):26761-6.

114. Corpeleijn E, Pelsers MM, Soenen S, Mensink M, Bouwman FG, Kooi ME, et al. Insulin acutely upregulates protein expression of the fatty acid transporter CD36 in human skeletal muscle in vivo. J Physiol Pharmacol 2008;59(1):77-83.

115. Evans K, Burdge GC, Wootton SA, Clark ML, Frayn KN. Regulation of dietary fatty acid entrapment in subcutaneous adipose tissue and skeletal muscle. Diabetes 2002;51(9):2684-90.

116. Teusink B, Voshol PJ, Dahlmans VE, Rensen PC, Pijl H, Romijn JA, et al. Contribution of fatty acids released from lipolysis of plasma triglycerides to total plasma fatty acid flux and tissue-specific fatty acid uptake. Diabetes 2003;52(3):614-20.

117. Karpe F, de Faire U, Mercuri M, Bond MG, Hellenius ML, Hamsten A. Magnitude of alimentary lipemia is related to intima-media thickness of the common carotid artery in middle-aged men. Atherosclerosis 1998;141(2):307-14.

118. Cohn JS, Johnson EJ, Millar JS, Cohn SD, Milne RW, Marcel YL, et al. Contribution of apoB-48 and apoB-100 triglyceride-rich lipoproteins (TRL) to postprandial increases in the plasma concentration of TRL triglycerides and retinyl esters. J Lipid Res 1993;34(12):2033-40.

119. Potts JL, Fisher RM, Humphreys SM, Coppack SW, Gibbons GF, Frayn KN. Peripheral triacylglycerol extraction in the fasting and post-prandial states. Clin Sci (Lond) 1991;81(5):621-6.

120. Coppack SW, Fisher RM, Gibbons GF, Humphreys SM, McDonough MJ, Potts JL, et al. Postprandial substrate deposition in human forearm and adipose tissues in vivo. Clin Sci (Lond) 1990;79(4):33948. 
121. Bickerton AS, Roberts R, Fielding BA, Hodson L, Blaak EE, Wagenmakers AJ, et al. Preferential uptake of dietary fatty acids in adipose tissue and muscle in the postprandial period. Diabetes 2007;56(1):168-76.

122. Miles JM, Park YS, Walewicz D, Russell-Lopez C, Windsor S, Isley WL, et al. Systemic and forearm triglyceride metabolism: fate of lipoprotein lipase-generated glycerol and free fatty acids. Diabetes 2004;53(3):521-7.

123. McGarry JD, Brown NF. The mitochondrial carnitine palmitoyltransferase system. From concept to molecular analysis. Eur J Biochem 1997;244(1):1-14.

124. Campbell SE, Tandon NN, Woldegiorgis G, Luiken JJ, Glatz JF, Bonen A. A novel function for fatty acid translocase (FAT)/CD36: involvement in long chain fatty acid transfer into the mitochondria. J Biol Chem 2004;279(35):36235-41.

125. Bezaire V, Bruce CR, Heigenhauser GJ, Tandon NN, Glatz JF, Luiken JJ, et al. Identification of fatty acid translocase on human skeletal muscle mitochondrial membranes: essential role in fatty acid oxidation. Am J Physiol Endocrinol Metab 2006;290(3):E509-15.

126. Sebastian D, Guitart M, Garcia-Martinez C, Mauvezin C, Orellana-Gavalda JM, Serra D, et al. Novel role of FATP1 in mitochondrial fatty acid oxidation in skeletal muscle cells. J Lipid Res 2009;50(9):1789-99.

127. Watt MJ. Storing up trouble: does accumulation of intramyocellular triglyceride protect skeletal muscle from insulin resistance? Clin Exp Pharmacol Physiol 2009;36(1):5-11.

128. Langfort J, Ploug T, Ihlemann J, Saldo M, Holm C, Galbo H. Expression of hormone-sensitive lipase and its regulation by adrenaline in skeletal muscle. Biochem J 1999;340 ( Pt 2)(459-65.

129. Langfort J, Ploug T, Ihlemann J, Enevoldsen LH, Stallknecht B, Saldo M, et al. Hormone-sensitive lipase (HSL) expression and regulation in skeletal muscle. Adv Exp Med Biol 1998;441(219-28.

130. Jocken JW, Smit E, Goossens GH, Essers YP, van Baak MA, Mensink M, et al. Adipose triglyceride lipase (ATGL) expression in human skeletal muscle is type I (oxidative) fiber specific. Histochem Cell Biol 2008;129(4):535-8.

131. Hagstrom-Toft E, Qvisth V, Nennesmo I, Ryden M, Bolinder H, Enoksson S, et al. Marked heterogeneity of human skeletal muscle lipolysis at rest. Diabetes 2002;51(12):3376-83.

132. Phillips SA, Choe CC, Ciaraldi TP, Greenberg AS, Kong AP, Baxi SC, et al. Adipocyte differentiationrelated protein in human skeletal muscle: relationship to insulin sensitivity. Obes Res 2005;13(8):1321-9.

133. Prats C, Donsmark M, Qvortrup K, Londos C, Sztalryd C, Holm C, et al. Decrease in intramuscular lipid droplets and translocation of HSL in response to muscle contraction and epinephrine. J Lipid Res 2006;47(11):2392-9.

134. Lee JS, Pinnamaneni SK, Eo SJ, Cho IH, Pyo JH, Kim CK, et al. Saturated, but not n-6 polyunsaturated, fatty acids induce insulin resistance: role of intramuscular accumulation of lipid metabolites. J Appl Physiol 2006;100(5):1467-74.

135. Buettner R, Scholmerich J, Bollheimer LC. High-fat diets: modeling the metabolic disorders of human obesity in rodents. Obesity (Silver Spring) 2007;15(4):798-808.

136. Storlien LH, Kraegen EW, Chisholm DJ, Ford GL, Bruce DG, Pascoe WS. Fish oil prevents insulin resistance induced by high-fat feeding in rats. Science 1987;237(4817):885-8.

137. Storlien LH, Jenkins AB, Chisholm DJ, Pascoe WS, Khouri S, Kraegen EW. Influence of dietary fat composition on development of insulin resistance in rats. Relationship to muscle triglyceride and omega-3 fatty acids in muscle phospholipid. Diabetes 1991;40(2):280-9.

138. Vessby B, Tengblad S, Lithell $\mathrm{H}$. Insulin sensitivity is related to the fatty acid composition of serum lipids and skeletal muscle phospholipids in 70-year-old men. Diabetologia 1994;37(10):1044-50.

139. Haugaard SB, Madsbad S, Hoy CE, Vaag A. Dietary intervention increases n-3 long-chain polyunsaturated fatty acids in skeletal muscle membrane phospholipids of obese subjects. Implications for insulin sensitivity. Clin Endocrinol (Oxf) 2006;64(2):169-78.

140. Pan DA, Lillioja S, Milner MR, Kriketos AD, Baur LA, Bogardus C, et al. Skeletal muscle membrane lipid composition is related to adiposity and insulin action. J Clin Invest 1995;96(6):2802-8. 
141. Borkman M, Storlien LH, Pan DA, Jenkins AB, Chisholm DJ, Campbell LV. The relation between insulin sensitivity and the fatty-acid composition of skeletal-muscle phospholipids. N Engl J Med 1993;328(4):238-44.

142. Randle PJ, Garland PB, Hales CN, Newsholme EA. The glucose fatty-acid cycle. Its role in insulin sensitivity and the metabolic disturbances of diabetes mellitus. Lancet 1963;1(7285):785-9.

143. Kelley DE, Mokan M, Simoneau JA, Mandarino $L$. Interaction between glucose and free fatty acid metabolism in human skeletal muscle. J Clin Invest 1993;92(1):91-8.

144. Boden G, Jadali F, White J, Liang Y, Mozzoli M, Chen X, et al. Effects of fat on insulin-stimulated carbohydrate metabolism in normal men. J Clin Invest 1991;88(3):960-6.

145. Boden G, Lebed B, Schatz M, Homko C, Lemieux S. Effects of acute changes of plasma free fatty acids on intramyocellular fat content and insulin resistance in healthy subjects. Diabetes 2001;50(7):1612-7.

146. Roden M, Krssak M, Stingl H, Gruber S, Hofer A, Furnsinn C, et al. Rapid impairment of skeletal muscle glucose transport/phosphorylation by free fatty acids in humans. Diabetes 1999;48(2):35864.

147. McGarry JD, Mannaerts GP, Foster DW. A possible role for malonyl-CoA in the regulation of hepatic fatty acid oxidation and ketogenesis. J Clin Invest 1977;60(1):265-70.

148. Phillips DI, Caddy S, Ilic V, Fielding BA, Frayn KN, Borthwick AC, et al. Intramuscular triglyceride and muscle insulin sensitivity: evidence for a relationship in nondiabetic subjects. Metabolism 1996;45(8):947-50.

149. Pan DA, Lillioja S, Kriketos AD, Milner MR, Baur LA, Bogardus C, et al. Skeletal muscle triglyceride levels are inversely related to insulin action. Diabetes 1997;46(6):983-8.

150. Krssak M, Falk Petersen K, Dresner A, DiPietro L, Vogel SM, Rothman DL, et al. Intramyocellular lipid concentrations are correlated with insulin sensitivity in humans: a $1 \mathrm{H}$ NMR spectroscopy study. Diabetologia 1999;42(1):113-6.

151. Perseghin G, Scifo P, De Cobelli F, Pagliato E, Battezzati A, Arcelloni C, et al. Intramyocellular triglyceride content is a determinant of in vivo insulin resistance in humans: a $1 \mathrm{H}-13 \mathrm{C}$ nuclear magnetic resonance spectroscopy assessment in offspring of type 2 diabetic parents. Diabetes 1999;48(8):1600-6.

152. Hegarty BD, Cooney GJ, Kraegen EW, Furler SM. Increased efficiency of fatty acid uptake contributes to lipid accumulation in skeletal muscle of high fat-fed insulin-resistant rats. Diabetes 2002;51(5):1477-84.

153. Schrauwen-Hinderling VB, Kooi ME, Hesselink MK, Moonen-Kornips E, Schaart G, Mustard KJ, et al. Intramyocellular lipid content and molecular adaptations in response to a 1-week high-fat diet. Obes Res 2005;13(12):2088-94.

154. Bachmann OP, Dahl DB, Brechtel K, Machann J, Haap M, Maier T, et al. Effects of intravenous and dietary lipid challenge on intramyocellular lipid content and the relation with insulin sensitivity in humans. Diabetes 2001;50(11):2579-84.

155. Itani SI, Ruderman NB, Schmieder F, Boden G. Lipid-induced insulin resistance in human muscle is associated with changes in diacylglycerol, protein kinase $\mathrm{C}$, and IkappaB-alpha. Diabetes 2002;51(7):2005-11.

156. Goodpaster BH, He J, Watkins S, Kelley DE. Skeletal muscle lipid content and insulin resistance: evidence for a paradox in endurance-trained athletes. J Clin Endocrinol Metab 2001;86(12):575561.

157. Tarnopolsky MA, Rennie CD, Robertshaw HA, Fedak-Tarnopolsky SN, Devries MC, Hamadeh MJ. Influence of endurance exercise training and sex on intramyocellular lipid and mitochondrial ultrastructure, substrate use, and mitochondrial enzyme activity. Am J Physiol Regul Integr Comp Physiol 2007;292(3):R1271-8.

158. He J, Watkins S, Kelley DE. Skeletal muscle lipid content and oxidative enzyme activity in relation to muscle fiber type in type 2 diabetes and obesity. Diabetes 2001;50(4):817-23. 
159. Moro C, Bajpeyi S, Smith SR. Determinants of intramyocellular triglyceride turnover: implications for insulin sensitivity. Am J Physiol Endocrinol Metab 2008;294(2):E203-13.

160. Blaak EE, Van Baak MA, Kemerink GJ, Pakbiers MT, Heidendal GA, Saris WH. Beta-adrenergic stimulation of energy expenditure and forearm skeletal muscle metabolism in lean and obese men. Am J Physiol 1994;267(2 Pt 1):E306-15.

161. Colberg SR, Simoneau JA, Thaete FL, Kelley DE. Skeletal muscle utilization of free fatty acids in women with visceral obesity. J Clin Invest 1995;95(4):1846-53.

162. Kelley DE, Simoneau JA. Impaired free fatty acid utilization by skeletal muscle in non-insulindependent diabetes mellitus. J Clin Invest 1994;94(6):2349-56.

163. Blaak EE, Wagenmakers AJ, Glatz JF, Wolffenbuttel BH, Kemerink GJ, Langenberg CJ, et al. Plasma FFA utilization and fatty acid-binding protein content are diminished in type 2 diabetic muscle. Am J Physiol Endocrinol Metab 2000;279(1):E146-54.

164. Blaak EE, van Aggel-Leijssen DP, Wagenmakers AJ, Saris WH, van Baak MA. Impaired oxidation of plasma-derived fatty acids in type 2 diabetic subjects during moderate-intensity exercise. Diabetes 2000;49(12):2102-7.

165. Mensink M, Blaak EE, van Baak MA, Wagenmakers AJ, Saris WH. Plasma free Fatty Acid uptake and oxidation are already diminished in subjects at high risk for developing type 2 diabetes. Diabetes 2001;50(11):2548-54.

166. Blaak EE, Wolffenbuttel BH, Saris WH, Pelsers MM, Wagenmakers AJ. Weight reduction and the impaired plasma-derived free fatty acid oxidation in type 2 diabetic subjects. J Clin Endocrinol Metab 2001;86(4):1638-44.

167. Thyfault JP, Kraus RM, Hickner RC, Howell AW, Wolfe RR, Dohm GL. Impaired plasma fatty acid oxidation in extremely obese women. Am J Physiol Endocrinol Metab 2004;287(6):E1076-81.

168. Corpeleijn E, Mensink M, Kooi ME, Roekaerts PM, Saris WH, Blaak EE. Impaired skeletal muscle substrate oxidation in glucose-intolerant men improves after weight loss. Obesity (Silver Spring) 2008;16(5):1025-32.

169. Goodpaster BH, Katsiaras A, Kelley DE. Enhanced fat oxidation through physical activity is associated with improvements in insulin sensitivity in obesity. Diabetes 2003;52(9):2191-7.

170. Bonen A, Parolin ML, Steinberg GR, Calles-Escandon J, Tandon NN, Glatz JF, et al. Triacylglycerol accumulation in human obesity and type 2 diabetes is associated with increased rates of skeletal muscle fatty acid transport and increased sarcolemmal FAT/CD36. Faseb J 2004;18(10):1144-6.

171. Kelley DE, He J, Menshikova EV, Ritov VB. Dysfunction of mitochondria in human skeletal muscle in type 2 diabetes. Diabetes 2002;51(10):2944-50.

172. Petersen KF, Dufour S, Befroy D, Garcia R, Shulman GI. Impaired mitochondrial activity in the insulin-resistant offspring of patients with type 2 diabetes. N Engl J Med 2004;350(7):664-71.

173. Phielix E, Schrauwen-Hinderling VB, Mensink M, Lenaers E, Meex R, Hoeks J, et al. Lower intrinsic ADP-stimulated mitochondrial respiration underlies in vivo mitochondrial dysfunction in muscle of male type 2 diabetic patients. Diabetes 2008;57(11):2943-9.

174. Aude YW, Mego P, Mehta JL. Metabolic syndrome: dietary interventions. Curr Opin Cardiol 2004;19(5):473-9.

175. Riccardi G, Giacco R, Rivellese AA. Dietary fat, insulin sensitivity and the metabolic syndrome. Clin Nutr 2004;23(4):447-56.

176. Corpeleijn E, Feskens EJ, Jansen EH, Mensink M, Saris WH, de Bruin TW, et al. Improvements in glucose tolerance and insulin sensitivity after lifestyle intervention are related to changes in serum fatty acid profile and desaturase activities: the SLIM study. Diabetologia 2006;49(10):2392-401.

177. Melanson EL, Astrup A, Donahoo WT. The relationship between dietary fat and fatty acid intake and body weight, diabetes, and the metabolic syndrome. Ann Nutr Metab 2009;55(1-3):229-43.

178. Mensink RP, Katan MB. Effect of dietary fatty acids on serum lipids and lipoproteins. A metaanalysis of 27 trials. Arterioscler Thromb Vasc Biol 1992;12(8):911-9.

179. Sacks FM, Katan M. Randomized clinical trials on the effects of dietary fat and carbohydrate on plasma lipoproteins and cardiovascular disease. Am J Med 2002;113 Suppl 9B(13S-24S. 
180. Petersen M, Taylor MA, Saris WH, Verdich C, Toubro S, Macdonald I, et al. Randomized, multicenter trial of two hypo-energetic diets in obese subjects: high- versus low-fat content. Int J Obes (Lond) 2006;30(3):552-60.

181. Nordmann AJ, Nordmann A, Briel M, Keller U, Yancy WS, Jr., Brehm BJ, et al. Effects of lowcarbohydrate vs low-fat diets on weight loss and cardiovascular risk factors: a meta-analysis of randomized controlled trials. Arch Intern Med 2006;166(3):285-93.

182. Vessby B, Unsitupa M, Hermansen K, Riccardi G, Rivellese AA, Tapsell LC, et al. Substituting dietary saturated for monounsaturated fat impairs insulin sensitivity in healthy men and women: The KANWU Study. Diabetologia 2001;44(3):312-9.

183. Summers LK, Fielding BA, Bradshaw HA, Ilic V, Beysen C, Clark ML, et al. Substituting dietary saturated fat with polyunsaturated fat changes abdominal fat distribution and improves insulin sensitivity. Diabetologia 2002;45(3):369-77.

184. Andersson A, Nalsen C, Tengblad S, Vessby B. Fatty acid composition of skeletal muscle reflects dietary fat composition in humans. Am J Clin Nutr 2002;76(6):1222-9.

185. Roberts R, Bickerton AS, Fielding BA, Blaak EE, Wagenmakers AJ, Chong MF, et al. Reduced oxidation of dietary fat after a short term high-carbohydrate diet. Am J Clin Nutr 2008;87(4):82431.

186. Gaster M, Rustan AC, Beck-Nielsen H. Differential utilization of saturated palmitate and unsaturated oleate: evidence from cultured myotubes. Diabetes 2005;54(3):648-56.

187. Rivellese AA, Giacco R, Annuzzi G, De Natale C, Patti L, Di Marino L, et al. Effects of monounsaturated vs. saturated fat on postprandial lipemia and adipose tissue lipases in type 2 diabetes. Clin Nutr 2008;27(1):133-41.

188. Madsen L, Petersen RK, Kristiansen K. Regulation of adipocyte differentiation and function by polyunsaturated fatty acids. Biochim Biophys Acta 2005;1740(2):266-86.

189. Festuccia WT, Laplante M, Berthiaume M, Gelinas Y, Deshaies Y. PPARgamma agonism increases rat adipose tissue lipolysis, expression of glyceride lipases, and the response of lipolysis to hormonal control. Diabetologia 2006;49(10):2427-36.

190. Kershaw EE, Schupp M, Guan HP, Gardner NP, Lazar MA, Flier JS. PPARgamma regulates adipose triglyceride lipase in adipocytes in vitro and in vivo. Am J Physiol Endocrinol Metab 2007;293(6):E1736-45.

191. Jump DB, Clarke SD. Regulation of gene expression by dietary fat. Annu Rev Nutr 1999;19(63-90.

192. Roche HM. Fatty acids and the metabolic syndrome. Proc Nutr Soc 2005;64(1):23-9.

193. Twickler TB, Dallinga-Thie GM, Cohn JS, Chapman MJ. Elevated remnant-like particle cholesterol concentration: a characteristic feature of the atherogenic lipoprotein phenotype. Circulation 2004;109(16):1918-25. 


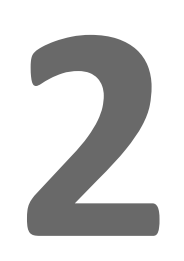

\section{Determinants of diet-induced changes in insulin sensitivity among subjects with the metabolic syndrome: the Lipgene}

Anneke M.J. van Hees, Audrey C. Tierney, Danielle I. Shaw, Hanne L. Gulseth, Juan A. Paniagua, Jolene McMonagle, Beata Kieć-Wilk, Ulf Risérus, Catherine Defoort, José López-Miranda, Aldona Dembińska-Kieć, Brita Karlström, Wim H.M. Saris, Christian A. Drevon, Helen M. Roche, Julie A. Lovegrove and Ellen E. Blaak

Submitted 


\section{Abstract}

Dietary intervention, aimed at weight loss or optimising dietary macronutrient composition, can affect insulin sensitivity and the onset of the metabolic syndrome (MetS). We investigated what factors influence diet-induced changes in insulin sensitivity in a large cohort of men and women $(n=486)$ with the MetS.

MetS subjects were randomised to four isoenergetic dietary treatments: high-fat SFA diet (HSFA), high-fat MUFA diet (HMUFA) and two low-fat high-complex carbohydrate diets (LFHCC), one supplemented with $1.24 \mathrm{~g} / \mathrm{d}$ long-chain $n-3$ PUFA (LFHCCn-3). Pre- and post-intervention fasting blood samples were drawn to measure lipid and adipokine concentrations. Determinants of changes in insulin sensitivity $\left(\mathrm{S}_{\mathrm{I}}\right)$ and insulin resistance $\left(\mathrm{HOMA}_{\mathrm{IR}}\right)$ were evaluated by univariate ANOVA. Changes in body weight were inversely associated with changes in $S_{1}(P=0.049)$, being most pronounced in subjects on the LFHCCn-3 diet. Effects of dietary intervention on $\mathrm{HOMA}_{\mathrm{IR}}$ depended on habitual fat intake and sex $(P=0.049)$; the HMUFA diet reduced $\mathrm{HOMA}_{\mathrm{IR}}$ in women with a habitual fat intake < 36 energy\% $(P=0.012)$, whereas the LFHCCn-3 diet reduced $\mathrm{HOMA}_{\mathrm{IR}}$ in women with a habitual fat intake $>36$ energy\% $(P=0.008)$. Also, changes in body weight $(P=0.004)$, fasting plasma triacylglycerol $P=0.013)$ and t-PA $(P=0.003)$ and changes in TNF- $\alpha$ on the LFHCC $n-3$ diet (diet* $\triangle$ TNF- $\alpha, P=0.040$ ) were independently and positively related to HOMA $_{\text {IR }}$.

Weight change was the strongest factor related to insulin sensitivity, although this study shows that the efficacy of dietary intervention to improve insulin sensitivity in the MetS is multifaceted, also depending on dietary background, sex and several metabolic and inflammatory factors associated with the MetS. 


\section{Introduction}

The metabolic syndrome (MetS) represents a cluster of risk factors for the development of type 2 diabetes mellitus and cardiovascular disease, and is characterised by abdominal obesity, insulin resistance (IR), hypertension, dyslipidaemia and a state of chronic, low-grade inflammation $(1,2)$. IR is closely linked with the MetS, obesity, inflammation and disturbed fatty acid metabolism $(3,4)$. Both the expansion of adipose tissue (i.e. obesity) and disturbances in its function are associated with increased production of pro-inflammatory cytokines such as tumour necrosis factor-alpha (TNF- $\alpha$ ) and a reduced secretion of adiponectin $(1,2,5)$. Also, the capacity of adipose tissue to store fatty acids may become limited in obesity, leading to ectopic fat accumulation in skeletal muscle, liver and pancreas, and subsequent development of IR $(6,7)$. In skeletal muscle and liver, pro-inflammatory cytokines may directly interfere with insulin signalling, and also contribute to the development of IR via effects on fatty acid metabolism and ectopic fat accumulation (8).

Lifestyle interventions are effective in improving insulin sensitivity or delaying the onset of IR and type 2 diabetes mellitus (9-11). Excessive energy intake, in particular high intakes of saturated fatty acids (SFA), have been associated with IR and the MetS $(4,12,13)$, whereas the association with unsaturated fatty acids is less clear (14). Isoenergetic substitution of dietary SFA by unsaturated fatty acids or carbohydrates may improve insulin sensitivity in healthy volunteers $(15,16)$. The LIPGENE human dietary intervention study investigated the effects of reducing SFA intake by altering the quality or reducing the quantity of dietary fat (under isoenergetic conditions) on insulin sensitivity in a large European cohort of men and women with the MetS. Overall, insulin sensitivity did not change after dietary fat modification in this study (17). However, it is possible that several factors may have affected individual responsiveness to the dietary intervention and thus influenced insulin sensitivity. Some data suggest that the impact of change in dietary fat quality on insulin sensitivity may depend on habitual fat intake (15). Moreover, other lifestyle factors such as smoking and physical activity may influence insulin sensitivity in the longer term (13) and positive effects could also be partly mediated by beneficial changes in plasma adipokine concentrations $(18,19)$. Insulin resistance assessed by $\mathrm{HOMA}_{\mathrm{R}}$ may have been affected differently by the LIPGENE dietary intervention than insulin sensitivity, as $\mathrm{HOMA}_{\mathrm{IR}}$ is merely a reflection of hepatic insulin resistance whereas $S_{1}$ reflects both hepatic and peripheral insulin sensitivity. Therefore, the aim of the present study was to investigate whether diet-induced changes in insulin sensitivity $\left(\mathrm{S}_{I}\right)$ and insulin resistance $\left(\mathrm{HOMA}_{\mathrm{I}}\right)$ could be associated with changes in metabolic, anthropometric and inflammatory characteristics of the MetS. 


\section{Methods}

The LIPGENE human dietary intervention study was a 12-week parallel, randomised, controlled study in subjects with the MetS, carried out at eight different centres across Europe: Ireland, United Kingdom, Norway, France, Netherlands, Spain, Poland and Sweden (17). The trial was part of the EU $6^{\text {th }}$ Framework integrated project 'Diet, genomics and the metabolic syndrome, an integrated nutrition, agrofood, social and economic analysis - LIPGENE'.

\section{Study population}

In total, 486 Caucasian subjects (220 men, 266 women) with the MetS, aged 35-70 y and body mass index (BMI) between 20 and $40 \mathrm{~kg} / \mathrm{m}^{2}$, were included in the LIPGENE study. The MetS was defined by a modified version of the NCEP ATP III report (20), with subjects meeting at least three of the following criteria: 1) fasting plasma glucose concentration between 5.5 and $7.0 \mathrm{mmol} / \mathrm{l} ; 2$ ) fasting plasma triacylglycerol (TAG) concentration $\geq 1.5 \mathrm{mmol} / \mathrm{l} ; 3$ ) fasting plasma HDL-cholesterol concentration $<1.0 \mathrm{mmol} / \mathrm{l}$ for men and $<1.3 \mathrm{mmol} / \mathrm{l}$ for women; 4) systolic blood pressure $\geq 130 \mathrm{~mm} \mathrm{Hg}$ and/or diastolic blood pressure $\geq 85 \mathrm{~mm} \mathrm{Hg}$ and/or treatment of previously diagnosed hypertension; 5) waist circumference $>102 \mathrm{~cm}$ for men and $>88 \mathrm{~cm}$ for women. Antihypertensive medication, oral contraceptives, hormone replacement therapy, multivitamin supplements and non-fatty acid based nutritional supplements were allowed if the subjects adhered to the same regimen during the entire study period. Exclusion criteria were pre-diagnosed diabetes or other endocrine disorders; chronic inflammatory conditions; kidney or liver dysfunction or iron deficiency; use of hypo-lipidaemic or anti-inflammatory medication; use of aspirin >1 per week, fatty acid supplements or high doses of antioxidant vitamins; consumption of $>2$ portions of oily fish per week; weight change $>3 \mathrm{~kg}$ within 3 months prior to the study start; highly trained or endurance athletes; and alcohol or drug abuse.

All subjects were informed about the study and written informed consent was attained prior to study participation. The study protocol was given a favourable ethical opinion for conduct by the local research ethics committee at each of the eight intervention centres.

\section{Experimental design}

Pre- and post-intervention, subjects underwent a 1-day clinical investigation protocol as described previously (17). In short, subjects came to one of the research centres after an overnight fast. Anthropometric measurements were completed and fasting blood samples were taken to measure plasma lipid concentrations and 
inflammatory markers. Thereafter, all subjects completed an insulin-modified intravenous glucose tolerance test (IVGTT) to measure insulin sensitivity as described previously (21).

\section{Dietary intervention study}

Subjects were randomly assigned to receive one of four intervention diets for 12 weeks:

1) High-fat (38\% energy (E\%)), SFA-rich diet (16 E\% SFA, 12 E\% monounsaturated fatty acids (MUFA), 6 E\% PUFA) (HSFA);

2) High-fat (38 E\%), MUFA-rich diet (8 E\% SFA, 20 E\% MUFA, 6 E\% PUFA) (HMUFA);

3) Isoenergetic low-fat (28 E\%), high-complex carbohydrate diet (8 E\% SFA, 11 E\% MUFA, 6 E\% PUFA), with $1 \mathrm{~g} / \mathrm{d}$ high oleic sunflower oil supplement (LFHCC);

4) Isoenergetic low-fat (28 E\%), high-complex carbohydrate diet (8 E\% SFA, $11 \mathrm{E} \%$ MUFA, 6 E\% PUFA), with $1.24 \mathrm{~g} / \mathrm{d}$ LC $n$-3 PUFA supplement (EPA and DHA, ratio 1.4 to 1 ) (LFHCCn-3).

Detailed descriptions of the food exchange model and assessment of compliance were published elsewhere (22). Subjects had to remain weight stable during the dietary intervention period (changes were allowed within the range of $2 \mathrm{~kg}$ ) and were asked to maintain their normal pattern of physical activity, alcohol consumption and smoking.

\section{Biochemical analyses}

Blood for lipid and apolipoprotein analyses was collected in potassium EDTA vacutainer tubes. Glucose samples were collected in fluoride oxalate vacutainers, and insulin and c-peptide samples in serum tubes. Blood samples for the analyses of cytokines and adhesion molecules were collected in serum separator vacutainers, and in citrate vacutainers for coagulation analyses. All samples were centrifuged immediately ( $10 \mathrm{~min}, 4{ }^{\circ} \mathrm{C}, 1500 \mathrm{~g}$ ), except for serum samples, which were allowed to clot for $30 \mathrm{~min}$ at room temperature before centrifugation. Plasma or serum was then aliquoted and stored $\left(-80^{\circ} \mathrm{C}\right)$ until analysis. Serum insulin and c-peptide concentrations were determined by solid phase, two-side fluoroimmunometric assays (AutoDELFIA Insulin and AutoDELFIA C-Peptide kits, Wallac Oy, Turku, Finland) using a 1235 AutoDELFIA automatic immunoassay system. Plasma TAG, FFA, glucose, total cholesterol, HDL-cholesterol and serum LDL-cholesterol concentrations were determined with an ILab 600 clinical chemical analyser (Instrumentation Laboratory, Warrington, UK) using enzymatic colourimetric kits. High sensitive ELISA kits were used to determine serum C-reactive protein (CRP) (BioCheck Inc., CA, USA), IL-6 (Bioscource Inc., CA, USA), TNF- $\alpha$, adiponectin, leptin (R\&D Systems, Minneapolis, MN, USA), plasma plasminogen activator inhibitor-1 
(PAI-1) and tissue plasminogen activator (t-PA) (Asserochrom ELISA kits, Diagnostica Stago, France).

\section{Calculations}

Insulin sensitivity $\left(S_{1}\right)$ was determined using the MINMOD Millennium program (version 6.02, Richard Bergman) (23). The homeostasis model assessment for insulin resistance $\left(\mathrm{HOMA}_{\mathrm{IR}}\right)$ was calculated from fasting glucose and insulin concentrations according to the equation of Matthews et al (24).

\section{Statistical methods}

Statistical analyses were performed using SPSS 15.0 for Windows (SPSS Inc.). All variables were checked for normal distribution and depending on normality, paired samples t-tests or Wilcoxon signed rank tests were used to test for within-subject differences pre- and post-intervention.

Univariate general linear model was used to evaluate which factors were associated with changes $(\Delta)$ in $\mathrm{S}_{\mathrm{I}}$ or $\mathrm{HOMA}_{\mathrm{IR}}$ after dietary intervention. The basic model was a full-factorial model including diet, sex, centre, habitual fat intake (below vs. above median of $36 \mathrm{E} \%$ ), age and $\Delta$ body weight as independent variables. Thereafter, the contribution of other variables (both main effect and interactions with diet and sex) was evaluated by adding them separately to the basic model (i.e. $\Delta$ waist, $\Delta$ systolic blood pressure, $\Delta$ diastolic blood pressure, $\Delta$ TAG, $\Delta$ HDL-cholesterol, $\Delta$ FFA, $\Delta$ adiponectin, $\Delta$ leptin, $\Delta$ TNF- $\alpha, \Delta$ IL-6, $\Delta$ CRP, $\Delta$ PAI-1 and $\Delta$ t-PA). In addition, the model was adjusted for the mean of each continuous variable in the model ((baseline $+12 w k) / 2)$. The $\Delta$ of each parameter was calculated as ( $12 w k$ - baseline). The dependent variables $\left(\Delta \mathrm{S}_{\mathrm{I}}\right.$ and $\Delta \mathrm{HOMA}_{\mathrm{IR}}$ ) were In-transformed to satisfy conditions of normality. Post hoc analyses were performed on significant interaction terms using one-way ANOVA between-groups or paired samples t-test withingroups. Statistical significance was set at $P<0.05$.

\section{Results}

A total of 417 subjects (185 men, 232 women) completed the LIPGENE dietary intervention study, 326 of whom had complete pre- and post-intervention measurements for $\mathrm{S}_{\mathrm{I}}$ and 408 for $\mathrm{HOMA}_{\mathrm{IR}}$. The main results of the LIPGENE dietary intervention study have been published elsewhere (17).

A total of 312 subjects were included in the analysis of determinants of change in $S_{1}$, as they had measurements for all variables in the statistical model. Subject characteristics of this population are given in Table 2.1. By definition, all subjects 
Table 2.1 Subject characteristics at baseline and after the 12-week dietary intervention period

\begin{tabular}{|c|c|c|}
\hline & Pre-intervention & Post-intervention \\
\hline Sex (men / women) ( $n)$ & $134 / 178$ & \\
\hline Age $(y)$ & $54.5(53.5-55.5)$ & \\
\hline Body weight (kg) & $90.6(89.1-92.1)$ & $90.1(88.6-91.6)^{*}$ \\
\hline BMI $\left(\mathrm{kg} / \mathrm{m}^{2}\right)$ & $32.4(31.9-32.9)$ & $32.2(31.7-32.7)^{*}$ \\
\hline Waist circumference $(\mathrm{cm})$ & $105.6(104.4-106.7)$ & $105.0(103.9-106.2)^{\#}$ \\
\hline Systolic blood pressure (mm Hg) & $138.4(136.6-140.1)$ & $133.7(132.2-135.3)^{*}$ \\
\hline Diastolic blood pressure $(\mathrm{mm} \mathrm{Hg})$ & $85.5(84.5-86.5)$ & $83.6(82.7-84.5)^{*}$ \\
\hline Plasma glucose (mmol/l) & $5.91(5.82-5.99)$ & $5.88(5.78-5.97)$ \\
\hline Plasma TAG (mmol/l) & $1.83(1.73-1.94)$ & $1.72(1.63-1.82)^{\S}$ \\
\hline Plasma HDL-C (mmol/l) & $1.09(1.06-1.12)$ & $1.11(1.08-1.15)^{\S}$ \\
\hline Plasma FFA $(\mu \mathrm{mol} / \mathrm{l})$ & $622(596-648)$ & $619(593-645)$ \\
\hline $\left.\mathrm{S}_{\mathrm{I}}\left(\mathrm{mU} / \mathrm{I}^{-1}\right) \cdot \mathrm{min}^{-1} \cdot 10^{-4}\right)$ & $2.81(2.63-2.93)$ & $2.79(2.62-2.96)$ \\
\hline $\mathrm{HOMA}_{\mathrm{IR}}$ & $2.73(2.57-2.90)$ & $2.62(2.44-2.81)^{\S}$ \\
\hline Serum adiponectin $(\mathrm{mg} / \mathrm{l})$ & $3.72(3.47-3.97)$ & $3.92(3.65-4.19)$ \\
\hline Serum leptin (ng/ml) & $23.18(20.82-25.54)$ & $22.49(20.00-24.98)^{\S}$ \\
\hline Serum TNF- $\alpha(p g / m l)$ & $5.03(4.52-5.55)$ & $4.46(4.01-4.91)^{\dagger}$ \\
\hline Serum IL-6 (pg/ml) & $5.08(4.61-5.55)$ & $4.80(4.34-5.27)$ \\
\hline Serum CRP (mg/l) & $5.14(4.68-5.59)$ & $4.95(4.56-5.34)$ \\
\hline Plasma PAl-1 (ng/ml) & $56.13(52.09-60.18)$ & $55.08(51.27-58.88)$ \\
\hline Plasma t-PA (ng/ml) & $8.65(8.20-9.10)$ & $8.34(7.88-8.80)$ \\
\hline
\end{tabular}

Values are mean $(95 \% \mathrm{Cl})$. Plasma and serum concentrations are measured during fasting.

${ }^{*} P<0.001,{ }^{\#} P<0.05$, pre- vs. post-intervention, paired samples t-test.

${ }^{\S} P \leq 0.01,{ }^{\dagger} P<0.05$, pre- vs. post-intervention, wilcoxon signed-rank test.

had the MetS. In the whole sample combining all four dietary intervention groups ( $n=312$ ), we observed an overall significant decrease in $\mathrm{HOMA}_{\mathrm{R}}$, body weight, waist circumference, systolic and diastolic blood pressure, fasting plasma TAG, serum leptin and serum TNF- $\alpha$ concentrations, and significant increase in HDL-cholesterol after dietary intervention $(P<0.05$, Table 2.1$)$. Insulin sensitivity did not significantly change after dietary intervention in the total group of subjects (Table 2.1).

\section{Determinants of change in insulin sensitivity $\left(S_{1}\right)$}

Dietary intervention was not significantly associated with changes in $\mathrm{S}_{1}$ in the basic model while adjusting for sex, centre, habitual fat intake, age and changes in body weight. The interaction term $\Delta$ body weight*diet, however, was significantly associated with change in $S_{1}(P=0.049)$, in which a decrease in body weight tended 
to be more strongly related to an increase in $\mathrm{S}_{\text {I }}$ on the LFHCCn-3 diet compared to the HSFA diet ( $P=0.08$, Figure 2.1).

After adding individual components of the MetS to the basic model, also no significant associations were observed. Only the interaction term $\Delta$ adiponectin*sex tended to be associated with $\Delta \mathrm{S}_{1}$, with changes in adiponectin concentrations being positively related to changes in $S_{1}$ in women, but negatively in men $(\beta=-0.078$, $P=0.05$; men vs. women). Changes in fasting leptin, TNF- $\alpha, \mathrm{IL}-6, \mathrm{CRP}, \mathrm{t}-\mathrm{PA}$ and PAI-1 concentrations were not influenced by dietary fat modification, and were not significantly associated with $\Delta \mathrm{S}_{\text {. }}$.

A

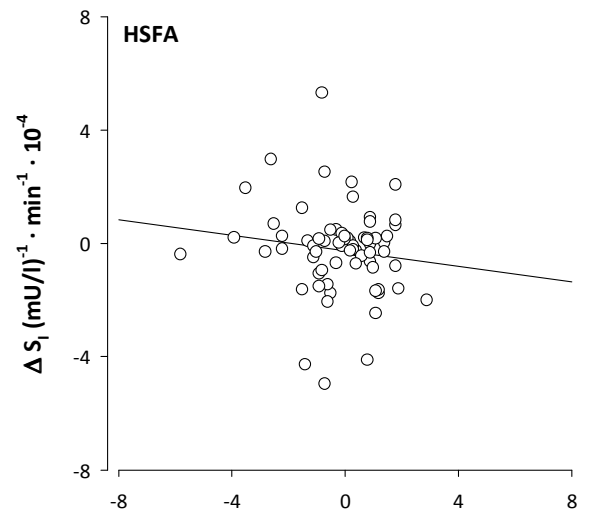

C

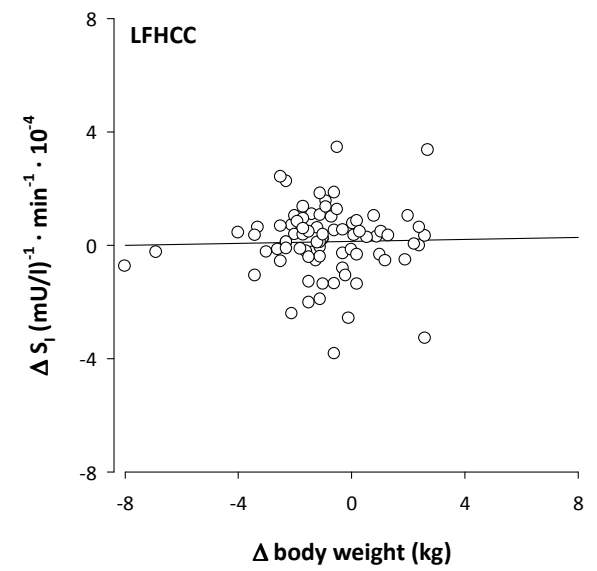

B

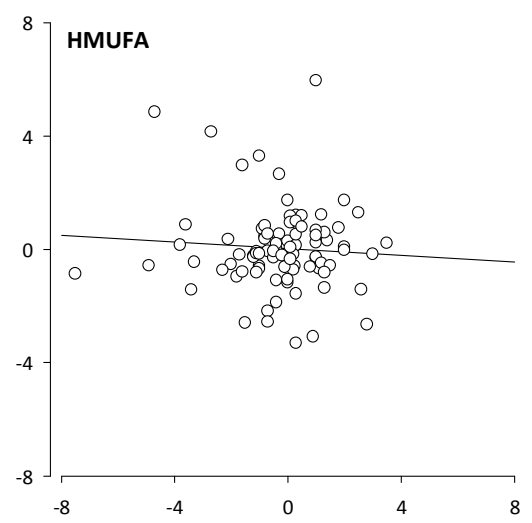

D

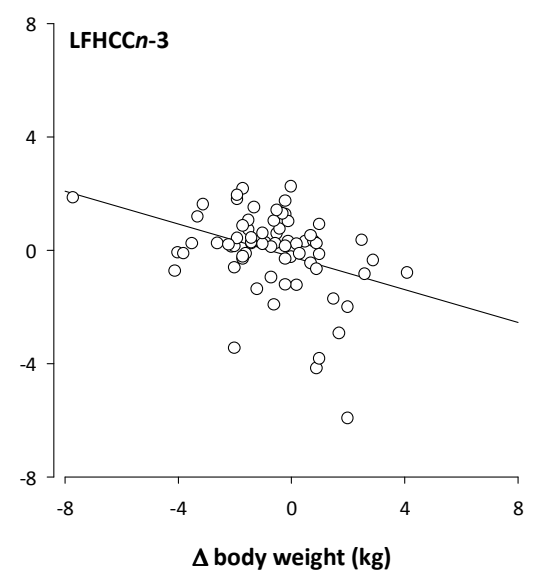

Figure 2.1 Associations between $\Delta \mathrm{SI}$ and $\Delta$ body weight in the dietary intervention groups ( $\Delta$ body weight*diet, $P=0.049$ ), which were most pronounced on the LFHCCn-3 diet compared to the HSFA diet ( $P=0.08$ ). (A) HSFA: $n=68$; (B) HMUFA: $n=91$; (C) LFHCC: $n=81$; (D) LFHCC $n-3: n=72$. 

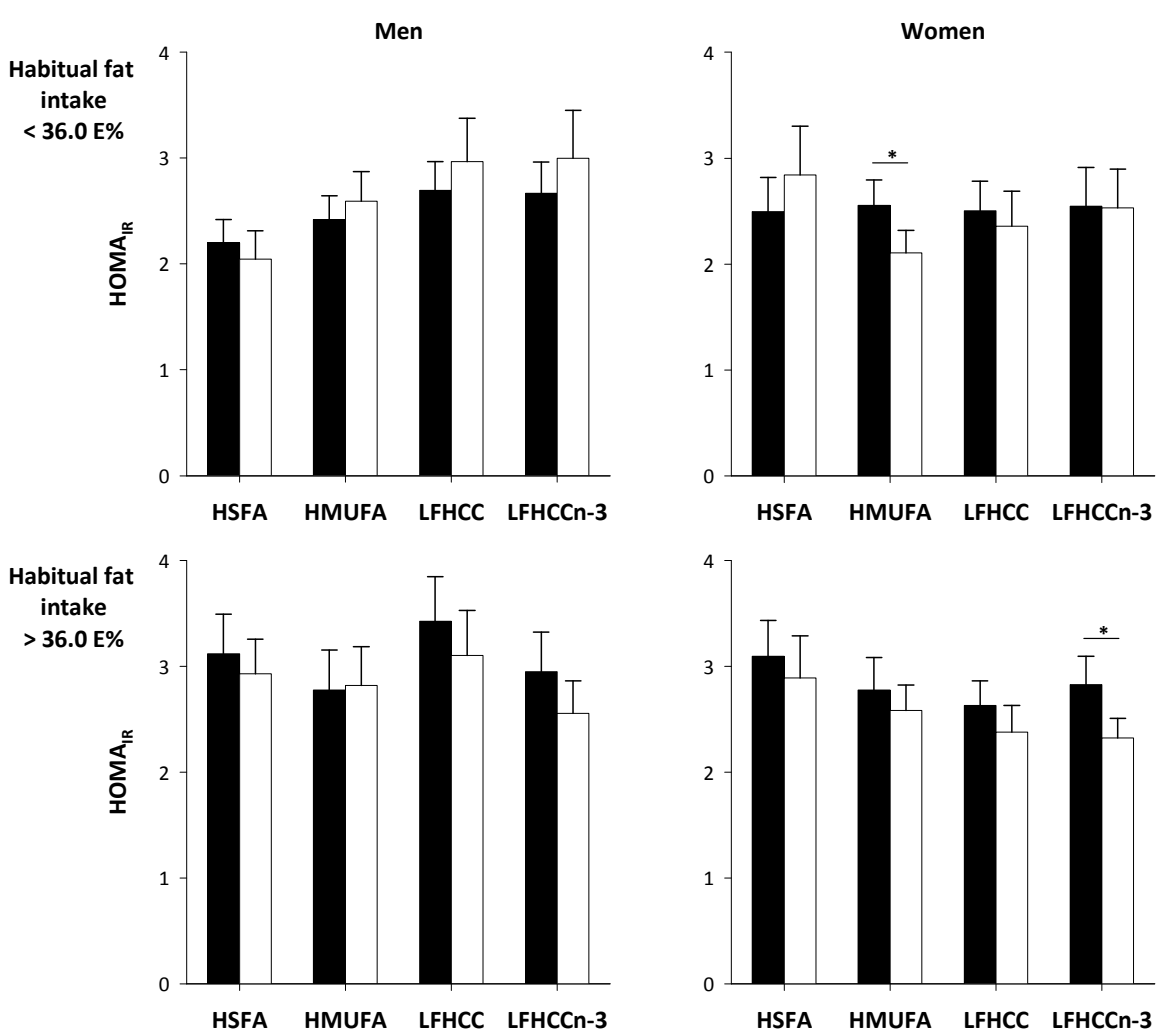

Figure 2.3 Pre- and post-intervention values for $\mathrm{HOMA}_{\mathbb{R}}$ according to habitual dietary fat intake, sex and dietary intervention groups (diet*sex*habitual fat intake, $P=0.032$ ). Filled bars: pre-intervention; open bars: post-intervention. Values are mean \pm SEM. Habitual fat intake < 36.0 E\%: $n=198$ (89 men, 109 women); Habitual fat intake > 36.0 E\%: $n=190$ (83 men, 107 women).

${ }^{*} P \leq 0.01$, post hoc testing pre- vs. post-intervention, paired samples t-test.

\section{Determinants of change in insulin resistance $\left(\mathrm{HOMA}_{\mathrm{IR}}\right)$}

In the basic model, changes in body weight were significantly associated with changes in $\mathrm{HOMA}_{\mathrm{R}}(\triangle$ body weight $\beta=0.047, P=0.004$ ), independent of dietary fat quantity or quality (Figure 2.2A). In addition, the interaction term diet*sex*habitual fat intake was significantly associated with changes in $\mathrm{HOMA}_{\mathrm{IR}}$ $(P=0.032)$, indicating that the effects of dietary intervention on $\mathrm{HOMA}_{\mathrm{IR}}$ depended on sex and habitual fat intake (Figure 2.3). Post hoc testing showed that $\mathrm{HOMA}_{\mathbb{R}}$ was significantly decreased in women on the HMUFA diet with a habitual fat intake below $36 \mathrm{E} \%(n=29, P=0.012)$, and in women on the LFHCC $n-3$ diet with a habitual fat intake above $36 \mathrm{E} \%(n=23, P=0.008)$ (Figure 2.3). 


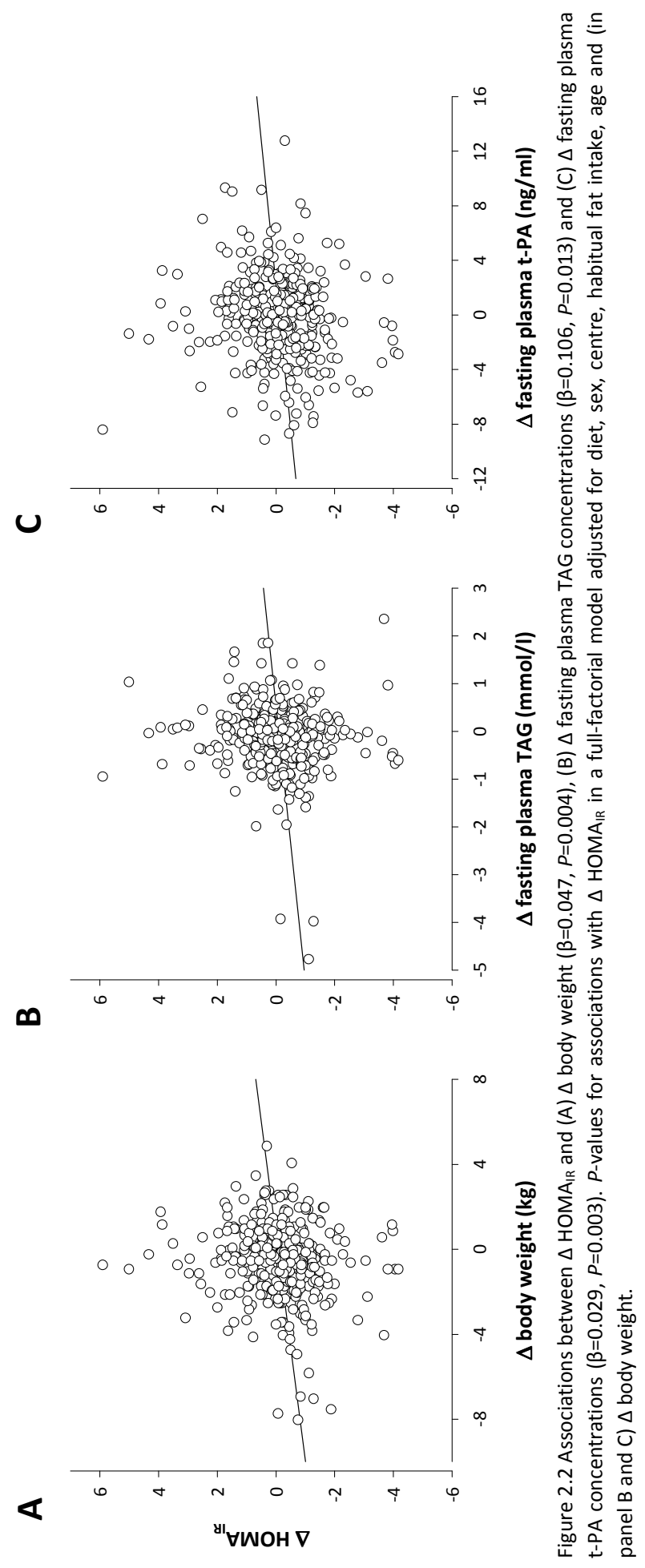


Further exploring the basic model, significant positive associations were observed for changes in fasting plasma TAG $(\beta=0.106, P=0.013)$ (Figure 2.2B) and changes in fasting plasma t-PA concentrations $(\beta=0.029, P=0.003$ ) (Figure $2.2 C)$ with changes in $\mathrm{HOMA}_{\mathrm{IR}}$. The interaction term $\Delta \mathrm{TNF}-\alpha^{*}$ diet $(P=0.040)$ was also significantly associated with $\triangle \mathrm{HOMA}_{\mathrm{IR}}$, with a more positive relationship between changes in TNF- $\alpha$ concentrations and HOMA $\mathrm{IR}_{\mathrm{R}}$ on the LFHCCn-3 diet as compared to the HSFA diet $(\beta=0.060, P=0.005$; Figure 2.4). In addition, the interaction term $\Delta$ adiponectin*sex tended to be associated with $\Delta \mathrm{HOMA}_{\mathrm{IR}}(\beta=-0.053, P=0.06$; men vs. women).

A

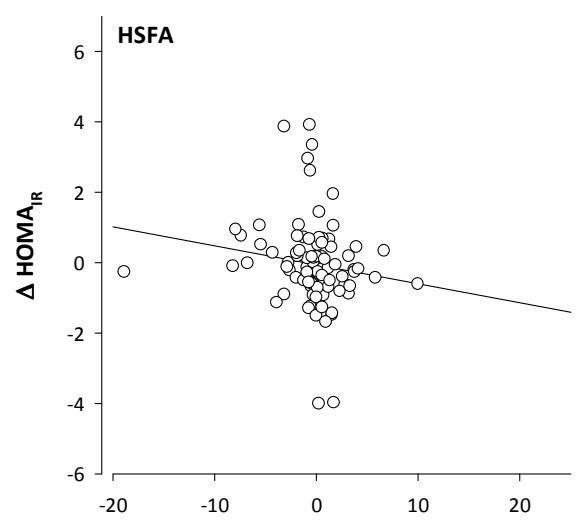

C

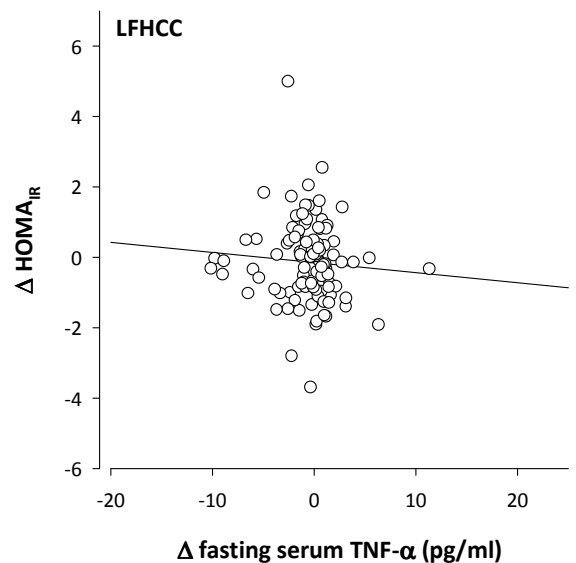

B

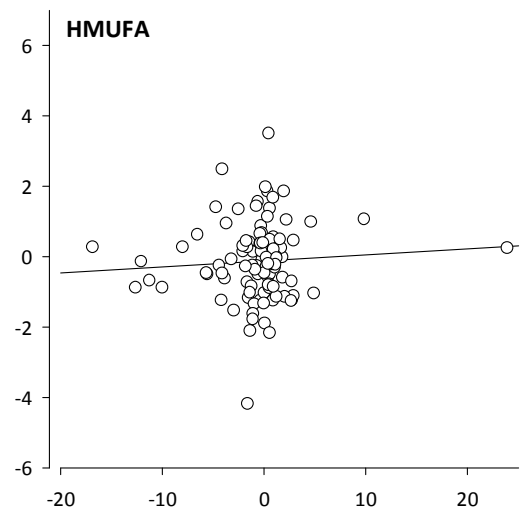

D

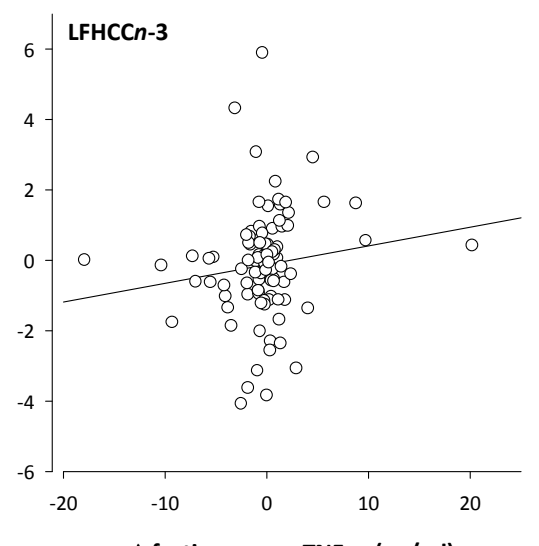

Figure 2.4 Associations between $\Delta \mathrm{HOMA}_{\mathrm{IR}}$ and $\Delta \mathrm{TNF}-\alpha$ in the dietary intervention groups ( $\Delta \mathrm{TNF}-\alpha^{*}$ diet, $P=0.040)$, which were most pronounced on the LFHCC $n-3$ diet compared to the HSFA diet $(\beta=0.060$, $P=0.005$ ). (A) HSFA: $n=88$; (B) HMUFA: $n=106$; (C) LFHCC: $n=102$; (D) LFHCC $n-3: n=92$. 


\section{Discussion}

In the present study we investigated several factors that may have affected individual responses on insulin sensitivity $\left(\mathrm{S}_{I}\right)$ and insulin resistance $\left(\mathrm{HOMA}_{\mathrm{IR}}\right)$ after a 12-week dietary intervention period with isoenergetic diets differing in both fat quantity and quality from LIPGENE study (17). Although the diets were designed to be isoenergetic in our study, small but significant decreases in body weight were observed in all intervention groups, which were significantly associated with changes in $\mathrm{HOMA}_{\mathrm{IR}}$. This relationship appeared to be diet-dependent for $\mathrm{S}_{1}$, with the strongest association between body weight and $S_{I}$ on the LFHCCn-3 diet. Interestingly, also on the LFHCCn-3 diet, a positive association was observed between changes in TNF- $\alpha$ and changes in $\mathrm{HOMA}_{\mathrm{IR}}$, independent of body weight. These data may suggest that besides changes in body mass, an improved adipose tissue function also may be responsible for the specific associations with insulin resistance observed on the LFHCC $n-3$ diet. LC $n-3$ PUFA may, via activation of PPARy, stimulate adipocyte differentiation and promote reduced production and secretion of pro-inflammatory cytokines such as TNF- $\alpha$, thereby improving adipose tissue function (25-27).

In the KANWU study, positive effects of substituting dietary SFA with MUFA on insulin sensitivity were only observed in subjects with a total fat intake less than 37 E\% before the start of the study (15). Thus, habitual dietary fat intake may be an important factor in the individual responsiveness to dietary intervention, especially in this pan-European multicentre study with large variations in baseline fat intake. The median of habitual dietary fat intake in our present study was $36 \mathrm{E} \%$. Comparing the groups below and above this median, we observed a significant association between changes in $\mathrm{HOMA}_{\mathrm{IR}}$ and the interaction between diet, sex and habitual fat intake. $\mathrm{HOMA}_{\mathbb{R}}$ was significantly reduced in women on the HMUFA diet $(n=29)$ with a habitual low-fat intake (<36 E\%) and in women on the LFHCCn-3 diet $(n=23)$ with a habitual high-fat intake (> $36 \mathrm{E} \%)$. The mechanisms behind these contrasting results are unclear and require further study, although these results emphasise a role of background diet and sex (15), in line with previous data from LIPGENE (17).

Independent of dietary fat modification, changes in fasting plasma TAG concentrations were positively associated with changes in $\mathrm{HOMA}_{\mathrm{IR}}$, but not with $\mathrm{S}_{\mathrm{I}}$. $\mathrm{HOMA}_{\mathrm{R}}$ is calculated based on fasting glucose and insulin concentrations and can be a reflection of hepatic insulin resistance, whereas $S_{I}$ is a measure of whole body insulin sensitivity. Thus, the observed association between fasting plasma TAG and $\mathrm{HOMA}_{\mathbb{R}}$, and not with $\mathrm{S}_{\mathrm{I}}$, may suggest that hepatic insulin resistance, associated with enhanced secretion of VLDL-TAG and glucose into the circulation, may underlie this relationship in our subjects with the MetS (28). 
The MetS is often characterised by low-grade inflammation, mainly due to an increased fat mass and disturbed adipose tissue function $(1,2,5)$. In the LIPGENE study, dietary fat modification had no significant effects on the inflammatory markers serum CRP and urinary 15-keto-dihydro-PGF ${ }_{2 \alpha}$ and a marker of oxidative stress (urinary 8-iso-PGF $2 \alpha$ ) (29). In the present analysis, however, an association was observed between changes in fasting serum adiponectin concentrations and changes in both $S_{1}$ and $\mathrm{HOMA}_{\mathbb{R}}$, which were dependent on sex. Serum adiponectin concentrations were positively associated with $S_{1}$ in women, but inversely in men. It has been reported that plasma adiponectin concentrations are higher in women $(30,31)$, and associated with lower risk for impaired glucose metabolism, particularly in women (32). This supports our sex-specific effects of adiponectin. Adiponectin may exert its positive effects on insulin sensitivity via modulation of glucose and fat metabolism in liver as well as skeletal muscle, or by interaction with proinflammatory cytokines such as TNF- $\alpha$ (30). The positive association found between changes in fasting plasma t-PA concentrations and changes in $\mathrm{HOMA}_{\mathrm{IR}}$, but not $\mathrm{S}_{\mathrm{I}}$, suggest a possible link between fibrinolysis and hepatic insulin resistance (33).

The 12-week dietary intervention with isoenergetic diets differing in both fat quantity and quality had no direct effects on insulin sensitivity in men and women with the MetS (17). However, we showed that dietary fat modification could mediate some effects via other factors related to the MetS. Beneficial effects of the LFHCCn-3 diet on insulin sensitivity were mediated via changes in body weight and changes in fasting TNF- $\alpha$ concentrations, possibly reflecting an improved adipose tissue function. Independent of dietary fat modification or changes in body weight, changes in $\mathrm{S}_{\mathrm{I}}$ were associated with changes in fasting serum adiponectin concentrations, especially in women, whereas changes in $\mathrm{HOMA}_{\mathbb{R}}$ were significantly associated with changes in fasting plasma TAG and t-PA concentrations. In conclusion, the impact of dietary intervention to improve insulin sensitivity in the MetS is multifaceted and may not only depend on the type of diet, but also on habitual diet, sex and several metabolic and inflammatory factors associated with the MetS. Body weight, however, was the strongest factor related to insulin sensitivity, indicating that lifestyle interventions aimed at weight loss may be the most effective in directly improving insulin sensitivity in men and women with the MetS.

\section{Acknowledgements}

We gratefully thank all volunteers for their time and motivation, and all researchers within the LIPGENE Human Dietary Intervention Study for their work and dedication to the project. 


\section{References}

1. Eckel RH, Grundy SM, Zimmet PZ. The metabolic syndrome. Lancet 2005;365(9468):1415-28.

2. Fernandez-Real JM, Ricart W. Insulin resistance and chronic cardiovascular inflammatory syndrome. Endocr Rev 2003;24(3):278-301.

3. Robinson LE, Buchholz AC, Mazurak VC. Inflammation, obesity, and fatty acid metabolism: influence of n-3 polyunsaturated fatty acids on factors contributing to metabolic syndrome. Appl Physiol Nutr Metab 2007;32(6):1008-24.

4. Dandona P, Aljada A, Chaudhuri A, Mohanty P, Garg R. Metabolic syndrome: a comprehensive perspective based on interactions between obesity, diabetes, and inflammation. Circulation 2005;111(11):1448-54.

5. Roche HM. Fatty acids and the metabolic syndrome. Proc Nutr Soc 2005;64(1):23-9.

6. Frayn KN. Adipose tissue as a buffer for daily lipid flux. Diabetologia 2002;45(9):1201-10.

7. Corcoran MP, Lamon-Fava S, Fielding RA. Skeletal muscle lipid deposition and insulin resistance: effect of dietary fatty acids and exercise. Am J Clin Nutr 2007;85(3):662-77.

8. Dyck DJ, Heigenhauser GJ, Bruce CR. The role of adipokines as regulators of skeletal muscle fatty acid metabolism and insulin sensitivity. Acta Physiol (Oxf) 2006;186(1):5-16.

9. Lindstrom J, Louheranta A, Mannelin M, Rastas M, Salminen V, Eriksson J, et al. The Finnish Diabetes Prevention Study (DPS): Lifestyle intervention and 3-year results on diet and physical activity. Diabetes Care 2003;26(12):3230-6.

10. Knowler WC, Barrett-Connor E, Fowler SE, Hamman RF, Lachin JM, Walker EA, et al. Reduction in the incidence of type 2 diabetes with lifestyle intervention or metformin. N Engl J Med 2002;346(6):393-403.

11. Roumen C, Corpeleijn E, Feskens EJ, Mensink M, Saris WH, Blaak EE. Impact of 3-year lifestyle intervention on postprandial glucose metabolism: the SLIM study. Diabet Med 2008;25(5):597-605.

12. Galgani JE, Uauy RD, Aguirre CA, Diaz EO. Effect of the dietary fat quality on insulin sensitivity. Br J Nutr 2008;100(3):471-9.

13. Riserus U, Arnlov J, Berglund L. Long-term predictors of insulin resistance: role of lifestyle and metabolic factors in middle-aged men. Diabetes Care 2007;30(11):2928-33.

14. Riserus U. Fatty acids and insulin sensitivity. Curr Opin Clin Nutr Metab Care 2008;11(2):100-5.

15. Vessby B, Unsitupa M, Hermansen K, Riccardi G, Rivellese AA, Tapsell LC, et al. Substituting dietary saturated for monounsaturated fat impairs insulin sensitivity in healthy men and women: The KANWU Study. Diabetologia 2001;44(3):312-9.

16. Perez-Jimenez F, Lopez-Miranda J, Pinillos MD, Gomez P, Paz-Rojas E, Montilla P, et al. A Mediterranean and a high-carbohydrate diet improve glucose metabolism in healthy young persons. Diabetologia 2001;44(11):2038-43.

17. Tierney AC, McMonagle J, Shaw DI, Gulseth HL, Helal O, Saris WHM, et al. Effects of dietary fat modification on insulin sensitivity and other risk factors of the metabolic syndrome - LIPGENE: an European randomized dietary intervention study. Int J Obes (Lond) 2010:in press.

18. Corpeleijn E, Feskens EJ, Jansen EH, Mensink M, Saris WH, Blaak EE. Lifestyle intervention and adipokine levels in subjects at high risk for type 2 diabetes: the Study on Lifestyle intervention and Impaired glucose tolerance Maastricht (SLIM). Diabetes Care 2007;30(12):3125-7.

19. Monzillo LU, Hamdy O, Horton ES, Ledbury S, Mullooly C, Jarema C, et al. Effect of lifestyle modification on adipokine levels in obese subjects with insulin resistance. Obes Res 2003;11(9):1048-54.

20. Third Report of the National Cholesterol Education Program (NCEP) Expert Panel on Detection, Evaluation, and Treatment of High Blood Cholesterol in Adults (Adult Treatment Panel III) final report. Circulation, 2002:3143-421.

21. Finegood DT, Hramiak IM, Dupre J. A modified protocol for estimation of insulin sensitivity with the minimal model of glucose kinetics in patients with insulin-dependent diabetes. J Clin Endocrinol Metab 1990;70(6):1538-49. 
22. Shaw DI, Tierney AC, McCarthy S, Upritchard J, Vermunt S, Gulseth HL, et al. LIPGENE foodexchange model for alteration of dietary fat quantity and quality in free-living participants from eight European countries. Br J Nutr 2008;101(5):750-9.

23. Boston RC, Stefanovski D, Moate PJ, Sumner AE, Watanabe RM, Bergman RN. MINMOD Millennium: a computer program to calculate glucose effectiveness and insulin sensitivity from the frequently sampled intravenous glucose tolerance test. Diabetes Technol Ther 2003;5(6):1003-15.

24. Matthews DR, Hosker JP, Rudenski AS, Naylor BA, Treacher DF, Turner RC. Homeostasis model assessment: insulin resistance and beta-cell function from fasting plasma glucose and insulin concentrations in man. Diabetologia 1985;28(7):412-9.

25. Sharma AM, Staels B. Review: Peroxisome proliferator-activated receptor gamma and adipose tissue--understanding obesity-related changes in regulation of lipid and glucose metabolism. J Clin Endocrinol Metab 2007;92(2):386-95.

26. Ferre P. The biology of peroxisome proliferator-activated receptors: relationship with lipid metabolism and insulin sensitivity. Diabetes 2004;53 Suppl 1:S43-50.

27. Oliver E, McGillicuddy F, Phillips C, Toomey S, Roche HM. The role of inflammation and macrophage accumulation in the development of obesity-induced type 2 diabetes mellitus and the possible therapeutic effects of long-chain n-3 PUFA. Proc Nutr Soc 2010;69(2):232-43.

28. Ginsberg HN, Zhang YL, Hernandez-Ono A. Regulation of plasma triglycerides in insulin resistance and diabetes. Arch Med Res 2005;36(3):232-40.

29. Petersson H, Riserus U, McMonagle J, Gulseth HL, Tierney AC, Morange S, et al. Effects of dietary fat modification on oxidative stress and inflammatory markers in the LIPGENE study. $\mathrm{Br} J \mathrm{Nutr}$ 2010;104(9):1357-62.

30. Swarbrick MM, Havel PJ. Physiological, pharmacological, and nutritional regulation of circulating adiponectin concentrations in humans. Metab Syndr Relat Disord 2008;6(2):87-102.

31. Cnop M, Havel PJ, Utzschneider KM, Carr DB, Sinha MK, Boyko EJ, et al. Relationship of adiponectin to body fat distribution, insulin sensitivity and plasma lipoproteins: evidence for independent roles of age and sex. Diabetologia 2003;46(4):459-69.

32. Snijder MB, Heine RJ, Seidell JC, Bouter LM, Stehouwer CD, Nijpels G, et al. Associations of adiponectin levels with incident impaired glucose metabolism and type 2 diabetes in older men and women: the hoorn study. Diabetes Care 2006;29(11):2498-503.

33. Eliasson MC, Jansson JH, Lindahl B, Stegmayr B. High levels of tissue plasminogen activator (tPA) antigen precede the development of type 2 diabetes in a longitudinal population study. The Northern Sweden MONICA study. Cardiovasc Diabetol 2003;2:19. 



\section{Skeletal muscle fatty acid handling in insulin resistant men}

Anneke M.J. van Hees, Anneke Jans, Gabby B. Hul, Helen M. Roche, Wim H.M. Saris and Ellen E. Blaak

Obesity 2011;19(7):1350-9. 


\section{Abstract}

Disturbances in skeletal muscle lipid metabolism may precede or contribute to the development of whole body insulin resistance. In this study, we examined fasting and postprandial skeletal muscle fatty acid (FA) handling in insulin resistant (IR) men.

Thirty men with the metabolic syndrome (NCEP-ATPIII) were included in this substudy to the LIPGENE study, and divided in two groups (IR and control) based on the median of insulin sensitivity $\left(\mathrm{S}_{1}=2.06\left(\mathrm{mU} / \mathrm{I}^{-1}\right) \cdot \mathrm{min}^{-1} \cdot 10^{-4}\right)$. Fasting and postprandial skeletal muscle FA handling were examined by combining the forearm balance technique with stable isotopes of palmitate. $\left[{ }^{2} \mathrm{H}_{2}\right]$-palmitate was infused intravenously to label endogenous triacylglycerol (TAG) and free fatty acids (FFA) in the circulation and $\left[\mathrm{U}^{13}{ }^{13} \mathrm{C}\right]$-palmitate was incorporated in a high-fat mixed meal (2.6 MJ, 61 energy\% fat) to label chylomicron-TAG. Muscle biopsies were taken to determine muscle TAG, diacylglycerol, FFA and phospholipid content, their fractional synthetic rates (FSR) and degree of saturation, as well as mRNA expression of genes involved in lipid metabolism.

In the first $2 \mathrm{~h}$ after meal consumption, forearm muscle $\left[{ }^{2} \mathrm{H}_{2}\right]$-labeled TAG extraction was higher in IR vs. control $(P=0.05)$. Fasting percentage saturation of muscle diacylglycerol was higher in IR vs. control $(P=0.016)$. No differences were observed for intramuscular TAG, diacylglycerol, FFA and phospholipid content, FSR and muscle mRNA expression.

In conclusion, increased muscle (hepatically-derived) TAG extraction during postprandial conditions and increased saturation of intramuscular diacylglycerol are associated with insulin resistance, suggesting that disturbances in skeletal muscle FA handling could play a role in the development of whole body insulin resistance and type 2 diabetes. 


\section{Introduction}

Disturbances in skeletal muscle lipid metabolism may play a central role in the development of insulin resistance (IR), the metabolic syndrome (MetS) and type 2 diabetes (1-3). Conditions of chronic excessive energy intake and/or a sedentary lifestyle may lead to an increased supply of triacylglycerol (TAG) and free fatty acids (FFA) to non-adipose tissues such as skeletal muscle and liver (lipid overflow hypothesis) (4). Together with an impaired capacity of skeletal muscle to oxidise fat (5-7), lipid overflow is hypothesised to create excess fat storage in skeletal muscle and liver. In particular the intramuscular accumulation of lipid metabolites like diacylglycerol, long-chain fatty acyl-CoA and ceramide, as well as the saturation of these lipid fractions, may reduce insulin action in skeletal muscle by interfering with insulin signalling and/or inducing inflammatory pathways (8-12).

The contribution of dietary fat (chylomicron-TAG) and endogenous fat (FFA and very low-density lipoprotein (VLDL)-TAG) to lipid overflow and intramuscular lipid accumulation is unknown. Elevated FFA concentrations may originate from an expanded fat mass or decreased peripheral clearance $(5,6,13)$, although findings are inconsistent (14). Insulin-mediated suppression of adipose tissue FFA output after meal ingestion has been considered to be impaired in the IR state, thereby contributing to increased systemic FFA concentrations, although postprandial FFA release per unit fat mass has been reported to be reduced in IR conditions (14). At the same time, it has been shown that the spillover of fatty acids (FA) derived from lipoprotein lipase (LPL)-mediated TAG-hydrolysis across adipose tissue is less suppressed during hyperinsulinaemia in obese type 2 diabetic patients compared to non-obese healthy controls (15). Plasma TAG concentrations may rise in the IR state due to increased supply of endogenous FFA to the liver and subsequent increased VLDL-TAG output. Also, dietary FA can make a substantial contribution to VLDL-TAG, already in the early postprandial phase $(16,17)$.

The contribution of plasma TAG to the FA delivery to skeletal muscle is not entirely clear. It has been demonstrated in healthy subjects that LPL prefers chylomicronTAG above VLDL-TAG for hydrolysis (18), although VLDL-TAG make a large contribution to circulating TAG, even in the postprandial phase (19). The uptake of TAG-derived FA after hydrolysis is thought to be highly efficient in skeletal muscle when compared to adipose tissue (20). However, others suggested that there is substantial release of TAG-derived FA into the plasma FFA pool (i.e. spillover) across skeletal muscle $(18,21)$, and that TAG-derived FA mix with the plasma FFA pool to compete for cellular uptake (22).

Most studies on VLDL- and chylomicron-TAG metabolism have been performed in healthy subjects and little is known about their metabolism in skeletal muscle during different conditions such as IR, the MetS and type 2 diabetes (23). A previous study showed that postprandial plasma VLDL- and chylomicron-TAG concentrations 
are elevated in the IR state (14). The aim of this study was to examine fasting and postprandial skeletal muscle FA handling in insulin resistant men compared to a control group, using a recently developed dual stable isotope tracer technique in combination with arteriovenous measurements across the forearm muscle which enables us to differentiate between the metabolic fate of dietary vs. endogenous FA. Additionally, muscle biopsies were taken to investigate skeletal muscle lipid metabolites, their fractional synthetic rates and the transcriptional regulation of FA metabolism.

\section{Methods}

The present study was performed in a sub-cohort of men in the Netherlands within the LIPGENE human dietary intervention study. In total, 30 men with the MetS at the age of 35-70 y and body mass index (BMI) between 27 and $38 \mathrm{~kg} / \mathrm{m}^{2}$ were included in this study. Definition of the MetS was based on the NCEP ATP III report (24), with subjects meeting at least three of the following criteria: 1) fasting plasma glucose concentration between 5.5 and $7.0 \mathrm{mmol} / \mathrm{l} ; 2$ ) fasting plasma TAG concentration $\geq 1.5 \mathrm{mmol} / \mathrm{l}$; 3) fasting plasma high-density lipoprotein (HDL)cholesterol concentration $<1.0 \mathrm{mmol} / \mathrm{l}$; 4) systolic blood pressure $\geq 130 \mathrm{~mm} \mathrm{Hg}$ and/or diastolic blood pressure $\geq 85 \mathrm{~mm} \mathrm{Hg}$ and/or treatment of previously diagnosed hypertension; 5) waist circumference $>102 \mathrm{~cm}$. Exclusion criteria included weight change $>3 \mathrm{~kg}$ within the 3 months prior to the study; diabetes or other endocrine disorders; chronic inflammatory conditions; kidney or liver dysfunction; use of hypolipidaemic or anti-inflammatory medication; use of antihypertensive medication in the class of $\beta$-blockers; use of aspirin > 1 per week; highly trained or endurance athletes; and alcohol abuse.

Subjects were split in two groups based on the median of insulin sensitivity $\left(\mathrm{S}_{1}\right)(2.06$ $\left.\left(\mathrm{mU} / \mathrm{I}^{-1}\right) \cdot \mathrm{min}^{-1} \cdot 10^{-4}\right)$ as measured during a frequently sampled insulin modified intravenous glucose tolerance test (IVGTT). Men below the median of $S_{1}$ were considered as the insulin resistant group (IR; $n=15)$, and men above the median as the control group (control; $n=15$ ). All subjects were informed about the nature of the study and written informed consent was attained prior to study participation. The study protocol was approved by the local Medical Ethical Committee of the Maastricht University.

\section{Experimental design}

Subjects came to the university after an overnight fast on two different occasions. On one day, subjects completed anthropometric measurements, donated a fasting blood sample and completed an IVGTT to measure $S_{1}$ as described previously 
$(25,26)$. Insulin sensitivity was the primary endpoint of the LIPGENE human dietary intervention study.

On a separate day, a tracer infusion study was performed to evaluate the contribution of dietary TAG (labeled with $\left[\mathrm{U}-{ }^{13} \mathrm{C}\right]$-palmitate) and endogenous TAG, i.e. VLDL, and circulating FFA (both labeled with $\left[{ }^{2} \mathrm{H}_{2}\right]$-palmitate) to lipid overflow and skeletal muscle FA handling during fasting and after the consumption of a highfat mixed meal, as validated previously (18).

\section{Tracer infusion study}

Subjects came to the university after an overnight fast and were asked to refrain from drinking alcohol and to perform no strenuous exercise $24 \mathrm{~h}$ prior to the study day. In addition, they were asked to avoid food products naturally enriched with $\left[{ }^{13} \mathrm{C}\right]$ for 7 days before the study day.

Skeletal muscle metabolism was studied in the forearm muscle, using arteriovenous concentration differences corrected for blood flow. Three catheters were inserted before the start of the experiment. One catheter was placed in the radial artery of the forearm to sample arterial blood, and in the same arm another catheter was placed in an antecubital vein for the infusion of the $\left[{ }^{2} \mathrm{H}_{2}\right]$-palmitate tracer. $A$ third catheter was placed retrogradely in a deep antecubital vein of the contralateral forearm to sample venous blood draining the forearm muscle. After taking an arterial and deep venous background sample at t-95 (i.e. $95 \mathrm{~min}$ before meal ingestion (t 0)), a continuous intravenous infusion of the stable isotope tracer $\left[{ }^{2} \mathrm{H}_{2}\right]$ palmitate (97\% enrichment, Cambridge Isotope Laboratories, Andover, MA, USA) complexed to albumin was started $\left(0.035 \mu \mathrm{mol} \cdot \mathrm{kg}\right.$ body weight $\left.{ }^{-1} \cdot \mathrm{min}^{-1}\right)$. Baseline blood sampling was started after one hour of tracer infusion to allow for isotopic equilibration to occur. Blood samples were taken simultaneously from the radial artery and the deep muscle vein at three time points during fasting $(\mathrm{t}-35, \mathrm{t}-20, \mathrm{t}-5)$ and six time points postprandially (t 30, t 60, t 90, t 120, t 180, t 240) after consumption of a high-fat mixed meal (t 0 ) containing $200 \mathrm{mg}\left[\mathrm{U}-{ }^{13} \mathrm{C}\right]$-palmitate (98\% enrichment, Cambridge Isotope Laboratories). Forearm blood flow was measured before each blood sampling as described previously (27).

The liquid test meal provided $2.6 \mathrm{MJ}$, consisting of 61 energy\% (E\%) fat $(35.5 \mathrm{E} \%$ saturated fat, $18.8 \mathrm{E} \%$ monounsaturated fat and $1.7 \mathrm{E} \%$ polyunsaturated fat), $33 \mathrm{E} \%$ carbohydrates and $6.3 \mathrm{E} \%$ protein. Subjects were asked to drink the test meal within $5 \mathrm{~min}$.

Skeletal muscle biopsies were taken before the start of the experiment during fasting and at the end of the postprandial measurement period ( $t 240$ ) to determine intramuscular TAG, diacylglycerol (DAG), FFA and phospholipid (PL) content, their degree of saturation, as well as the fractional synthetic rate (FSR) of TAG, DAG and $\mathrm{PL}$ (see skeletal muscle lipids). Furthermore, mRNA expression of genes involved in 
lipid metabolism was determined (see skeletal muscle mRNA expression). Biopsies were taken from the vastus lateralis muscle under local anaesthesia of the skin and fascia using the Bergström method with suction (28), cleaned from any visible fat and blood, immediately frozen in isopentane at its melting point and stored at $-80^{\circ} \mathrm{C}$ until analysis.

\section{Biochemical analyses}

Blood was collected in tubes containing ethylenediaminetetraacetic acid, centrifuged $\left(1000 \mathrm{~g}, 10 \mathrm{~min}, 4^{\circ} \mathrm{C}\right)$ and plasma was immediately frozen in liquid nitrogen and stored at $-80^{\circ} \mathrm{C}$ until analysis. Plasma FFA and 3-hydroxybutyrate were analysed using standard enzymatic techniques automated on a Cobas Fara centrifugal spectrophotometer (Roche Diagnostica, Basel, Switzerland). Plasma TAG, glycerol, glucose and lactate were analysed enzymatically on a Cobas Mira automated spectrophotometer. Plasma insulin was measured with a double antibody radioimmunoassay (Linco Research Inc., St. Charles, MO, USA). Plasma total cholesterol, HDL-cholesterol and low-density lipoprotein (LDL)-cholesterol were determined with an ILab 600 clinical chemical analyser (Instrumentation Laboratory, Warrington, UK), using enzymatic colourimetric kits. Haematocrit was determined in heparinised blood using a microcapillary system.

To determine isotope enrichment of plasma FFA and TAG, total lipids were extracted from the plasma using chloroform-methanol 2:1 (vol/vol). The FFA and TAG fractions were separated by thin-layer chromatography and derivatised to their methyl esters for the analysis of plasma palmitate. Plasma fractions were analysed for the ${ }^{13} \mathrm{C}$-to- ${ }^{12} \mathrm{C}$ ratio on a gas chromatography continuous-flow isotope ratio-mass spectrometer (Finnigan MAT-252 GC-IRMS, Bremen, Germany) and for enrichment of $\left[{ }^{2} \mathrm{H}_{2}\right]$ (Finnigan Incos-XL GC-MS). The methyl ester of palmitate contains 17 carbon atoms and therefore, the tracer/tracee ratio (TTR) of palmitate was corrected for the extra methyl group. Plasma palmitate concentrations ( $\mu \mathrm{mol} / \mathrm{l}$ ) were analysed on an analytical GC with ion flame detection using heptadecanoic acid as internal standard.

\section{Skeletal muscle lipids}

Skeletal muscle biopsies were lyophilised and dissected free of extramyocellular lipid, blood and connective tissue. Total lipids were extracted from 10-20 mg muscle sample using chloroform-methanol $(2: 1 \mathrm{vol} / \mathrm{vol})$ and internal standards, and thereafter evaporated under nitrogen at $37^{\circ} \mathrm{C}$. The extracted lipids were separated into FFA, DAG, TAG and PL by thin-layer chromatography and transferred into tubes for methylation. The TAG and DAG fractions were methylated by adding $1 \mathrm{ml}$ of toluene-methanol-(BF3-methanol $14 \%$ ) (20\%-55\%-25\% vol/vol) and incubated in 
capped tubes for $30 \mathrm{~min}$ at $100^{\circ} \mathrm{C}$. The PL fraction was methylated by adding $1 \mathrm{ml}$ of (BF3-methanol $14 \%$ ) and incubation in capped tubes for $90 \mathrm{~min}$ at $100{ }^{\circ} \mathrm{C}$. The FFA fraction was methylated by adding $1 \mathrm{ml}$ of methanol-(BF3-methanol $14 \%$ ) (50\%$50 \% \mathrm{vol} / \mathrm{vol}$ ) and incubation in capped tubes at room temperature for $15 \mathrm{~min}$. After incubation, $2 \mathrm{ml}$ pentane was added to the samples, vortexed and centrifuged $\left(1000 \mathrm{~g}, 5 \mathrm{~min}, 20^{\circ} \mathrm{C}\right.$ ), followed by isolation of pentane extracts (upper phase) and evaporation under nitrogen at $30^{\circ} \mathrm{C}$. Finally, the residues were dissolved in isooctane and concentrations of fatty acids in the fractions were determined using an analytical GC. Stable isotope enrichment of the lipid fractions was determined by measuring the ${ }^{13} \mathrm{C}$-to- $-{ }^{12} \mathrm{C}$ ratio on a GC-IRMS (Finnigan MAT-252).

\section{Skeletal muscle mRNA expression}

RNA was isolated from approximately $25 \mathrm{mg}$ of snap frozen muscle tissue. The tissues were homogenised in $1 \mathrm{ml}$ Trizol for RNA stabilisation and RNA was isolated according to a standardised protocol as described by the manufacturer. Next, RNA was purified using the RNeasy mini kit (Qiagen Benelux B.V., Venlo, The Netherlands) and dissolved in RNase/DNase free water. RNA was quantified and checked for purity on the NanoDrop 1000 (NanoDrop Technologies, Wilmington, DE, USA), and considered suitable for further processing at ratios between 260/280 and $260 / 230$ of $>1.7$. Integrity was evaluated using the BioAnalyzer (Agilent, Palo Alto CA, USA) and considered to be intact with an RNA integrity number $>7.0$. Isolated RNA was reverse transcribed using the iScript cDNA synthesis Kit. The qPCR reactions were performed in a volume of $25 \mu$ l containing $12.5 \mathrm{ng}$ CDNA, 1 x IQ SYBR Green Supermix and $400 \mathrm{nM}$ of gene-specific forward and reverse primers (Supplemental table). cDNA was amplified using a two-step programme (40 cycles of $10 \mathrm{sec}$ at $95^{\circ} \mathrm{C}$ and $45 \mathrm{sec}$ at $60^{\circ} \mathrm{C}$ ) with a MyiQ system (Bio-Rad, Laboratories, Veenendaal, The Netherlands). Gene expression levels of LPL, peroxisome proliferator-activated receptor $\alpha(P P A R \alpha)$, PPARy coactivator $1 \alpha(P G C 1 \alpha)$, acetylCoA carboxylase 2 (ACC2), muscle carnitine palmitoyltransferase $1 b$ (mCPT1b), sterol regulatory element binding protein 1c (SREBP1c), SREBP2 and carbohydrate responsive element-binding protein (ChREBP) were expressed relative to the geometric mean of two internal reference genes, i.e. ribosomal protein L13a (RPL13a) and $\beta$-2-microglobulin.

\section{Calculations}

Insulin sensitivity $\left(\mathrm{S}_{\mathrm{I}}\right)$ was determined using the MINMOD Millennium program (26). Net fluxes of metabolites (labeled and unlabeled) across the forearm were calculated by multiplying arteriovenous concentration differences by forearm plasma flow. Plasma flow was calculated by multiplying forearm blood flow with (1 - 
haematocrit / 100). A positive flux indicates net uptake across forearm muscle, whereas a negative flux indicates net release. Fractional extraction of metabolites (\%) was calculated as the arteriovenous concentration difference divided by the arterial concentration. As a measure of efficiency of substrate removal from the circulation, substrate clearance across forearm muscle was calculated by multiplying fractional extraction with forearm plasma flow.

Fasting rate of appearance of FFA $\left(\mathrm{Ra}_{\mathrm{FFA}}\right)\left(\mu \mathrm{mol} \cdot \mathrm{kg}^{-1} \cdot \mathrm{min}^{-1}\right)$ was calculated using Steele's equation for steady state, and Steele's single-pool non-steady state equations adapted for use with stable isotopes in the postprandial state (29). Labeled FFA and TAG concentrations were calculated as the product of TTR of [U$\left.{ }^{13} \mathrm{C}\right]$ - and $\left[{ }^{2} \mathrm{H}_{2}\right]$-palmitate and the concentration of palmitate in FFA and TAG. Fractional extraction of $\left[\mathrm{U}^{13} \mathrm{C}\right]$-palmitate derived from the hydrolysis of $\left[\mathrm{U}-{ }^{13} \mathrm{C}\right]-$ labeled TAG (i.e. percentage 'entrapment') across forearm muscle was calculated as described previously, with the assumption that a proportion of FA derived from TAG hydrolysis may not be taken up by skeletal muscle (18).

Fractional synthetic rates of skeletal muscle TAG, DAG and PL were calculated by using skeletal muscle FFA as the precursor pool for lipid synthesis (30). The increase in TTR of $\left[\mathrm{U}^{13} \mathrm{C}\right]$ from fasting to $4 \mathrm{~h}$ postprandially was divided by the enrichment of skeletal muscle FFA and expressed as percentage per hour $(\% / \mathrm{h})$. The degree of saturation of skeletal muscle TAG, DAG, PL and FFA (\%) was calculated by dividing the sum of saturated FA by the total amount of FA in a fraction. $\Delta 9$-desaturase activity was estimated as the proportion palmitoleic acid (C16:1n-7) to palmitic acid (C16:0), and as the proportion oleic acid (C18:1n-9) to stearic acid (C18:0). Total skeletal muscle TAG, DAG, FFA and PL contents were estimated as the sum of the particular FA content of the assessed fraction.

Postprandial area under the curve (AUC) and incremental AUC (iAUC) of metabolites and substrate fluxes were calculated using the trapezium rule. Besides the total (i)AUC (0-4 h after meal ingestion), also the 'early' (0-2 h) and 'mid' (2-4 h) (i)AUC were calculated to obtain more detailed information about the time course of postprandial responses.

\section{Statistical methods}

All statistical analyses were performed using SPSS 15.0 for Windows (SPSS Inc.) and were defined a priori. Data are presented as means \pm standard error of mean (SEM). Independent samples t-tests were used to test for differences between the IR and control group during fasting and the postprandial period ('total', 'early' and 'mid'). Repeated-measures ANOVA was used to test for changes in time between groups (group by time effect) during the postprandial period. Statistical significance was set at $P<0.05$. 


\section{Results}

By definition, $S_{\mid}$was different between $I R$ men and controls (1.28 \pm 0.12 vs. $3.22 \pm 0.27 \mathrm{mU} / \mathrm{I}^{-1} \cdot \mathrm{min}^{-1} \cdot 10^{-4}$ ) (Table 3.1). Groups were otherwise matched for age, $\mathrm{BMI}$, fat mass, blood pressure and fasting total cholesterol, HDL-cholesterol and LDL-cholesterol concentrations.

Table 3.1 Subject characteristics

\begin{tabular}{|c|c|c|c|}
\hline & IR & Control & $P$-value \\
\hline$n$ & 15 & 15 & \\
\hline Age (y) & $58 \pm 2$ & $58 \pm 2$ & 0.983 \\
\hline Body weight $(\mathrm{kg})$ & $99.5 \pm 1.9$ & $96.3 \pm 2.4$ & 0.304 \\
\hline BMI $\left(\mathrm{kg} / \mathrm{m}^{2}\right)$ & $31.8 \pm 0.6$ & $30.6 \pm 0.7$ & 0.206 \\
\hline Waist $(\mathrm{cm})$ & $110 \pm 2$ & $109 \pm 1$ & 0.650 \\
\hline Waist-hip ratio & $1.05 \pm 0.01$ & $1.04 \pm 0.01$ & 0.794 \\
\hline Fat mass $(\mathrm{kg})$ & $27.6 \pm 2.0$ & $25.2 \pm 1.0$ & 0.231 \\
\hline Systolic blood pressure (mm Hg) & $135 \pm 4$ & $137 \pm 4$ & 0.687 \\
\hline Diastolic blood pressure (mm Hg) & $85 \pm 3$ & $86 \pm 3$ & 0.795 \\
\hline Insulin sensitivity $\left.\left(\mathrm{mU} / \mathrm{I}^{-1}\right) \cdot \mathrm{min}^{-1} \cdot 10^{-4}\right)$ & $1.28 \pm 0.12$ & $3.22 \pm 0.27$ & $<0.001$ \\
\hline Glucose (mmol/l) & $5.57 \pm 0.11$ & $5.33 \pm 0.09$ & 0.088 \\
\hline Insulin (mU/I) & $15.6 \pm 1.7$ & $12.3 \pm 0.8$ & 0.111 \\
\hline Free fatty acids ( $\mu \mathrm{mol} / \mathrm{l})$ & $593 \pm 45$ & $504 \pm 26$ & 0.099 \\
\hline Triacylglycerol (mmol/l) & $1.49 \pm 0.15$ & $1.32 \pm 0.18$ & 0.497 \\
\hline Total cholesterol (mmol/l) & $5.17 \pm 0.19$ & $5.00 \pm 0.20$ & 0.550 \\
\hline HDL-cholesterol (mmol/I) & $0.89 \pm 0.05$ & $0.97 \pm 0.06$ & 0.279 \\
\hline LDL-cholesterol (mmol/I) & $3.32 \pm 0.24$ & $2.92 \pm 0.21$ & 0.213 \\
\hline
\end{tabular}

Values are mean \pm SEM. $P$-value for difference between groups, Student's t-test for unpaired samples. Fat mass: $n=9$ (IR) and $n=14$ (control).

\section{Arterial metabolites, forearm blood flow and forearm muscle metabolism}

Fasting arterial plasma glucose concentrations tended to be higher in the IR group compared to the control group $(P=0.09)$, whereas postprandial concentrations were similar between groups (Figure 3.1A). Arterial plasma insulin concentrations were comparable between groups in the fasting state, but the postprandial insulin response was higher in the IR group compared to control (iAUC/min: $33.4 \pm 4.1$ vs. $23.9 \pm 2.2 \mathrm{mU} / \mathrm{l}, P=0.05$ ) (Figure 3.1B). Fasting arterial plasma lactate concentrations were higher in IR men compared to control $(0.88 \pm 0.11$ vs. $0.57 \pm 0.04 \mathrm{mmol} / \mathrm{I}$, $P=0.01$ ) and remained significantly higher throughout the entire postprandial period (AUC/min: $1.19 \pm 0.08$ vs. $0.88 \pm 0.07 \mathrm{mmol} / \mathrm{l}, \quad P=0.005$ ). Arterial plasma 3- 
hydroxybutyrate concentrations did not differ between groups at any time (data not shown).

Forearm blood flow and net glucose uptake and glycerol release across forearm muscle were similar between groups, both during fasting and after meal ingestion (Table 3.2). Also, no significant differences were observed in fasting and postprandial net release of lactate and net uptake 3-hydroxybutyrate across forearm muscle between groups (data not shown).

A

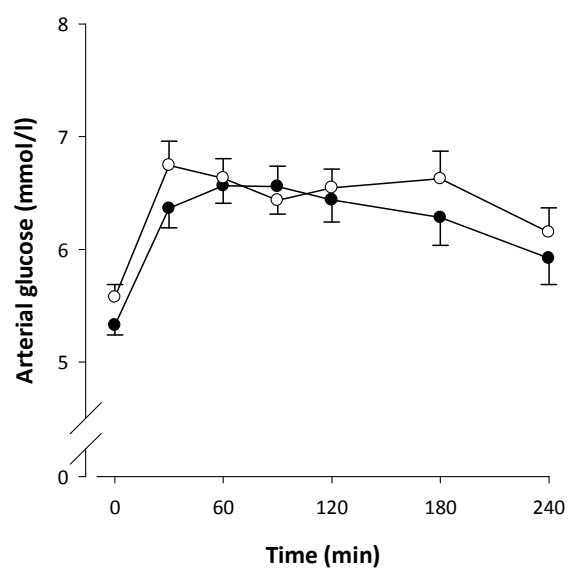

B

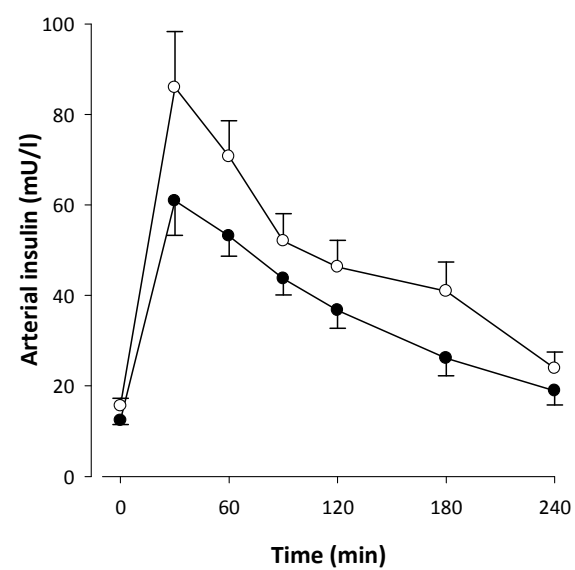

Figure 3.1 Arterial plasma glucose (A) and insulin (B) concentrations during fasting (t 0 ) and after consumption of a high-fat mixed meal. $\bullet$; control group, 0 ; IR group.

Values are mean \pm SEM.

\section{Whole body and forearm muscle FFA metabolism}

Whole body FFA metabolism

Arterial FFA concentrations were slightly higher in the IR group than the control group during fasting and tended to remain higher after the high-fat mixed meal (AUC/min: $410 \pm 22$ vs. $356 \pm 19 \mu \mathrm{mol} / \mathrm{l}, \quad P=0.07$ ) (Figure 3.2A). $\left[{ }^{2} \mathrm{H}_{2}\right]$-labeled palmitate was infused intravenously, mixed with the plasma FFA pool, and reached steady state concentrations during fasting measurements. After meal ingestion, $\left[{ }^{2} \mathrm{H}_{2}\right]$-palmitate concentrations in plasma FFA were suppressed in both groups. Also the $\mathrm{Ra}_{\mathrm{FFA}}$ decreased after meal ingestion in both groups, indicating suppression of whole body lipolysis, with no differences between groups (Figure 3.2B). [ $\left.{ }^{13} \mathrm{C}\right]$ labeled palmitate (resulting from spillover of FA derived from chylomicron-TAG hydrolysis) appeared in the plasma FFA pool from $60 \mathrm{~min}$ after meal ingestion and concentrations increased throughout the postprandial period. There were no 
differences in arterial concentrations of $\left[{ }^{2} \mathrm{H}_{2}\right]$ - or $\left[{ }^{13} \mathrm{C}\right]$-labeled palmitate in FFA between groups at any time (data not shown).

The TTR of $\left[{ }^{2} \mathrm{H}_{2}\right]$-palmitate in FFA was significantly higher in arterial vs. deep venous plasma at all time-points during the study day in both the IR and control group (respectively $P=0.01$ and $P<0.001$, source by time effect), indicating dilution of the $\left[{ }^{2} \mathrm{H}_{2}\right]$-tracer in the plasma FFA pool across forearm muscle (Figure $3.2 \mathrm{C}$ ). On the other hand, the TTR of $\left[{ }^{13} \mathrm{C}\right]$-palmitate in FFA was not different in arterial vs. deep venous plasma at all time-points in both groups (respectively $P=0.98$ and $P=0.90$, source by time effect) (Figure 3.2D).

A

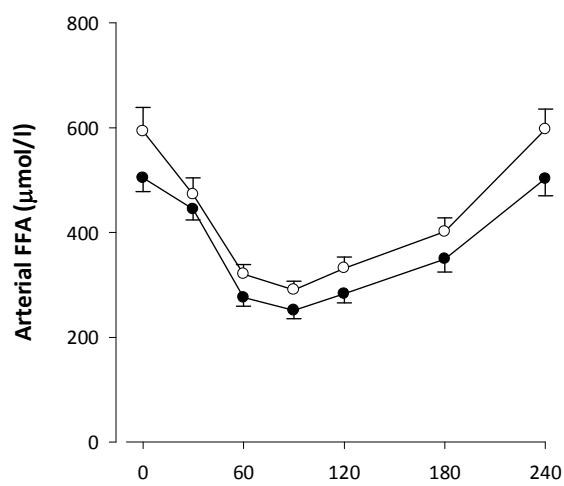

C

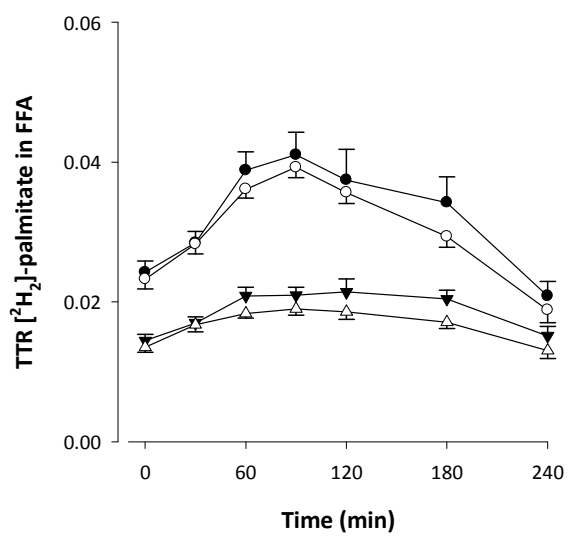

B

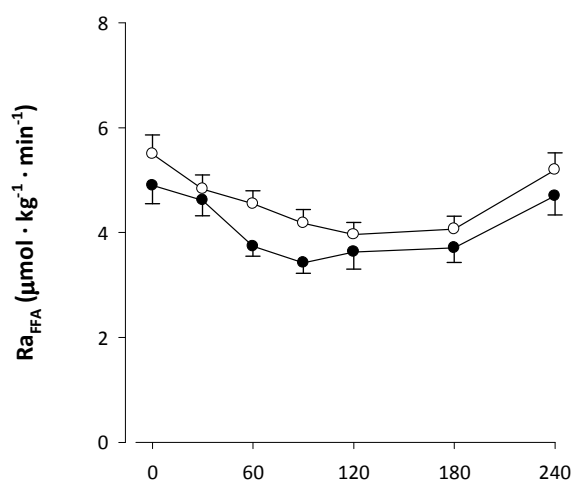

D

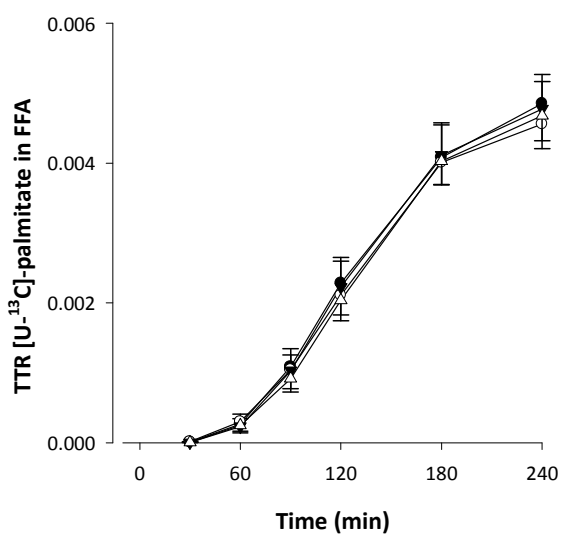

Figure 3.2 Arterial plasma free fatty acid (FFA) concentrations (A), rate of appearance of FFA ( $\left.\operatorname{Ra}_{\mathrm{FFA}}\right)(\mathrm{B})$ and tracer/tracee ratio (TTR) of $\left[{ }^{2} \mathrm{H}_{2}\right]$-palmitate $(\mathrm{C})$ and $\left[{ }^{13} \mathrm{C}\right]$-palmitate (D) in the plasma FFA fraction during fasting $(\mathrm{t} 0)$ and after consumption of a high-fat mixed meal. Black symbols; control group, white symbols; IR group. Panel C and D: circles; arterial plasma concentrations, triangles; forearm venous plasma concentrations. Values are mean \pm SEM. 


\section{Forearm muscle FFA metabolism}

Fasting and postprandial net FFA extraction across forearm muscle (arteriovenous difference multiplied by forearm plasma flow) were not different between groups. Furthermore, there was consistent net uptake of $\left[{ }^{2} \mathrm{H}_{2}\right]$-labeled palmitate across forearm muscle during the entire study period, without significant differences between groups (Table 3.2).

Table 3.2 Fasting and postprandial lipid metabolism

\begin{tabular}{llll}
\hline & & $\mathrm{IR}(n=15)$ & Control $(n=14)$ \\
\hline Forearm blood flow & fasting $\left(\mathrm{ml} \cdot 100 \mathrm{ml}^{-1} \cdot \mathrm{min}^{-1}\right)$ & $2.12 \pm 0.15$ & $2.51 \pm 0.34$ \\
& postprandial $(0-4 \mathrm{~h})$ & $2.24 \pm 0.15$ & $2.73 \pm 0.33$
\end{tabular}

Net flux across forearm muscle

\begin{tabular}{|c|c|c|c|}
\hline \multirow[t]{3}{*}{ Glucose } & fasting $\left(\mu \mathrm{mol} \cdot 100 \mathrm{ml}^{-1} \cdot \mathrm{min}^{-1}\right)$ & $0.23 \pm 0.06$ & $0.21 \pm 0.10$ \\
\hline & early postprandial (0-2 h) & $0.77 \pm 0.09$ & $0.88 \pm 0.11$ \\
\hline & mid postprandial (2-4 h) & $0.62 \pm 0.11$ & $0.70 \pm 0.13$ \\
\hline \multirow[t]{3}{*}{ Glycerol } & fasting $\left(\mathrm{nmol} \cdot 100 \mathrm{ml}^{-1} \cdot \mathrm{min}^{-1}\right)$ & $-27.8 \pm 10.1$ & $-23.1 \pm 8.3$ \\
\hline & early postprandial (0-2 h) & $-26.8 \pm 4.7$ & $-17.7 \pm 13.0$ \\
\hline & mid postprandial (2-4 h) & $-17.5 \pm 4.8$ & $-27.0 \pm 9.5$ \\
\hline \multirow[t]{3}{*}{ Free fatty acids (FFA) } & fasting $\left(\mathrm{nmol} \cdot 100 \mathrm{ml}^{-1} \cdot \mathrm{min}^{-1}\right)$ & $-17.3 \pm 34.0$ & $-21.3 \pm 21.7$ \\
\hline & early postprandial (0-2 h) & $-48.5 \pm 21.0$ & $-42.2 \pm 10.5$ \\
\hline & mid postprandial (2-4 h) & $3.5 \pm 14.1$ & $19.0 \pm 10.7$ \\
\hline \multirow[t]{3}{*}[{}^{2}\mathrm{H}_{2}]{-palmitate FFA } & fasting $\left(\mathrm{nmol} \cdot 100 \mathrm{ml}^{-1} \cdot \mathrm{min}^{-1}\right)$ & $1.60 \pm 0.18$ & $1.54 \pm 0.16$ \\
\hline & early postprandial (0-2 h) & $1.39 \pm 0.14$ & $1.34 \pm 0.11$ \\
\hline & mid postprandial (2-4 h) & $1.62 \pm 0.14$ & $1.77 \pm 0.20$ \\
\hline \multirow[t]{3}{*}{ Triacylglycerol (TAG) } & fasting $\left(\mathrm{nmol} \cdot 100 \mathrm{ml}^{-1} \cdot \mathrm{min}^{-1}\right)$ & $30.5 \pm 7.7$ & $-10.3 \pm 31.1$ \\
\hline & early postprandial (0-2 h) & $88.1 \pm 32.0$ & $35.1 \pm 13.3$ \\
\hline & mid postprandial (2-4 h) & $30.1 \pm 71.3$ & $-7.2 \pm 32.6$ \\
\hline \multirow[t]{3}{*}[{}^{2}\mathrm{H}_{2}]{-palmitate TAG } & fasting $\left(\mathrm{nmol} \cdot 100 \mathrm{ml}^{-1} \cdot \mathrm{min}^{-1}\right)$ & $1.07 \pm 0.99$ & $0.08 \pm 0.22$ \\
\hline & early postprandial (0-2 h) & $1.08 \pm 0.72$ & $-0.64 \pm 0.36^{*}$ \\
\hline & mid postprandial (2-4 h) & $1.42 \pm 1.38$ & $-0.30 \pm 2.08$ \\
\hline \multirow[t]{3}{*}[\mathrm{U}-{}^{13}\mathrm{C}]{-palmitate TAG } & fasting $\left(\mathrm{nmol} \cdot 100 \mathrm{ml}^{-1} \cdot \mathrm{min}^{-1}\right)$ & NA & NA \\
\hline & early postprandial (0-2 h) & $0.45 \pm 0.07$ & $0.39 \pm 0.12$ \\
\hline & mid postprandial (2-4 h) & $1.05 \pm 0.24$ & $0.58 \pm 0.37$ \\
\hline
\end{tabular}

Values are mean \pm SEM. Postprandial data are expressed as AUC/min. A positive flux indicates net uptake across forearm muscle, whereas a negative flux indicates net release. NA, not applicable.

$\left[{ }^{2} \mathrm{H}_{2}\right]$-palmitate FFA: $n=14$ (IR) and $n=12$ (control). [ $\left.{ }^{2} \mathrm{H}_{2}\right]$-palmitate TAG: IR $n=15$ (IR) and $n=13$ (control).

" $P=0.05$, IR vs. control, Student's t-test for unpaired samples. 


\section{Whole body and forearm muscle TAG metabolism}

\section{Whole body TAG metabolism}

Arterial plasma TAG concentrations were similar between groups during fasting and increased after meal ingestion, without significant differences between groups (Figure 3.3A). The $\left[{ }^{2} \mathrm{H}_{2}\right]$-palmitate tracer could be measured in plasma TAG from the first baseline sample onward, reflecting incorporation of the intravenously infused tracer into VLDL-TAG (Figure 3.3B). The $\left[{ }^{13} \mathrm{C}\right]$-palmitate tracer, given with the meal, appeared in plasma TAG from $60 \mathrm{~min}$ after meal ingestion, representing chylomicron-TAG in the circulation (Figure 3.3B). Both labeled TAG fractions rose up to $4 \mathrm{~h}$ postprandially, without significant differences between groups at any time.

\section{Forearm muscle TAG metabolism}

Extraction of $\left[{ }^{2} \mathrm{H}_{2}\right]$-palmitate in TAG across forearm muscle was higher in the IR group than the control group in the early phase after meal ingestion $\left(\mathrm{AUC}_{0-2} \mathrm{~h}\right.$ : $P=0.05$ ), indicating increased LPL-mediated hydrolysis of VLDL-TAG at the capillary bed of forearm muscle in IR men (Table 3.2, Figure 3.3C).

Extraction of $\left[{ }^{13} \mathrm{C}\right]$-palmitate in TAG across forearm muscle could be measured from 60 min onward and was not different between groups, although values for extraction were higher in the mid-postprandial period (2-4 h postprandially) in IR subjects (not significant) (Table 3.2, Figure 3.3D). Fractional extraction of $\left[{ }^{13} \mathrm{C}\right]-$ palmitate in TAG across forearm muscle was consistently greater than the fractional extraction of $\left[{ }^{2} \mathrm{H}_{2}\right]$-palmitate in TAG throughout the whole postprandial period, without differences between groups (data not shown).

The fractional extraction of $\left[{ }^{13} \mathrm{C}\right]$-palmitate derived from chylomicron-TAG hydrolysis ('entrapment') was about $100 \%$ during the entire postprandial period in both groups, indicating a highly efficient forearm muscle uptake of FA derived from LPL-mediated TAG hydrolysis. Specific entrapment of FA derived from VLDL-TAG hydrolysis could not be calculated because both circulating FFA and VLDL-TAG are labeled with $\left[{ }^{2} \mathrm{H}_{2}\right]$-palmitate.

\section{Intramuscular lipid metabolism}

\section{Lipid content}

Skeletal muscle TAG, DAG, FFA and PL content were comparable between groups at baseline, although muscle TAG tended to be slightly higher in IR men vs. control $(213.0 \pm 40.7$ vs. $136.6 \pm 20.7 \mu \mathrm{mol} / \mathrm{g}$ dry weight, $P=0.11)$ (Table 3.3). Muscle PL content increased after the high-fat mixed meal in IR men compared the control group (change from fasting: $28.29 \pm 11.22$ vs. $-4.30 \pm 9.83 \mu \mathrm{mol} / \mathrm{g}$ dry weight, $P=0.038$ ). No differences between groups were observed for changes in muscle TAG, DAG and FFA content (data not shown). 
A

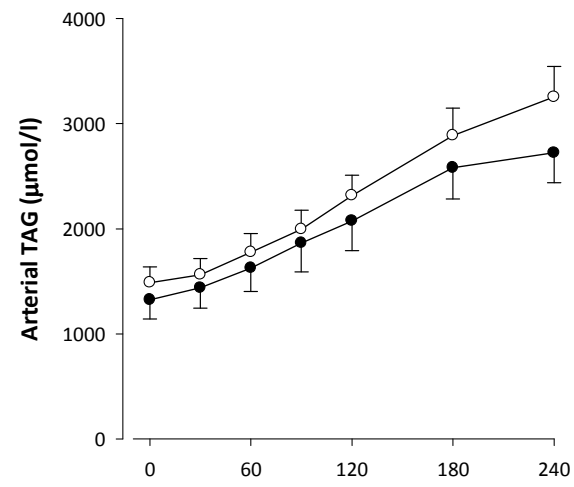

C

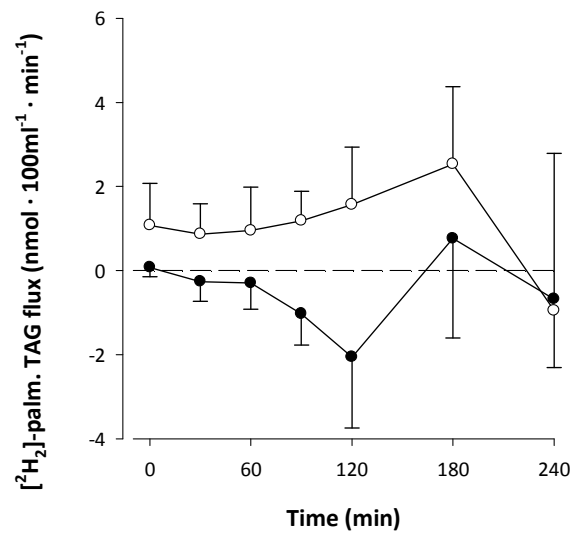

B

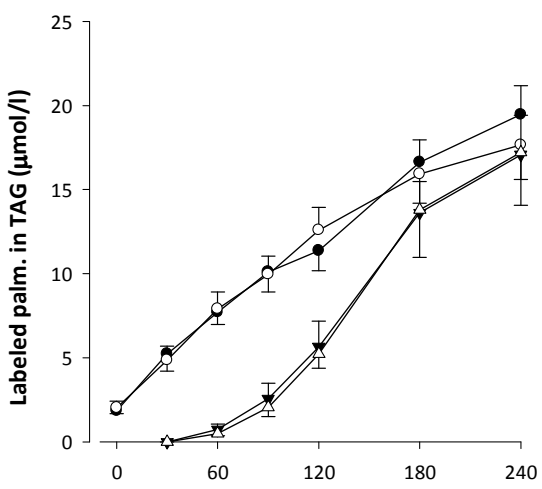

D

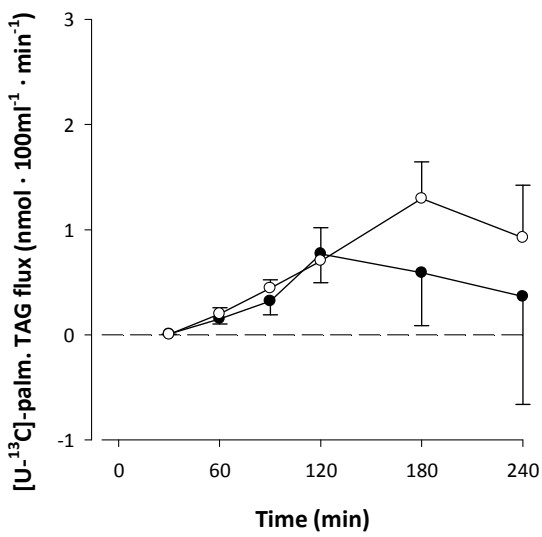

Figure 3.3 Arterial plasma triacylglycerol (TAG) concentrations (A), $\left[{ }^{2} \mathrm{H}_{2}\right]-$ and $\left[{ }^{13} \mathrm{C}\right]$-palmitate concentrations in the plasma TAG fraction (B) and the net flux of $\left[{ }^{2} \mathrm{H}_{2}\right]$-palmitate TAG (C) and $\left[{ }^{13} \mathrm{C}\right]-$ palmitate TAG (D) across forearm muscle during fasting (t 0 ) and after consumption of a high-fat mixed meal. A positive flux indicates net uptake across forearm muscle, whereas a negative flux indicates net

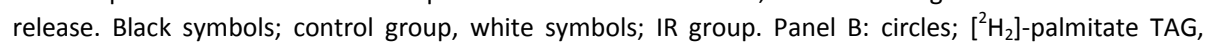
triangles; $\left[{ }^{13} \mathrm{C}\right]$-palmitate TAG. Values are mean \pm SEM.

\section{Composition}

Intramuscular lipid composition was different between groups at baseline with a higher degree of saturation of skeletal muscle DAG in IR men compared to control (43 \pm 4 vs. $34 \pm 2 \%, P=0.026$ ) (Table 3.3). This difference was largely explained by a higher percentage of palmitic acid (C16:0; $24 \pm 1$ vs. $21 \pm 1 \%, P=0.08)$ and a lower percentage of oleic acid (C18:1n-9; $34 \pm 2$ vs. $40 \pm 1 \%, P=0.042$ ) in the DAG fraction of IR men vs. control (Figure 3.4). In addition, intramuscular TAG and PL fractions of IR men contained higher proportions of dihomo- - -linolenic acid (C20:3n-6; TAG: $P=0.030$, PL: $P=0.07)$ and arachidonic acid (C20:4n-6; TAG: $P=0.08$; PL: $P=0.016)$ compared to control (Figure 3.4). 
After consumption of the high-fat mixed meal, no differences were observed between groups for changes in saturation of muscle TAG, DAG and FFA (data not shown). In intramuscular PL, the proportion of both dihomo- $\gamma$-linolenic acid (C20:3n-6; $-0.10 \pm 0.07$ vs. $0.06 \pm 0.05 \%, P=0.06$ ) and arachidonic acid (C20:4n-6; $-1.32 \pm 0.51$ vs. $0.92 \pm 0.56 \%, P=0.007$ ) were significantly decreased after the highfat mixed meal in IR men compared to control.

Estimated $\Delta 9$-desaturase activity was not different between groups at baseline and did not significantly change after consumption of the high-fat mixed meal.

\section{Fractional synthetic rate}

The FSR of skeletal muscle TAG, DAG and PL was comparable between groups (Table 3.3), indicating that a similar proportion of palmitate from the intramuscular FFA pool was directed towards storage in IR men and control after the high-fat mixed meal.

Table 3.3 Skeletal muscle lipid content and saturation during fasting, and their fractional synthetic rates

\begin{tabular}{llll}
\hline & IR & Control & $P$-value \\
\hline TAG & & & \\
Total ( $\mu \mathrm{mol} / \mathrm{g}$ dry weight) & $213.0 \pm 40.7(12)$ & $136.6 \pm 20.7(12)$ & 0.109 \\
Saturation (\%) & $37.5 \pm 1.2(12)$ & $36.9 \pm 1.6(12)$ & 0.740 \\
FSR (\%/h) & $0.36 \pm 0.10(9)$ & $0.36 \pm 0.10(13)$ & 0.965 \\
DAG & & & \\
Total ( $\mu \mathrm{mol} / \mathrm{g}$ dry weight) & $9.92 \pm 1.57(12)$ & $8.40 \pm 0.80(12)$ & 0.398 \\
Saturation (\%) & $43.2 \pm 3.8(12)$ & $33.5 \pm 1.5(12)$ & $0.026^{*}$ \\
FSR (\%/h) & $0.34 \pm 0.07(10)$ & $0.33 \pm 0.07(12)$ & 0.930 \\
PL & & & 0.218 \\
Total ( $\mu \mathrm{mol} / \mathrm{g}$ dry weight) & $62.19 \pm 5.86(14)$ & $73.95 \pm 7.24(14)$ & 0.796 \\
Saturation (\%) & $42.3 \pm 1.4(14)$ & $41.9 \pm 0.9(14)$ & 0.709 \\
FSR (\%/h) & $0.10 \pm 0.01(13)$ & $0.09 \pm 0.01(14)$ & \\
\hline
\end{tabular}

Values are mean \pm SEM $(n)$. The FSR is determined after consumption of a high-fat mixed meal.

${ }^{*} P<0.05$, IR vs. control, Student's t-test for unpaired samples.

\section{Skeletal muscle mRNA expression}

Postabsorptive skeletal muscle mRNA expression of LPL and genes involved in lipid oxidation and lipid synthesis were comparable between groups (Table 3.4). Postprandially, there was a significant down-regulation of $\mathrm{mCPT} 1 \mathrm{~b}(P=0.048)$ as well as a tendency for up-regulation of LPL $(P=0.09)$ in the total group of subjects $(n=14$, data not shown). Between groups, however, there were no significant differences in postprandial gene expression (Table 3.4). Subject characteristics of the IR men $(n=6)$ 


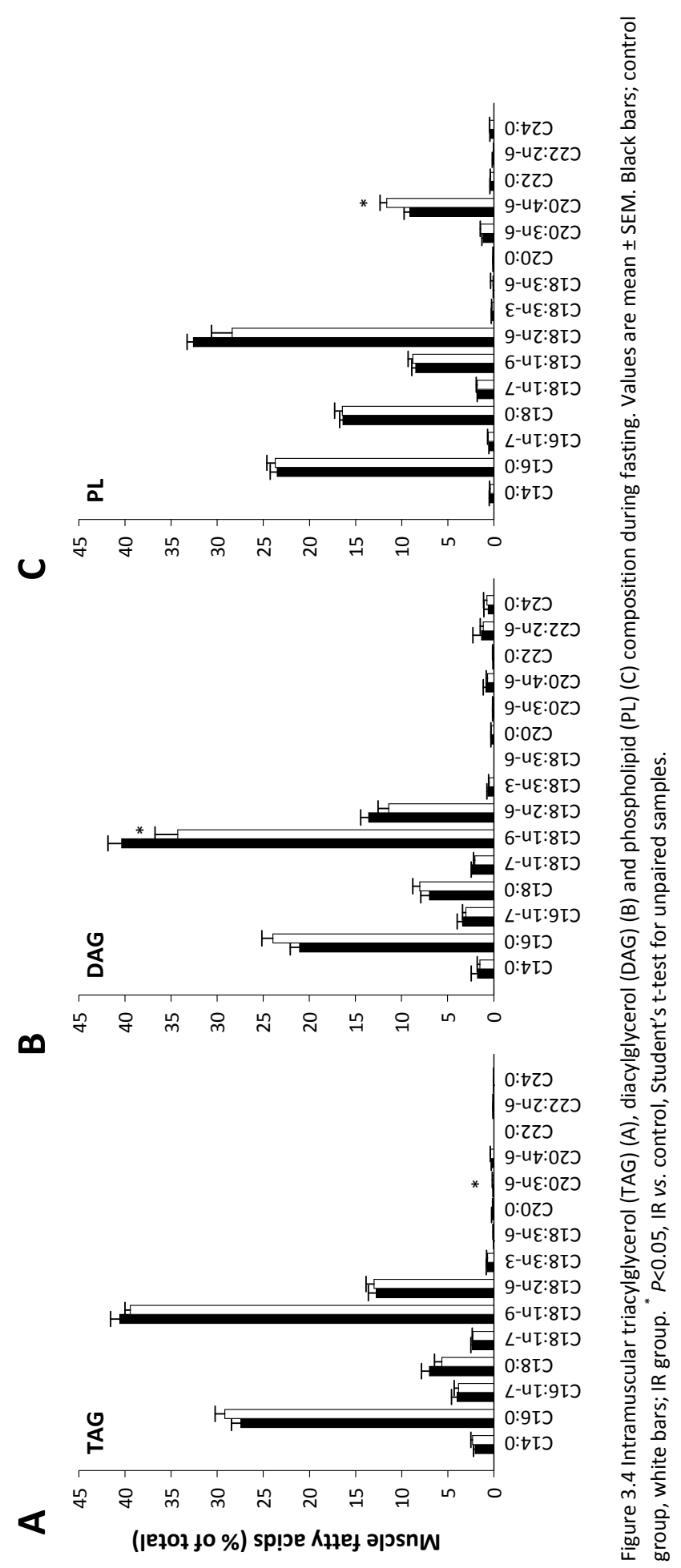


and control $(n=8)$ in this sub-analysis were comparable to those presented in Table 3.1.

Table 3.4 Skeletal muscle mRNA normalised expression during fasting and after consumption of a high-fat mixed meal

\begin{tabular}{lllll}
\hline & $\begin{array}{l}\text { IR }(n=6) \\
\text { fasting }\end{array}$ & fold change & $\begin{array}{l}\text { Control }(n=8) \\
\text { fasting }\end{array}$ & fold change \\
\hline LPL & $0.37 \pm 0.05$ & $2.2 \pm 1.2$ & $0.46 \pm 0.10$ & $3.3 \pm 1.1$ \\
PPAR $\alpha$ & $1.49 \pm 0.18$ & $0.9 \pm 0.2$ & $1.46 \pm 0.24$ & $1.0 \pm 0.3$ \\
PGC1 $\alpha$ & $0.38 \pm 0.07$ & $2.7 \pm 0.9$ & $0.48 \pm 0.09$ & $2.3 \pm 1.0$ \\
ACC2 & $2.01 \pm 0.43$ & $0.7 \pm 0.2$ & $1.71 \pm 0.32$ & $1.3 \pm 0.5$ \\
mCPT1b & $1.31 \pm 0.39$ & $0.6 \pm 0.1$ & $1.74 \pm 0.29$ & $1.0 \pm 0.4$ \\
SREBP1c & $0.90 \pm 0.22$ & $0.9 \pm 0.2$ & $0.82 \pm 0.15$ & $1.1 \pm 0.2$ \\
SREBP2 & $1.68 \pm 0.22$ & $0.8 \pm 0.2$ & $1.88 \pm 0.32$ & $1.0 \pm 0.3$ \\
ChREBP & $1.13 \pm 0.15$ & $0.7 \pm 0.2$ & $1.30 \pm 0.40$ & $1.1 \pm 0.4$ \\
\hline
\end{tabular}

Values are mean \pm SEM, expressed in arbitrary units. Fold change is calculated as $(4 \mathrm{~h} / 0 \mathrm{~h})$. No significant differences between groups, Student's t-test for unpaired samples.

\section{Discussion}

In this study we examined fasting and postprandial skeletal muscle FA handling in IR men. By using a dual stable isotope technique we were able to differentiate between the contribution of circulating FFA, endogenous (VLDL)-TAG and dietary (chylomicron)-TAG to skeletal muscle FA metabolism, and observed a significant difference in the handling of VLDL-TAG between IR men and control. In IR men, a higher net extraction of VLDL-TAG across forearm muscle was observed during the first $2 \mathrm{~h}$ after meal ingestion, despite a similar supply of plasma TAG. Furthermore, intramuscular lipid composition was different between groups with a higher fasting percentage saturation of muscle DAG in IR men.

To our knowledge this is the first study showing differential quantitative handling of hepatically derived TAG by forearm muscle in IR men and the underlying mechanisms for this observation remain to be elucidated. Findings may extent to chylomicron-TAG as also the uptake of this particle tended to increase more in the IR group at the end of the postprandial period, although not statistically significant. However, measurements were not performed in the late postprandial phase (i.e. 4$6 \mathrm{~h}$ postprandially), as it has been shown that dietary FA appear in the VLDL-TAG fraction from 2-3 $\mathrm{h}$ after meal ingestion, making it difficult to completely separate chylomicron-TAG and VLDL-TAG in the late postprandial phase using the current dual stable isotope technique (16-18). The importance of TAG metabolism in insulin resistance extends results from a previous study investigating fatty acid metabolism 
using the same dual stable isotope methodology (14), although Bickerton et al showed no differences in postprandial chylomicron-TAG extraction and VLDL-TAG extraction. In that study, IR men and controls were selected from a healthy population with overweight, whereas we studied the isolated effects of insulin sensitivity in subjects with the MetS. Further in vivo research in subjects with varying phenotypes is needed to obtain more insight in the importance of skeletal muscle FA metabolism in insulin resistance.

Inhibitory effects of insulin on skeletal muscle LPL activity may be impaired in the insulin resistant state, resulting in increased postprandial skeletal muscle TAG extraction. In this study skeletal muscle LPL mRNA was not differentially expressed after meal ingestion, but a role of LPL cannot be excluded since it has been shown that LPL activity is mainly regulated at posttranscriptional and posttranslational levels (31-33).

Apart from the observed differences in lipid uptake, also the partitioning of FA within skeletal muscle has previously been shown to be more directed towards storage than oxidation in the IR state (1). An increased TAG fractional synthetic rate may protect the muscle from excess FFA concentrations and subsequent accumulation of lipid metabolites that may interfere with insulin signalling. In this study the FSR of intramuscular lipid fractions was not different between IR men and control, which is in line with findings from a recent study of intramuscular lipid synthesis in smokers and non-smokers with clear differences in insulin sensitivity (34). Also, mRNA normalised expression levels of several key genes important in skeletal muscle FA uptake, mitochondrial FA transport, oxidation and synthesis were not significantly different between IR men and control. Our results indicate that a similar proportion of FA from the intramuscular FFA pool was directed towards storage in the different lipid fractions in IR men and control. Increased extraction of (VLDL)-TAG across skeletal muscle combined with a similar intramuscular FSR may be a trigger for intramuscular lipid accumulation in the insulin resistant state.

Saturation of muscle DAG was significantly higher in IR men compared to control at baseline, mainly reflected by a higher proportion of palmitic acid (C16:0) and a lower proportion of oleic acid (C18:1n-9). This finding is in line with results from studies in human muscle cell lines and rodents showing that long-chain saturated fatty acids accumulate preferentially as DAG and are associated with insulin resistance, whereas unsaturated fatty acids are more readily converted into TAG $(12,35,36)$. In another study, incubation of C2C12 myotubes with palmitate was associated with increased DAG accumulation and reduced insulin action, whereas incubation with oleic acid had no effects (37). The activity of $\Delta 9$-desaturase in muscle could play an important role in the partitioning of fatty acids and can be estimated by the ratio of $\mathrm{C} 18: 1 n-9$ to $\mathrm{C} 18: 0$. It has been suggested that increased $\Delta 9$-desaturase expression in human skeletal muscle is associated with obesity by stimulating FA storage in intramuscular TAG rather than FA oxidation (38). On the 
other hand, increased $\Delta 9$-desaturase activity in the obese IR state may be protective for further insulin resistance by stimulating intramuscular TAG accumulation and subsequently reducing the accumulation of saturated $F A$ in muscle DAG and ceramide $(39,40)$. In this study there were no differences in estimated $\Delta 9$ desaturase activity between IR men and control during fasting and after the high-fat mixed meal. It is important to mention that total DAG content as measured by others and us might not reflect the DAG component that may interfere with insulin signalling and contribute to the development of insulin resistance $(34,37)$. Therefore, future research should elucidate which specific DAG form may be related to skeletal muscle insulin resistance. Nevertheless, the present findings implicate a relationship between a higher saturation of intramuscular DAG and the presence of IR.

All subjects in our study were selected from a population of subjects with the MetS. However, insulin resistance was not a requirement for the definition of the MetS in this study and because of the range in $S_{1}$ it was possible to create two groups with a pronounced difference in insulin sensitivity. Mean values of $S_{I}$ in the IR group were slightly higher than values described in literature for type 2 diabetic patients $(41,42)$, whereas mean values of $S_{1}$ in the control group were comparable with values reported for healthy subjects with normal glucose tolerance $(41,43)$. Moreover, postprandial arterial insulin concentrations were higher in IR men vs. control, whereas postprandial arterial glucose concentrations and glucose uptake across the forearm muscle were comparable between groups. These data indicate that men in the IR group were indeed more insulin resistant as compared to men in the control group, both at whole body and forearm muscle level. Since insulin resistance is normally related to increased body weight, an abdominal fat distribution and increased lipids, our subject selection may be artificial due to the fact that all subjects had the metabolic syndrome. On the other hand, from a mechanistic point of view this may represent a strength of the study showing the metabolic disturbances related to insulin sensitivity per se, independent of the other characteristics of the metabolic syndrome. We observed only small differences in skeletal muscle FA handling between groups which may be related to how subjects were selected. Nevertheless, these small differences in TAG extraction may be of relevance for skeletal muscle fat storage in the longer term. Therefore, we believe that the current results provide new and relevant insights in the relationship between skeletal muscle FA metabolism and insulin resistance, which have to be confirmed and investigated further in a larger number of subjects selected from an IR population and a healthy control population.

In conclusion, by combining this dual stable isotope technique with skeletal muscle lipid analyses, we were able to demonstrate that insulin resistance is associated with increased postprandial forearm muscle (hepatically-derived) TAG uptake and 
increased saturation of muscle DAG. Although there were only small differences between groups in skeletal muscle TAG extraction, in the longer term this may be one of the mechanisms contributing to intramuscular lipid accumulation, insulin resistance and the development of type 2 diabetes.

\section{Acknowledgements}

We gratefully thank all volunteers for their time and motivation, and J. Stegen, W. Sluijsmans, H. Aydeniz, R. Jacobs and A. Gijsen for their excellent analytical support.

\section{Supplemental data}

Supplemental table Gene-specific forward and reverse primers for qPCR

\begin{tabular}{lll}
\hline Gene & Forward primer sequence $\left(5^{\prime}-3^{\prime}\right)$ & Reverse primer sequence $\left(3^{\prime}-5^{\prime}\right)$ \\
\hline B2M & GGACTTCGAGCAAGAGATGG & AGCACTGTGTTGGCGTACAG \\
RPL13 $\alpha$ & CCTGGAGGAGAAGAGGAAAGAGA & TTGAGGACCTCTGTGTATTTGTCAA \\
LPL & CATCTCTTGGGATACAGCCTTG & GGGCTTCTGCATACTCAAAGT \\
PPAR $\alpha$ & AAAAGCCTAAGGAAACCGTTCTG & TATCGTCCGGGTGGTTGCT \\
PGC1 $\alpha$ & CCAGGTCAAGATCAAGGTCTCCAG & TTCGGTGCGTGCGGTGTC \\
ACC2 & GCAAGAACGTGTGGGGTTACT & TCGTAGTGGGCTTGCTGAAAA \\
mCPT1b & CGGGACAGGGGTAAGTTCTG & TCTCGCAGGTCTGCTTTTGTG \\
SREBP1c & ACACAGCAACCAGAAACTCAAGC & GCCGACACCAGATCCTTCAGAG \\
SREBP2 & GCACCACTCCGCAGACGAG & TGGACTTGAGGCTCAAGGACTTG \\
ChREBP & GCCTCAAGGTGAGCAAAGCTA & GCTGGCACAGGTTAATGGC \\
\hline
\end{tabular}

RPL13a, ribosomal protein L13a; B2M, $\beta$-2-microglobulin; LPL, lipoprotein lipase; PPAR $\alpha$, peroxisome proliferator-activated receptor $\alpha$; PGC1 $\alpha$, PPARy coactivator $1 \alpha$; ACC2, acetyl-CoA carboxylase; mCPT1, muscle carnitine palmitoyltransferase 1b; SREBP, sterol regulatory element binding protein; ChREBP, carbohydrate responsive element-binding protein. 


\section{References}

1. Blaak EE. Basic disturbances in skeletal muscle fatty acid metabolism in obesity and type 2 diabetes mellitus. Proc Nutr Soc 2004;63(2):323-30.

2. Savage DB, Petersen KF, Shulman GI. Disordered lipid metabolism and the pathogenesis of insulin resistance. Physiol Rev 2007;87(2):507-20.

3. Petersen KF, Dufour S, Savage DB, Bilz S, Solomon G, Yonemitsu S, et al. The role of skeletal muscle insulin resistance in the pathogenesis of the metabolic syndrome. Proc Natl Acad Sci U S A 2007;104(31):12587-94.

4. Frayn KN. Adipose tissue as a buffer for daily lipid flux. Diabetologia 2002;45(9):1201-10.

5. Blaak EE, Wagenmakers AJ, Glatz JF, Wolffenbuttel BH, Kemerink GJ, Langenberg CJ, et al. Plasma FFA utilization and fatty acid-binding protein content are diminished in type 2 diabetic muscle. Am J Physiol Endocrinol Metab 2000;279(1):E146-54.

6. Mensink M, Blaak EE, van Baak MA, Wagenmakers AJ, Saris WH. Plasma free Fatty Acid uptake and oxidation are already diminished in subjects at high risk for developing type 2 diabetes. Diabetes 2001;50(11):2548-54.

7. Kelley DE, Goodpaster B, Wing RR, Simoneau JA. Skeletal muscle fatty acid metabolism in association with insulin resistance, obesity, and weight loss. Am J Physiol 1999;277(6 Pt 1):E113041.

8. Corcoran MP, Lamon-Fava S, Fielding RA. Skeletal muscle lipid deposition and insulin resistance: effect of dietary fatty acids and exercise. Am J Clin Nutr 2007;85(3):662-77.

9. Schmitz-Peiffer C. Signalling aspects of insulin resistance in skeletal muscle: mechanisms induced by lipid oversupply. Cell Signal 2000;12(9-10):583-94.

10. Schrauwen P, Hesselink MK. Oxidative capacity, lipotoxicity, and mitochondrial damage in type 2 diabetes. Diabetes 2004;53(6):1412-7.

11. Roden M. How free fatty acids inhibit glucose utilization in human skeletal muscle. News Physiol Sci 2004;19:92-6.

12. Montell E, Turini M, Marotta M, Roberts M, Noe V, Ciudad CJ, et al. DAG accumulation from saturated fatty acids desensitizes insulin stimulation of glucose uptake in muscle cells. Am J Physiol Endocrinol Metab 2001;280(2):E229-37.

13. Coppack SW, Evans RD, Fisher RM, Frayn KN, Gibbons GF, Humphreys SM, et al. Adipose tissue metabolism in obesity: lipase action in vivo before and after a mixed meal. Metabolism 1992;41(3):264-72.

14. Bickerton AS, Roberts R, Fielding BA, Tornqvist H, Blaak EE, Wagenmakers AJ, et al. Adipose tissue fatty acid metabolism in insulin-resistant men. Diabetologia 2008;51(8):1466-74.

15. Riemens SC, Sluiter WJ, Dullaart RP. Enhanced escape of non-esterified fatty acids from tissue uptake: its role in impaired insulin-induced lowering of total rate of appearance in obesity and Type Il diabetes mellitus. Diabetologia 2000;43(4):416-26.

16. Heath RB, Karpe F, Milne RW, Burdge GC, Wootton SA, Frayn KN. Selective partitioning of dietary fatty acids into the VLDL TG pool in the early postprandial period. J Lipid Res 2003;44(11):2065-72.

17. Heath RB, Karpe F, Milne RW, Burdge GC, Wootton S, Frayn KN. Dietary fatty acids make a rapid and substantial contribution to VLDL-triacylglycerol in the fed state. Am J Physiol Endocrinol Metab 2007;292(3);E732-9.

18. Bickerton AS, Roberts R, Fielding BA, Hodson L, Blaak EE, Wagenmakers AJ, et al. Preferential uptake of dietary fatty acids in adipose tissue and muscle in the postprandial period. Diabetes 2007;56(1):168-76.

19. Cohn JS, Johnson EJ, Millar JS, Cohn SD, Milne RW, Marcel YL, et al. Contribution of apoB-48 and apoB-100 triglyceride-rich lipoproteins (TRL) to postprandial increases in the plasma concentration of TRL triglycerides and retinyl esters. J Lipid Res 1993;34(12):2033-40.

20. Evans K, Burdge GC, Wootton SA, Clark ML, Frayn KN. Regulation of dietary fatty acid entrapment in subcutaneous adipose tissue and skeletal muscle. Diabetes 2002;51(9):2684-90. 
21. Miles JM, Park YS, Walewicz D, Russell-Lopez C, Windsor S, Isley WL, et al. Systemic and forearm triglyceride metabolism: fate of lipoprotein lipase-generated glycerol and free fatty acids. Diabetes 2004;53(3):521-7.

22. Teusink B, Voshol PJ, Dahlmans VE, Rensen PC, Pijl H, Romijn JA, et al. Contribution of fatty acids released from lipolysis of plasma triglycerides to total plasma fatty acid flux and tissue-specific fatty acid uptake. Diabetes 2003;52(3):614-20.

23. Karpe F, Bickerton AS, Hodson L, Fielding BA, Tan GD, Frayn KN. Removal of triacylglycerols from chylomicrons and VLDL by capillary beds: the basis of lipoprotein remnant formation. Biochem Soc Trans 2007;35(Pt 3):472-6.

24. Third Report of the National Cholesterol Education Program (NCEP) Expert Panel on Detection, Evaluation, and Treatment of High Blood Cholesterol in Adults (Adult Treatment Panel III) final report. Circulation 2002;106(25):3143-421.

25. Finegood DT, Hramiak IM, Dupre J. A modified protocol for estimation of insulin sensitivity with the minimal model of glucose kinetics in patients with insulin-dependent diabetes. J Clin Endocrinol Metab 1990;70(6):1538-49.

26. Boston RC, Stefanovski D, Moate PJ, Sumner AE, Watanabe RM, Bergman RN. MINMOD Millennium: a computer program to calculate glucose effectiveness and insulin sensitivity from the frequently sampled intravenous glucose tolerance test. Diabetes Technol Ther 2003;5(6):1003-15.

27. Goossens GH, Blaak EE, Schiffers PM, Saris WH, van Baak MA. Effect of short-term ACE inhibitor treatment on peripheral insulin sensitivity in obese insulin-resistant subjects. Diabetologia 2006;49(12):3009-16.

28. Bergstrom J, Hermansen L, Hultman E, Saltin B. Diet, muscle glycogen and physical performance. Acta Physiol Scand 1967;71(2):140-50.

29. Wolfe RR. Radioactive and stable isotope tracers in biomedicine: principles and practice of kinetic analysis. New York, USA: Wiley-Liss, 1992.

30. Guo Z, Jensen MD. Intramuscular fatty acid metabolism evaluated with stable isotopic tracers. J Appl Physiol 1998;84(5):1674-9.

31. Semenkovich CF, Wims M, Noe L, Etienne J, Chan L. Insulin regulation of lipoprotein lipase activity in 3T3-L1 adipocytes is mediated at posttranscriptional and posttranslational levels. J Biol Chem 1989;264(15):9030-8.

32. Doolittle MH, Ben-Zeev O, Elovson J, Martin D, Kirchgessner TG. The response of lipoprotein lipase to feeding and fasting. Evidence for posttranslational regulation. J Biol Chem 1990;265(8):4570-7.

33. Wang $\mathrm{H}$, Eckel RH. Lipoprotein lipase: from gene to obesity. Am J Physiol Endocrinol Metab 2009;297(2):E271-88.

34. Bergman BC, Perreault L, Hunerdosse DM, Koehler MC, Samek AM, Eckel RH. Intramuscular lipid metabolism in the insulin resistance of smoking. Diabetes 2009;58(10):2220-7.

35. Lee JS, Pinnamaneni SK, Eo SJ, Cho IH, Pyo JH, Kim CK, et al. Saturated, but not n-6 polyunsaturated, fatty acids induce insulin resistance: role of intramuscular accumulation of lipid metabolites. J Appl Physiol 2006;100(5):1467-74.

36. Gaster M, Rustan AC, Beck-Nielsen H. Differential utilization of saturated palmitate and unsaturated oleate: evidence from cultured myotubes. Diabetes 2005;54(3):648-56.

37. Chavez JA, Summers SA. Characterizing the effects of saturated fatty acids on insulin signaling and ceramide and diacylglycerol accumulation in 3T3-L1 adipocytes and C2C12 myotubes. Arch Biochem Biophys 2003;419(2):101-9.

38. Hulver MW, Berggren JR, Carper MJ, Miyazaki M, Ntambi JM, Hoffman EP, et al. Elevated stearoylCoA desaturase-1 expression in skeletal muscle contributes to abnormal fatty acid partitioning in obese humans. Cell Metab 2005;2(4):251-61.

39. Pinnamaneni SK, Southgate RJ, Febbraio MA, Watt MJ. Stearoyl CoA desaturase 1 is elevated in obesity but protects against fatty acid-induced skeletal muscle insulin resistance in vitro. Diabetologia 2006;49(12):3027-37. 
40. Peter A, Weigert C, Staiger H, Machicao F, Schick F, Machann J, et al. Individual stearoyl-coa desaturase 1 expression modulates endoplasmic reticulum stress and inflammation in human myotubes and is associated with skeletal muscle lipid storage and insulin sensitivity in vivo. Diabetes 2009;58(8):1757-65.

41. Avignon A, Boegner C, Mariano-Goulart D, Colette C, Monnier L. Assessment of insulin sensitivity from plasma insulin and glucose in the fasting or post oral glucose-load state. Int J Obes Relat Metab Disord 1999;23(5):512-7.

42. Saad MF, Anderson RL, Laws A, Watanabe RM, Kades WW, Chen YD, et al. A comparison between the minimal model and the glucose clamp in the assessment of insulin sensitivity across the spectrum of glucose tolerance. Insulin Resistance Atherosclerosis Study. Diabetes 1994;43(9):111421.

43. Erichsen L, Agbaje OF, Luzio SD, Owens DR, Hovorka R. Population and individual minimal modeling of the frequently sampled insulin-modified intravenous glucose tolerance test. Metabolism 2004;53(10):1349-54. 



\section{4}

\section{Effects of dietary fat modification on skeletal muscle fatty acid handling in the metabolic syndrome}

Anneke M.J. van Hees, Wim H.M. Saris, Gabby B. Hul, Nicolaas C. Schaper, Bas E. Timmermans, Julie A. Lovegrove, Helen M. Roche and Ellen E. Blaak for the LIPGENE Consortium

International Journal of Obesity 2010;34(5):859-70. 


\section{Abstract}

In the metabolic syndrome (MetS), increased fat storage in non-adipose tissues such as skeletal muscle may be related to insulin resistance (lipid overflow hypothesis). The objective of this study was to examine the effects of dietary fat modification on the capacity of skeletal muscle to handle dietary and endogenous fatty acids (FA). In total, 29 men with the MetS were randomly assigned to one of four diets for 12 weeks: a high-fat saturated fat diet (HSFA, $n=6$ ), a high-fat monounsaturated fat diet (HMUFA, $n=7$ ) and two low-fat high-complex carbohydrate diets supplemented with (LFHCC $n-3, n=8$ ) or without (LFHCC, $n=8$ ) $1.24 \mathrm{~g}$ per day docosahexaenoic and eicosapentaenoic acid. Fasting and postprandial skeletal muscle FA handling was examined by measuring arterio-venous concentration differences across the forearm muscle. $\left[{ }^{2} \mathrm{H}_{2}\right]$-palmitate was infused intravenously to label endogenous triacylglycerol (TAG) and free fatty acids in the circulation and subjects received a high-fat mixed meal (2.6 MJ, 61 energy\% fat) containing $\left[\mathrm{U}-{ }^{13} \mathrm{C}\right]$-palmitate to label chylomicron-TAG.

Postprandial circulating TAG concentrations were significantly lower after dietary intervention in the LFHCC $n-3$ group compared to the HSFA group ( $\triangle$ iAUC $-139 \pm 67$ vs. $\left.167 \pm 70 \mu \mathrm{mol} \cdot \mathrm{I}^{-1} \cdot \mathrm{min}^{-1}, P=0.009\right)$, together with decreased concentrations of $\left[\mathrm{U}-{ }^{13} \mathrm{C}\right]$-labeled TAG, representing dietary FA. Fasting TAG clearance across forearm muscle was decreased on the HSFA diet, whereas no differences were observed in postprandial forearm muscle FA handling between diets.

Chronic manipulation of dietary fat quantity and quality did not affect forearm muscle FA handling in men with the MetS. Postprandial TAG concentrations decreased on the LFHCCn-3 diet, which could be (partly) explained by lower concentration of dietary FA in the circulation. 


\section{Introduction}

The metabolic syndrome (MetS) represents a clustering of risk factors for the development of type 2 diabetes and cardiovascular disease (1). Skeletal muscle and adipose tissue are important organs in regulating fatty acid (FA) metabolism and disturbances in their function may lead to insulin resistance (IR) and dyslipidaemia as seen in the MetS $(2,3)$. When the capacity of adipose tissue to store lipid becomes insufficient, most often associated with chronic excessive energy intake (in particular by means of dietary fat) and/or a sedentary lifestyle, this may lead to an increased supply of triacylglycerol (TAG) and free fatty acids (FFA) to non-adipose tissues, such as skeletal muscle and liver (lipid overflow hypothesis) (3). Consequently, if the uptake of FA exceeds the capacity or the need to oxidise fat in skeletal muscle or liver, the FA are stored, leading to ectopic fat accumulation. Moreover, it has been reported that the capacity to oxidise fat in IR skeletal muscle is impaired $(4,5)$. Ectopic fat disposition, in particular the accumulation of lipid metabolites, may reduce insulin action in skeletal muscle by interfering with insulin signaling and/or by inducing inflammatory pathways (6-8).

Dietary intervention, aimed at reducing the intake of saturated fat, may improve lipid metabolism and insulin action in the MetS, possibly through effects on lipid overflow and skeletal muscle FA handling. It remains an issue of debate whether saturated fat should be replaced by carbohydrates or unsaturated fat, and so far, little information is available on the relation between dietary fat quantity and quality and skeletal muscle FA handling in vivo. Polyunsaturated fatty acids (PUFA) may chronically stimulate adipocyte differentiation (9), thereby increasing lipid storage in adipose tissue and reducing lipid overflow towards muscle. In addition, there are indications from both human muscle cell lines and rodents that saturated fatty acids (SFA) accumulate preferentially as diacylglycerol, thereby inhibiting insulin signaling, whereas unsaturated FA are more readily converted into TAG $(10,11)$. Also, replacing SFA by unsaturated FA may favour fat oxidation above storage (10), and a 3-day high-carbohydrate diet has been shown to induce changes in partitioning of FA in healthy subjects, leading to increased fat deposition in liver and muscle (12).

Recently, a dual stable isotope study was validated to study FA handling in adipose tissue and skeletal muscle in detail (13), which offers, in combination with tissue balance techniques, unique possibilities for studying the contribution of dietary vs. endogenous FA to lipid overflow and storage in skeletal muscle. Using this technique, the aim of this study was to examine the effects of a 12-week dietary intervention with isoenergetic diets varying in both fat quality and quantity on fasting and postprandial skeletal muscle FA handling in a subcohort of men with the MetS within the LIPGENE human dietary intervention study. 


\section{Methods}

The LIPGENE human dietary intervention study was a randomised, controlled trial, carried out at eight different centres across Europe as part of the EU Sixth Framework project LIPGENE. In total, 486 volunteers with the MetS at the age of 3570 years and body mass index between 20 and $40 \mathrm{~kg} / \mathrm{m}^{2}$ were included in this study and randomly assigned to receive one of four dietary intervention treatments for a 12-week period (14). This study was performed in a subcohort of men in the Netherlands within this study.

All subjects were informed about the nature of the study and written informed consent was attained before study participation. The study protocol was approved by the local research ethics committees at each of the eight intervention centres.

\section{Subjects}

In total, 29 men with the MetS were included in this study. The definition of the MetS was based on the NCEP ATP III report (15), with subjects meeting at least three of the following criteria: (1) fasting plasma glucose concentration between 5.5 and $7.0 \mathrm{mmol} / \mathrm{l}$; (2) fasting plasma TAG concentration $\geq 1.5 \mathrm{mmol} / \mathrm{l}$; (3) fasting plasma high-density lipoprotein cholesterol concentration $<1.0 \mathrm{mmol} / \mathrm{l}$; (4) systolic blood pressure $\geq 130 \mathrm{~mm} \mathrm{Hg}$, diastolic blood pressure $\geq 85 \mathrm{~mm} \mathrm{Hg}$, or treatment of previously diagnosed hypertension; (5) waist circumference $>102 \mathrm{~cm}$. Exclusion criteria included weight change $>3 \mathrm{~kg}$ within 3 months before the study start; diabetes or other endocrine disorders; chronic inflammatory conditions; kidney or liver dysfunction; use of hypolipidaemic or anti-inflammatory medication; use of antihypertensive medication in the class of $\beta$-blockers; use of aspirin $>1$ per week, FA supplements or high doses of antioxidant vitamins; consumption of $>2$ portions of oily fish per week; highly trained or endurance athletes; and alcohol abuse.

\section{Dietary intervention study}

Subjects were randomly assigned to one of four intervention diets:

1) High-fat (38\% energy (E\%)) SFA-rich diet (16 E\% SFA, 12 E\% monounsaturated fatty acids (MUFA), 6 E\% PUFA) (HSFA);

2) High-fat (38 E\%) MUFA-rich diet (8 E\% SFA, 20 E\% MUFA, 6 E\% PUFA) (HMUFA);

3) Isoenergetic low-fat (28 E\%), high-complex carbohydrate diet (8 E\% SFA, 11 E\% MUFA, 6 E\% PUFA), with a control high-oleic acid sunflower-seed oil capsule (1 g per day) (LFHCC);

4) Isoenergetic low-fat (28 E\%), high-complex carbohydrate diet (8 E\% SFA, $11 \mathrm{E} \%$ MUFA, 6 E\% PUFA), with a long-chain (LC) $n$-3 PUFA supplement (1.24 g per day of eicosapentaenoic and docosahexaenoic acid, ratio 1.4:1) (LFHCCn-3). 
A range of fat-modified food products (margarines, cooking and baking fats, mayonnaise, dressing and biscuits) were produced by Unilever Food \& Health Research Institute (Unilever R\&D, Vlaardingen, the Netherlands) and provided to subjects with specific dietetic counseling. Carbohydrate exchanges were used to ensure that all diets were isoenergetic and one exchange of carbohydrates was considered as $35 \mathrm{~g}$ of complex carbohydrates (i.e. one potato, slice of brown bread, handful of rice). Loders-Croklaan (Wormerveer, the Netherlands) supplied the study capsules used in diet LFHCC and LFHCCn-3.

All subjects completed 3-day weighed food diaries at baseline, week 6 and week 12, and centre-specific dietary analysis programmes were used to analyse the food diaries. A detailed description of the food exchange model and assessment of compliance was published elsewhere (14). Subjects had to remain weight stable (changes were allowed within the range of $2 \mathrm{~kg}$ ) during the intervention period and were asked to maintain their normal pattern of physical activity, alcohol consumption and smoking.

\section{Experimental design}

Pre- and post-intervention, subjects came to the university after an overnight fast on two different occasions. On one day, subjects brought their fasting urine sample (first void), completed anthropometric measurements, donated a fasting blood sample, and completed an insulin modified intravenous glucose tolerance test to measure insulin sensitivity as described previously $(16,17)$. Insulin sensitivity was the primary end point of the LIPGENE human dietary intervention study.

On a separate day, a postprandial study was performed to evaluate the contribution of dietary TAG (labeled with [U- ${ }^{13} \mathrm{C}$ ]-palmitate), endogenous TAG, that is, very lowdensity lipoprotein (VLDL) and circulating FFA (both labeled with $\left[{ }^{2} \mathrm{H}_{2}\right]$-palmitate) to plasma lipid concentrations and skeletal muscle FA handling during fasting and after the consumption of a high-fat mixed meal, as validated previously (13).

\section{Postprandial study}

Subjects came to the university after an overnight fast and were asked to refrain from drinking alcohol and to perform no strenuous exercise $24 \mathrm{~h}$ before the study day. In addition, they were asked to avoid food products naturally enriched with $\left[{ }^{13} \mathrm{C}\right]$ for 7 days before the study day.

Skeletal muscle metabolism was studied in the forearm muscle, using arteriovenous concentration differences corrected for blood flow. Three catheters were inserted before the start of the experiment. In one arm, a catheter was placed in the radial artery of the forearm to sample arterial blood and another catheter was placed in an antecubital vein for the infusion of $\left[{ }^{2} \mathrm{H}_{2}\right]$-palmitate. A third catheter was placed 
retrogradely in a deep antecubital vein of the contralateral forearm to sample venous blood draining the forearm muscle.

After taking an arterial and deep venous background sample at t -95 (i.e. $95 \mathrm{~min}$ before meal ingestion), a continuous intravenous infusion of the stable isotope tracer $\left[{ }^{2} \mathrm{H}_{2}\right]$-palmitate (97 \% enrichment; Cambridge Isotope Laboratories, Andover MA, USA) complexed to albumin was started $\left(0.035 \mu \mathrm{mol} \cdot \mathrm{min}^{-1}\right.$ per $\mathrm{kg}$ body weight) using a calibrated infusion pump (IVAC560 pump; IVAC corporation, San Diego, CA, USA). Fasting blood sampling was started after $1 \mathrm{~h}$ of tracer infusion to allow for isotopic equilibration to occur. Blood samples were taken simultaneously from the radial artery and the deep muscle vein at three time points during fasting ( $t-35, t-20$ and $t-5$ ) and at six time points postprandially ( $\mathrm{t} \mathrm{30,t} \mathrm{60,t} \mathrm{90,t} \mathrm{120,}$ $t 180$ and $t$ 240) after consumption of a standardised high-fat mixed meal (t 0 ) containing $200 \mathrm{mg}\left[\mathrm{U}-{ }^{13} \mathrm{C}\right]$-palmitate (98\% enrichment; Cambridge Isotope Laboratories).

Forearm blood flow was measured before each blood sampling by venous occlusion plethysmography (EC5R plethysmograph; Hokanson, Bellevue, WA, USA), using mercury-in-silastic strain gauges applied to the widest part of the forearm. During measurement periods, the hand circulation was occluded by rapid inflation of a handcuff placed around the wrist to a pressure of $200 \mathrm{~mm} \mathrm{Hg}$. In this way, blood flow was assessed without interference of the hand circulation. Blood sampling was performed directly after blood flow measurements, with continuous occlusion of the hand circulation to exclude metabolism of the hand.

The liquid test meal provided 2.6 MJ, consisting of 61 E\% fat (35.5 E\% SFA, 18.8 E\% MUFA and 1.7 E\% PUFA), 33 E\% carbohydrate and 6.3 E\% protein. Subjects were asked to drink the test meal within $5 \mathrm{~min}$. The same test meal was provided preand post-intervention.

Energy expenditure, whole-body substrate utilisation and respiratory quotient were measured using an open-circuit ventilated hood system during fasting and at $t 30$, t 60, t 90, t 120, t 180 and t 240 after meal ingestion.

\section{Biochemical analyses}

Blood was collected in tubes containing ethylenediaminetertaacetic acid, centrifuged (1000 g, $10 \mathrm{~min}, 4^{\circ} \mathrm{C}$ ) and plasma was immediately frozen in liquid nitrogen and stored at $-80{ }^{\circ} \mathrm{C}$ until analysis. Plasma FFA (Wako NEFA C kit Wako, Sopar Biochemicals, Koekelberg, Belgium) and 3-hydroxybutyrate (Sigma, St Louis, MO, USA) were analysed using standard enzymatic techniques automated on a Cobas Fara centrifugal spectrophotometer (Roche Diagnostica, Basel, Switzerland). Plasma TAG (Sigma), glycerol (EnzyPlus; Diffchamb, Västa Frölunda, Sweden), glucose and lactate (ABX Diagnostics, Montpellier, France) were analysed enzymatically on a Cobas Mira automated spectrophotometer (Roche Diagnostica). 
Plasma insulin was measured with a double antibody radioimmunoassay (Linco Research Inc., St Charles, MO, USA). Plasma total cholesterol, high-density lipoprotein cholesterol and low-density lipoprotein cholesterol were determined with an ILab 600 clinical chemical analyser (Instrumentation Laboratory, Warrington, UK), using enzymatic colourimetric kits. Haematocrite was determined in heparinised blood using a microcapillary system.

To determine the tracer enrichment in plasma FFA and TAG, we extracted total lipids from the plasma using chloroform/methanol 2:1. The FFA and TAG fractions were separated by thin-layer chromatography and derivatised to their methyl esters for the analysis of plasma palmitate. Plasma fractions were analysed for the ${ }^{13} \mathrm{C} /{ }^{12} \mathrm{C}$ ratio in a gas chromatography continuous-flow isotope ratio-mass spectrometer (Finnigan MAT-252 GC-IRMS, Bremen, Germany) and for enrichment of $\left[{ }^{2} \mathrm{H}_{2}\right]$ (Finnigan Incos-XL GC-MS, Bremen, Germany). The methyl ester of palmitate contains 17 carbon atoms and therefore, the tracer/tracee ratio of palmitate was corrected for the extra methyl group. Plasma palmitate concentrations ( $\mu \mathrm{mol} / \mathrm{l}$ ) were analysed on an analytical GC with ion flame detection using heptadecanoic acid as internal standard.

\section{Calculations}

Insulin sensitivity $\left(S_{1}\right)$ was determined using the MINMOD Millennium program (version 6.02; R Bergman. Los Angeles, CA, USA) (17). The homeostasis model assessment for insulin resistance $\left(\mathrm{HOMA}_{\mathrm{IR}}\right)$ was calculated according to Matthews et al (18). The net flux of metabolites (labeled and unlabeled) across the forearm muscle was calculated by multiplying the arteriovenous concentration difference by forearm plasma flow (FPF). Plasma flow was calculated by multiplying forearm blood flow with (1 - haematocrite / 100). A positive flux indicates net uptake across forearm muscle, whereas a negative flux indicates net release. Fractional extraction of metabolites (in \%) was calculated as the arteriovenous concentration difference divided by the arterial concentration. To obtain a measure of efficiency of substrate removal from the circulation, we calculated substrate clearance across forearm muscle by multiplying the fractional extraction with FPF.

Fasting rate of appearance of FFA $\left(\mathrm{Ra}_{\mathrm{FFA}}\right)\left(\mu \mathrm{mol} \cdot \mathrm{kg}^{-1} \cdot \mathrm{min}^{-1}\right)$ was calculated with Steele's equation for steady state, whereas Steele's single-pool non-steady-state equations adapted for use with stable isotopes was used to calculate $\mathrm{Ra}_{\mathrm{FFA}}$ in the postprandial state (19). Labeled FFA and TAG concentrations were calculated as the product of tracer/tracee ratio of $\left[{ }^{2} \mathrm{H}_{2}\right]$ - and $\left[\mathrm{U}-{ }^{13} \mathrm{C}\right]$-palmitate and the palmitate concentration in FFA and TAG, respectively. Total (unidirectional) uptake of FA derived from the circulating FFA pool or from lipoprotein lipase (LPL)-mediated TAG hydrolysis were calculated as described previously, with the assumption of incomplete uptake of TAG-derived FA by forearm muscle (13). 


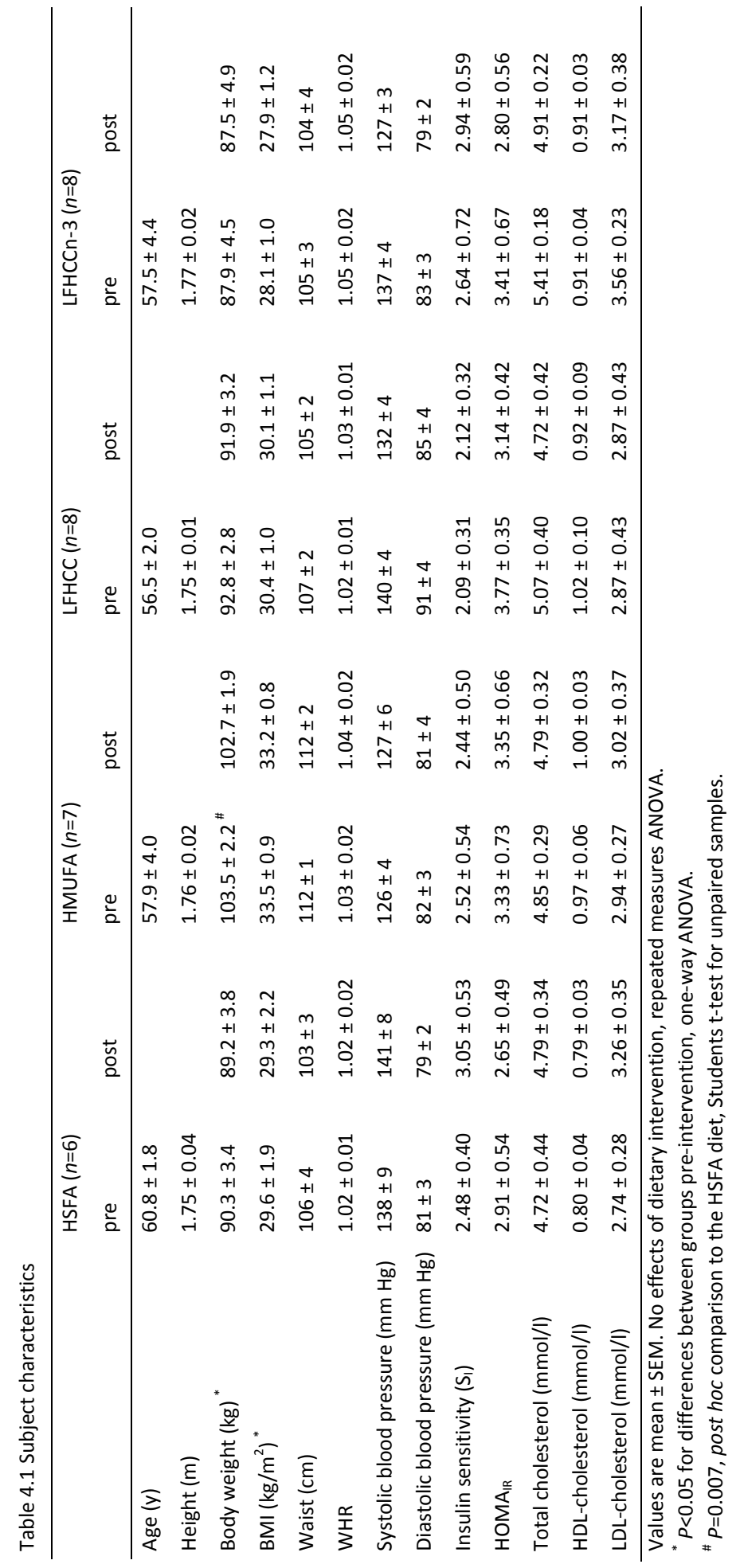


For comparing postprandial responses, the incremental area under the curve (iAUC) of metabolites and substrate fluxes was calculated using the trapezium rule. The iAUC was calculated for the 'total' (0-4 $\mathrm{h}$ after meal ingestion), 'early' (0-2 h) and 'mid' (2-4 h) postprandial phase.

\section{Statistical methods}

Statistical analyses were performed using SPSS 15.0 for Windows (SPSS Inc., Chicago, IL, USA). All data are presented as mean \pm standard error of the mean (SEM). One-way analysis of variance (ANOVA) was used to test for differences between dietary intervention groups pre-intervention. Repeated-measures ANOVA was applied to test for differences in changes between groups pre- and postintervention, with time as within-subjects factor and diet as between-subjects factor. When a significant diet by time interaction was observed, post hoc testing was performed on change data (post-pre) using unpaired t-tests comparing each diet (HMUFA, LFHCC and LFHCCn-3) to the HSFA diet. Statistical significance was set at $P<0.05$.

\section{Results}

In total, 29 men with the MetS completed pre- and post-intervention measurements (HSFA, $n=6$; HMUFA, $n=7$; LFHHC, $n=8$; and LFHCC $n-3, n=8$ ). Subject characteristics were comparable between groups pre-intervention, except for body weight $(P=0.019$, one-way ANOVA), which was higher in the HMUFA group as compared to the HSFA group ( $P=0.007$, post hoc) (Table 4.1 ). By definition, subjects primarily had a large waist circumference, elevated blood pressure and low fasting plasma high-density lipoprotein cholesterol concentrations, whereas mean fasting plasma glucose and TAG concentrations were only slightly elevated. Dietary intervention did not result in significant changes in the characteristics of the MetS and did not change insulin sensitivity $\left(S_{I}\right)$ and insulin resistance $\left(H O M A_{I R}\right)$ in this subcohort of the LIPGENE study (Table 4.1).

\section{Dietary macronutrient intake}

Dietary analyses in the total LIPGENE cohort showed that the food-exchange model was successfully implemented in the study overall (14). Also in this subcohort of the LIPGENE study, dietary fat intake (E\%) during intervention was significantly higher in the HSFA and HMUFA diets than in both LFHCC diets, which was achieved by higher intakes of carbohydrates (E\%) in the LFHCC diets as compared to the high-fat diets. Furthermore, subjects on the HSFA diet had significantly higher intakes of SFA (E\%) 
when compared to the other diets, whereas subjects on the HMUFA diet had significantly higher intakes of MUFA (E\%) than the other diets. Subjects on the LFHCC and LFHCC $n-3$ diet reported $\geq 85 \%$ compliance to the placebo and LC $n-3$ PUFA capsules (14).

A

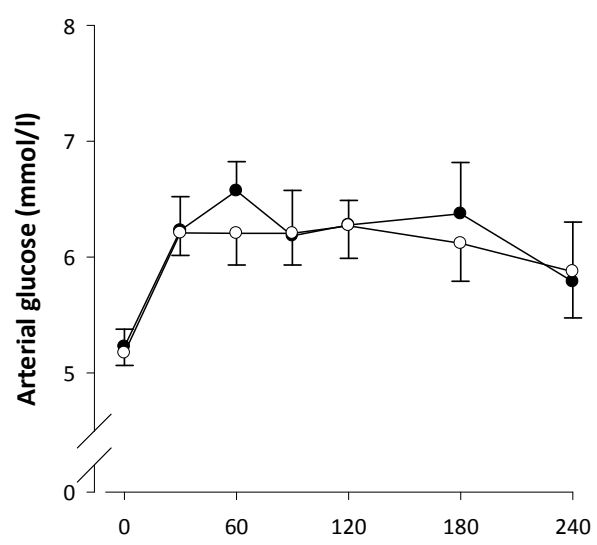

C

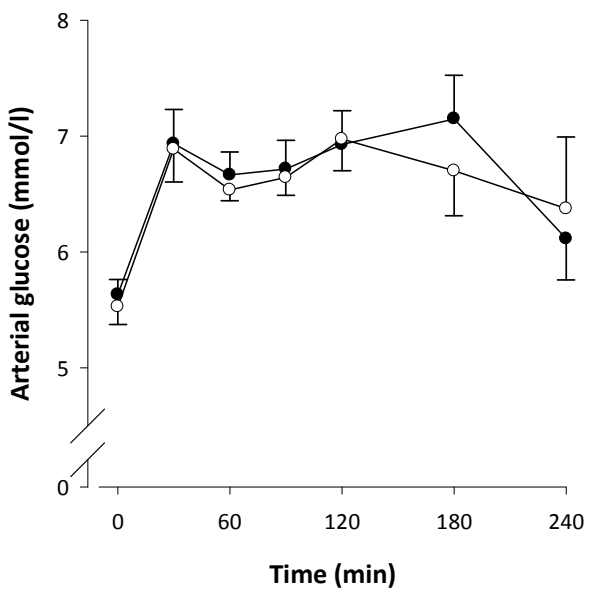

B

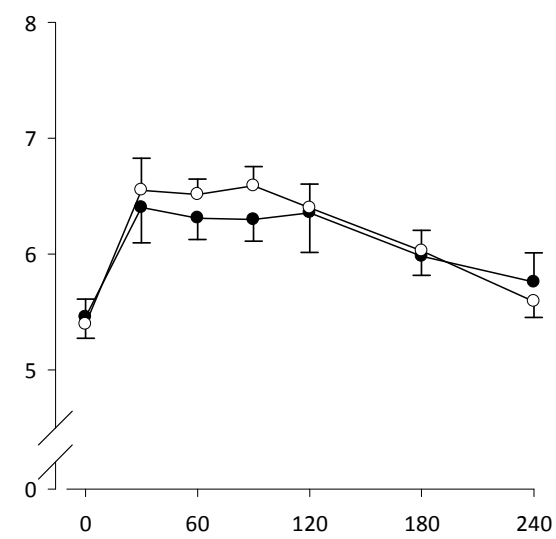

D

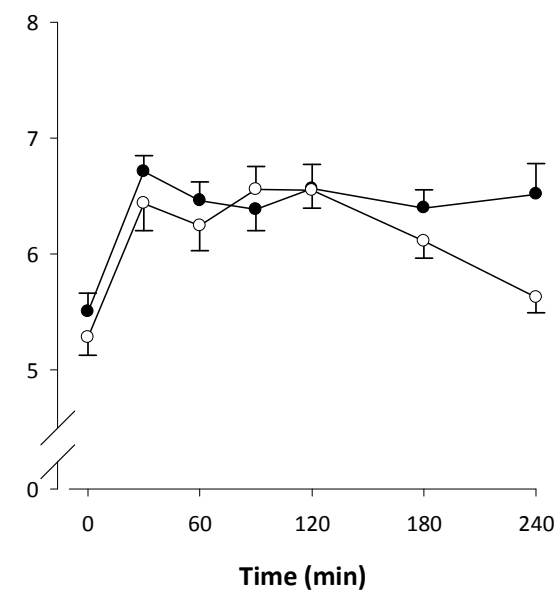

Figure 4.1 Plasma circulating glucose concentrations during fasting $(\mathrm{t} \quad 0)$ and postprandially after consumption of a high-fat mixed meal ( $\bullet$, pre-intervention; $\bigcirc$, post-intervention). (A) HSFA diet, (B) HMUFA diet, (C) LFHCC diet, (D) LFHCC $n-3$ diet. Values are mean \pm SEM.

\section{Arterial metabolites, forearm muscle metabolism and forearm blood flow}

Arterial plasma glucose (Figure 4.1), insulin (Figure 4.2), lactate, free glycerol and 3hydroxybutyrate concentrations during fasting and after meal ingestion were comparable between groups pre- and post-intervention. In addition, no significant 
changes in fluxes of glucose, lactate, free glycerol and 3-hydroxybutyrate across the forearm muscle were observed between diets (data not shown).

Pre-intervention forearm blood flow was significantly higher in subjects on the HSFA diet as compared to the other diets during fasting ( $P=0.005$, one-way ANOVA) and postprandially after meal ingestion ( $P=0.002$, one-way ANOVA) (Table 4.2). No pronounced diet-induced changes were observed after intervention.
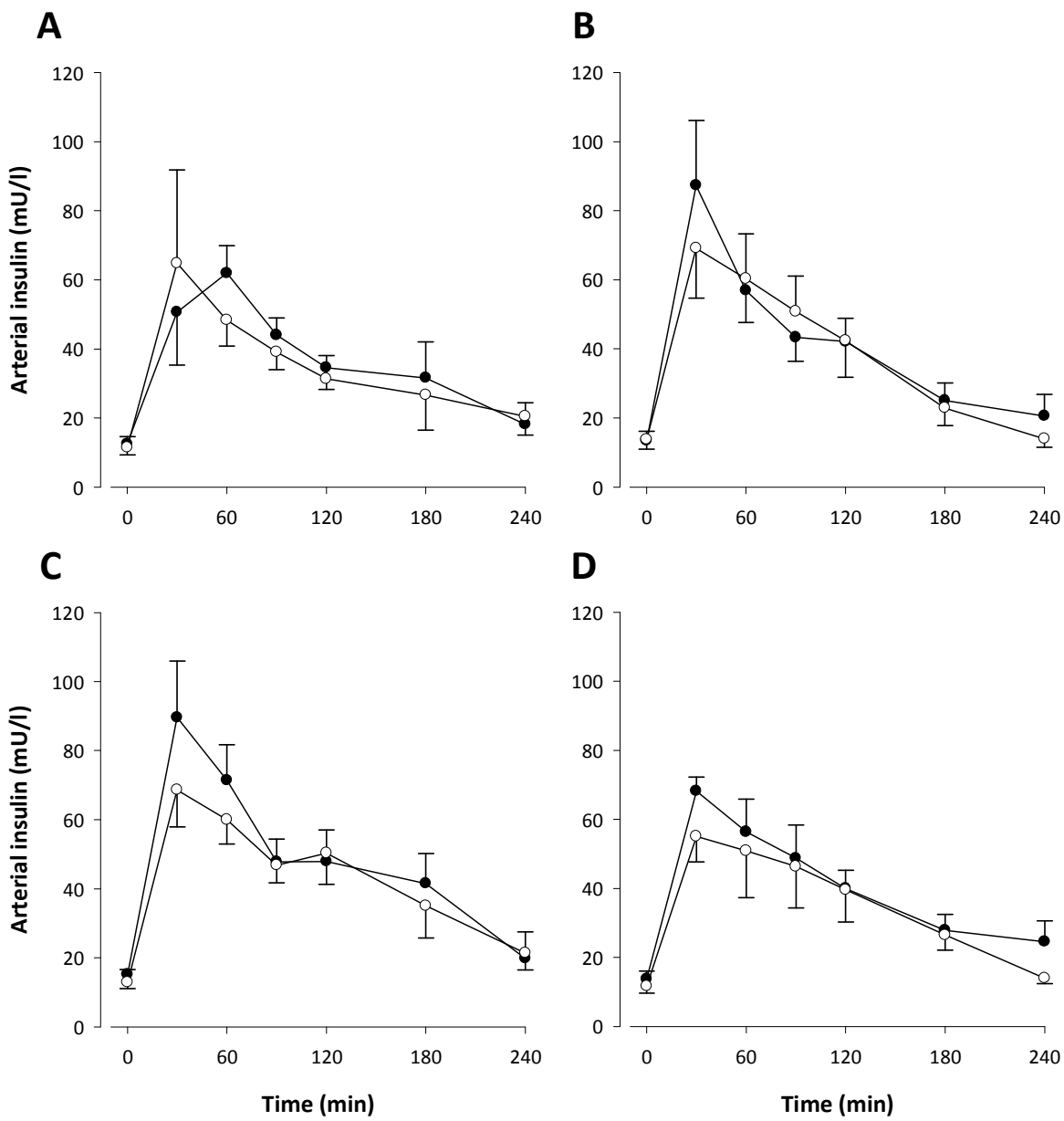

Figure 4.2 Plasma circulating insulin concentrations during fasting (t 0 ) and postprandially after consumption of a high-fat mixed meal ( $\bullet$, pre-intervention; $\circ$, post-intervention). (A) HSFA diet, (B) HMUFA diet, (C) LFHCC diet, (D) LFHCC $n-3$ diet. Values are mean \pm SEM. 


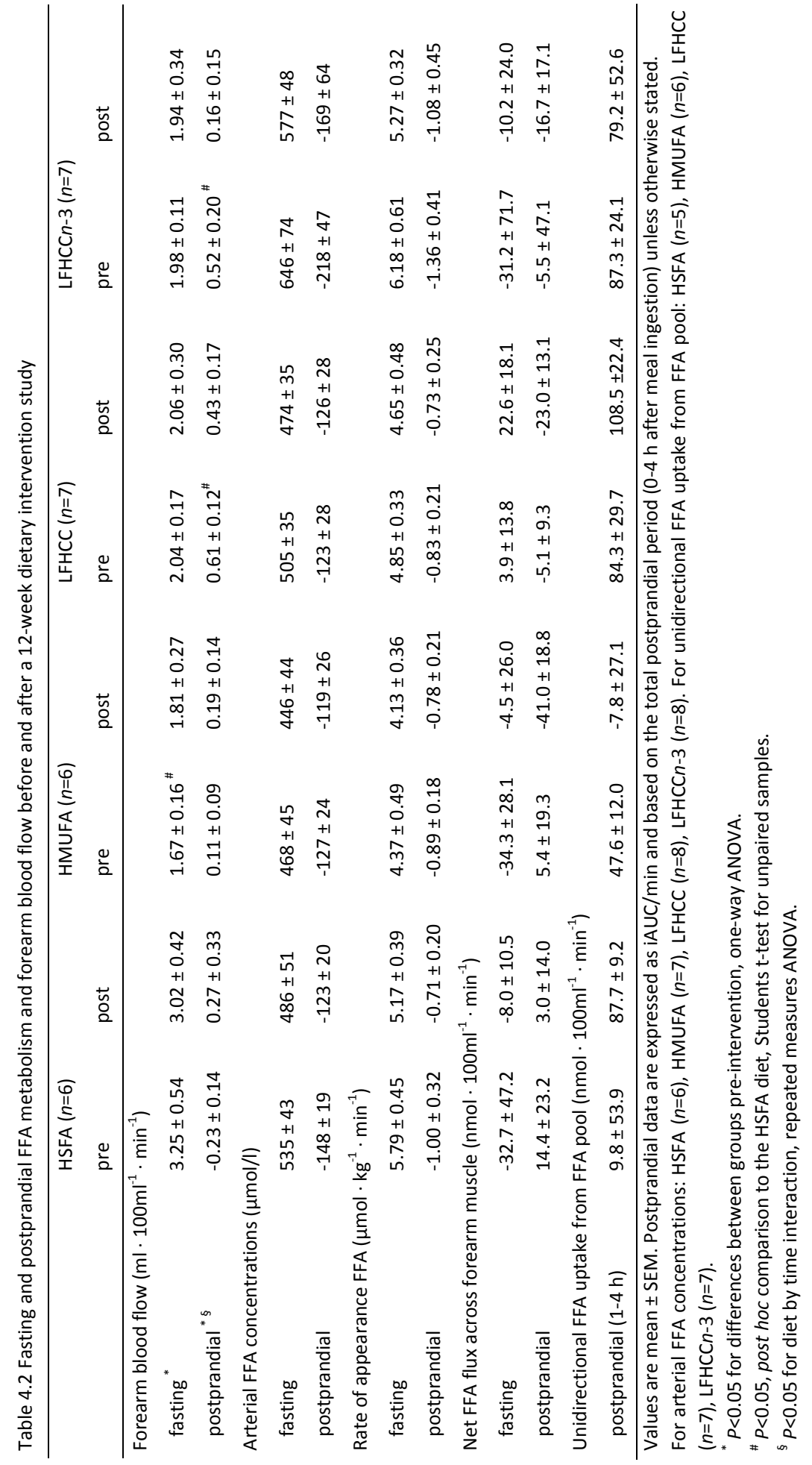




\section{Whole-body and forearm muscle FFA metabolism}

\section{Whole-body FFA metabolism}

Fasting arterial FFA concentrations were similar between groups pre-intervention and did not change differently after dietary intervention (Figure 4.3, Table 4.2). Postprandially, arterial FFA concentrations decreased during the first $2 \mathrm{~h}$ and returned to fasting values after $4 \mathrm{~h}$ at all times (Figure 4.3). In subjects on the HSFA diet, however, we observed a steeper increase in arterial FFA concentrations in the mid-postprandial period ( $\mathrm{iAUC}_{2-4 \mathrm{~h}}$ ) after dietary intervention $(P=0.020$, diet by time interaction), as compared to the HMUFA ( $P=0.046)$ and LFHCC diet $(P=0.030)$. Consistent with these findings, the $\mathrm{Ra}_{\mathrm{FFA}}$ in the circulation decreased after meal

A
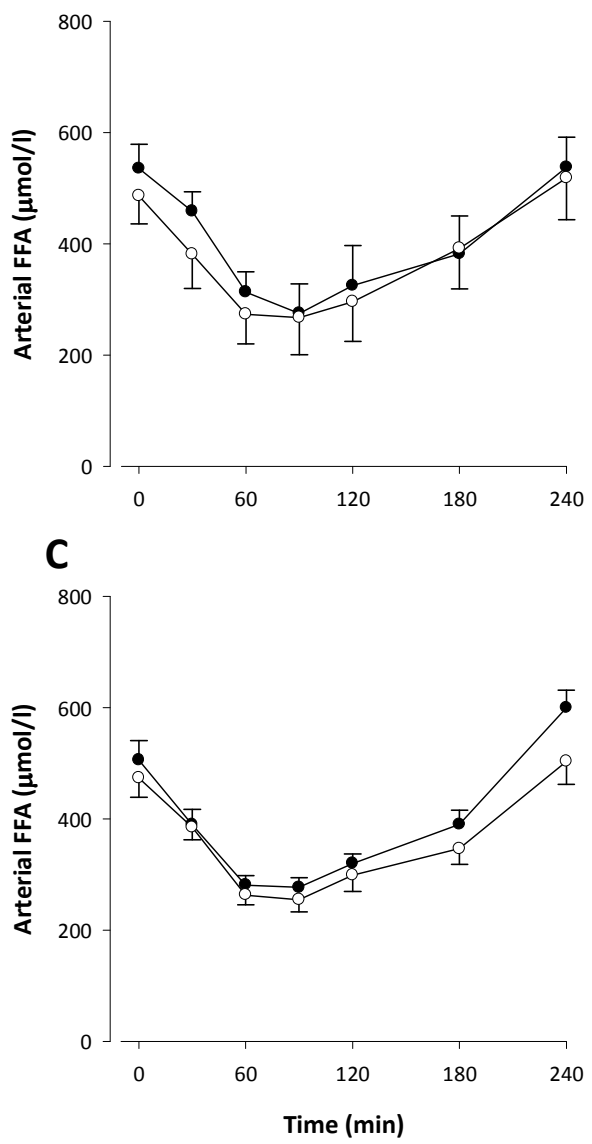

B

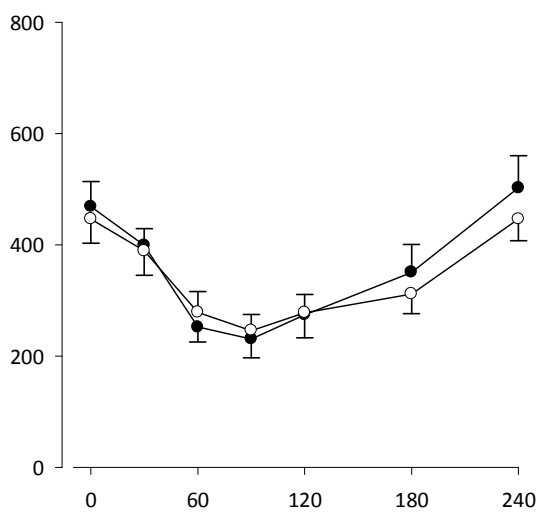

D

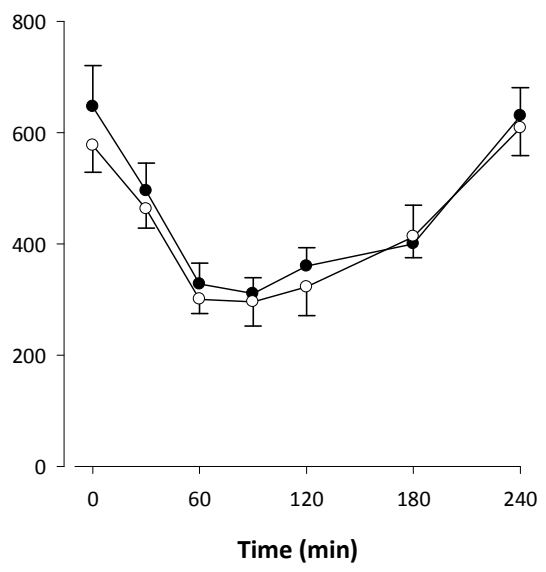

Figure 4.3 Plasma circulating FFA concentrations during fasting (t 0 ) and postprandially after consumption of a high-fat mixed meal ( $\bullet$, pre-intervention; $\circ$, post-intervention). (A) HSFA diet, (B) HMUFA diet, (C) LFHCC diet, (D) LFHCCn-3 diet. Values are mean \pm SEM. 
ingestion at all times, which is indicative of suppression of whole-body lipolysis (Table 4.2). After dietary intervention, a tendency toward a higher increase in the $\mathrm{Ra}_{\mathrm{FFA}}$ in the mid-postprandial period (iAUC $\mathrm{i}_{2-4} \mathrm{~h}, \mathrm{P}=0.063$ for diet by time interaction) was observed on the HSFA diet as compared to the LFHCC diet (change in iAUC, respectively, $0.66 \pm 0.31$ vs. $-0.28 \pm 0.20 \mu \mathrm{mol} \cdot \mathrm{kg}^{-1} \cdot \mathrm{min}^{-1}, P=0.020$ ).

$\left[{ }^{2} \mathrm{H}_{2}\right]$-labeled palmitate was infused intravenously, mixed with the plasma FFA pool and the tracer/tracee ratio reached a steady state during fasting measurements. $\left[{ }^{13} \mathrm{C}\right]$-labeled palmitate (resulting from spillover of FA derived from chylomicron-TAG hydrolysis) was also present in the plasma FFA pool, appearing in the circulation from $60 \mathrm{~min}$ after the meal and rising up to approximately $0.8 \mu \mathrm{mol} / \mathrm{l}$ at the end of the postprandial period. There were no differences in tracer/tracee ratio or arterial concentrations of $\left[{ }^{2} \mathrm{H}_{2}\right]$ - or $\left[{ }^{13} \mathrm{C}\right]$-labeled palmitate in FFA between groups at all times.

\section{Forearm muscle FFA metabolism}

The net flux of plasma FFA across forearm muscle (arteriovenous concentration difference multiplied by FPF) was negative during the first $2 \mathrm{~h}$ of the postprandial period in all intervention groups, indicating a net release of FFA by forearm muscle, without significant differences between the groups pre- and post-intervention (Table 4.2). At the same time, a consistent (unidirectional) uptake of FFA derived from the circulating FFA pool was observed in all groups (fractional extraction of $\left[{ }^{2} \mathrm{H}_{2}\right]$-palmitate multiplied by arterial FFA concentrations), without significant changes after dietary intervention (Table 4.2).

\section{Whole-body and forearm muscle TAG metabolism}

\section{Whole-body TAG metabolism}

Arterial plasma TAG concentrations and labeled TAG concentrations $\left(\left[{ }^{2} \mathrm{H}_{2}\right]-\right.$ and $\left[{ }^{13} \mathrm{C}\right]$-palmitate) are shown in Figures 4.4 and 4.5, respectively. The $\left[{ }^{2} \mathrm{H}_{2}\right]$-palmitate tracer could be measured in the plasma TAG fraction from the first fasting sample onward, reflecting incorporation of the intravenously infused tracer into VLDL-TAG. The $\left[{ }^{13} \mathrm{C}\right]$-palmitate tracer was given with the high-fat mixed test meal and appeared in plasma TAG from 60 min after the meal, representing chylomicron-TAG in the circulation. Plasma concentrations of both $\left[{ }^{2} \mathrm{H}_{2}\right]$ - and $\left[{ }^{13} \mathrm{C}\right]$-labeled TAG increased throughout the $4 \mathrm{~h}$ postprandial period (Figure 4.5).

The postprandial TAG response (iAUC, 0-4 h) was significantly changed after dietary intervention ( $P=0.026$, diet by time interaction) (Table 4.3 ), with a decreased postprandial TAG response on the LFHCCn-3 diet as compared to the HSFA diet (change in iAUC respectively $-139 \pm 67$ vs. $167 \pm 70 \mu \mathrm{mol} \cdot \mathrm{I}^{-1} \cdot \mathrm{min}^{-1}, P=0.009$, post hoc). In addition, the postprandial $\left[{ }^{13} \mathrm{C}\right]$-labeled TAG response was significantly different between groups after dietary intervention in the mid-postprandial period 
(iAUC ${ }_{2-4}$ h) $\left(P=0.043\right.$, diet by time interaction), whereas the postprandial $\left[{ }^{2} \mathrm{H}_{2}\right]$ labeled TAG response was not different after intervention $(P=0.401$, diet by time interaction) (Figure 4.5). These data may indicate that the decreased postprandial TAG response on the LFHCC $n-3$ diet was largely explained by a decrease in plasma concentrations of $\left[{ }^{13} \mathrm{C}\right]$-labeled TAG.

A

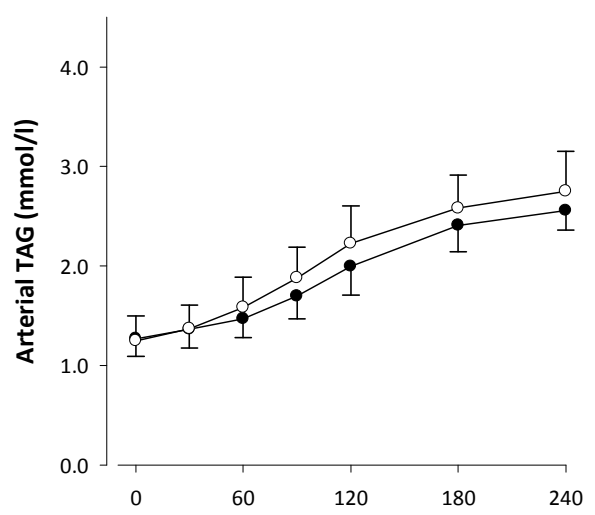

C

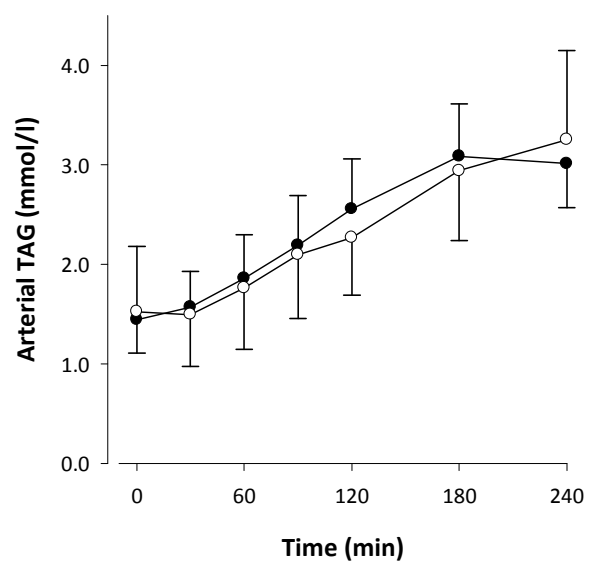

B

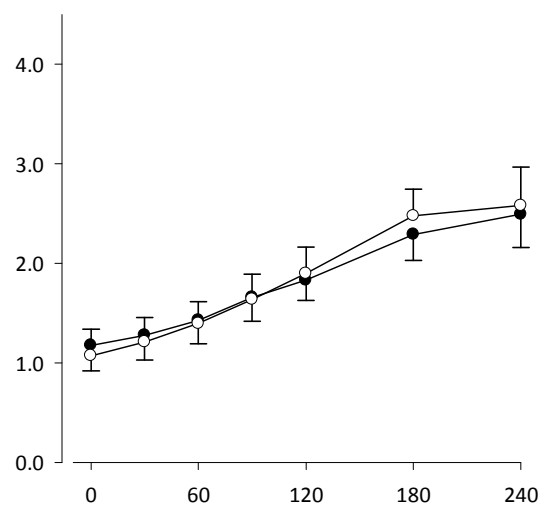

D

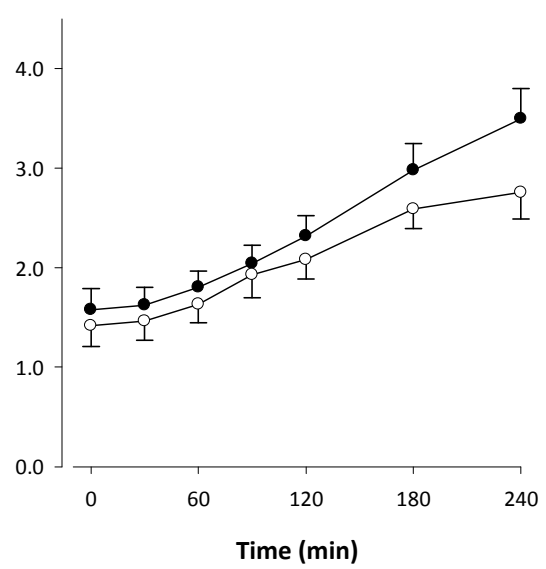

Figure 4.4 Plasma circulating TAG concentrations during fasting $(t)$ and postprandially after consumption of a high-fat mixed meal ( $\bullet$, pre-intervention; $\triangle$, post-intervention). (A) HSFA diet, (B) HMUFA diet, (C) LFHCC diet, (D) LFHCCn-3 diet. Values are mean \pm SEM.

\section{Forearm muscle TAG metabolism}

Fractional extraction of $\left[{ }^{13} \mathrm{C}\right]$-labeled TAG across forearm muscle could be measured from 60 min until the end of the postprandial period and was higher than the fractional extraction of $\left[{ }^{2} \mathrm{H}_{2}\right]$-labeled TAG. Moreover, there was a consistent (unidirectional) uptake of FA derived from TAG hydrolysis across forearm muscle 


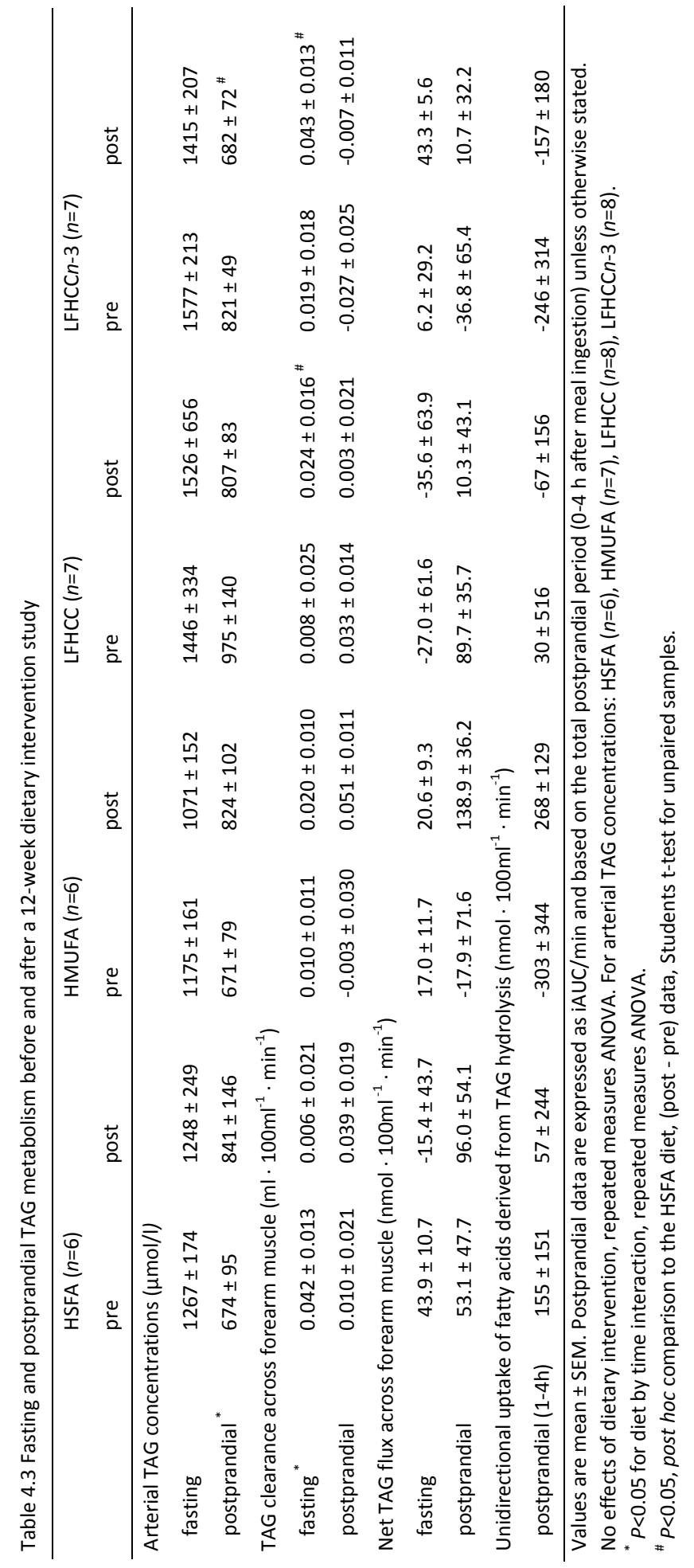


(calculated based on the fractional extraction of $\left[\mathrm{U}-{ }^{13} \mathrm{C}\right]$-palmitate derived from $\left[{ }^{13} \mathrm{C}\right]$-labeled TAG hydrolysis and the arteriovenous concentration difference of total TAG) (Table 4.3). The net flux of plasma TAG across forearm muscle (arteriovenous concentration difference multiplied by FPF) was not different between groups preand post-intervention.

During fasting, the clearance of plasma TAG across forearm muscle (fractional extraction of TAG multiplied by FPF) was significantly changed after dietary intervention ( $P=0.023$, diet by time interaction), with a decreased clearance of TAG on the HSFA diet as compared to the LFHCC ( $P=0.022)$ and LFHCCn-3 diet $(P=0.017)$. In the postprandial state, no differences were observed between diets in forearm muscle TAG clearance (Table 4.3).

Altogether, albeit postprandial arterial unlabeled and $\left[{ }^{13} \mathrm{C}\right]$-labeled TAG concentrations were lower in subjects on the LFHCCn-3 diet as compared to the HSFA diet, no significant changes in postprandial net uptake, extraction or clearance of both unlabeled and labeled TAG across forearm muscle were observed.

\section{Energy expenditure and whole-body substrate metabolism}

Whole-body energy expenditure, respiratory quotient, carbohydrate oxidation and fat oxidation during fasting and after meal ingestion were comparable between groups pre- and post-intervention (data not shown).

\section{Discussion}

This study shows that isoenergetic modulation of dietary fat quality and quantity did not affect postprandial skeletal muscle FA handling and insulin sensitivity in men with the MetS, whereas in the fasting state clearance of plasma TAG across forearm muscle was decreased on the HSFA diet as compared to the LFHCC and LFHCCn-3 diet. Postprandial arterial TAG concentrations, derived from dietary fat, were lower after the LFHCCn-3 diet as compared to the HSFA diet.

\section{Skeletal muscle fatty acid handling}

Lifestyle intervention can improve metabolic flexibility of skeletal muscle, which refers to the ability of the muscle to increase fat oxidation upon increased FA availability and to switch between fat and carbohydrate oxidation under different conditions, such as the fasting-to-fed state $(20,21)$. These interventions were mainly aimed at weight loss and/or chronic exercise training, and little information is available on the effects of dietary fat composition on in vivo skeletal muscle FA handling and metabolic flexibility (21). A specific objective of the LIPGENE study was 
A

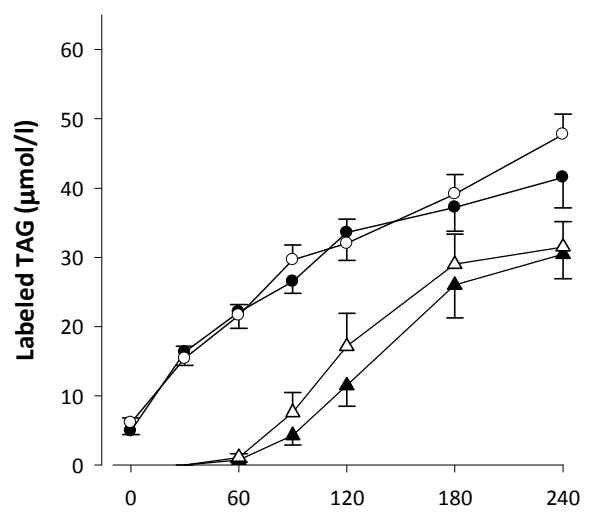

C

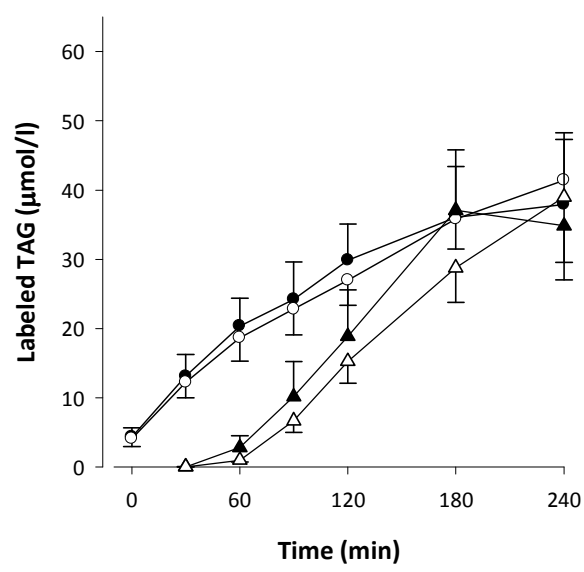

B

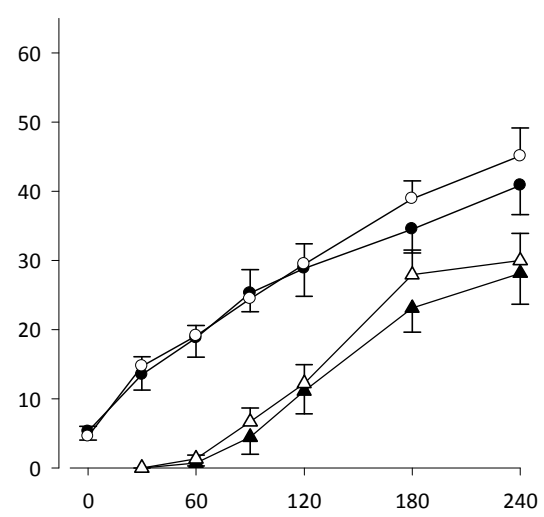

D

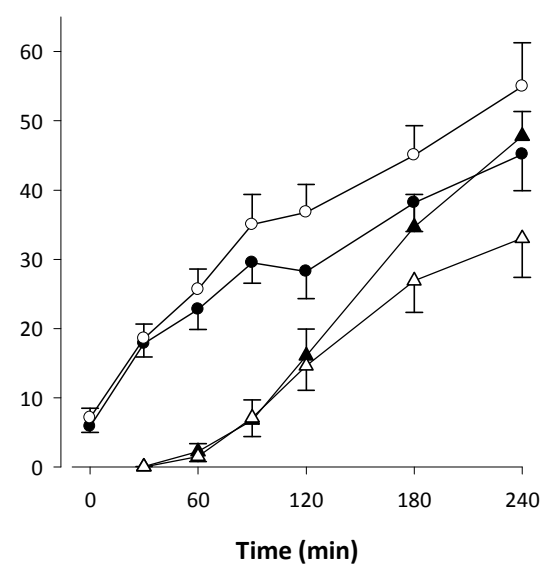

Figure 4.5 Plasma circulating $\left[{ }^{2} \mathrm{H}_{2}\right]$ - and $\left[{ }^{13} \mathrm{C}\right]$-labeled triacylglycerol (TAG) concentrations during fasting (t 0 ) and postprandially after consumption of a high-fat mixed meal (black symbols; pre-intervention, white symbols; post-intervention). $\left[{ }^{2} \mathrm{H}_{2}\right]$-labeled TAG (circles) represents endogenous fat, $\left[{ }^{13} \mathrm{C}\right]$-labeled TAG (triangles) represents dietary fat. (A) HSFA diet, (B) HMUFA diet, (C) LFHCC diet, (D) LFHCCn-3 diet. Values are mean \pm SEM.

to define the effect of isoenergetic modification of dietary fat quality and quantity. To our knowledge this is the first time that skeletal muscle FA handling was studied in vivo before and after a longer-term dietary fat intervention in weight-stable men with the MetS.

Studies in rodents show that the quality of FA (SFA, MUFA, $n-3$ and $n-6$ PUFA) can influence insulin action due to effects on FA incorporation into different lipid fractions, altered substrate oxidation and/or modulation of phospholipids in the muscle membrane (11,22-24). Also, short-term high-fat diets have been linked to increased intramyocellular lipid content and skeletal muscle IR in both rodent and human studies $(22,25-27)$, which could be ascribed to increased FA uptake upon 
increased FA availability (25). In this study, a 12-week intervention on dietary fat quality and quantity did not affect the postprandial uptake of endogenous and dietary FA by forearm muscle and did not have an effect on fat oxidation.

During fasting conditions, clearance of plasma TAG across forearm muscle was decreased on the HSFA diet as compared to both LFHCC diets, indicating decreased efficiency of TAG removal on the HSFA diet. At the same time, fasting fat oxidation was not changed on the diets, indicating no effects on FA partitioning between oxidation and storage. This seems to be in contrast with a recent study in healthy subjects showing that a 3-day high-carbohydrate diet, when compared to a high-fat diet, leads to repartitioning of dietary FA from oxidation toward storage in both muscle and liver, together with lower fasting and postprandial clearance of TAG across muscle (12). This could be related to the duration of the diet (short term vs. 12 week). It can be speculated that forearm muscle FA uptake may have been increased during the first week(s) of dietary intervention, such as described in shortterm studies, and that an increased intramyocellular lipid content led to a decreased FFA concentration gradient across the muscle membrane, thereby decreasing FA uptake in the longer term (21). Another possibility is the fact that we carefully designed the diets to be isoenergetic. A chronic positive energy balance, mainly due to excessive fat intake, would most probably have a larger impact on nutritional partitioning, and in particular lipid storage (21).

Taken together, our data suggest that isoenergetic variation in dietary fat quantity and quality did not affect forearm muscle FA metabolism and insulin sensitivity, indicating that man may be well capable of adapting to longer-term changes in the diet. Also, in the total LIPGENE human dietary intervention study, powered to study the effects of dietary fat quantity and quality on insulin sensitivity in 480 men and women, no effects on insulin sensitivity were observed (28).

\section{Circulating lipids}

On the HSFA diet a slightly more rapid increase in arterial FFA concentrations and $\mathrm{Ra}_{\mathrm{FFA}}$ were observed in the mid-postprandial period, which may be indicative of a reduced postprandial suppression of adipose tissue lipolysis and subsequent lipid overflow into the circulation on the HSFA diet. However, this was not accompanied by any change in FA uptake across forearm muscle.

This study showed that an LFHCCn-3 diet decreased postprandial circulating TAG concentrations as compared to an isoenergetic HSFA diet. This lipid-lowering effect of LC $n-3$ PUFA is well documented, but underlying mechanisms are still unclear. It has been shown in humans that omega-3 supplementation accelerates the clearance of chylomicron-TAG, thereby lowering postprandial TAG concentrations (29), whereas on the other hand studies report that fish-oil may enhance postprandial hepatic fat oxidation and/or decrease VLDL-TAG output by the liver 
(30). The unique dual stable isotope technique in combination with measurements of arteriovenous concentrations differences across forearm muscle that was applied in this study enabled us to study the direction of the different fluxes in circulating lipid fractions in the postprandial period in more detail. We were able to show that the attenuated postprandial TAG response on the LFHCCn-3 diet could be (partly) explained by lower meal-derived FA in the circulation, mainly in the midpostprandial period (2-4 h), whereas no difference or even an increase in endogenous-derived circulating VLDL-TAG was observed. This suggests that LC $n-3$ PUFA, when supplemented to a low-fat diet, mainly exert their TAG-lowering effect through enhanced clearance of chylomicron-TAG from the circulation and/or through an attenuated or decelerated chylomicron-TAG output by the intestine, but not through decreased hepatic VLDL-TAG output. These data are in line with previous reported findings that dietary supplementation with LC $n-3$ PUFA increases LPL activity in healthy subjects and hypertriacylglycerolemic patients $(29,31,32)$, and that chylomicrons are the preferred substrate for LPL-mediated hydrolysis, both across adipose tissue and skeletal muscle (13). Because we observed no differences in postprandial TAG uptake across forearm muscle, increased LPL activity in the capillary bed of adipose tissue seems to be a plausible explanation for the lower arterial TAG concentrations after the LFHCCn-3 diet.

Several methodological issues remain to be addressed. First, the sample size in this study was relatively small for detecting changes in skeletal muscle FA handling as a result of a chronic dietary intervention. Therefore, we cannot exclude that small differences in forearm muscle metabolism were present after dietary intervention, which could not be detected in our groups. Second, a small negative flux of FFA across the forearm muscle was observed during fasting in most dietary intervention groups, which was not significantly different from zero. FFA fluxes across the forearm muscle often fluctuate around zero, as there is both release and uptake of FFA across the muscle at the same time $(4,33,34)$. Although we cannot exclude a small contribution from subcutaneous and perivascular adipose tissue, these FA most likely mainly derive from lipolysis of intramyocellular lipids or adipocytes between muscle bundles (extramyocellular), or from impaired uptake of TAGderived FA (i.e. spillover) across skeletal muscle.

Overall, we showed that the range of dietary fat intake (both quantity and quality) under conditions of isoenergetic exchange in this study was insufficient to affect forearm muscle FA handling and whole-body insulin sensitivity in the longer term, although fasting TAG clearance seems to be reduced on the HSFA diet. Decreased postprandial plasma TAG concentrations on an LFHCCn-3 diet, possibly explained by an increased capacity of adipose tissue to take up (dietary) FA by increased LPL activity, may in the longer term have beneficial effects on skeletal muscle insulin sensitivity by reducing lipid overflow to the skeletal muscle. 


\section{Acknowledgements}

We thank all volunteers for their time and motivation and all researchers within the LIPGENE Human Dietary Intervention Study for their work and dedication to the project. We also thank J. Stegen, W. Sluijsmans, H. Aydeniz, R. Jacobs and A. Gijsen for their excellent analytical support and M. Ockeloen-Van der Hulst, T. HermansLimpens, D. Mintjens, P. Goyens, N. Jansink and A. van de Loo for their excellent practical support and dietary advice. 


\section{References}

1. Eckel RH, Grundy SM, Zimmet PZ. The metabolic syndrome. Lancet 2005;365(9468):1415-28.

2. Blaak EE. Basic disturbances in skeletal muscle fatty acid metabolism in obesity and type 2 diabetes mellitus. Proc Nutr Soc 2004;63(2):323-30.

3. Frayn KN. Adipose tissue as a buffer for daily lipid flux. Diabetologia 2002;45(9):1201-10.

4. Blaak EE, Wagenmakers AJ, Glatz JF, Wolffenbuttel BH, Kemerink GJ, Langenberg CJ, et al. Plasma FFA utilization and fatty acid-binding protein content are diminished in type 2 diabetic muscle. Am J Physiol Endocrinol Metab 2000;279(1):E146-54.

5. Mensink M, Blaak EE, van Baak MA, Wagenmakers AJ, Saris WH. Plasma free Fatty Acid uptake and oxidation are already diminished in subjects at high risk for developing type 2 diabetes. Diabetes 2001;50(11):2548-54.

6. Corcoran MP, Lamon-Fava S, Fielding RA. Skeletal muscle lipid deposition and insulin resistance: effect of dietary fatty acids and exercise. Am J Clin Nutr 2007;85(3):662-77.

7. Schmitz-Peiffer $C$. Signalling aspects of insulin resistance in skeletal muscle: mechanisms induced by lipid oversupply. Cell Signal 2000;12(9-10):583-94.

8. Schrauwen $\mathrm{P}$, Hesselink MK. Oxidative capacity, lipotoxicity, and mitochondrial damage in type 2 diabetes. Diabetes 2004;53(6):1412-7.

9. Madsen L, Petersen RK, Kristiansen K. Regulation of adipocyte differentiation and function by polyunsaturated fatty acids. Biochim Biophys Acta 2005;1740(2):266-86.

10. Gaster M, Rustan AC, Beck-Nielsen H. Differential utilization of saturated palmitate and unsaturated oleate: evidence from cultured myotubes. Diabetes 2005;54(3):648-56.

11. Lee JS, Pinnamaneni SK, Eo SJ, Cho IH, Pyo JH, Kim CK, et al. Saturated, but not n-6 polyunsaturated, fatty acids induce insulin resistance: role of intramuscular accumulation of lipid metabolites. J Appl Physiol 2006;100(5):1467-74.

12. Roberts R, Bickerton AS, Fielding BA, Blaak EE, Wagenmakers AJ, Chong MF, et al. Reduced oxidation of dietary fat after a short term high-carbohydrate diet. Am J Clin Nutr 2008;87(4):82431.

13. Bickerton AS, Roberts R, Fielding BA, Hodson L, Blaak EE, Wagenmakers AJ, et al. Preferential uptake of dietary fatty acids in adipose tissue and muscle in the postprandial period. Diabetes 2007;56(1):168-76.

14. Shaw DI, Tierney AC, McCarthy S, Upritchard J, Vermunt S, Gulseth HL, et al. LIPGENE foodexchange model for alteration of dietary fat quantity and quality in free-living participants from eight European countries. Br J Nutr 2008;101(5):750-9.

15. Third Report of the National Cholesterol Education Program (NCEP) Expert Panel on Detection, Evaluation, and Treatment of High Blood Cholesterol in Adults (Adult Treatment Panel III) final report. Circulation, 2002:3143-421.

16. Finegood DT, Hramiak IM, Dupre J. A modified protocol for estimation of insulin sensitivity with the minimal model of glucose kinetics in patients with insulin-dependent diabetes. J Clin Endocrinol Metab 1990;70(6):1538-49.

17. Boston RC, Stefanovski D, Moate PJ, Sumner AE, Watanabe RM, Bergman RN. MINMOD Millennium: a computer program to calculate glucose effectiveness and insulin sensitivity from the frequently sampled intravenous glucose tolerance test. Diabetes Technol Ther 2003;5(6):1003-15.

18. Matthews DR, Hosker JP, Rudenski AS, Naylor BA, Treacher DF, Turner RC. Homeostasis model assessment: insulin resistance and beta-cell function from fasting plasma glucose and insulin concentrations in man. Diabetologia 1985;28(7):412-9.

19. Wolfe RR. Radioactive and stable isotope tracers in biomedicine: principles and practice of kinetic analysis. New York, USA: Wiley-Liss, 1992.

20. Corpeleijn E, Mensink M, Kooi ME, Roekaerts PM, Saris WH, Blaak EE. Impaired skeletal muscle substrate oxidation in glucose-intolerant men improves after weight loss. Obesity (Silver Spring) 2008;16(5):1025-32. 
21. Corpeleijn E, Saris WH, Blaak EE. Metabolic flexibility in the development of insulin resistance and type 2 diabetes: effects of lifestyle. Obes Rev 2009;10(2):178-93.

22. Buettner R, Scholmerich J, Bollheimer LC. High-fat diets: modeling the metabolic disorders of human obesity in rodents. Obesity (Silver Spring) 2007;15(4):798-808.

23. Storlien LH, Jenkins AB, Chisholm DJ, Pascoe WS, Khouri S, Kraegen EW. Influence of dietary fat composition on development of insulin resistance in rats. Relationship to muscle triglyceride and omega-3 fatty acids in muscle phospholipid. Diabetes 1991;40(2):280-9.

24. Storlien LH, Kraegen EW, Chisholm DJ, Ford GL, Bruce DG, Pascoe WS. Fish oil prevents insulin resistance induced by high-fat feeding in rats. Science 1987;237(4817):885-8.

25. Hegarty BD, Cooney GJ, Kraegen EW, Furler SM. Increased efficiency of fatty acid uptake contributes to lipid accumulation in skeletal muscle of high fat-fed insulin-resistant rats. Diabetes 2002;51(5):1477-84.

26. Schrauwen-Hinderling VB, Kooi ME, Hesselink MK, Moonen-Kornips E, Schaart G, Mustard KJ, et al. Intramyocellular lipid content and molecular adaptations in response to a 1-week high-fat diet. Obes Res 2005;13(12):2088-94.

27. Krssak M, Falk Petersen K, Dresner A, DiPietro L, Vogel SM, Rothman DL, et al. Intramyocellular lipid concentrations are correlated with insulin sensitivity in humans: a $1 \mathrm{H}$ NMR spectroscopy study. Diabetologia 1999;42(1):113-6.

28. Tierney AC, Gulseth HL, Defoort C, Lovegrove JA, Blaak E, Lopez-Miranda J, et al. The effects of dietary fat modification on metabolic markers of the metabolic syndrome - insights from the LIPGENE Dietary Intervention Study. Diabetologia 2008;51:S108.

29. Park $Y$, Harris WS. Omega-3 fatty acid supplementation accelerates chylomicron triglyceride clearance. J Lipid Res 2003;44(3):455-63.

30. Harris WS, Bulchandani D. Why do omega-3 fatty acids lower serum triglycerides? Curr Opin Lipidol 2006;17(4):387-93.

31. Rivellese AA, Maffettone A, Vessby B, Uusitupa M, Hermansen K, Berglund L, et al. Effects of dietary saturated, monounsaturated and n-3 fatty acids on fasting lipoproteins, LDL size and post-prandial lipid metabolism in healthy subjects. Atherosclerosis 2003;167(1):149-58.

32. Harris WS, Lu G, Rambjor GS, Walen Al, Ontko JA, Cheng Q, et al. Influence of n-3 fatty acid supplementation on the endogenous activities of plasma lipases. Am J Clin Nutr 1997;66(2):254-60.

33. Colberg SR, Simoneau JA, Thaete FL, Kelley DE. Skeletal muscle utilization of free fatty acids in women with visceral obesity. J Clin Invest 1995;95(4):1846-53.

34. Kelley DE, Simoneau JA. Impaired free fatty acid utilization by skeletal muscle in non-insulindependent diabetes mellitus. J Clin Invest 1994;94(6):2349-56. 



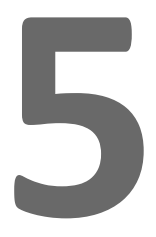

Adipose triglyceride lipase and hormonesensitive lipase protein expression in subcutaneous adipose tissue are decreased after an isoenergetic low-fat high-complex carbohydrate diet in the metabolic syndrome

Anneke M.J. van Hees, Johan W.E. Jocken, Yvonne Essers, Helen M. Roche, Wim H.M. Saris and Ellen E. Blaak

Submitted 


\section{Abstract}

Disturbances in the regulation of endogenous lipolysis are related to obesity, insulin resistance and the metabolic syndrome (MetS) and may be modulated by dietary fat quality and quantity.

Men and women with the MetS were randomly assigned to one of four isoenergetic diets: a high-fat saturated fat diet $(n=10)$, a high-fat monounsaturated fat diet $(n=7)$ and two low-fat high-complex carbohydrate (LFHCC) diets, one supplemented with 1.24 g/day long-chain $n$-3 PUFA (LFHCC: $n=7$, LFHCC $n-3: n=8$ ). Subcutaneous adipose tissue biopsies were taken before and after the 12-week dietary intervention period. ATGL and HSL mRNA and protein expression were determined. Whole body rate of appearance of free fatty acids $\left(\mathrm{Ra}_{\mathrm{FFA}}\right)$ was determined by intravenous infusion of $\left[{ }^{2} \mathrm{H}_{2}\right]$-palmitate in a subgroup of men $(n=20)$.

Adipose tissue ATGL and HSL mRNA and protein expression were not affected by alterations in dietary fat composition. Pooled analysis comparing the low- and highfat diets showed that ATGL and HSL protein expression were significantly reduced after the LFHCC diets $(P=0.04)$, irrespective of long-chain $n$-3 PUFA. Moreover, the metabolic profile was improved by the LFHCC diets, with lower fasting insulin, $\mathrm{HOMA}_{\mathrm{IR}}$ and (LDL)-cholesterol concentrations $(P \leq 0.05)$. Changes in ATGL and HSL protein expression were positively associated with changes in whole body $\mathrm{Ra}_{\mathrm{FFA}}$ $(P<0.03)$.

The low-fat high-complex carbohydrate diets reduced ATGL and HSL protein expression and significantly improved the metabolic profile of MetS subjects. Under isoenergetic conditions, dietary fat quantity, rather than composition, may be most important for modulating subcutaneous adipose tissue ATGL and HSL protein expression. 


\section{Introduction}

The metabolic syndrome (MetS) represents a clustering of risk factors for the development of type 2 diabetes and cardiovascular disease, of which insulin resistance and central obesity have each been considered to be the primary underlying factor $(1,2)$. The MetS is often characterised by elevated levels of free fatty acid (FFA) and triacylglycerol (TAG) in the circulation, possibly originating from an expanded adipose tissue mass and/or impaired buffering capacity of the adipose tissue (3). An increased supply of lipids (i.e. lipid overflow) to non-adipose tissues such as skeletal muscle and liver is associated with many aspects of the MetS such as insulin resistance, atherosclerosis and hepatic steatosis (4), suggesting that adipose tissue function is an important factor in the pathogenesis of the MetS.

The balance of fat storage and release in adipose tissue is a highly regulated process, under control of several factors like hormones, adipokines and cytokines (5). Impaired insulin-mediated suppression of lipolysis may increase circulating FFA concentrations in the obese insulin resistant state (6), although in vivo studies have shown that the release of fatty acids per unit fat mass is reduced with increasing fasting plasma insulin concentrations in the insulin resistant state (7-9), leading to the hypothesis that hyperinsulinaemia may prevent excessive fatty acid efflux from the expanded adipose tissue and worsening of the insulin resistant state. One of the molecular mechanisms responsible for this effect may be a reduced expression of the lipolytic enzymes hormone-sensitive lipase (HSL) and adipose triglyceride lipase (ATGL) in the insulin resistant vs. insulin sensitive state, as has been shown by Jocken et al (10).

HSL and ATGL are responsible for over $95 \%$ of total TAG hydrolysis in mice (11), but also lipid droplet-covering proteins like perilipin may play a critical role in the regulation of these lipolytic enzymes $(4,5,12)$. Human data on the absolute expression of ATGL and HSL and their relationship with insulin resistance and obesity are inconsistent. ATGL mRNA and protein content in subcutaneous adipose tissue have shown to be reduced in obese subjects with insulin resistance (10), whereas others reported increased ATGL mRNA but decreased ATGL protein levels in adipose tissue of obese subjects (13). Diet could be an important factor in the prevention of the MetS, i.e. by modulating endogenous lipolysis and reducing lipid overflow, but so far little is known about the possible regulation of lipolysis by diet. Recently it has been shown that a high-fat diet increased basal TAG lipase activity and ATGL protein content, but decreased HSL phosphorylation in C57BL/6J mice (14). Moreover, some human studies showed a reduction in ATGL and HSL mRNA and protein expression after weight loss, independent of the fat content of the diet $(10,15)$, whereas others observed no change in ATGL mRNA and an increase in HSL mRNA after weight loss by bariatric surgery (16). Besides the effects of weight loss, also dietary fatty acids per se can modulate gene expression and thus adipose tissue 
function. Polyunsaturated fatty acids (PUFA) may modulate lipolytic gene expression via agonising effects on the transcription factor peroxisome proliferatoractivated receptor- $\gamma$ (PPAR $\gamma$ ), as it has been shown that thiazolidinedione insulinsensitising drugs are associated with increased adipose tissue ATGL and HSL MRNA expression in rodents $(17,18)$ and increased ATGL mRNA and protein expression in 3T3-L1 adipocytes (19). A diet rich in monounsaturated fatty acids (MUFA) has been shown to increase TAG hydrolase activity in type 2 diabetic patients when compared to an isoenergetic high saturated fat diet (20). To our knowledge, however, no information is known about the isoenergetic effects of dietary macronutrient composition on gene or protein expression of lipolytic enzymes in (human) adipose tissue.

The aim of the present study was to investigate the effects of a 12-week dietary intervention with four isoenergetic diets varying in both fat quantity and quality on whole body lipolysis and corresponding changes in subcutaneous adipose tissue gene and protein expression of ATGL and HSL in men and women with the MetS.

\section{Methods}

This study was performed in the Maastricht subcohort of the LIPGENE human dietary intervention study (21). In total, 32 subjects (23 male, 9 female) with the MetS were included in this substudy based on the criteria described in the NCEP ATP III report 2002 (22). Details on in- and exclusion criteria for participation in this study are described elsewhere $(21,23)$. All subjects were informed about the nature of the study and written informed consent was attained prior to study participation. The study protocol was approved by the local Medical Ethical Committee of Maastricht University.

\section{Experimental design}

All subjects underwent a one-day clinical investigation protocol before and at the end of a 12-week dietary intervention period. Subjects arrived at the university after an overnight fast and were asked to refrain from drinking alcohol and to perform no strenuous exercise $24 \mathrm{~h}$ prior to the study day. During fasting, a subcutaneous adipose tissue biopsy was taken from the abdominal region, anthropometric measurements were performed and a fasting venous blood sample was drawn. On a separate occasion (also pre- and post-intervention), measurements of whole body rate of appearance of free fatty acids were performed during fasting in a subgroup of 20 men. 


\section{Dietary intervention}

Subjects were randomly assigned to receive one of four isoenergetic intervention diets for 12 weeks:

1) High-fat (38 energy (E\%)) saturated fatty acid (SFA)-rich diet (16 E\% SFA, 12 E\% MUFA, 6 E\% PUFA) (HSFA);

2) High-fat (38 E\%) MUFA-rich diet (8 E\% SFA, 20 E\% MUFA, 6 E\% PUFA) (HMUFA);

3) Isoenergetic low-fat (28E\%), high-complex carbohydrate diet (8 E\% SFA, $11 \mathrm{E} \%$ MUFA, 6 E\% PUFA), with a control high-oleic acid sunflower-seed oil capsule (1 g per day) (LFHCC);

4) Isoenergetic low-fat (28 E\%), high-complex carbohydrate diet (8 E\% SFA, 11 E\% MUFA, 6 E\% PUFA), with a long-chain $n$-3 PUFA supplement (1.24 g per day of eicosapentaenoic and docosahexaenoic, ratio 1.4:1) (LFHCCn-3).

Detailed descriptions of the food exchange model and assessment of compliance were published elsewhere (24). Subjects had to remain weight stable during the intervention period (changes were allowed within the range of $2 \mathrm{~kg}$ ) and were asked to maintain their normal pattern of physical activity, alcohol consumption and smoking.

\section{Adipose tissue biopsy}

Subcutaneous adipose tissue biopsies were taken after an overnight fast before and at the end of the 12-week dietary intervention period. Biopsies were performed under local anaesthesia of the skin and underlying tissue on the left or the right side of the abdomen (approximately $5 \mathrm{~cm}$ lateral from the umbilicus) using a Hepafix ${ }^{\circledR}$ luer Lock syringe and a $14 \mathrm{G} \times 31 / 8^{\prime \prime}(2.10 \times 80 \mathrm{~mm})$ Sterican ${ }^{\circledR}$ needle (B. Braun Melsungen $A G)$. The biopsies were washed in physiological saline and stored at -80 ${ }^{\circ} \mathrm{C}$ until analysis. All adipose tissue samples were used for ATGL and HSL protein expression analyses $(n=32)$, whereas ATGL and HSL mRNA expression levels were assessed in a subset of remaining adipose tissue samples $(n=21)$.

\section{Whole body rate of appearance of free fatty acids}

Subjects came to the university after an overnight fast and were asked to refrain from drinking alcohol and to perform no strenuous exercise $24 \mathrm{~h}$ prior to the study day. Two catheters were inserted before the start of the experiment. One catheter was placed in the radial artery of the forearm to sample arterial blood and another catheter was placed in an antecubital vein for the infusion of $\left[{ }^{2} \mathrm{H}_{2}\right]$-palmitate. After taking an arterial background sample, a continuous intravenous infusion of the stable isotope tracer $\left[{ }^{2} \mathrm{H}_{2}\right]$-palmitate $(97 \%$ enrichment, Cambridge Isotope Laboratories, USA) complexed to albumin was started $\left(0.035 \mu \mathrm{mol} \cdot \mathrm{kg}\right.$ body weight ${ }^{-}$

${ }^{1} \cdot \mathrm{min}^{-1}$ ) using a calibrated infusion pump (IVAC560 pump, San Diego, CA). Blood 
sampling was started after $1 \mathrm{~h}$ of tracer infusion to allow for isotopic equilibration to occur. Three blood samples were taken from the radial artery at a 15 min interval for the analysis of fasting arterial plasma FFA and $\mathrm{Ra}_{\mathrm{FFA}}$.

\section{Biochemical analyses}

Blood was collected in tubes containing EDTA for the analyses of plasma glucose, FFA, insulin and total-, HDL- and LDL-cholesterol. All samples were centrifuged immediately (1000 g, $\left.10 \mathrm{~min}, 4^{\circ} \mathrm{C}\right)$, except for serum which was allowed to clot at room temperature (30 $\mathrm{min}$ ). After centrifugation, plasma and serum aliquots were immediately frozen in liquid nitrogen and stored at $-80{ }^{\circ} \mathrm{C}$ until analysis. Plasma FFA (NEFA C-kit Wako, Sopar Biochemicals, Belgium) was analysed using a standard enzymatic technique automated on a Cobas Fara centrifugal spectrophotometer (Roche Diagnostica, Basel, Switzerland) and plasma glucose was analysed enzymatically on a Cobas Mira automated spectrophotometer (Roche Diagnostica). Plasma insulin was measured using a double antibody radioimmunoassay (Linco Research Inc., St. Charles, USA). Plasma total cholesterol, HDL-cholesterol and LDLcholesterol were determined with an ILab 600 clinical chemical analyser (Instrumentation Laboratory, Warrington, UK), using enzymatic colourimetric kits.

To determine tracer enrichment in plasma FFA and $\mathrm{Ra}_{\mathrm{FFA}}$, total lipids were extracted from the plasma using chloroform-methanol 2:1. The FFA fraction was separated by thin-layer chromatography and derivatised to its methyl esters for the analysis of plasma palmitate and for the analysis of enrichment with $\left[{ }^{2} \mathrm{H}_{2}\right]$ on a Finnigan Incos$\mathrm{XL}$ GC-MS. The methyl ester of palmitate contains 17 carbon atoms and therefore, the tracer/tracee ratio (TTR) of palmitate was corrected for the extra methyl group. Plasma palmitate concentrations $(\mu \mathrm{mol} / \mathrm{l})$ were analysed on an analytical $\mathrm{GC}$ with ion flame detection using heptadecanoic acid as internal standard.

\section{ATGL and HSL mRNA analyses}

Total RNA was extracted from adipose tissue biopsies using the TRIzol reagent (Invitrogen). Reverse transcription of $300 \mathrm{ng}$ of total RNA was performed using iScript cDNA synthesis kit (Bio-Rad) and ATGL and HSL mRNA was determined by qRT-PCR with the help of the MyiQ single colour RT PCR detection system (Bio-Rad). Reactions were performed in duplicate on the same plate in the total volume of 25 $\mu \mathrm{l}$ containing $5 \mu \mathrm{l}$ 1:6 cDNA, $12.5 \mu \mathrm{l}$ SYBR green master mix (IQ SYBR Green Supermix) and gene-specific primers for ATGL and HSL (Biolegio, Nijmegen, The Netherlands). Expression was normalised by the geometric mean of two internal reference genes, i.e. ribosomal protein L13a (RPL13a) and $\beta$-2-microglobulin (25). 


\section{ATGL and HSL protein analyses}

About $100 \mathrm{mg}$ adipose tissue was ground to fine powder under liquid nitrogen and homogenised in $200 \mu \mathrm{l}$ of ice-cold RIPA buffer $(150 \mathrm{mmol} / \mathrm{I} \mathrm{NaCl}, 1 \% \mathrm{NP}-40,0.5 \%$ deoxychilic acid (DOC), $0.1 \% \mathrm{SDS}, 50 \mathrm{mmol} / \mathrm{l}$ Tris $\mathrm{pH}=8.0$ ). The homogenate was vortexed for $5 \mathrm{~min}$ and centrifuged $\left(14000 \mathrm{rpm}, 30 \mathrm{~min}, 10^{\circ} \mathrm{C}\right)$. The infranatant was collected and aliquots were immediately frozen in liquid nitrogen and stored at -80 ${ }^{\circ} \mathrm{C}$ until analysis.

Proteins were separated using $7.5 \%$ SDS-PAGE and then transferred to a Hybond ECL nitrocellulose membrane (Amersham). The blot was blocked using $5 \%$ non-fat dry milk (NFDM)/phosphate buffered saline (PBS)/0.1\%Tween and washed for 10 min in PBS/0.1\%Tween. For the detection of ATGL, an affinity purified polyclonal antibody was raised in rabbit against a 15 amino-acid peptide of human ATGL (Cell Signalling, \#2138) and the blot was incubated overnight at $4{ }^{\circ} \mathrm{C}$ with the ATGL antibody $(1: 1000)$ in $0.5 \%$ NFDM/PBS/0.1\%Tween. For the detection of HSL and $\beta$ actin, blots were incubated with antibodies for HSL (rabbit polyclonal antibody, raised and purified against recombinant human HSL, 1:1000) and $\beta$-actin (Santa Cruz, sc-47778, 1:1000) for $1 \mathrm{~h}$ at room temperature. The HSL antibody was a kindly gift from Prof. dr. C. Holm (Lund University, Sweden). For ATGL and HSL, a horseradish peroxidase-conjugated anti-rabbit immunoglobulin was used as secondary antibody, and for $\beta$-actin a horseradish peroxidase-conjugated antimouse immunoglobulin was used.

The antigen-antibody complexes were visualised using enhanced chemiluminescence (SuperSignal West Dura, Pierce, USA) and a ChemiDoc XRS system, and thereafter quantified using Quantity One ${ }^{\circledR}$ 1-D analysis software (Bio-Rad). Optical density units are expressed as adjusted volume (Adj. Vol. OD, sum of pixels inside the volume boundary $x$ area of a single pixel (in $\mathrm{mm}^{2}$ ) minus the local background volume). To control for differences in loading, ATGL and HSL values are expressed relative to $\beta$-actin protein levels. Inter-run correction was performed by running the same control adipose tissue sample on every gel.

\section{Calculations}

Fasting rate of appearance of FFA $\left(\mathrm{Ra}_{\mathrm{FFA}}\right)$ was calculated using Steele's equation for steady state (26) and expressed per $\mathrm{kg}$ body weight $\left(\mu \mathrm{mol} \cdot \mathrm{kg}^{-1} \cdot \mathrm{min}^{-1}\right)$ and per total body weight $\left(\mu \mathrm{mol} \cdot \mathrm{min}^{-1}\right)$. The homeostasis model assessment for insulin resistance $\left(\mathrm{HOMA}_{\mathrm{IR}}\right)$ was calculated according to Matthews et al (27).

\section{Statistical methods}

Statistical analyses were performed using SPSS 15.0 for Windows (SPSS Inc.). All data are presented as means \pm SEM. Baseline differences between dietary interven- 
tion groups were evaluated using one-way ANOVA. Repeated-measures ANOVA was used to test for differences in changes between groups pre- and post-intervention, with 'time' as within-subjects factor and 'diet' as between-subjects factor. Besides this comparison between the four dietary intervention groups, results were also pooled for both high-fat diets and both low-fat diets and analysed between groups (HSFA + HMUFA vs. LFHCC + LFHCCn-3) using an independent samples t-test and within groups using a paired samples t-test. Bivariate correlations were calculated between changes in ATGL and HSL protein expression and changes in body weight, $\mathrm{BMI}$, waist circumference, fasting plasma insulin and $\mathrm{HOMA}_{\mathrm{IR}}$. Changes in fasting $\mathrm{Ra}_{\mathrm{FFA}}$ and fasting plasma FFA were correlated with changes in ATGL and HSL protein expression in the subgroup of men. Statistical significance was set at $P<0.05$.

Table 5.1 Subject characteristics before and after the 12-week high-fat and low-fat high-complex carbohydrate diets

\begin{tabular}{|c|c|c|c|c|c|}
\hline & $\mathrm{HF}$ & & LFHCC & & $P$-value \\
\hline & pre & post & pre & post & diet*time \\
\hline$n$ (male / female) & $17(12 / 5)$ & & $15(11 / 4)$ & & \\
\hline Age (y) & $56.4 \pm 2.3$ & & $59.1 \pm 2.5$ & & \\
\hline Body weight (kg) & $96.5 \pm 3.2$ & $96.0 \pm 3.2$ & $88.9 \pm 3.4$ & $87.5 \pm 3.4$ & 0.083 \\
\hline BMI $\left(\mathrm{kg} / \mathrm{m}^{2}\right)^{*}$ & $32.4 \pm 1.1$ & $32.2 \pm 1.2$ & $29.1 \pm 0.9$ & $28.6 \pm 0.8$ & 0.073 \\
\hline Waist $(\mathrm{cm})^{*}$ & $111 \pm 2$ & $110 \pm 2$ & $105 \pm 2$ & $102 \pm 2$ & 0.083 \\
\hline $\mathrm{HOMA}_{\mathrm{IR}}$ & $2.78 \pm 0.35$ & $2.88 \pm 0.50$ & $2.61 \pm 0.27$ & $1.99 \pm 0.23$ & 0.049 \\
\hline Plasma insulin (mU/I) & $10.5 \pm 1.1$ & $10.5 \pm 1.5$ & $9.8 \pm 0.1$ & $7.5 \pm 0.9$ & 0.041 \\
\hline Plasma glucose (mmol/l) & $5.81 \pm 0.16$ & $5.91 \pm 0.19$ & $6.00 \pm 0.14$ & $5.95 \pm 0.15$ & 0.290 \\
\hline Plasma FFA ( $\mu \mathrm{mol} / \mathrm{I})$ & $593 \pm 64$ & $621 \pm 45$ & $574 \pm 27$ & $556 \pm 25$ & 0.399 \\
\hline Plasma TAG (mmol/l) & $1.67 \pm 0.20$ & $1.49 \pm 0.16$ & $1.93 \pm 0.39$ & $1.51 \pm 0.14$ & 0.479 \\
\hline Plasma total-C (mmol/l) & $4.82 \pm 0.19$ & $4.72 \pm 0.17$ & $5.10 \pm 0.24$ & $4.59 \pm 0.24$ & 0.009 \\
\hline Plasma LDL-C (mmol/I) & $2.89 \pm 0.18$ & $3.00 \pm 0.19$ & $3.15 \pm 0.25$ & $2.85 \pm 0.26$ & 0.052 \\
\hline Plasma HDL-C (mmol/l) & $0.90 \pm 0.03$ & $0.91 \pm 0.04$ & $0.99 \pm 0.06$ & $0.95 \pm 0.06$ & 0.252 \\
\hline $\operatorname{Ra}_{\mathrm{FFA}}\left(\mu \mathrm{mol} \cdot \mathrm{kg}^{-1} \cdot \mathrm{min}^{-1}\right)$ & $5.13 \pm 0.45$ & $4.96 \pm 0.27$ & $5.18 \pm 0.53$ & $4.75 \pm 0.35$ & 0.646 \\
\hline
\end{tabular}

Data are mean \pm SEM. HF: high-fat diets, LFHCC: low-fat high-complex carbohydrate diets, C: cholesterol. $\mathrm{Ra}_{\mathrm{FFA}}: n=10$ (HF), $n=10$ (LFHCC). $P$-values for diet*time, repeated-measures ANOVA, are shown in table.

${ }^{*} P<0.05$, difference at baseline HF vs. LFHCC diets, independent samples t-test.

\section{Results}

In this subcohort of the total LIPGENE study, subject characteristics were comparable between groups at baseline and did not change differently after the 12week dietary intervention period (Supplemental table). 
Subject characteristics were also compared between the pooled high- and low-fat diets (HSFA + HMUFA vs. LFHCC + LFHCCn-3). Waist circumference and BMI were significantly lower on the LFHCC diets at baseline and tended to decrease after dietary intervention compared to the high-fat diets (Table 5.1). Significant differences between groups were observed for changes in $\operatorname{HOMA}_{\mathbb{R}}(P=0.049)$, fasting plasma insulin concentrations $(P=0.041)$ and fasting plasma total cholesterol $(P=0.009)$ and LDL-cholesterol concentrations $(P=0.05)$, with all parameters being more decreased on the LFHCC diets (Table 5.1). Fasting $\mathrm{Ra}_{\mathrm{FFA}}$ was not different between the high-fat and LFHCC diets, both at baseline and after dietary intervention (Table 5.1).

\section{Subcutaneous adipose tissue ATGL and HSL mRNA expression before and after dietary intervention}

Adipose tissue ATGL and HSL mRNA expression were not affected by dietary intervention (Figure 5.1), although HSL mRNA expression tended to decrease after intervention with the LFHCCn-3 diet $(P=0.06)$. Comparing the high-fat and the LFHCC diets, HSL mRNA expression tended to decrease on the LFHCC diets $(P=0.05)$, but changes were not statistically different compared to the high-fat diets. Positive correlations were observed for HSL and ATGL mRNA expression at baseline ( $r=0.877$, $P<0.001)$. Changes in HSL and ATGL mRNA expression after dietary intervention were also correlated $(r=0.927, P<0.001)$, as has been shown before by Jocken et al (10).

A

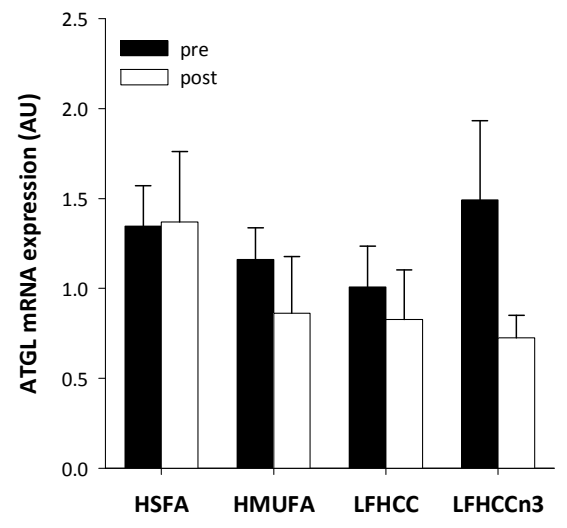

B

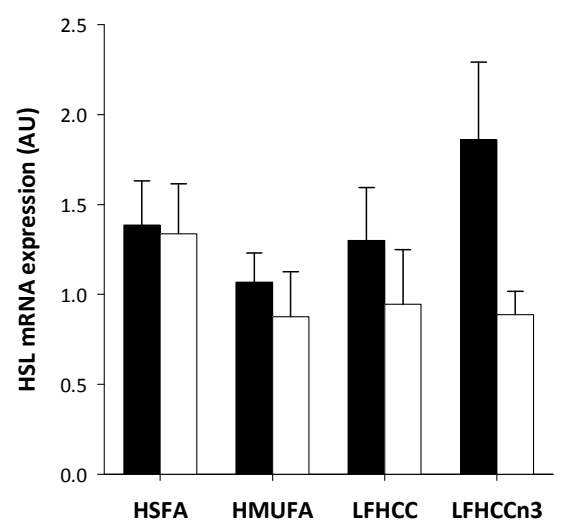

Figure 5.1 ATGL (A) and HSL (B) mRNA expression in subcutaneous adipose tissue of subjects with the MetS before and after dietary intervention. Values are mean \pm SEM. HSFA: $n=7$, HMUFA: $n=5$, LFHCC: $n=4$, LFHCC $n-3: n=5$. 


\section{Subcutaneous adipose tissue ATGL and HSL protein expression was altered by fat quantity but not fat quality}

Protein expression levels of ATGL and HSL in subcutaneous adipose tissue were not different between groups at baseline and were not affected by dietary intervention (Figure 5.2). Comparing the high-fat and LFHCC diets showed a significant diet*time interaction for HSL protein expression $(P=0.029)$ and a trend for ATGL protein expression $(P=0.09)$, indicating differential effects of dietary fat quantity on the expression of these lipolytic enzymes. More specifically, HSL and ATGL protein expression were significantly decreased in subjects on the LFHCC diets $(P=0.04)$ and did not change on the high-fat diets (Figure 5.2, embedded panels).

HSL and ATGL protein expression were strongly correlated at baseline in the total group of subjects $(r=0.728, P<0.001)$ (Table 5.2). Changes in HSL and ATGL protein expression after dietary intervention were significantly correlated in subjects on the high-fat diets ( $r=0.601, P=0.014$ ) and LFHCC diets ( $r=0.651, P=0.016$ ) (Table 5.2).
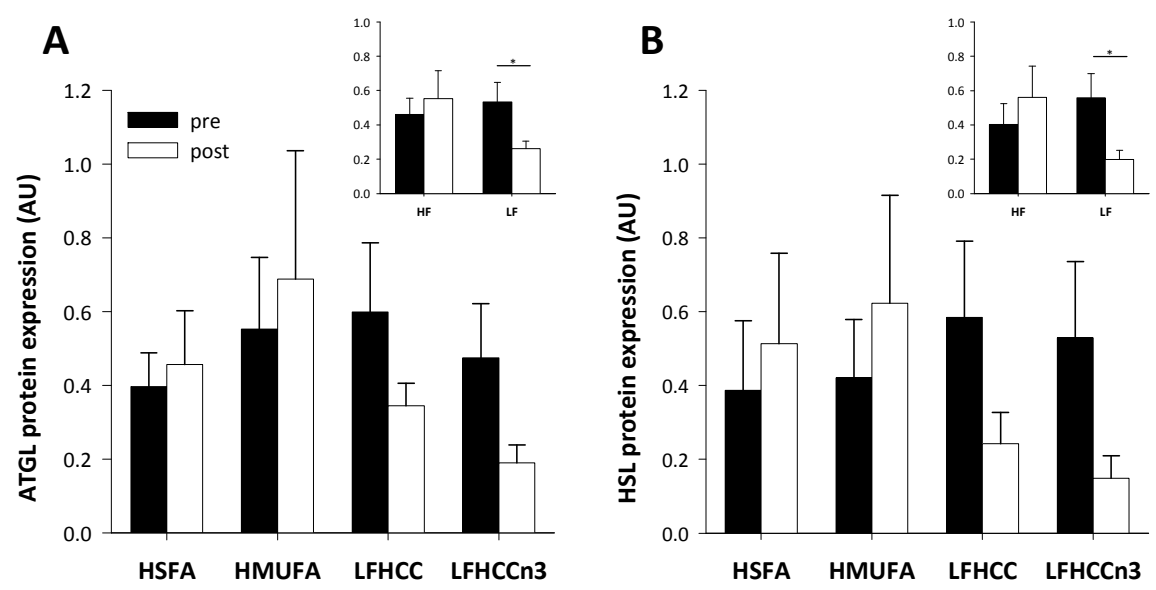

Figure 5.2 ATGL (A) and HSL (B) protein expression in subcutaneous adipose tissue of subjects with the MetS before and after dietary intervention. Changes in ATGL and HSL protein expression were different between the high- and low-fat diets (ATGL: $P=0.09$, HSL: $P=0.029$, independent samples t-test) (embedded in panels), but not between the four isoenergetic diets. Values are mean $\pm \mathrm{SEM}$.

* $P=0.04$, pre- vs. post-intervention, paired samples t-test.

\section{ATGL and HSL protein expression in relation to insulin resistance and adiposity}

Changes in ATGL and HSL protein expression as a result of dietary intervention were not related to changes in body weight or BMI. Trends were observed on the high-fat diets for an inverse relationship between changes in ATGL and fasting plasma insulin 
concentrations $(r=-0.461, P=0.06)$ and changes in ATGL and $\operatorname{HOMA}_{\mathbb{R}}(r=-0.450$, $P=0.07$ ) (data not shown).

Changes in waist circumference were significantly positively related to changes in HSL protein expression in subjects on the LFHCC diets ( $r=0.612, P=0.026)$, also after correction for changes in body weight $(r=0.633, P=0.027)$. In addition, changes in waist circumference tended to correlate with changes in ATGL protein expression in subjects on the LFHCC diets ( $r=0.470, P=0.08$ ) (Table 5.2).

Table 5.2 Pearson correlation coefficients for changes in ATGL and HSL protein expression

\begin{tabular}{|c|c|c|c|c|c|c|c|}
\hline & & \multicolumn{3}{|c|}{$\triangle \mathrm{ATGL}$} & \multicolumn{3}{|c|}{$\Delta \mathrm{HSL}$} \\
\hline & & $\mathrm{HF}$ & LFHCC & Total & $\mathrm{HF}$ & LFHCC & Total \\
\hline$n$ & & 17 & 15 & 32 & 16 & 13 & 29 \\
\hline \multirow[t]{2}{*}{$\triangle \mathrm{HSL}$} & $r$ & .601 & .651 & .649 & - & - & - \\
\hline & $P$-value & .014 & .016 & $<.001$ & - & - & - \\
\hline \multirow[t]{2}{*}{$\Delta$ Waist } & $r$ & .164 & .470 & .325 & .114 & .612 & .381 \\
\hline & $P$-value & .529 & .077 & .070 & .675 & .026 & .041 \\
\hline \multirow[t]{2}{*}{$\Delta \mathrm{Ra}_{\mathrm{FFA}}$ fasting } & $r$ & .611 & .433 & .510 & .417 & .651 & .530 \\
\hline & $P$-value & .061 & .212 & .022 & .264 & .080 & .029 \\
\hline \multirow[t]{2}{*}{$\Delta$ FFA fasting } & $r$ & .719 & .381 & .490 & .113 & .466 & .363 \\
\hline & $P$-value & .019 & .277 & .028 & .772 & .244 & .152 \\
\hline
\end{tabular}

Pearson correlation coefficient $(r)$ and corresponding $P$-values are shown in table. $\Delta$ is calculated as (post - pre). ATGL and HSL protein expression are expressed in arbitrary units. HF: high-fat diets, LFHCC: low-fat high-complex carbohydrate diets, Total: all subjects. Ra $\mathrm{FFA}_{\mathrm{A}}$ and FFA: ATGL: $n=10$ (HF), $n=10$ (LFHCC); HSL: $n=9$ (HF), $n=8$ (LFHCC).

\section{Changes in ATGL and HSL protein expression correlate with whole body $\mathrm{Ra}_{\mathrm{FFA}}$}

Changes in fasting $\mathrm{Ra}_{\mathrm{FFA}}\left(\mu \mathrm{mol} \cdot \mathrm{kg}^{-1} \cdot \mathrm{min}^{-1}\right.$ ) after dietary intervention were significantly positively related to changes in both ATGL $(r=0.510, P=0.022)$ and HSL $(r=0.530, P=0.029)$ protein expression in the subgroup of men (Figure 5.3 , Table 5.2). In addition, changes in fasting plasma FFA concentrations as a result of dietary intervention were also significantly correlated with changes in ATGL $(r=0.490$, $P=0.028)$, but not with changes in HSL $(r=0.363, P=0.152)$ protein expression in the subgroup of men (Table 5.2). Correlations were less pronounced in the high-fat and LFHCC diets (Table 5.2). 
A

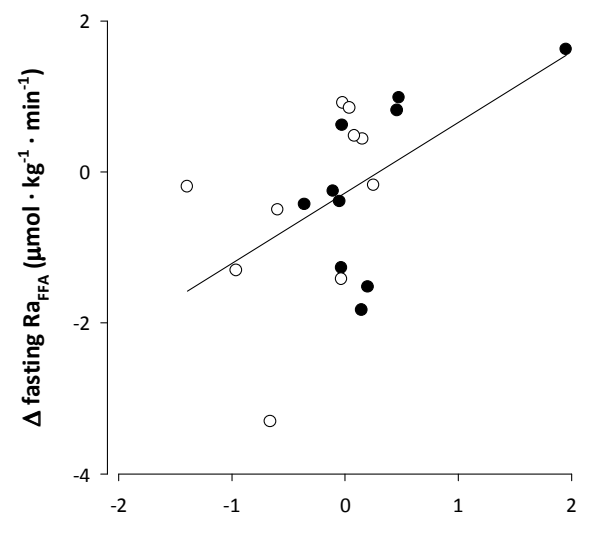

$\Delta$ ATGL protein expression (AU)
B

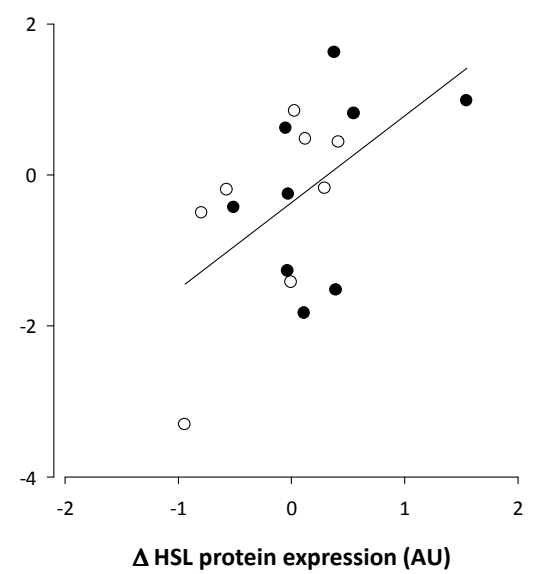

Figure 5.3 Significant positive correlations between changes in fasting rate of appearance of FFA and changes in ATGL $(r=0.510, P=0.022)(A)$ and HSL $(r=0.530, P=0.029)(B)$ protein expression as a result of dietary intervention in the subgroup of men (ATGL: $n=20$, HSL: $n=17$ ). •: HSFA and HMUFA, 0 : LFHCC and LFHCCn-3.

\section{Discussion}

This study investigated the effects of four isoenergetic diets varying in fat quantity and quality on subcutaneous adipose tissue mRNA and protein expression of lipolytic enzymes and on whole body lipolysis in men and women with the MetS. ATGL and HSL mRNA expression were not affected by dietary intervention, whereas ATGL and HSL protein expression were significantly decreased on both low-fat, highcomplex carbohydrate diets compared to no change or an increase in protein expression on both high-fat diets. Dietary fat quality (SFA/MUFA/long-chain $n-3$ PUFA) had no additional effect on changes in protein expression levels, suggesting that dietary fat quantity is more important than dietary fat quality in the regulation of adipose tissue lipolysis under isoenergetic conditions. Moreover, variations in ATGL and HSL protein expression as a result of dietary intervention were positively related to variations in the rate of appearance of FFA in the circulation. Based on these findings we may speculate that the differential effects of dietary fat quantity on ATGL and HSL protein expression in the subcutaneous adipose tissue may have contributed to a reduced lipid outflow from the adipose tissue, although no significant diet effects on Ra $a_{F F A}$ were observed in this study.

In this subcohort, subjects on the LFHCC diets showed improvements in their metabolic profile with a reduction in fasting insulin, $\mathrm{HOMA}_{\mathbb{R}}$ and (LDL)-cholesterol concentrations compared to subjects on the high-fat diets. The concomitant reduction in insulin resistance and ATGL and HSL protein expression on the LFHCC 
diets seems to be in contradiction with studies in 3T3-L1 adipocytes and rodents showing that, after treatment with PPARY agonists, improvements in insulin sensitivity are related to increased adipose tissue ATGL and HSL expression (17-19) and with human in vivo data showing an inverse correlation between fasting insulin and ATGL and HSL protein expression (10). A strong direct association between fasting insulin concentrations and lipolytic protein expression was not observed on the high-fat or LFHCC diets in this study, suggesting that protein expression may have been modulated via other mechanisms than direct modulation of gene expression by specific fatty acids.

The change in waist circumference was significantly associated with a downregulation of HSL protein on the LFHCC diets. Comparable with changes observed in obese insulin resistant subjects after significant weight loss of around $8.7 \mathrm{~kg}(10,15)$, a downregulation of lipolytic enzymes may protect the body from adipose tissue loss in times of a reduced supply of dietary fat to the adipose tissue. However, the reduction in body weight on the LFHCC diets was relatively small (around $1.4 \mathrm{~kg}$ ) and the changes in ATGL and HSL protein expression levels were depending on dietary fat quantity in the present isoenergetic study, whereas fat quantity does not seem to affect changes in ATGL and HSL mRNA and protein on a hypocaloric diet $(10,15)$.

The effects of dietary intervention on ATGL and HSL mRNA expression were not evident, although HSL mRNA levels tended to decrease on the LFHCC diets in accordance with HSL protein levels. The lack of a direct association between mRNA and protein levels of ATGL and HSL in the adipose tissue has been reported before $(13,28)$ and suggests that posttranscriptional and/or posttranslational regulation is important for lipolytic enzyme activity. With respect to posttranslational modification, the actual rate of adipose tissue lipolysis has been shown to depend on the activation of the lipolytic enzymes (i.e. by phosphorylation, translocation to the lipid droplet and/or interaction with other proteins) rather than absolute protein levels (4). Therefore, we measured lipid mobilisation from adipose tissue by calculating the rate of appearance of FFA into the circulation as an indirect measure of lipolytic enzyme activity. No differential effects of dietary fat modification on $\mathrm{Ra}_{\mathrm{FFA}}$ were observed, but we did observe a significant positive correlation between changes in fasting $\mathrm{Ra}_{\mathrm{FFA}}$ and changes in ATGL and HSL protein expression in the total group of subjects. Although we cannot separate between the different fat depots and their contribution to $\mathrm{Ra}_{\mathrm{FFA}}$, these data indicate that HSL and ATGL protein expression levels in subcutaneous adipose tissue may be appropriate measures of intracellular lipolytic enzyme activity. More importantly, the decreased expression of lipolytic enzymes on the LFHCC diets might have resulted in a lower release of FFA into the circulation and contributed to the improved metabolic profile as shown by lower levels of circulating (LDL)-cholesterol and improved insulin sensitivity in 
subjects on the low-fat, high-complex carbohydrate diets compared to the high-fat diets.

In conclusion, the low-fat high-complex carbohydrate diets were associated with a reduced ATGL and HSL protein expression and significant improvements in the metabolic profile of men and women with the MetS, possibly related to a reduced lipid overflow from the adipose tissue. The present results indicate that, under isoenergetic conditions, dietary fat quantity is more important than dietary fat quality in modulating subcutaneous adipose tissue ATGL and HSL protein expression.

\section{Acknowledgements}

The authors thank all volunteers for their time and motivation, and Gabby Hul for her excellent technical support.

\section{Supplemental data}




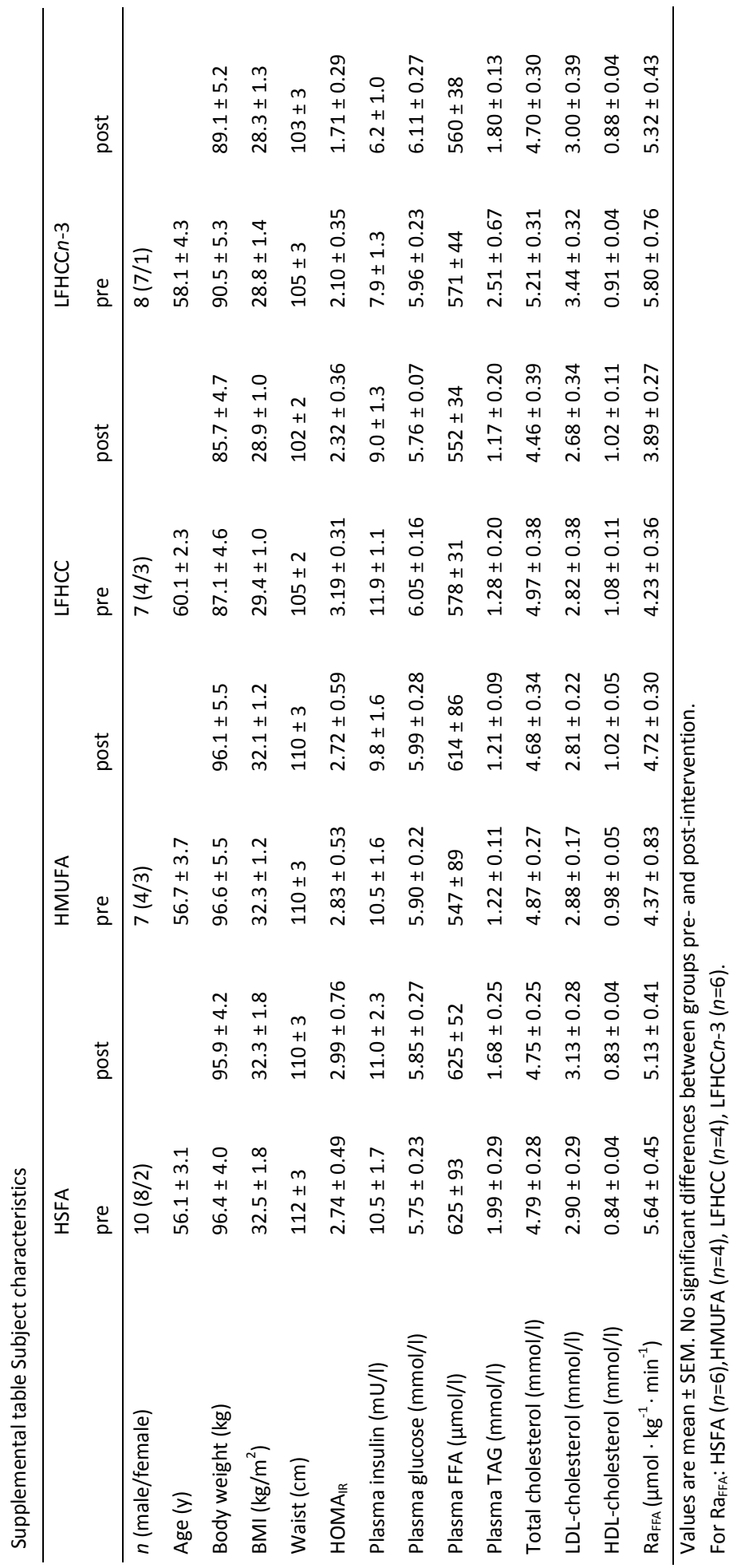




\section{References}

1. Eckel RH, Grundy SM, Zimmet PZ. The metabolic syndrome. Lancet 2005;365(9468):1415-28.

2. Petersen KF, Dufour S, Savage DB, Bilz S, Solomon G, Yonemitsu S, et al. The role of skeletal muscle insulin resistance in the pathogenesis of the metabolic syndrome. Proc Natl Acad Sci U S A 2007;104(31):12587-94.

3. Frayn KN. Adipose tissue as a buffer for daily lipid flux. Diabetologia 2002;45(9):1201-10.

4. Watt MJ, Steinberg GR. Regulation and function of triacylglycerol lipases in cellular metabolism. Biochem J 2008;414(3):313-25.

5. Zechner R, Kienesberger PC, Haemmerle G, Zimmermann R, Lass A. Adipose triglyceride lipase and the lipolytic catabolism of cellular fat stores. J Lipid Res 2009;50(1):3-21.

6. Blaak EE. Fatty acid metabolism in obesity and type 2 diabetes mellitus. Proc Nutr Soc 2003;62(3):753-60.

7. Bickerton AS, Roberts R, Fielding BA, Tornqvist $H$, Blaak EE, Wagenmakers AJ, et al. Adipose tissue fatty acid metabolism in insulin-resistant men. Diabetologia 2008;51(8):1466-74.

8. Campbell PJ, Carlson MG, Nurjhan N. Fat metabolism in human obesity. Am J Physiol 1994;266(4 Pt 1):E600-5.

9. Karpe F, Tan GD. Adipose tissue function in the insulin-resistance syndrome. Biochem Soc Trans 2005;33(Pt 5):1045-8.

10. Jocken JW, Langin D, Smit E, Saris WH, Valle C, Hul GB, et al. Adipose triglyceride lipase and hormone-sensitive lipase protein expression is decreased in the obese insulin-resistant state. J Clin Endocrinol Metab 2007;92(6):2292-9.

11. Schweiger M, Schreiber R, Haemmerle G, Lass A, Fledelius C, Jacobsen $P$, et al. Adipose triglyceride lipase and hormone-sensitive lipase are the major enzymes in adipose tissue triacylglycerol catabolism. J Biol Chem 2006;281(52):40236-41.

12. Jocken JW, Blaak EE. Catecholamine-induced lipolysis in adipose tissue and skeletal muscle in obesity. Physiol Behav 2008;94(2):219-30.

13. Steinberg GR, Kemp BE, Watt MJ. Adipocyte triglyceride lipase expression in human obesity. Am J Physiol Endocrinol Metab 2007;293(4):E958-64.

14. Gaidhu MP, Anthony NM, Patel P, Hawke TJ, Ceddia RB. Dysregulation of lipolysis and lipid metabolism in visceral and subcutaneous adipocytes by high-fat diet: role of ATGL, HSL, and AMPK. Am J Physiol Cell Physiol 2010;298(4):C961-71.

15. Viguerie N, Vidal H, Arner P, Holst C, Verdich C, Avizou S, et al. Adipose tissue gene expression in obese subjects during low-fat and high-fat hypocaloric diets. Diabetologia 2005;48(1):123-31.

16. Mairal A, Langin D, Arner P, Hoffstedt J. Human adipose triglyceride lipase (PNPLA2) is not regulated by obesity and exhibits low in vitro triglyceride hydrolase activity. Diabetologia 2006;49(7):162936.

17. Shen WJ, Patel S, Yu Z, Jue D, Kraemer FB. Effects of rosiglitazone and high fat diet on lipase/esterase expression in adipose tissue. Biochim Biophys Acta 2007;1771(2):177-84.

18. Festuccia WT, Laplante M, Berthiaume M, Gelinas Y, Deshaies Y. PPARgamma agonism increases rat adipose tissue lipolysis, expression of glyceride lipases, and the response of lipolysis to hormonal control. Diabetologia 2006;49(10):2427-36.

19. Kershaw EE, Schupp M, Guan HP, Gardner NP, Lazar MA, Flier JS. PPARgamma regulates adipose triglyceride lipase in adipocytes in vitro and in vivo. Am J Physiol Endocrinol Metab 2007;293(6):E1736-45.

20. Rivellese AA, Giacco R, Annuzzi G, De Natale C, Patti L, Di Marino L, et al. Effects of monounsaturated vs. saturated fat on postprandial lipemia and adipose tissue lipases in type 2 diabetes. Clin Nutr 2008;27(1):133-41.

21. Tierney AC, McMonagle J, Shaw DI, Gulseth HL, Helal O, Saris WHM, et al. Effects of dietary fat modification on insulin sensitivity and other risk factors of the metabolic syndrome - LIPGENE: an European randomized dietary intervention study. Int J Obes (Lond) 2010:in press. 
22. Third Report of the National Cholesterol Education Program (NCEP) Expert Panel on Detection, Evaluation, and Treatment of High Blood Cholesterol in Adults (Adult Treatment Panel III) final report. Circulation, 2002:3143-421.

23. van Hees AM, Saris WH, Hul GB, Schaper NC, Timmerman BE, Lovegrove JA, et al. Effects of dietary fat modification on skeletal muscle fatty acid handling in the metabolic syndrome. Int J Obes (Lond) 2010;34(5):859-70.

24. Shaw DI, Tierney AC, McCarthy S, Upritchard J, Vermunt S, Gulseth HL, et al. LIPGENE foodexchange model for alteration of dietary fat quantity and quality in free-living participants from eight European countries. Br J Nutr 2008;101(5):750-9.

25. Vandesompele J, De Preter K, Pattyn F, Poppe B, Van Roy N, De Paepe A, et al. Accurate normalization of real-time quantitative RT-PCR data by geometric averaging of multiple internal control genes. Genome Biol 2002;3(7):RESEARCH0034.

26. Wolfe RR. Radioactive and stable isotope tracers in biomedicine: principles and practice of kinetic analysis. New York, USA: Wiley-Liss, 1992.

27. Matthews DR, Hosker JP, Rudenski AS, Naylor BA, Treacher DF, Turner RC. Homeostasis model assessment: insulin resistance and beta-cell function from fasting plasma glucose and insulin concentrations in man. Diabetologia 1985;28(7):412-9.

28. Ray H, Pinteur C, Frering V, Beylot M, Large V. Depot-specific differences in perilipin and hormonesensitive lipase expression in lean and obese. Lipids Health Dis 2009;8:58. 



\section{6}

Fasting and postprandial remnant-like particle cholesterol concentrations in obese participants are associated with plasma triglycerides, insulin resistance, and body fat distribution

Anneke M.J. van Hees, Wim H.M. Saris, Geesje M. Dallinga-Thie, Gabby B. Hul, J. Alfredo Martinez, Jean-Michel Oppert, Vladimir Stich, Arne Astrup, Peter Arner, Thorkild I. A. Sørensen and Ellen E. Blaak

Journal of Nutrition 2008;138(12):2399-405. 


\section{Abstract}

Elevated plasma concentrations of remnant-like particle cholesterol (RLP-C) are atherogenic. However, factors that determine RLP-C are not fully understood. This study evaluates which factors affect RLP-C in the fasting and postprandial state, using multiple regression analyses in a large cohort of lean and obese participants. All participants $(n=740)$ underwent a test meal challenge containing 95 energy\% fat (energy content $50 \%$ of predicted daily resting metabolic rate). Fasting and postprandial concentrations of circulating metabolites were measured over a $3 \mathrm{~h}$ period. Obese participants $(n=613)$ also participated in a 10 -week weight loss programme $(-2510 \mathrm{~kJ} / \mathrm{d})$, being randomised to either a low-fat or a high-fat diet (2025 vs. 40-45 energy\% fat). Postprandial RLP-C was associated with fasting RLP-C, waist-hip ratio (WHR), $\mathrm{HOMA}_{\mathrm{IR}}$ (homeostasis model assessment index for insulin resistance) $(P<0.001)$ and age, independently of $\mathrm{BMI}$ and gender (adjusted $\left.\mathrm{R}^{2}=0.70\right)$. These factors were also related to fasting RLP-C $(P<0.010)$, along with gender and physical activity (adjusted $\mathrm{R}^{2}=0.23$ ). The dietary intervention resulted in significantly lower fasting RLP-C concentrations, independently mediated by weight loss, improvements in $\mathrm{HOMA}_{\mathrm{IR}}$ and the fat content of the prescribed diet. However, after inclusion of plasma triacylglycerol (TAG), HDL-cholesterol and FFA concentrations in the models, $H_{O M A_{I R}}$ and WHR no longer significantly predicted fasting RLP-C, although WHR remained a predictor of postprandial RLP-C $(P=0.002)$. Plasma TAG was strongly associated with both fasting and postprandial RLP-C $(P<0.001)$. In conclusion, plasma RLP-C concentrations are mainly associated with plasma TAG concentrations. Interestingly, the high-fat diet was more effective at decreasing fasting RLP-C concentrations in obese participants than the low-fat diet. 


\section{Introduction}

Insulin-resistant conditions like obesity and type 2 diabetes mellitus are strongly associated with hyperlipidaemia and an increased risk for atherosclerosis and cardiovascular disease (1). An atherogenic lipoprotein profile is characterised by high plasma concentrations of triacylglycerol (TAG)-rich lipoproteins (TRL), small, dense LDL and low plasma concentrations of HDL-cholesterol (HDL-C) (2). Moreover, high plasma concentrations of remnant-like particles (RLP), which are formed when TRL are partly depleted of TAG by lipoprotein lipase, are considered to be highly atherogenic $(2,3)$. In this context, it has been suggested that plasma RLP-cholesterol (RLP-C), and not plasma TAG, is an independent risk factor for the development of cardiovascular disease (4-6). Several studies have been performed to determine which factors may play a role in RLP metabolism and show associations with insulin resistance, BMI, upper body obesity, other blood lipids, gender and age (7-15). However, most of these studies were performed in a relatively small number of participants so that multiple factors could not be taken into account. Moreover, data on the influence of lifestyle factors such as diet and physical activity are limited. Results of a study investigating the effect of dietary composition on plasma RLP-C suggest that a 2-week high-carbohydrate diet (60 energy\% (E\%) carbohydrate) increased plasma TAG and decreased plasma HDL-C concentrations but also led to increased fasting and postprandial RLP-C concentrations compared with a 2-week low-carbohydrate diet (40 E\% carbohydrate) (16). On the other hand, it has been shown that reducing the total fat content of the diet causes weight loss and better weight maintenance, which can also have a favourable effect on the blood lipid profile (17). Nevertheless, little information is available on the relative effects of weight loss and dietary fat modification on plasma RLP-C concentrations.

The objective of this part of the European multicentre trial Nutrient-Gene Interactions in Human Obesity-Implications for Dietary Guidelines (NUGENOB) was to take the drawbacks of earlier studies into account and investigate the factors that affect plasma RLP-C concentrations in a large cohort of lean and obese participants with a detailed phenotype, both in the fasting state and postprandially after the consumption of a high-fat meal. Second, we investigated determinants of change in fasting RLP-C concentration after a 10-week hypo-energetic diet with either a highor low-fat content in the obese participants who participated in the NUGENOB trial. 


\section{Methods}

The study was a randomised, parallel, 2-arm, open-label, 10-week dietary intervention of 2 hypo-energetic diets performed in 8 different centres across 7 European countries: United Kingdom, The Netherlands, France (2 centres), Spain, Czech Republic, Sweden and Denmark. The trial was part of the multicentre EU FP5 project NUGENOB.

\section{Participants}

In total, 740 Caucasian participants (552 women) were included in the NUGENOB study. Inclusion criteria were age 20-50 y, BMI between 18.5 and $25 \mathrm{~kg} / \mathrm{m}^{2}$ for lean participants and $\mathrm{BMI} \geq 30.0 \mathrm{~kg} / \mathrm{m}^{2}$ for obese participants. After baseline measurements, only the obese participants were allowed to enter the weight loss programme. Details on participant recruitment and exclusion criteria are described elsewhere (18).

All participants were informed about the nature of the study and gave written informed consent prior to study participation. The study protocol was approved by the ethical committee at each of the participating centres.

\section{Experimental design}

All participants underwent a $1 \mathrm{~d}$ clinical investigation protocol. Participants arrived at the research centre after a $12 \mathrm{~h}$ overnight fast and a preceding $3 \mathrm{~d}$ dietary run-in period, during which they were to keep their habitual diet and avoid excessive physical activity and alcohol consumption. After the participants voided their bladders, they underwent anthropometric and body composition assessments (as described in Petersen et al (18)). Thereafter, participants stayed on a bed for $3.5 \mathrm{~h}$, during which circulating hormones and metabolites were determined before and after a high-fat test meal. At least $30 \mathrm{~min}$ before the start of the resting measurement, a catheter was inserted in an antecubital forearm vein for blood sampling. Blood was drawn in the fasting state and every $60 \mathrm{~min}$ following the test meal for the next $3 \mathrm{~h}$. Plasma concentrations of glucose, insulin, FFA, TAG, total cholesterol, HDL-C and RLP-C were determined pre- and postprandially. Furthermore, postprandial RLP-C was also measured $6 \mathrm{~h}$ postprandially in a subgroup of 113 participants to compare $3 \mathrm{~h}$ and $6 \mathrm{~h} \mathrm{RLP-C}$ concentrations. During the whole experiment, the room was kept thermoneutral at $25{ }^{\circ} \mathrm{C}$. The obese participants who participated in the weight loss programme also underwent a second clinical investigation; at the end of the 10-week dietary intervention, anthropometric measurements and body composition assessments were repeated and a venous blood sample was obtained after an overnight fast. 


\section{Test meal}

The fluid test meal (double cream with $40 \%$ fat/100 g adjusted with butter in 2 centres) consisted of $95 \mathrm{E} \%$ (percent of total energy content fat load) fat, $60 \%$ of which was saturated fat, $3 \mathrm{E} \%$ carbohydrate and $2 \mathrm{E} \%$ protein. Based on the predicted metabolic rate, the energy content was fixed at $50 \%$ of the predicted basal metabolic rate (19) and ranged from 1697 to $6590 \mathrm{~kJ}$. Participants were asked to drink the test meal within $10 \mathrm{~min}$.

\section{Dietary intervention study}

Stratified block randomisation was used with centre, gender and 3 age groups (20$29,30-39$ and $40-50$ y) as strata and a block size of 12 to assign obese participants to either a low-fat diet or a high-fat diet. The target macronutrient composition of the low-fat diet was $20-25 \%$ of total energy from fat, $15 \%$ from protein and 60-65\% from carbohydrate. The target macronutrient composition of the high-fat diet was 40-45 \% of total energy from fat, $15 \%$ from protein and $40-45 \%$ from carbohydrate. Both diets were designed to provide $2510 \mathrm{~kJ} / \mathrm{d}$ less than the individually estimated energy requirement based on an initial resting metabolic rate multiplied by 1.3. Information about how the diet was controlled is given in detail elsewhere (18).

\section{Biochemical analyses}

All blood analyses were performed in the laboratory of one of the centres. Plasma glucose concentrations ( $A B X$ diagnostics), TAG (Sigma; $A B X$ diagnostics) and total cholesterol (cholesterol 100; $A B X$ diagnostics) were measured on a COBAS Mira automated spectrophotometric analyser (Roche Diagnostica). Plasma FFA (NEFA C kit; Wako Chemicals) and HDL-C (HDL-C Roche) were measured on a COBAS FARAH centrifugal spectrophotometer (Roche Diagnostica). Standard samples with known concentrations were included in each analysis for quality control. Plasma insulin concentrations were measured with a double antibody RIA (Insulin RIA 100; KabiPharmacia). RLP-C concentrations were measured in plasma using an immunoseparation technique developed by Nakajima et al (20). The RLP fraction was prepared by mixing $5 \mu \mathrm{l}$ of plasma with $300 \mu \mathrm{l}$ immunoseparation gel suspension, containing a mixture of 2 monoclonal antibodies, i.e. anti-human apolipoprotein A-I (H-12) and anti-human apolipoprotein-B-100 (JI-H). The reaction mixture was gently shaken for $2 \mathrm{~h}$ at room temperature on a special mixer (RLPmixer J100-A, Photal, Otsuka Electronics). After incubation, $200 \mu \mathrm{l}$ of supernatant was used for the measurements of cholesterol (RLP-C) on a COBAS Mira S autoanalyser ( $A B X$ diagnostics). 


\section{Calculations}

The homeostasis model assessment for insulin resistance $\left(\mathrm{HOMA}_{\mathrm{R}}\right)$ was calculated from fasting glucose and fasting insulin according to the equation of Matthews et al (21). An estimate of total habitual physical activity was obtained by means of the Baecke questionnaire using the sum of work, sport and leisure scores of the questionnaire $(22,23)$. For comparing postprandial responses, we calculated the incremental area under the curve (iAUC) according to the trapezium rule. Postprandial RLP-C is expressed as the plasma concentration of RLP-C at t 180 min, because only baseline and $3 \mathrm{~h}$ values of RLP-C were available.

\section{Statistical methods}

Statistical analyses were performed using SPSS 14.0 for Windows (SPSS Inc.). All variables were checked for normal distribution and non-normally distributed data were In-transformed to satisfy conditions of normality. Student's t test for unpaired samples was used to compare participant characteristics at baseline (lean vs. obese, low- vs. high-fat diet group) and repeated-measures ANOVA was used to test for differences in time between groups. Multiple regression analysis was performed to evaluate which factors were associated with plasma RLP-C concentrations, both in the fasting state and postprandially after a high-fat meal. The dependent variable in each multiple regression model was In-transformed to satisfy conditions of normality. Independent variables were included in the analyses in 2 steps; gender, $\mathrm{BMI}$, age, $\mathrm{HOMA}_{\mathrm{IR}}$, waist:hip ratio (WHR), baseline dietary fat intake, total physical activity and/or fasting plasma RLP-C were included in model 1 and plasma concentrations of TAG, FFA and HDL-C (fasting or as IAUC in the postprandial model) were included in model 2 . Determinants of change $(\Delta)$ in fasting RLP-C were also evaluated in 2 models, with the independent variables gender, diet, age, $\Delta$ weight, $\Delta$ $\mathrm{HOMA}_{\mathrm{IR}}$ and $\triangle \mathrm{WHR}$ in model 1 and change in fasting plasma TAG, FFA and HDL-C in model 2. The $\Delta$ was calculated as ( $10 \mathrm{wk}-0 \mathrm{wk}$ ) and the models were corrected for the mean values of each $\Delta$ variable $(10 w k+0 w k / 2)$. Furthermore, all models as described above were corrected for centre (dummy variables) and, in the postprandial model, for the energy content of the high-fat test meal. To avoid multicollinearity, predictors with a correlation $>0.80$ were not included in the model simultaneously. The relative impact of the predictors is demonstrated as the standardised $\beta$-coefficient and its significance value. The adjusted $R^{2}\left(\operatorname{adj} . R^{2}\right.$ ) of each model is indicated in the tables. Significance was set at $P<0.05$. 


\section{Results}

At baseline, obese participants had higher plasma concentrations of RLP-C, TAG, FFA and total cholesterol and a higher $\mathrm{HOMA}_{\mathrm{IR}}$ than lean participants $(P<0.001)$ (Table 6.1). Furthermore, the obese participants in the low- and high-fat groups at baseline did not differ. Fasting plasma RLP-C concentrations decreased in both groups due to the hypocaloric diet, with a greater reduction in the high-fat group $(-0.07 \pm 0.01$ $\mathrm{mmol} / \mathrm{l})$ than in the low-fat group $(-0.03 \pm 0.01 \mathrm{mmol} / \mathrm{l} ; P=0.019)$. Also, the decrease in fasting TAG was greater in the high-fat group $(-0.17 \pm 0.03 \mathrm{mmol} / \mathrm{l})$ than in the low-fat group $(-0.03 \pm 0.02 \mathrm{mmol} / \mathrm{l} ; P=0.007)$, whereas participants that consumed the low-fat diet had a greater reduction in plasma total cholesterol and HDL-C concentrations (Table 6.1). Dietary goals were achieved in this study (Table 6.2) and are, along with the flow of participants in the NUGENOB study, described in detail elsewhere (18). After the high-fat meal, plasma RLP-C, TAG and insulin concentrations increased and there was a postprandial decrease in plasma FFA concentrations (Figure 6.1).

Table 6.1 Subject characteristics at baseline and after a 10-week hypocaloric diet

\begin{tabular}{|c|c|c|c|c|}
\hline & \multicolumn{2}{|l|}{ Baseline } & \multicolumn{2}{|c|}{$\Delta$ after dietary intervention } \\
\hline & lean & obese & low-fat diet & high-fat diet \\
\hline$n$ & 127 (38 M) & $613(150 \mathrm{M})$ & 317 (82 M) & 296 (71 M) \\
\hline Age $(y)$ & $34 \pm 1$ & $37 \pm 0^{*}$ & & \\
\hline BMI $\left(\mathrm{kg} / \mathrm{m}^{2}\right)$ & $23.8 \pm 0.3$ & $36.0 \pm 0.2^{*}$ & $-2.5 \pm 0.1$ & $-2.4 \pm 0.1$ \\
\hline Waist-hip ratio & $0.81 \pm 0.01$ & $0.89 \pm 0.00^{*}$ & $-0.02 \pm 0.00$ & $-0.02 \pm 0.00$ \\
\hline $\mathrm{HOMA}_{\mathrm{IR}}$ & $1.11 \pm 0.06$ & $2.61 \pm 0.07^{*}$ & $-0.29 \pm 0.09$ & $-0.38 \pm 0.10$ \\
\hline Dietary fat intake (E\%) & $34.4 \pm 0.6$ & $36.4 \pm 0.3^{*}$ & & \\
\hline Total physical activity (AU) & $8.22 \pm 0.10$ & $7.42 \pm 0.05^{*}$ & & \\
\hline Plasma RLP-C (mmol/l) & $0.25 \pm 0.01$ & $0.33 \pm 0.01^{*}$ & $-0.03 \pm 0.01$ & $-0.07 \pm 0.01^{\S}$ \\
\hline Plasma TAG (mmol/l) & $0.74 \pm 0.03$ & $1.10 \pm 0.03^{*}$ & $-0.03 \pm 0.02$ & $-0.17 \pm 0.03^{\#}$ \\
\hline Plasma FFA ( $\mu \mathrm{mol} / \mathrm{I})$ & $418 \pm 12$ & $520 \pm 6^{*}$ & $-33 \pm 10$ & $-28 \pm 11$ \\
\hline Plasma HDL-C (mmol/l) & $1.34 \pm 0.03$ & $1.12 \pm 0.01^{*}$ & $-0.09 \pm 0.01$ & $-0.04 \pm 0.01^{\#}$ \\
\hline Plasma Total-C (mmol/l) & $4.59 \pm 0.08$ & $4.92 \pm 0.04^{*}$ & $-0.37 \pm 0.04$ & $-0.25 \pm 0.03^{\#}$ \\
\hline
\end{tabular}

Values are means \pm SEM. The change $(\Delta)$ of each value is calculated as (10 week - baseline).

${ }^{*} P<0.001$, lean vs. obese, Student's t-test for unpaired samples.

${ }^{\#} P<0.01 ;{ }^{\S} P<0.05$, diet*time interaction, repeated-measures ANOVA. 

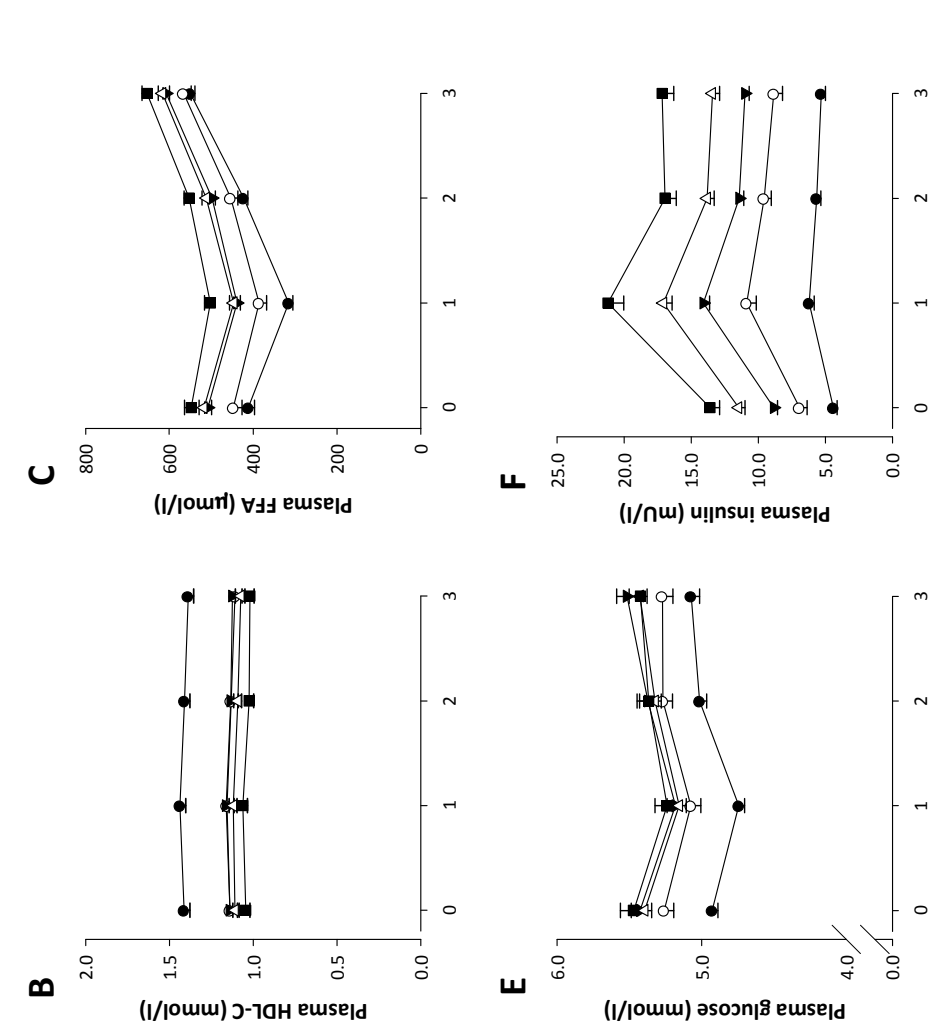

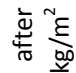

它 总

o

$\pm \bar{\Sigma}$

玉

घू

产 京

프롱

득 음

.气 究

항 $\sum_{0}^{\infty}$

巴)

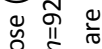

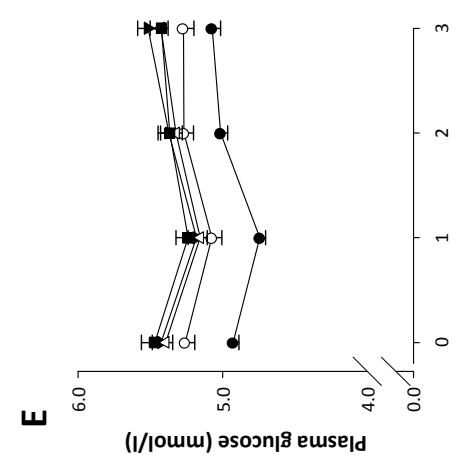

드

品 $\frac{2}{\frac{\pi}{2}}$

$\tilde{\overline{0}}^{N} \xi$

ฮ

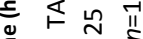

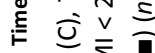
苻部 嵌

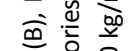

บ

完䒿 $\hat{\bar{\Sigma}}$

I $\sum_{\substack{0 \\ 0}}$
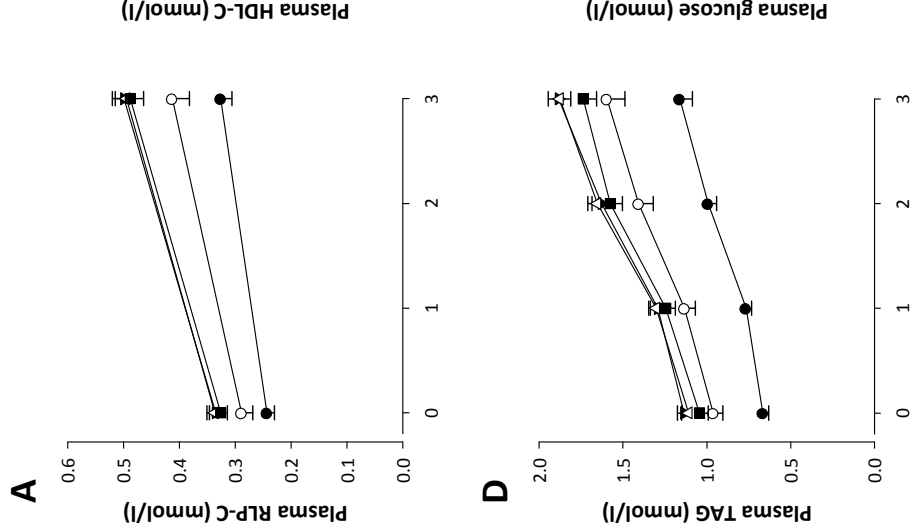

这究

บ

产 号

ডั

ก $\frac{0}{0} \unlhd$

三

है ᄃ $\frac{1}{60}$ u ह $\frac{m}{\Sigma}$ है 즘 으 항

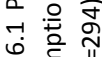
产密 
Table 6.2 Composition of the habitual diet of lean and obese subjects at baseline and the composition of the low- and high-fat hypocaloric intervention diets in obese subjects

\begin{tabular}{llll}
\hline & habitual diet & low-fat diet & high-fat diet \\
\hline $\mathrm{n}$ & 740 & 302 & 285 \\
Energy intake (kJ/day) & $9118 \pm 103$ & $6518 \pm 88$ & $6846 \pm 85^{*}$ \\
Fat (E\%) & $36.1 \pm 0.3$ & $25.1 \pm 0.3$ & $41.3 \pm 0.3^{*}$ \\
Carbohydrate (E\%) & $45.8 \pm 0.3$ & $56.6 \pm 0.3$ & $41.5 \pm 0.3^{*}$ \\
Protein (E\%) & $16.3 \pm 0.1$ & $17.8 \pm 0.2$ & $17.0 \pm 0.2^{*}$ \\
Alcohol (E\%) & $1.8 \pm 0.1$ & $0.4 \pm 0.1$ & $0.2 \pm 0.1^{\#}$ \\
Dietary fibre (g/day) & $18.5 \pm 0.3$ & $22.6 \pm 0.4$ & $19.1 \pm 0.4^{*}$ \\
\hline
\end{tabular}

Values are means \pm SEM. The composition of the diets is based on a 3-day-weighed food record. A small number of subjects did not complete a 3-day weighed food record after the 10-week dietary intervention period. " $P<0.01 ;{ }^{\#} P<0.05$, low-fat $v$ s. high-fat diet, Student's t-test for unpaired samples.

\section{Determinants of fasting RLP-C concentrations}

In multiple regression, $\mathrm{HOMA}_{\mathrm{IR}}$, gender, age, WHR and total physical activity were positively associated with fasting RLP-C (adj. $R^{2}=0.23$ ), with higher concentrations in men than in women (Table 6.3). In model 2, fasting TAG was the strongest positive predictor $(P<0.001)$ for fasting RLP-C concentrations (adj. $\left.R^{2}=0.60\right)$, whereas the degree of insulin resistance and WHR were no longer significantly associated with fasting RLP-C.

Table 6.3 Determinants of fasting plasma RLP-C in multiple regression analyses

\begin{tabular}{lllll}
\hline$n=740$ & Model 1 & & Model 2 & \\
& $\beta$ & $P$-value & $\beta$ & $P$-value \\
\hline (Constant) & & $<0.001$ & & $<0.001$ \\
Gender (male vs. female) & 0.156 & $<0.001$ & 0.109 & 0.001 \\
BMI (kg/m ${ }^{2}$ ) & 0.041 & 0.315 & 0.082 & 0.008 \\
Age (y) & 0.096 & 0.007 & 0.042 & 0.102 \\
HOMA & 0.235 & $<0.001$ & -0.029 & 0.326 \\
Waist-hip ratio & 0.157 & 0.004 & 0.011 & 0.781 \\
Dietary fat intake (E\%) & 0.027 & 0.463 & 0.030 & 0.266 \\
Total physical activity (AU) & 0.085 & 0.012 & 0.074 & 0.003 \\
Plasma TAG (fasting) (mmol/l) & - & - & 0.712 & $<0.001$ \\
Plasma FFA (fasting) ( $\mu$ mol/l) & - & - & -0.020 & 0.474 \\
Plasma HDL-C (fasting) (mmol/l) & - & - & -0.001 & 0.985 \\
\hline
\end{tabular}

The dependent is fasting plasma RLP-C in mmol/l. For statistical analyses, the dependent variable was Intransformed. Both models include the indicated variables in addition to centre.

Model 1 Adj. $R^{2}=0.23$, Model 2 Adj. $R^{2}=0.60$. 


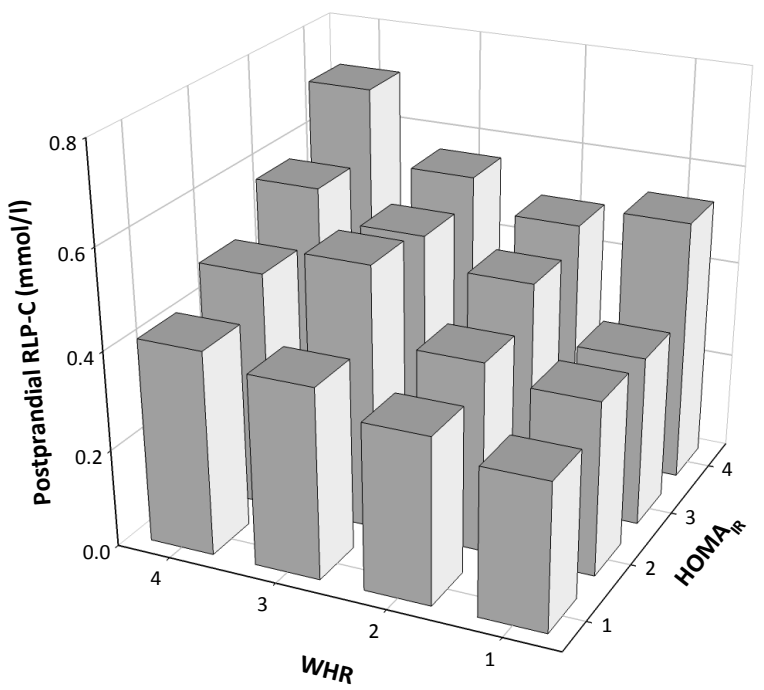

Figure 6.2 Postprandial plasma RLP-C concentrations ( $3 \mathrm{~h}$ ) according to WHR and $H_{O M A_{I R}}$ quartiles. Quartile 1 corresponds with the lowest WHR and $H_{O M A}$ values and quartile 4 with the highest values. Values are mean.

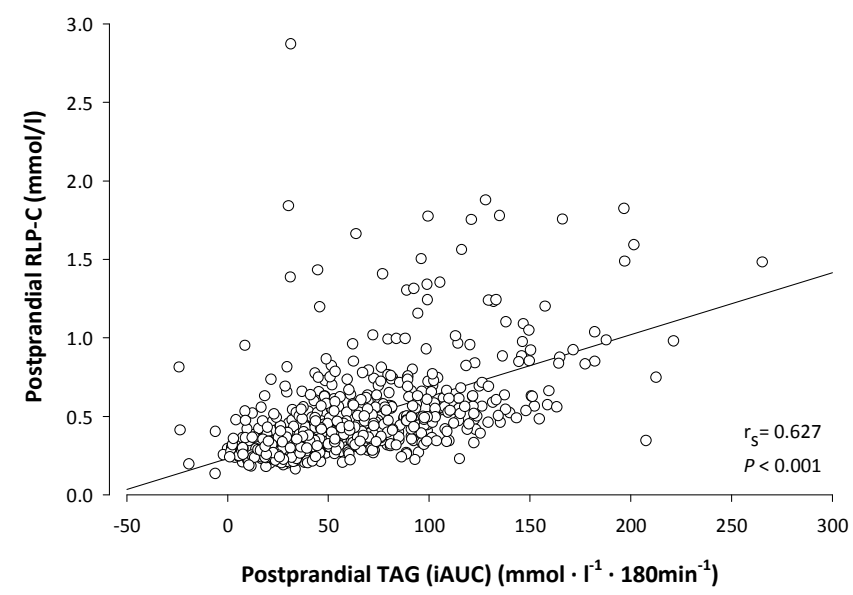

Figure 6.3 Strong relationship between the postprandial response of plasma TAG (iAUC) and plasma RLP-C (3 h) after a high-fat meal. Spearman correlation coefficient $\left(r_{s}\right)$ and significance value $(P)$ are shown in the figure.

\section{Determinants of postprandial RLP-C after a high-fat load}

Fasting RLP-C, $\mathrm{HOMA}_{\mathbb{R}}$, WHR (all $\left.P<0.001\right)$ and age $(P=0.023)$ were significantly associated with the plasma $R L P-C$ response to the high-fat meal (adj. $R^{2}=0.70$ ) (Table 6.4). Means of postprandial RLP-C according to $W H R$ and $H O M A_{I R}$ quartiles are illustrated in Figure 6.2. Furthermore, WHR was still associated with postprandial 
RLP-C after inclusion of TAG, HDL-C and FFA iAUC in model $2(P=0.002)$, whereas $\mathrm{HOMA}_{\mathrm{IR}}$ was not $(P=0.274)$. Plasma TAG iAUC was strongly related to postprandial $\operatorname{RLP}-C(\beta=0.278 ; P<0.001)$ (adj. $\left.R^{2}=0.76\right)$, which was also confirmed in a correlation analysis (Figure 6.3). Plasma concentrations of RLP-C at 3 and $6 \mathrm{~h}$ postprandially were strongly correlated $\left(r_{s}=0.779 ; P<0.001\right)$ in a subgroup of 113 participants (data not shown).

Table 6.4 Determinants of postprandial plasma RLP-C after a high-fat meal containing 95 E\% fat

\begin{tabular}{|c|c|c|c|c|}
\hline \multirow[t]{2}{*}{$n=712$} & \multicolumn{2}{|c|}{ Model 1} & \multicolumn{2}{|c|}{ Model 2} \\
\hline & $\beta$ & $P$-value & $\beta$ & $P$-value \\
\hline (Constant) & & $<0.001$ & & $<0.001$ \\
\hline Gender (male vs. female) & 0.041 & 0.156 & 0.029 & 0.269 \\
\hline $\mathrm{BMI}\left(\mathrm{kg} / \mathrm{m}^{2}\right)$ & 0.028 & 0.288 & 0.032 & 0.185 \\
\hline Age (y) & 0.052 & 0.023 & 0.036 & 0.079 \\
\hline $\mathrm{HOMA}_{\mathrm{IR}}$ & 0.104 & $<0.001$ & 0.026 & 0.274 \\
\hline Waist-hip ratio & 0.142 & $<0.001$ & 0.100 & 0.002 \\
\hline Dietary fat intake (E\%) & 0.025 & 0.307 & 0.009 & 0.685 \\
\hline Total physical activity (AU) & 0.040 & 0.067 & 0.018 & 0.358 \\
\hline Plasma RLP-C (fasting) (mmol/l) & 0.669 & $<0.001$ & 0.599 & $<0.001$ \\
\hline Plasma TAG (iAUC) $\left(\mathrm{mmol} \cdot I^{-1} \cdot 180 \mathrm{~min}^{-1}\right)$ & - & - & 0.278 & $<0.001$ \\
\hline Plasma FFA (iAUC) $\left(\mu \mathrm{mol} \cdot \mathrm{I}^{-1} \cdot 180 \mathrm{~min}^{-1}\right)$ & - & - & 0.045 & 0.022 \\
\hline Plasma HDL-C (iAUC) $\left(\left.\mathrm{mmol} \cdot\right|^{-1} \cdot 180 \mathrm{~min}^{-1}\right)$ & - & - & -0.031 & 0.109 \\
\hline
\end{tabular}

The dependent is $3 \mathrm{~h}$ plasma RLP-C in mmol/l. For statistical analyses, the dependent variable was $\mathrm{ln}$ transformed. Both models include the indicated variables in addition to centre and the $\mathrm{E} \%$ fat meal of measured basal metabolic rate. Model $1 \mathrm{Adj} . \mathrm{R}^{2}=0.70$, Model $2 \mathrm{Adj} . \mathrm{R}^{2}=0.76$.

\section{Determinants of change in fasting RLP-C after dietary intervention}

Both weight loss and improvement in insulin resistance were significantly related to a decrease in fasting RLP-C (adj. $\mathrm{R}^{2}=0.29$ ) after dietary intervention (Table 6.5). Furthermore, model 1 confirmed the observation we described above, i.e. that the high-fat diet was more beneficial than the low-fat diet in improving RLP-C concentrations in obese participants $(\beta=-0.075 ; P=0.030)$ and this diet effect was independent of the degree of weight loss and the change in insulin resistance. In model 2, however, these diet and $\mathrm{HOMA}_{\mathrm{IR}}$ effects disappeared and a decrease in fasting TAG concentrations was the strongest predictor of a decrease in fasting RLP$C$ concentrations (adj. $\left.R^{2}=0.51\right)$. 
Table 6.5 Determinants of changes in fasting plasma RLP-C after a 10-week hypoenergetic diet containing either $20-25$ or $40-45$ E\% fat

\begin{tabular}{lllll}
\hline$n=613$ & Model 1 & & Model 2 & \\
& $\beta$ & $P$-value & $\beta$ & $P$-value \\
\hline (Constant) & & 0.615 & & 0.520 \\
Gender (male vs. female) & -0.042 & 0.384 & 0.046 & 0.273 \\
Diet (high- vs. low-fat) & -0.075 & 0.030 & -0.006 & 0.841 \\
Age (y) & -0.053 & 0.157 & -0.004 & 0.905 \\
$\Delta$ Weight (kg) & 0.240 & $<0.001$ & 0.149 & $<0.001$ \\
$\Delta$ HOMA & 0.121 & 0.001 & 0.051 & 0.104 \\
$\Delta$ Waist-hip ratio & -0.007 & 0.847 & -0.012 & 0.683 \\
$\Delta$ plasma TAG (fasting) (mmol/l) & - & - & 0.534 & $<0.001$ \\
$\Delta$ plasma FFA (fasting) $(\mu \mathrm{mol} / \mathrm{l})$ & - & - & 0.054 & 0.078 \\
$\Delta$ plasma HDL-C (fasting) $(\mathrm{mmol} / \mathrm{l})$ & - & - & -0.018 & 0.598 \\
\hline
\end{tabular}

The dependent is the change in fasting plasma RLP-C in mmol/l. For statistical analyses, the dependent variable was In-transformed. Both models include the indicated variables in addition to centre and the mean values (10 wk $+0 \mathrm{wk}) / 2$ ) of each change variable. The change $(\Delta)$ of each variable was calculated as (10 wk - 0 wk). Model 1 Adj. $R^{2}=0.29$, Model 2 Adj. $R^{2}=0.51$.

\section{Discussion}

Elevated plasma concentrations of RLP-C are atherogenic and have been shown to be an independent risk factor for the development of cardiovascular disease (5). However, factors that are associated with plasma RLP-C concentrations are not fully understood. This study demonstrates that both fasting and postprandial plasma RLP-C are strongly related to $\mathrm{HOMA}_{\mathrm{IR}}$ and WHR, which is consistent with earlier indications from the literature $(7-11,24,25)$. When adding plasma TAG, FFA and HDL-C to the models, however, plasma TAG was the strongest predictor of both fasting and postprandial RLP-C, and in the fasting model, the associations with $\mathrm{HOMA}_{\mathrm{IR}}$ and WHR were no longer significant. It has been shown before in a study in obese children that fasting RLP-C was significantly associated with systolic blood pressure and $\mathrm{HOMA}_{\mathrm{R}}$, whereas only TAG was associated with RLP-C after inclusion of other lipids in the model (7). This may be due to the high correlation between plasma RLP-C and plasma TAG, which is not surprising, because a large part of plasma TAG is carried in TRL and RLP particles. It may well be that although RLP represents the more atherogenic fraction, measuring RLP-C is not necessary to assess this risk, because plasma TAG mirrors plasma RLP-C.

Men had significantly higher fasting RLP-C concentrations than women and RLP-C concentrations increased with age, which is consistent with previous findings $(14,26)$. In the postprandial response to the high-fat meal, however, the gender 
effects on plasma RLP-C were explained by the effect of body fat distribution; WHR was significantly associated with postprandial RLP-C, independent of gender, BMI, the degree of insulin resistance and postprandial circulating TAG concentrations, suggesting that body fat distribution is directly linked to RLP-C in the postprandial phase. Abdominal obesity plays an important role in postprandial TRL metabolism in both men and women $(13,27)$. Based on our results, the association between WHR and postprandial RLP-C seems to be stronger than the association with gender.

The postprandial response after the high-fat meal was measured over a $3 \mathrm{~h}$ period, which is a relatively short time for studying postprandial lipid profiles. Therefore, we analysed RLP-C concentrations $6 \mathrm{~h}$ postprandially in a subgroup of the total cohort and showed that RLP-C concentrations at $3 \mathrm{~h}$ were highly correlated with $6 \mathrm{~h}$ values. Although this indicates that our postprandial model reflects conditions after a $6 \mathrm{~h}$ postprandial period, it remains a limitation of this study that we could not measure RLP-C accumulation over the total postprandial period.

To detect disturbances in lipid metabolism, a pure high-fat load was administered as a metabolic stressor. We acknowledge that the very slight insulin response after this high-fat load may have induced slightly different postprandial lipid responses in this study compared with, e.g., a high-fat mixed meal. Despite this, we observed similar associations between plasma RLP-C and $\mathrm{HOMA}_{\mathbb{R}}, \mathrm{WHR}$ and plasma TAG concentrations to those shown previously $(10,11)$.

We observed a small positive association between habitual physical activity and fasting RLP-C, which is not consistent with earlier findings about the relationship between total physical activity and plasma lipoprotein concentrations $(12,28,29)$. The underlying mechanisms for this association remain to be elucidated.

Weight loss improved fasting RLP-C concentrations, even after correction for age, gender and changes in $\mathrm{HOMA}_{\mathrm{IR}}$ and WHR, showing that weight loss per se can be an appropriate tool to improve fasting and postprandial RLP concentrations (30). Furthermore, weight loss was comparable after both diets, indicating that it was not the macronutrient composition of the diet that influenced a reduction in body weight but the total energy intake, because both diets were designed to provide $2510 \mathrm{~kJ} / \mathrm{d}$ less than the individually estimated daily energy requirement (18). Therefore, it is interesting that despite a similar weight loss, a high-fat diet leads to a better improvement in both fasting RLP-C concentrations and fasting TAG concentrations than a low-fat diet in obese participants. This observation extends the results of Abbasi et al (16), showing that in healthy participants, both fasting and postprandial RLP-C concentrations are significantly lower after a high-fat diet than after a low-fat diet and may be explained by the higher carbohydrate content of the low-fat diet compared with the high-fat diet. It has been described previously for the total NUGENOB cohort that the beneficial effects of the dietary intervention on plasma TAG, LDL-C and total cholesterol were mainly the result of weight loss per se, with additional effects of diet composition (18). 
Furthermore, improvements in insulin resistance were also significantly related to a decrease in fasting RLP-C, independent of weight loss. Again, after inclusion of fasting TAG in the model, these effects disappeared and only weight loss and a decrease in fasting TAG were associated with decreased plasma RLP-C, emphasising the outcomes of the baseline fasting and postprandial models.

In summary, this multicentre study demonstrates that plasma RLP-C concentrations are related to body fat distribution (WHR) and the degree of insulin resistance $\left(\mathrm{HOMA}_{\mathrm{IR}}\right)$, both fasting and $3 \mathrm{~h}$ postprandial after a high-fat load. However, taking other plasma lipid concentrations into account, plasma TAG appeared to be a strong determinant of plasma RLP-C.

The present mode of dietary intervention shows that, independent of weight loss, a high-fat diet is more effective in lowering fasting plasma RLP-C concentrations in obesity than a low-fat diet.

\section{Acknowledgements}

NUGENOB is the acronym of the project 'Nutrient-Gene interactions in human obesity - implications for dietary guidelines' supported by the European Community (Contract no. QLK1-CT-2000-00618), see the web-site www.nugenob.org. 


\section{References}

1. Ginsberg HN. Insulin resistance and cardiovascular disease. J Clin Invest 2000;106(4):453-8.

2. Twickler TB, Dallinga-Thie GM, Cohn JS, Chapman MJ. Elevated remnant-like particle cholesterol concentration: a characteristic feature of the atherogenic lipoprotein phenotype. Circulation 2004;109(16):1918-25.

3. Zilversmit DB. Atherogenic nature of triglycerides, postprandial lipidemia, and triglyceride-rich remnant lipoproteins. Clin Chem 1995;41(1):153-8.

4. McNamara JR, Shah PK, Nakajima K, Cupples LA, Wilson PW, Ordovas JM, et al. Remnant-like particle (RLP) cholesterol is an independent cardiovascular disease risk factor in women: results from the Framingham Heart Study. Atherosclerosis 2001;154(1):229-36.

5. Karpe F, Boquist S, Tang R, Bond GM, de Faire U, Hamsten A. Remnant lipoproteins are related to intima-media thickness of the carotid artery independently of LDL cholesterol and plasma triglycerides. J Lipid Res 2001;42(1):17-21.

6. Nordestgaard BG, Benn M, Schnohr P, Tybjaerg-Hansen A. Nonfasting triglycerides and risk of myocardial infarction, ischemic heart disease, and death in men and women. JAMA 2007;298(3):299-308.

7. Choi YJ, Jo YE, Kim YK, Ahn SM, Jung SH, Kim HJ, et al. High plasma concentration of remnant lipoprotein cholesterol in obese children and adolescents. Diabetes Care 2006;29(10):2305-10.

8. Watanabe $\mathrm{N}$, Taniguchi $\mathrm{T}$, Taketoh $\mathrm{H}$, Kitagawa $\mathrm{Y}$, Namura $\mathrm{H}$, Yoneda N, et al. Elevated remnant-like lipoprotein particles in impaired glucose tolerance and type 2 diabetic patients. Diabetes Care 1999;22(1):152-6.

9. Ohnishi H, Saitoh S, Takagi S, Ohata J, Isobe T, Kikuchi Y, et al. Relationship between insulinresistance and remnant-like particle cholesterol. Atherosclerosis 2002;164(1):167-70.

10. Chan DC, Watts GF, Barrett PH, Mamo JC, Redgrave TG. Markers of triglyceride-rich lipoprotein remnant metabolism in visceral obesity. Clin Chem 2002;48(2):278-83.

11. Funada J, Sekiya M, Otani T, Watanabe K, Sato M, Akutsu H. The close relationship between postprandial remnant metabolism and insulin resistance. Atherosclerosis 2004;172(1):151-4.

12. Imke C, Rodriguez BL, Grove JS, McNamara JR, Waslien C, Katz AR, et al. Are remnant-like particles independent predictors of coronary heart disease incidence? The Honolulu Heart study. Arterioscler Thromb Vasc Biol 2005;25(8):1718-22.

13. Mekki N, Christofilis MA, Charbonnier M, Atlan-Gepner C, Defoort C, Juhel C, et al. Influence of obesity and body fat distribution on postprandial lipemia and triglyceride-rich lipoproteins in adult women. J Clin Endocrinol Metab 1999;84(1):184-91.

14. McNamara JR, Shah PK, Nakajima K, Cupples LA, Wilson PW, Ordovas JM, et al. Remnant lipoprotein cholesterol and triglyceride reference ranges from the Framingham Heart Study. Clin Chem 1998;44(6 Pt 1):1224-32.

15. Ai M, Tanaka A, Ogita K, Sekinc M, Numano F, Numano F, et al. Relationship between plasma insulin concentration and plasma remnant lipoprotein response to an oral fat load in patients with type 2 diabetes. J Am Coll Cardiol 2001;38(6):1628-32.

16. Abbasi F, McLaughlin T, Lamendola C, Kim HS, Tanaka A, Wang T, et al. High carbohydrate diets, triglyceride-rich lipoproteins, and coronary heart disease risk. Am J Cardiol 2000;85(1):45-8.

17. Astrup A, Grunwald GK, Melanson EL, Saris WH, Hill JO. The role of low-fat diets in body weight control: a meta-analysis of ad libitum dietary intervention studies. Int J Obes Relat Metab Disord 2000;24(12):1545-52.

18. Petersen M, Taylor MA, Saris WH, Verdich C, Toubro S, Macdonald I, et al. Randomized, multicenter trial of two hypo-energetic diets in obese subjects: high- versus low-fat content. Int J Obes (Lond) 2006;30(3):552-60.

19. Energy and protein requirements. Report of a joint FAO/WHO/UNU Expert Consultation. World Health Organ Tech Rep Ser 1985;724(1-206. 
20. Nakajima K, Saito T, Tamura A, Suzuki M, Nakano T, Adachi M, et al. Cholesterol in remnant-like lipoproteins in human serum using monoclonal anti apo B-100 and anti apo A-I immunoaffinity mixed gels. Clin Chim Acta 1993;223(1-2):53-71.

21. Matthews DR, Hosker JP, Rudenski AS, Naylor BA, Treacher DF, Turner RC. Homeostasis model assessment: insulin resistance and beta-cell function from fasting plasma glucose and insulin concentrations in man. Diabetologia 1985;28(7):412-9.

22. Philippaerts RM, Westerterp KR, Lefevre J. Doubly labelled water validation of three physical activity questionnaires. Int J Sports Med 1999;20(5):284-9.

23. Montoye HJ, Kemper HCG, Saris WHM, Washburn RA. Measuring physical activity and energy expenditure. Champaign, Illinois: Human Kinetics, 1996.

24. Satoh A, Adachi $H$, Tsuruta $M$, Hirai $Y$, Hiratsuka A, Enomoto $M$, et al. High plasma level of remnantlike particle cholesterol in the metabolic syndrome. Diabetes Care 2005;28(10):2514-8.

25. Abbasi F, McLaughlin T, Lamendola C, Yeni-Komshian H, Tanaka A, Wang $T$, et al. Fasting remnant lipoprotein cholesterol and triglyceride concentrations are elevated in nondiabetic, insulinresistant, female volunteers. J Clin Endocrinol Metab 1999;84(11):3903-6.

26. Schaefer EJ, McNamara JR, Shah PK, Nakajima K, Cupples LA, Ordovas JM, et al. Elevated remnantlike particle cholesterol and triglyceride levels in diabetic men and women in the Framingham Offspring Study. Diabetes Care 2002;25(6):989-94.

27. Couillard C, Bergeron N, Pascot A, Almeras N, Bergeron J, Tremblay A, et al. Evidence for impaired lipolysis in abdominally obese men: postprandial study of apolipoprotein B-48- and B-100containing lipoproteins. Am J Clin Nutr 2002;76(2):311-8.

28. Kraus WE, Houmard JA, Duscha BD, Knetzger KJ, Wharton MB, McCartney JS, et al. Effects of the amount and intensity of exercise on plasma lipoproteins. N Engl J Med 2002;347(19):1483-92.

29. O'Donovan G, Owen A, Kearney EM, Jones DW, Nevill AM, Woolf-May K, et al. Cardiovascular disease risk factors in habitual exercisers, lean sedentary men and abdominally obese sedentary men. Int J Obes (Lond) 2005;29(9):1063-9.

30. Dallongeville J, Gruson E, Dallinga-Thie G, Pigeyre M, Gomila S, Romon M. Effect of weight loss on the postprandial response to high-fat and high-carbohydrate meals in obese women. Eur J Clin Nutr 2007;61(6):711-8. 


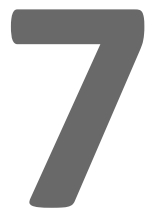

General discussion 
The metabolic syndrome (MetS) is a heterogeneous condition characterised by abdominal obesity, hyperglycaemia, insulin resistance, dyslipidaemia and hypertension. The number of people with the MetS worldwide is increasing rapidly together with the global epidemic of obesity $(1,2)$. Disturbances in fatty acid metabolism play an important role in the MetS, involving a complex interaction between adipose tissue, skeletal muscle and liver. In the obese insulin resistant state, both lipid overflow from the adipose tissue and increased endogenous production of lipoproteins by the liver can increase the supply of triacylglycerol (TAG) and free fatty acids (FFA) to skeletal muscle and subsequently increase the storage of excess lipids, thereby promoting the development of insulin resistance in skeletal muscle. In addition, intrinsic disturbances in skeletal muscle fatty acid metabolism may contribute to a dysbalance between fatty acid uptake and oxidation, thereby also promoting intramyocellular lipid accumulation. Dietary intervention, aimed at reducing the intake of saturated fat, may improve lipid metabolism and insulin sensitivity in the MetS, possibly through effects on lipid overflow from the adipose tissue and skeletal muscle fatty acid handling. This thesis describes research performed as part of the LIPGENE human dietary intervention study; a 12-week parallel, randomised, controlled, European multicentre study designed to investigate the effects of dietary fat modification on insulin sensitivity and various risk factors of the MetS. In a subcohort of men and women with the MetS in Maastricht we examined fatty acid metabolism in skeletal muscle and adipose tissue in detail, including the modulating effects of the amount and/or type of dietary fatty acids on adipose tissue and skeletal muscle fatty acid metabolism.

\section{FATTY ACID METABOLISM IN THE METABOLIC SYNDROME}

Several factors may contribute to increased circulating FFA and TAG concentrations in the obese insulin resistant state, thereby creating lipid overflow to non-adipose tissues such as skeletal muscle. In chapter 3 we firstly investigated the different dietary vs. endogenous fatty acids that can contribute to lipid overflow, including 1 ) the release of FFA into the circulation by adipose tissue, 2) incomplete uptake of fatty acids by adipose tissue after hydrolysis of very low-density lipoprotein (VLDL)TAG and/or chylomicron-TAG (fatty acid spillover), and 3) impaired TAG clearance (from VLDL or chylomicrons) from the circulation by adipose tissue. Secondly, the contribution of these different fat sources to skeletal muscle fatty acid uptake and storage was investigated. To study the metabolic fate of dietary vs. endogenous fatty acids, a dual stable isotope technique was applied. $\left[\mathrm{U}_{-}{ }^{13} \mathrm{C}\right]$-palmitate was added to a high-fat mixed meal to label chylomicron-TAG in the circulation and $\left[{ }^{2} \mathrm{H}_{2}\right]$-palmitate was infused intravenously to label the endogenous pool of fatty acids. As $\left[{ }^{2} \mathrm{H}_{2}\right]$-palmitate can be incorporated into TAG in the liver, $\left[{ }^{2} \mathrm{H}_{2}\right]$-labeled TAG 
could be used as a measure of VLDL-TAG in the circulation. Moreover, this stable isotope technique was combined with measurements of arteriovenous concentration differences across the forearm muscle to investigate skeletal muscle fatty acid handling and the specific contribution of chylomicron-TAG, VLDL-TAG and circulating FFA. In this section the possible sources of lipid overflow will be discussed in the light of results from chapter $\mathbf{3}$, followed by a discussion on the contribution of chylomicron-TAG vs. VLDL-TAG and circulating FFA to skeletal muscle lipid handling and intramyocellular lipid accumulation in the obese insulin resistant state.

\section{Fat sources contributing to lipid overflow in the obese insulin resistant state}

\section{Impaired regulation of circulating FFA concentrations?}

An increased fat mass and/or reduced insulin-mediated suppression of fatty acid release from the adipose tissue would theoretically result in lipid overflow and could be largely responsible for the increased plasma FFA concentrations that are often observed in obesity and insulin resistance (3-7). Contrary to this general paradigm, however, several studies show that plasma FFA concentrations are only slightly increased or not increased at all in obesity or insulin resistant conditions (810). Although some studies show that insulin-mediated suppression of fatty acid release from the adipose tissue is impaired in insulin resistant conditions (3-5), leading to increased circulating FFA concentrations, other studies show a downregulation of lipolysis and a reduction in FFA release per unit fat mass in insulin resistance and obesity $(8,9)$. An elegant study performed in over 100 non-diabetic men and women with varying levels of adiposity (body mass index (BMI) 18.1 to $44.3 \mathrm{~kg} / \mathrm{m}^{2}$ ) showed that the release of fatty acids by the adipose tissue is substantially down-regulated with increasing fat mass, although this was not enough to completely compensate for the mass action effect of increased adiposity on FFA release in obese vs. lean individuals or females vs. males (11). In chapter 3 we measured the rate of appearance of fatty acids $\left(R_{\mathrm{FFA}}\right)$ in the circulation during fasting and after consumption of a high-fat mixed meal by using the intravenously infused $\left[{ }^{2} \mathrm{H}_{2}\right]$-palmitate tracer. We observed no differences in fasting whole body $\mathrm{Ra}_{\mathrm{FFA}}$ and in the degree of suppression of whole body $\mathrm{Ra}_{\mathrm{FFA}}$ postprandially between insulin resistant men and controls with comparable body weight and waist circumference, which is consistent with previous studies in obese and/or insulin resistant subjects $(9,12-14)$. Our data suggest that there are no marked impairments in the postprandial regulation of adipose tissue lipolysis in the insulin resistant state that result in lipid overflow into the circulation.

Besides the regulation of FFA release from the adipose tissue, also the efficiency of fatty acid trapping by adipose tissue after extracellular lipolysis of circulating TAG by lipoprotein lipase (LPL) may contribute to increased systemic FFA concentrations. As 
such, fatty acid trapping has been shown to be reduced during hyperinsulinaemia in obese type 2 diabetes patients compared to non-obese healthy controls (15). Plasma chylomicron-TAG is most likely the largest contributor to this fatty acid spillover as postprandial trapping of VLDL-derived fatty acids across adipose tissue has shown to be more efficient than that of chylomicron-derived fatty acids in healthy subjects (16) and chylomicron-TAG is the preferred substrate for hydrolysis in the postprandial state (chapter 4). In chapter 3, however, we observed no differences between insulin resistant men and controls in postprandial concentrations of $\left[{ }^{13} \mathrm{C}\right]$-labeled palmitate in the circulation after consumption of a meal containing $\left[\mathrm{U}^{13} \mathrm{C}\right]$-palmitate, indicating that fatty acid spillover derived from the hydrolysis of chylomicron-TAG was not different. These findings are consistent with previous data comparing BMI-matched insulin resistant men and controls (9). Nevertheless, a recent study measured a lower chylomicron-TAG derived spillover of fatty acids in abdominally obese men compared to lean males, resulting in a lower contribution of this particular spillover fraction to total circulating FFA concentrations (10). Differences might be more apparent when comparing extremes of obesity rather than extremes of insulin resistance with comparable BMI and more research is needed to understand the dynamics of fatty acid spillover across adipose tissue.

Also postprandial $\left[{ }^{2} \mathrm{H}_{2}\right]$-labeled palmitate concentrations were comparable between insulin resistant men and controls in chapter $\mathbf{3}$, indicating no differences in fatty acid spillover from VLDL-TAG. It should be noted, however, that this measurement reflects not only fatty acids derived from VLDL-TAG hydrolysis but also from the circulating FFA pool, making it difficult to tease out the contribution of VLDL-TAG to the spillover fraction per se. Finally, circulating $\left[{ }^{2} \mathrm{H}_{2}\right]$ - and $\left[{ }^{13} \mathrm{C}\right]$-labeled palmitate levels may also derive from spillover across other tissues such as skeletal muscle, although fatty acid trapping across skeletal muscle is thought to be highly efficient (17). Indeed, efficiency of $\left[{ }^{13} \mathrm{C}\right]$-labeled palmitate extraction from chylomicron-TAG across the forearm muscle was approximately $100 \%$ in chapter $\mathbf{3}$, indicating that the $\left[{ }^{13} \mathrm{C}\right]$-labeled palmitate concentrations measured in plasma most likely reflect spillover across adipose tissue.

\section{Impaired regulation of circulating TAG concentrations?}

Systemic VLDL-TAG concentrations were consistently higher than chylomicron-TAG concentrations during the postprandial phase in all subjects (chapter 3 ), which is consistent with previous studies showing the largest contribution of VLDL-TAG to total circulating TAG concentrations despite insulin-mediated suppression of hepatic VLDL secretion $(9,18,19)$. Furthermore, there were no differences between insulin resistant men and controls with respect to circulating concentrations of both chylomicron-TAG and VLDL-TAG after ingestion of a high-fat mixed meal, suggesting that the clearance of chylomicron-TAG and VLDL-TAG across adipose tissue was 
similar. This was not anticipated since increased TAG concentrations in the obese insulin resistant state are often ascribed to impairments in adipose tissue TAG clearance from the circulation, possibly due to reduced stimulating effects of insulin on LPL-activity $(3,18,20,21)$ or decreased substrate delivery to LPL due to a blunted upregulation of adipose tissue blood flow $(6,22)$. Furthermore, increased VLDL-TAG concentrations have been reported in the insulin resistant state (14). The lack of difference in absolute circulating levels of chylomicron-TAG, VLDL-TAG and total TAG between insulin resistant men and controls in chapter $\mathbf{3}$ may partly be explained by the characteristics of our study population; subjects with the MetS were divided in two groups based on the median of insulin sensitivity. Although we achieved good differentiation with respect to insulin sensitivity (mean values of insulin sensitivity were in line with those reported in literature for type 2 diabetes subjects and healthy volunteers), there were no differences between groups in BMI, body fat and other risk factors of the MetS, indicating that we studied metabolic disturbances related to insulin sensitivity per se. Based on the results described in chapter 3 we hypothesise that other characteristics of the MetS, like obesity, may possibly play a larger role in determining circulating TAG concentrations than insulin resistance per se.

\section{Skeletal muscle fatty acid handling and the impact of lipid supply}

Regardless of the debate whether plasma FFA concentrations are increased in obesity and insulin resistant conditions or not, differences in the ability to take up fatty acids by skeletal muscle have been reported as well. Although postprandial suppression of fatty acid uptake from the circulating FFA pool has shown to be blunted in leg muscle of type 2 diabetic patients, mainly ascribed to increased plasma FFA concentrations (23), other studies show no effect of FFA supply per se on skeletal muscle fatty acid uptake during insulin-stimulated conditions in obese vs. lean individuals (24) or impaired vs. normal glucose tolerance (25). In line with the latter, no differences were observed in net and total FFA uptake (both total FFA and $\left[{ }^{2} \mathrm{H}_{2}\right]$ - and $\left[{ }^{13} \mathrm{C}\right]$-labeled palmitate) across skeletal muscle between the insulin resistant men and controls in the postprandial state (chapter 3 ), despite slightly higher total arterial FFA concentrations in the insulin resistant men. This argues against a role of enhanced fatty acid supply or increased muscle FFA uptake as a direct cause of ectopic fat accumulation. On the other hand, however, lipid infusion studies that are frequently used as a model for lipid-induced insulin resistance show that artificially elevated plasma FFA concentrations in healthy individuals indeed induce skeletal muscle insulin resistance $(26,27)$, also in a dose-dependent manner (28). These studies provide relevant insights in the biological mechanisms of fatty acid induced insulin resistance, but one should allow for the possibility that plasma 
FFA concentrations are not markedly elevated in all obese and/or insulin resistant individuals.

Despite the comparable supply of TAG to skeletal muscle (see 'Impaired regulation of circulating TAG concentrations?'), we observed a higher net extraction of VLDLTAG across muscle in the insulin resistant men compared to control during the first two hours after meal consumption (chapter 3 ). This finding may possibly extend to chylomicron-TAG as also the uptake of these particles tended to increase more in the insulin resistant men at the end of the 4 hour postprandial period. It should be noted that the contribution of chylomicron-TAG and VLDL-TAG to postprandial TAG metabolism is difficult to study due to rapid recycling of dietary fatty acids into VLDL particles. That means that chylomicron-TAG labeled with $\left[\mathrm{U}-{ }^{13} \mathrm{C}\right]$-palmitate can be cleared by the liver and the $\left[\mathrm{U}-{ }^{13} \mathrm{C}\right]$-palmitate can be incorporated in VLDL-TAG and released in the circulation within 2-3 hours after a meal $(19,29)$. Although the majority of measured dietary fatty acids in the circulation represents chylomicronTAG in the first 3 postprandial hours, approximately $20 \%$ of dietary fatty acids, and thus $\left[\mathrm{U}-{ }^{13} \mathrm{C}\right]$-palmitate, is incorporated in VLDL-TAG after 6 hours (29-31). Nevertheless, the fact that we found an increased extraction of VLDL-TAG in the early postprandial phase implies increased postprandial efficiency of (VLDL)-TAG removal across skeletal muscle in the insulin resistant state. This apparent importance of TAG metabolism in insulin resistance is in line with results from a previous study investigating fatty acid metabolism using the same dual stable isotope methodology, in which the insulin resistant state was closely related to increased TAG rather than increased FFA concentrations, most likely due to increased TAG synthesis in the liver (9).

Activity and expression of lipoprotein lipase (LPL) could be important determinants of muscle TAG extraction and insulin resistance as studies in mice show that specific overexpression of LPL in skeletal muscle induces insulin resistance in this particular tissue, but not in other tissues such as the liver (32), whereas skeletal muscle LPL knockout mice show the opposite effects (33). Moreover, insulin has been shown to inhibit skeletal muscle LPL activity, contrary to its stimulating effects on adipose tissue LPL activity (34). Therefore, it can be hypothesised that insulin-mediated inhibition of skeletal muscle LPL is impaired when the insulin resistant state is already present, resulting in decreased suppression of TAG extraction and possibly enhanced intramyocellular lipid accumulation. In chapter $\mathbf{3}$, fasting and postprandial skeletal muscle LPL mRNA expression were not different between groups, but a role of LPL cannot be excluded since it has been shown that LPL activity is mainly regulated at posttranscriptional and posttranslational levels (35-37). 


\section{Intramyocellular lipid partitioning}

Metabolic flexibility is an important characteristic of the skeletal muscle, as the dynamic process of adjusting lipid oxidation to fatty acid uptake and intramyocellular TAG (IMTG) turnover may prevent the development of insulin resistance via reduced accumulation of lipid metabolites $(38,39)$. Indeed, the capacity to increase intramyocellular fat oxidation during conditions of increased fatty acid supply such as fasting and exercise has shown to be impaired in (visceral) obesity and type 2 diabetes (24,40-42), whereas postprandial suppression of muscle fat oxidation has shown to be impaired in type 2 diabetes and obesity $(23,24,43)$. This may promote increased partitioning of fatty acids towards storage and intramyocellular lipid accumulation (44). Although accumulation of IMTG has been associated with skeletal muscle insulin resistance in human (45-47), it is now evident that bioactive lipid metabolites such as diacylglycerol (DAG), long-chain fatty acyl-CoA and ceramide are most likely responsible for fatty acid induced insulin resistance (48). Therefore, we studied intramyocellular lipid content in the muscle biopsies that were taken from insulin resistant men and controls in chapter 3 . There were no differences in intramyocellular DAG, FFA and phospholipid content between insulin resistant men and controls during fasting, whereas the muscle TAG content (IMTG) tended to be increased in the insulin resistant state (chapter $\mathbf{3}$ ). Notably, saturation of muscle DAG was found to be increased in the insulin resistant state, which could be largely explained by an increased percentage of palmitic acid and a decreased percentage of oleic acid. These findings are consistent with a study showing comparable muscle DAG content but increased degree of saturation in diabetic vs. non-diabetic obese individuals (49). Also, these data extend results from studies in human muscle cell lines and rodents showing that long-chain saturated fatty acids accumulate preferentially as DAG and are associated with insulin resistance, whereas unsaturated fatty acids are more readily converted into TAG (50-52). Other studies, on the other hand, show no differences with respect to total DAG content as well as degree of saturation in obese vs. lean (53) or insulin resistant vs. insulin sensitive obese individuals (54) or observed increased DAG content in obese and obese type 2 diabetic individuals (55). Different DAG species and degree of saturation, cellular localisation of DAG and muscle fibre type may determine the effect of intramyocellular DAG on insulin sensitivity and should be considered in future studies.

Increased IMTG synthesis via upregulation of lipogenic enzymes has been linked to protection against fatty acid induced insulin resistance in rodents and human $(56,57)$. There were no differences in TAG fractional synthetic rate (rate of incorporation of $\left[\mathrm{U}^{13} \mathrm{C}\right]$-labeled palmitate from the intramyocellular FFA pool) between the insulin resistant men and controls, nor in the fractional synthetic rate of muscle DAG and phospholipids (chapter 3), being in line with previous findings (58). Also, analyses of mRNA normalised expression levels of several key genes 
important in skeletal muscle fatty acid uptake, mitochondrial fatty acid transport, oxidation and synthesis showed no significant differences between insulin resistant men and controls. Although one should keep in mind that mRNA expression levels are not fully representative of protein expression levels and activity, these data imply that intramyocellular lipid partitioning was comparable between insulin resistant men and controls in our study.

\section{Conclusions}

The results described in chapter 3 suggest that both direct fatty acid release from the adipose tissue as well as postprandial fatty acid spillover of dietary and endogenous fatty acids may not substantially contribute to increased postprandial lipid overflow in the obese insulin resistant state, which is reinforced by observations that circulating FFA concentrations are not consistently increased in individuals with obesity an/or insulin resistance. Moreover, we observed no marked differences in lipid overflow from either endogenous (VLDL)- or dietary (chylomicron)-TAG in insulin resistant men compared to controls. Therefore, the present findings challenge the theory of enhanced lipid supply, and thus lipid overflow, as a direct cause of ectopic fat accumulation and skeletal muscle insulin resistance in the obese insulin resistant state. Despite the similar supply of TAG in insulin resistant men and controls, we demonstrated that insulin resistance is associated with increased postprandial TAG extraction across the forearm muscle, without differences in intramyocellular lipid partitioning. These differences in TAG extraction, although small, may on the longer term give rise to increased muscle lipid storage which is a strong marker of skeletal muscle insulin resistance.

\section{DIETARY FAT MODIFICATION IN THE METABOLIC SYNDROME}

The ideal diet for individuals with the MetS should be one with a favourable effect on each of the different components of the condition (59). Caloric restriction and increased physical activity promote weight loss and subsequent improvements in all abnormalities clustering in the MetS, including insulin sensitivity (60). In addition, dietary fat quality can affect insulin sensitivity, independent of effects on weight reduction $(60,61)$. Despite the fact that there is increasing evidence for a causal relationship between dietary fat and obesity, type 2 diabetes and the MetS, the optimal amount and type of dietary fat has not been fully elucidated (62). There is a general consensus that the saturated fat content of the diet has to be reduced in the prevention of type 2 diabetes and the MetS, but the key question remains whether saturated fat should be replaced by carbohydrates or unsaturated fat. The LIPGENE human dietary intervention study was designed to investigate the effects 
of reducing dietary saturated fat by isoenergetic alteration of fat quantity and quality on insulin sensitivity and various risk factors of the MetS. Men and women with the MetS were randomised to four isoenergetic dietary treatments for 12 weeks: a control high-fat diet rich in saturated fat (HSFA), a high-fat diet rich in monounsaturated fat (HMUFA) and two low-fat high-complex carbohydrate diets (LFHCC), one supplemented with $1.24 \mathrm{~g} / \mathrm{d}$ long-chain $n-3$ polyunsaturated fatty acids (LFHCCn-3).

\section{Dietary intervention and insulin sensitivity}

There were no marked effects of dietary fat modification on insulin sensitivity $\left(S_{1}\right.$, derived from the intravenous glucose tolerance test) or other risk factors of the MetS such as fasting glucose and insulin concentrations, (LDL)-cholesterol concentrations, waist circumference, blood pressure and inflammation in the MetS subjects that participated in the LIPGENE study $(63,64)$. This is in line with recent findings from the RISCK trial showing no favourable effects of 24-week isoenergetic replacement of SFA with MUFA or carbohydrates on $S_{1}$ in subjects at risk for the MetS (65). The LIPGENE intervention, however, did significantly affect markers of lipid metabolism and body weight. Plasma TAG and FFA were reduced on the LFHCCn-3 diet, in particular in men, whereas plasma HDL-cholesterol was increased on the HSFA and HMUFA diets. Also, despite the isoenergetic design of the study, body weight was slightly decreased on both LFHCC diets (<1\%) (63).

Individuals' habitual diet may be an important determinant of the effectiveness of dietary intervention, as has previously been demonstrated in the KANWU study (66). In that study in healthy subjects, beneficial effects of a MUFA- vs. SFA-enriched diet on insulin sensitivity were only observed in subjects with a habitual low dietary fat intake (<37 energy\%). As subjects from the LIPGENE study were selected from different European countries with a broad range in habitual dietary fat intake (67), post hoc analyses were performed to investigate these putative effects of habitual fat intake on the outcome of our study as well. This was done by including habitual fat intake as a possible determinant in the multiple regression models that were used in chapter 2 to evaluate which factors contribute to changes in $S_{\text {I }}$ and $H O M A_{I R}$ during dietary intervention among subjects with the MetS. In this multiple regression analysis, we showed that insulin sensitivity significantly improved (HOMA $_{I R}$ reduced) in women on the HMUFA diet, but only at a habitual fat intake below the median (<36 energy\% of total energy). This may be explained by the greater increment in MUFA intake in the female habitual low-fat vs. high-fat consumers (10.9 to 18.8 energy\% vs. 17.4 to 19.7 energy\%). As such, our current findings argue in favour of changing dietary fat quality rather than reducing fat quantity in the treatment of insulin resistance in the MetS, although the effect to be expected may be subgroup specific and dependent on habitual fat intake. 
Furthermore, the role of background diet is most likely not limited to dietary fat quantity alone. Considering the heterogeneity of habitual dietary fat intake in the European LIPGENE population, the quality of fat in the habitual diet as well as the choice of a HSFA diet as a control diet may have interfered with our observed intervention effects. This can be partly prevented in future studies by adding a runin period to the study protocol during which baseline diet composition can be standardised across individuals. Furthermore, the exploratory nature of these observations shows that potential effects on $\mathrm{HOMA}_{\mathbb{R}}$ as a marker of insulin resistance need to be highlighted and further investigated.

\section{Effects of dietary fat modification on lipid overflow and skeletal muscle lipid handling}

Reducing the intake of saturated fat may improve insulin action in the MetS, possibly through effects on lipid overflow from the adipose tissue and effects on skeletal muscle fatty acid handling. Therefore, we investigated the effects of the 12week LIPGENE dietary intervention (see 'Dietary fat modification in the metabolic syndrome') on fasting and postprandial skeletal muscle fatty acid metabolism in a subcohort of men with the MetS (chapter 4). By means of the dual stable isotope tracer technique in combination with arteriovenous measurements across the forearm muscle during fasting and after a high-fat mixed meal (see 'Fatty acid metabolism in the metabolic syndrome') we were able to study the effect of dietary fat modification on the contribution of dietary vs. endogenous fatty acids to lipid overflow and skeletal muscle fatty acid handling in vivo. Additional adipose tissue samples were obtained in a subgroup of men and women to assess the effects of the LIPGENE dietary intervention on lipolytic enzyme expression in subcutaneous adipose tissue as a possible contributor to lipid overflow (chapter 5).

\section{Circulating TAG}

In chapter 4 we showed that the LFHCCn-3 diet reduced the postprandial TAG response to a high-fat mixed meal compared to an isoenergetic HSFA diet, suggesting that LC $n-3$ PUFA supplementation reduces lipid overflow in the MetS. Interestingly, these improvements were largely achieved by decreased chylomicronTAG concentrations in the circulation, whereas VLDL-TAG concentrations were not different. The effect of LC $n$-3 PUFA on circulating chylomicron-TAG concentrations may be explained by several factors such as attenuated or decelerated output by the intestine and/or improvements in chylomicron-TAG clearance across adipose tissue. The latter would be in line with previous studies showing that dietary supplementation with LC $n$-3 PUFA increases LPL activity in healthy individuals and hypertriacylglycerolaemic patients, both after a standardised meal and after a meal resembling the diet that was followed (68-70), and with the observation that 
chylomicron-TAG is the preferred substrate for LPL in the postprandial state (chapter 4).

\section{Adipose tissue lipolysis and circulating FFA concentrations}

Impairments in the regulation of adipose tissue lipolysis can largely contribute to circulating FFA concentrations and lipid overflow into the circulation, and therefore we examined the impact of dietary intervention on the expression of the two major lipolytic enzymes, adipose triglyceride lipase (ATGL) and hormone-sensitive lipase (HSL), in subcutaneous adipose tissue during fasting (chapter 5). Both ATGL and HSL protein expression levels decreased on the LFHCC diets and increased on the highfat diets, without additional effects of dietary fat quality (SFA, MUFA, LC $n-3$ PUFA) on these expression levels, suggesting that dietary fat quantity is more important in regulating ATGL and HSL protein expression under isoenergetic conditions. Because changes in ATGL and HSL protein expression were positively associated with changes in $\mathrm{Ra}_{\mathrm{FFA}}$ in a subgroup of men (chapter $\mathbf{5}$ ), the reduction in lipolytic enzyme expression could be interpreted as a beneficial effect of the LFHCC diets on lipid overflow by reducing $\mathrm{Ra}_{\mathrm{FFA}}$. As such, this would add to the observation of decreased circulating dietary TAG concentrations on the LFHCCn-3 diet that were most likely explained by increased clearance of TAG across the adipose tissue (chapter 4). However, this is merely speculative since we observed no significant decrease in fasting $\mathrm{Ra}_{\mathrm{FFA}}$ on the LFHCC diets (chapter 4) and the actual activity of the lipolytic enzymes highly depends on posttranscriptional and posttranslational modification. The latter was also reflected by the lack of a direct association between mRNA and protein expression levels of ATGL and HSL in chapter $\mathbf{5}$, which has been reported before as well $(71,72)$.

\section{Skeletal muscle lipid handling}

No effects of dietary intervention were observed on postprandial TAG and FFA uptake across the forearm muscle, despite the decrease in postprandial circulating TAG concentrations on the LFHCCn-3 diet as well as the slightly decreased postprandial circulating FFA concentrations on the HMUFA and LFHCC diets (chapter 4). In line with the results from chapter 3, these data imply that minor changes in lipid overflow, if any, do not affect the postprandial uptake of endogenous and dietary fatty acids by forearm muscle in the MetS. In chapter 4, however, we observed a decreased clearance (fractional extraction multiplied by forearm blood flow) of TAG across skeletal muscle during fasting after the HSFA diet $v s$. the LFHCC diets. This seems inconsistent with results from a recent crossover study in healthy individuals, showing that both fasting and postprandial TAG clearance as well as fat oxidation after a mixed meal were increased after a 3-day high-fat diet compared to an isocaloric 3-day high-carbohydrate diet (73). This apparent discrepancy may be partly explained by the duration of the dietary 
interventions ( 3 days vs. 12 weeks). Short-term high-fat diets in rodents and human have been linked to increased IMTG concentrations and skeletal muscle insulin resistance $(47,74-76)$, probably due to increased lipid uptake upon availability (75). It could be speculated that these short-term effects may have occurred in the men on the HSFA diet in our study as well, which eventually lowered the efficiency of fatty acid uptake after 12 weeks, possibly due to a decreased fatty acid gradient across the muscle membrane (39).

\section{Conclusions}

Overall, we showed that the isoenergetic modulation of dietary fat quantity and quality in the LIPGENE study was insufficient to affect whole body insulin sensitivity and skeletal muscle fatty acid handling in men with the MetS. On the other hand we showed that addition of a relatively low dose of LC $n-3$ PUFA ( $1.24 \mathrm{~g} /$ day) to a lowfat high-complex carbohydrate diet improves postprandial (chylomicron)-TAG metabolism and that ATGL and HSL protein expression in subcutaneous adipose tissue decrease on the low-fat high-complex carbohydrate diets. Based on these findings we speculate that a low-fat high-complex carbohydrate diet, supplemented with LC $n$-3 PUFA, can reduce lipid outflow from the adipose tissue and thereby improve skeletal muscle insulin sensitivity on the longer term. However, further studies are needed to confirm this hypothesis.

\section{The role of TAG-rich particles and their remnants in obesity}

Obesity, insulin resistance, hypertension and disturbances in postprandial lipid metabolism are strongly linked to an atherogenic lipoprotein phenotype (77) and these factors are all described in the MetS. Increased concentrations of lipoprotein remnants, and in particular their cholesterol content, are considered to be highly atherogenic and may underlie the increased risk for cardiovascular disease in the MetS. Remnant-like particles (RLP) derive from TAG-rich lipoproteins (VLDL and chylomicrons) after partial depletion of TAG by LPL and are normally cleared from the circulation by the liver. Studies show that circulating levels of RLP are increased in visceral obesity, insulin resistance and type 2 diabetes (78-80), being largely explained by impaired hepatic clearance of these particles $(80,81)$. Due to hydrolysis of TAG, RLP are relatively rich in cholesterol and some suggest that plasma RLPcholesterol, rather than plasma TAG, is an independent risk factor for the development of cardiovascular disease. The study described in chapter 6 was part of the larger NUGENOB study investigating the effects of a hypoenergetic low-fat $v$ s. a hypoenergetic high-fat diet (20-25 energy\% vs. $40-45$ energy\% fat) on body weight, body composition and the metabolic profile in obesity. Within the NUGENOB study we investigated the factors determining plasma RLP-C 
concentrations during fasting, after a high-fat load and after the dietary intervention. We showed that, in obese individuals, plasma RLP-cholesterol concentrations are related to body fat distribution (waist-hip ratio) and insulin resistance $\left(\mathrm{HOMA}_{\mathrm{I}}\right)$, and that reductions in fasting RLP-cholesterol concentrations after weight loss are associated with improvements in insulin resistance (chapter 6 ). These findings are indicative of an important role for insulin resistance in RLPcholesterol metabolism.

Interestingly, a hypocaloric high-fat diet was found to be more effective in reducing plasma RLP-cholesterol concentrations than an hypocaloric low-fat diet, despite similar effects on body weight (chapter 6 ), thereby extending observations from a weight-stable dietary intervention study in healthy subjects showing detrimental effects of a low-fat vs. high-fat diet on RLP-cholesterol concentrations (82).

\section{CONCLUDING REMARKS AND FUTURE RESEARCH}

The studies described in this thesis provide better insight in the complex regulation of skeletal muscle fatty acid metabolism in the metabolic syndrome and the modulating effects of dietary intervention. The main outcomes of this thesis as well as concluding remarks and suggestions for future research are summarised in this section.

1. postprandial forearm muscle (hepatically-derived) TAG extraction is increased in the insulin resistant state (chapter 3 ). Although the differences in skeletal muscle TAG extraction between groups were small and all individuals were selected from a population with the MetS, in the longer term this may be one of the mechanisms contributing to intramyocellular lipid accumulation and the development of type 2 diabetes.

2. the direct role of lipid overflow in the development of skeletal muscle insulin resistance is challenged by the observations that a) TAG extraction across forearm muscle is increased despite comparable circulating plasma TAG concentrations, and b) forearm FFA uptake is not different between insulin resistant men and controls despite slightly increased circulating plasma FFA concentrations in insulin resistant men (chapter 3 ). As we studied metabolic disturbances related to insulin resistance per se, independent of obesity and other characteristics of the MetS, we cannot exclude that lipid overflow is not present and/or important in other metabolic conditions. Future research should be performed to test the lipid overflow theory in obesity and/or insulin resistance $v s$. a healthy control population.

3. intramyocellular TAG, DAG, FFA and phospholipid content, as well as their fractional synthetic rates, are not different between insulin resistant men and controls, whereas saturation of intramyocellular DAG is increased in the insulin 
resistant state (chapter 3 ). This indicates that the composition of intramyocellular lipid fractions is more important than their absolute content in insulin resistance. It would be interesting to address the effects of fractional synthetic rate, absolute lipid content, fatty acid composition, stereospecificity and cellular localisation of the different intramyocellular lipid fractions on skeletal muscle insulin sensitivity.

4. isoenergetic variation in dietary fat quantity and quality has no marked effects on forearm muscle fatty acid metabolism, except for a decrease in fasting TAG clearance across forearm muscle after a 12-week HSFA diet (chapter 4), indicating that men may be well capable of adapting to longer-term isoenergetic changes in the diet. A chronic positive energy balance, mainly due to excessive fat consumption, would probably exert larger effects on skeletal muscle lipid handling.

5. whole body TAG metabolism plays a central role in obesity, insulin resistance and the MetS as shown by results from the stable isotope studies (chapter $\mathbf{3}$ and 4) and the multiple regression analyses (chapter 2 and 6).

6. postprandial circulating TAG concentrations after a high-fat mixed meal are decreased in men with the MetS after 12-week consumption of a LFHCCn-3 diet, which can be (partly) explained by a decrease in dietary TAG in the circulation (chapter 4). This indicates that LC $n$-3 PUFA, when supplemented to a low-fat diet (28 energy\% fat), mainly exert their TAG-lowering effects through enhanced clearance of chylomicron-TAG from the circulation and/or attenuated or decelerated intestinal chylomicron-TAG output. It would be interesting to study the impact of dietary intervention on intestinal lipid metabolism in relation to postprandial fatty acid metabolism. Moreover, as people in general consume more than 28 energy\% fat in their habitual diet, the effects of LC $n-3$ PUFA supplementation to a moderate- or high-fat diet should be studied as well.

7. ATGL and HSL protein expression levels in subcutaneous adipose tissue of men and women with the MetS are decreased after consumption of a low-fat highcomplex carbohydrate diet (chapter 5), suggesting that dietary fat quantity may be more important than dietary fat quality in modulating adipose tissue ATGL and HSL protein expression.

8. under hypocaloric conditions, a high-fat diet is more beneficial than a low-fat diet in reducing plasma RLP-cholesterol and TAG concentrations in obesity (chapter 6), whereas under isocaloric conditions a LFHCCn-3 diet appears to be most beneficial for individuals with the MetS (chapter 2 and 4).

9. the effects of dietary fat modification on fatty acid metabolism and insulin sensitivity are not unambiguous and depend on several factors such as gender, habitual fat intake and effects on body weight (chapter 2, 4 and 6). We suggest that dietary advice should be tailored to specific subgroups or at an individual level to achieve desirable effects. 


\section{References}

1. Eckel RH, Grundy SM, Zimmet PZ. The metabolic syndrome. Lancet 2005;365(9468):1415-28.

2. Zimmet P, Alberti KG, Shaw J. Global and societal implications of the diabetes epidemic. Nature 2001;414(6865):782-7.

3. Coppack SW, Evans RD, Fisher RM, Frayn KN, Gibbons GF, Humphreys SM, et al. Adipose tissue metabolism in obesity: lipase action in vivo before and after a mixed meal. Metabolism 1992;41(3):264-72.

4. Laws A, Hoen HM, Selby JV, Saad MF, Haffner SM, Howard BV. Differences in insulin suppression of free fatty acid levels by gender and glucose tolerance status. Relation to plasma triglyceride and apolipoprotein B concentrations. Insulin Resistance Atherosclerosis Study (IRAS) Investigators. Arterioscler Thromb Vasc Biol 1997;17(1):64-71.

5. Groop LC, Bonadonna RC, DelPrato S, Ratheiser K, Zyck K, Ferrannini E, et al. Glucose and free fatty acid metabolism in non-insulin-dependent diabetes mellitus. Evidence for multiple sites of insulin resistance. J Clin Invest 1989;84(1):205-13.

6. Mitrou P, Boutati E, Lambadiari V, Maratou E, Komesidou V, Papakonstantinou A, et al. Rates of lipid fluxes in adipose tissue in vivo after a mixed meal in morbid obesity. Int J Obes (Lond) 2010;34(4):770-4.

7. Boden G. Obesity and free fatty acids. Endocrinol Metab Clin North Am 2008;37(3):635-46, viii-ix.

8. Jocken JW, Goossens GH, van Hees AM, Frayn KN, van Baak M, Stegen J, et al. Effect of betaadrenergic stimulation on whole-body and abdominal subcutaneous adipose tissue lipolysis in lean and obese men. Diabetologia 2008;51(2):320-7.

9. Bickerton AS, Roberts R, Fielding BA, Tornqvist $H$, Blaak EE, Wagenmakers AJ, et al. Adipose tissue fatty acid metabolism in insulin-resistant men. Diabetologia 2008;51(8):1466-74.

10. McQuaid SE, Hodson L, Neville MJ, Dennis AL, Cheeseman J, Humphreys SM, et al. Downregulation of adipose tissue Fatty Acid trafficking in obesity: a driver for ectopic fat deposition? Diabetes 2011;60(1):47-55.

11. Mittendorfer B, Magkos F, Fabbrini E, Mohammed BS, Klein S. Relationship between body fat mass and free fatty acid kinetics in men and women. Obesity (Silver Spring) 2009;17(10):1872-7.

12. Mittendorfer B, Fields DA, Klein S. Excess body fat in men decreases plasma fatty acid availability and oxidation during endurance exercise. Am J Physiol Endocrinol Metab 2004;286(3):E354-62.

13. Hickner RC, Racette SB, Binder EF, Fisher JS, Kohrt WM. Suppression of whole body and regional lipolysis by insulin: effects of obesity and exercise. J Clin Endocrinol Metab 1999;84(11):3886-95.

14. Hodson L, Bickerton AS, McQuaid SE, Roberts R, Karpe F, Frayn KN, et al. The contribution of splanchnic fat to VLDL triglyceride is greater in insulin-resistant than insulin-sensitive men and women: studies in the postprandial state. Diabetes 2007;56(10):2433-41.

15. Riemens SC, Sluiter WJ, Dullaart RP. Enhanced escape of non-esterified fatty acids from tissue uptake: its role in impaired insulin-induced lowering of total rate of appearance in obesity and Type Il diabetes mellitus. Diabetologia 2000;43(4):416-26.

16. Ruge T, Hodson L, Cheeseman J, Dennis AL, Fielding BA, Humphreys SM, et al. Fasted to fed trafficking of Fatty acids in human adipose tissue reveals a novel regulatory step for enhanced fat storage. J Clin Endocrinol Metab 2009;94(5):1781-8.

17. Evans K, Burdge GC, Wootton SA, Clark ML, Frayn KN. Regulation of dietary fatty acid entrapment in subcutaneous adipose tissue and skeletal muscle. Diabetes 2002;51(9):2684-90.

18. Potts JL, Coppack SW, Fisher RM, Humphreys SM, Gibbons GF, Frayn KN. Impaired postprandial clearance of triacylglycerol-rich lipoproteins in adipose tissue in obese subjects. Am J Physiol 1995;268(4 Pt 1):E588-94.

19. Bickerton AS, Roberts R, Fielding BA, Hodson L, Blaak EE, Wagenmakers AJ, et al. Preferential uptake of dietary fatty acids in adipose tissue and muscle in the postprandial period. Diabetes 2007;56(1):168-76. 
20. Panarotto D, Remillard P, Bouffard L, Maheux P. Insulin resistance affects the regulation of lipoprotein lipase in the postprandial period and in an adipose tissue-specific manner. Eur J Clin Invest 2002;32(2):84-92.

21. Annuzzi G, Giacco R, Patti L, Di Marino L, De Natale C, Costabile G, et al. Postprandial chylomicrons and adipose tissue lipoprotein lipase are altered in type 2 diabetes independently of obesity and whole-body insulin resistance. Nutr Metab Cardiovasc Dis 2008;18(8):531-8.

22. Goossens $\mathrm{GH}$. The role of adipose tissue dysfunction in the pathogenesis of obesity-related insulin resistance. Physiol Behav 2008;94(2):206-18.

23. Kelley DE, Simoneau JA. Impaired free fatty acid utilization by skeletal muscle in non-insulindependent diabetes mellitus. J Clin Invest 1994;94(6):2349-56.

24. Kelley DE, Goodpaster B, Wing RR, Simoneau JA. Skeletal muscle fatty acid metabolism in association with insulin resistance, obesity, and weight loss. Am J Physiol 1999;277(6 Pt 1):E113041.

25. Corpeleijn E, Mensink M, Kooi ME, Roekaerts PM, Saris WH, Blaak EE. Impaired skeletal muscle substrate oxidation in glucose-intolerant men improves after weight loss. Obesity (Silver Spring) 2008;16(5):1025-32.

26. Boden G, Lebed B, Schatz M, Homko C, Lemieux S. Effects of acute changes of plasma free fatty acids on intramyocellular fat content and insulin resistance in healthy subjects. Diabetes 2001;50(7):1612-7.

27. Bachmann OP, Dahl DB, Brechtel K, Machann J, Haap M, Maier T, et al. Effects of intravenous and dietary lipid challenge on intramyocellular lipid content and the relation with insulin sensitivity in humans. Diabetes 2001;50(11):2579-84.

28. Belfort R, Mandarino L, Kashyap S, Wirfel K, Pratipanawatr T, Berria R, et al. Dose-response effect of elevated plasma free fatty acid on insulin signaling. Diabetes 2005;54(6):1640-8.

29. Heath RB, Karpe F, Milne RW, Burdge GC, Wootton SA, Frayn KN. Selective partitioning of dietary fatty acids into the VLDL TG pool in the early postprandial period. J Lipid Res 2003;44(11):2065-72.

30. Barrows BR, Parks EJ. Contributions of different fatty acid sources to very low-density lipoproteintriacylglycerol in the fasted and fed states. J Clin Endocrinol Metab 2006;91(4):1446-52.

31. Cohn JS, Johnson EJ, Millar JS, Cohn SD, Milne RW, Marcel YL, et al. Contribution of apoB-48 and apoB-100 triglyceride-rich lipoproteins (TRL) to postprandial increases in the plasma concentration of TRL triglycerides and retinyl esters. J Lipid Res 1993;34(12):2033-40.

32. Kim JK, Fillmore JJ, Chen Y, Yu C, Moore IK, Pypaert M, et al. Tissue-specific overexpression of lipoprotein lipase causes tissue-specific insulin resistance. Proc Natl Acad Sci U S A 2001;98(13):7522-7.

33. Wang H, Knaub LA, Jensen DR, Young Jung D, Hong EG, Ko HJ, et al. Skeletal muscle-specific deletion of lipoprotein lipase enhances insulin signaling in skeletal muscle but causes insulin resistance in liver and other tissues. Diabetes 2009;58(1):116-24.

34. Lithell H, Boberg J, Hellsing K, Lundqvist G, Vessby B. Lipoprotein-lipase activity in human skeletal muscle and adipose tissue in the fasting and the fed states. Atherosclerosis 1978;30(1):89-94.

35. Semenkovich CF, Wims M, Noe L, Etienne J, Chan L. Insulin regulation of lipoprotein lipase activity in 3T3-L1 adipocytes is mediated at posttranscriptional and posttranslational levels. J Biol Chem 1989;264(15):9030-8.

36. Doolittle MH, Ben-Zeev O, Elovson J, Martin D, Kirchgessner TG. The response of lipoprotein lipase to feeding and fasting. Evidence for posttranslational regulation. J Biol Chem 1990;265(8):4570-7.

37. Wang $\mathrm{H}$, Eckel $\mathrm{RH}$. Lipoprotein lipase: from gene to obesity. Am J Physiol Endocrinol Metab 2009;297(2):E271-88.

38. Galgani JE, Moro C, Ravussin E. Metabolic flexibility and insulin resistance. Am J Physiol Endocrinol Metab 2008;295(5):E1009-17.

39. Corpeleijn E, Saris WH, Blaak EE. Metabolic flexibility in the development of insulin resistance and type 2 diabetes: effects of lifestyle. Obes Rev 2009;10(2):178-93. 
40. Blaak EE, Van Baak MA, Kemerink GJ, Pakbiers MT, Heidendal GA, Saris WH. Beta-adrenergic stimulation of energy expenditure and forearm skeletal muscle metabolism in lean and obese men. Am J Physiol 1994;267(2 Pt 1):E306-15.

41. Colberg SR, Simoneau JA, Thaete FL, Kelley DE. Skeletal muscle utilization of free fatty acids in women with visceral obesity. J Clin Invest 1995;95(4):1846-53.

42. Blaak EE, van Aggel-Leijssen DP, Wagenmakers AJ, Saris WH, van Baak MA. Impaired oxidation of plasma-derived fatty acids in type 2 diabetic subjects during moderate-intensity exercise. Diabetes 2000;49(12):2102-7.

43. Goodpaster BH, Katsiaras A, Kelley DE. Enhanced fat oxidation through physical activity is associated with improvements in insulin sensitivity in obesity. Diabetes 2003;52(9):2191-7.

44. Blaak EE. Basic disturbances in skeletal muscle fatty acid metabolism in obesity and type 2 diabetes mellitus. Proc Nutr Soc 2004;63(2):323-30.

45. Phillips DI, Caddy S, Ilic V, Fielding BA, Frayn KN, Borthwick AC, et al. Intramuscular triglyceride and muscle insulin sensitivity: evidence for a relationship in nondiabetic subjects. Metabolism 1996;45(8):947-50.

46. Pan DA, Lillioja S, Kriketos AD, Milner MR, Baur LA, Bogardus C, et al. Skeletal muscle triglyceride levels are inversely related to insulin action. Diabetes 1997;46(6):983-8.

47. Krssak M, Falk Petersen K, Dresner A, DiPietro L, Vogel SM, Rothman DL, et al. Intramyocellular lipid concentrations are correlated with insulin sensitivity in humans: a $1 \mathrm{H}$ NMR spectroscopy study. Diabetologia 1999;42(1):113-6.

48. Watt MJ. Storing up trouble: does accumulation of intramyocellular triglyceride protect skeletal muscle from insulin resistance? Clin Exp Pharmacol Physiol 2009;36(1):5-11.

49. Anastasiou CA, Kavouras SA, Lentzas Y, Gova A, Sidossis LS, Melidonis A. Diabetes mellitus is associated with increased intramyocellular triglyceride, but not diglyceride, content in obese humans. Metabolism 2009;58(11):1636-42.

50. Montell E, Turini M, Marotta M, Roberts M, Noe V, Ciudad CJ, et al. DAG accumulation from saturated fatty acids desensitizes insulin stimulation of glucose uptake in muscle cells. Am J Physiol Endocrinol Metab 2001;280(2):E229-37.

51. Lee JS, Pinnamaneni SK, Eo SJ, Cho IH, Pyo JH, Kim CK, et al. Saturated, but not n-6 polyunsaturated, fatty acids induce insulin resistance: role of intramuscular accumulation of lipid metabolites. J Appl Physiol 2006;100(5):1467-74.

52. Gaster M, Rustan AC, Beck-Nielsen H. Differential utilization of saturated palmitate and unsaturated oleate: evidence from cultured myotubes. Diabetes 2005;54(3):648-56.

53. Jocken JW, Moro C, Goossens GH, Hansen D, Mairal A, Hesselink MK, et al. Skeletal muscle lipase content and activity in obesity and type 2 diabetes. J Clin Endocrinol Metab 2010;95(12):5449-53.

54. Coen PM, Dube JJ, Amati F, Stefanovic-Racic M, Ferrell RE, Toledo FG, et al. Insulin resistance is associated with higher intramyocellular triglycerides in type I but not type II myocytes concomitant with higher ceramide content. Diabetes 2010;59(1):80-8.

55. Itani SI, Ruderman NB, Schmieder F, Boden G. Lipid-induced insulin resistance in human muscle is associated with changes in diacylglycerol, protein kinase C, and IkappaB-alpha. Diabetes 2002;51(7):2005-11.

56. Schenk S, Horowitz JF. Acute exercise increases triglyceride synthesis in skeletal muscle and prevents fatty acid-induced insulin resistance. J Clin Invest 2007;117(6):1690-8.

57. Liu L, Zhang Y, Chen N, Shi X, Tsang B, Yu YH. Upregulation of myocellular DGAT1 augments triglyceride synthesis in skeletal muscle and protects against fat-induced insulin resistance. J Clin Invest 2007;117(6):1679-89.

58. Bergman BC, Perreault L, Hunerdosse DM, Koehler MC, Samek AM, Eckel RH. Intramuscular lipid metabolism in the insulin resistance of smoking. Diabetes 2009;58(10):2220-7.

59. Aude YW, Mego P, Mehta JL. Metabolic syndrome: dietary interventions. Curr Opin Cardiol 2004;19(5):473-9. 
60. Riccardi G, Giacco R, Rivellese AA. Dietary fat, insulin sensitivity and the metabolic syndrome. Clin Nutr 2004;23(4):447-56.

61. Corpeleijn E, Feskens EJ, Jansen EH, Mensink M, Saris WH, de Bruin TW, et al. Improvements in glucose tolerance and insulin sensitivity after lifestyle intervention are related to changes in serum fatty acid profile and desaturase activities: the SLIM study. Diabetologia 2006;49(10):2392-401.

62. Melanson EL, Astrup A, Donahoo WT. The relationship between dietary fat and fatty acid intake and body weight, diabetes, and the metabolic syndrome. Ann Nutr Metab 2009;55(1-3):229-43.

63. Tierney AC, McMonagle J, Shaw DI, Gulseth HL, Helal O, Saris WHM, et al. Effects of dietary fat modification on insulin sensitivity and other risk factors of the metabolic syndrome - LIPGENE: an European randomized dietary intervention study. Int J Obes (Lond) 2010:in press.

64. Petersson H, Riserus U, McMonagle J, Gulseth HL, Tierney AC, Morange S, et al. Effects of dietary fat modification on oxidative stress and inflammatory markers in the LIPGENE study. $\mathrm{Br} \mathrm{J}$ Nutr 2010;104(9):1357-62.

65. Jebb SA, Lovegrove JA, Griffin BA, Frost GS, Moore CS, Chatfield MD, et al. Effect of changing the amount and type of fat and carbohydrate on insulin sensitivity and cardiovascular risk: the RISCK (Reading, Imperial, Surrey, Cambridge, and Kings) trial. Am J Clin Nutr 2010;92(4):748-58.

66. Vessby B, Unsitupa M, Hermansen K, Riccardi G, Rivellese AA, Tapsell LC, et al. Substituting dietary saturated for monounsaturated fat impairs insulin sensitivity in healthy men and women: The KANWU Study. Diabetologia 2001;44(3):312-9.

67. Shaw DI, Tierney AC, McCarthy S, Upritchard J, Vermunt S, Gulseth HL, et al. LIPGENE foodexchange model for alteration of dietary fat quantity and quality in free-living participants from eight European countries. Br J Nutr 2008;101(5):750-9.

68. Rivellese AA, Maffettone A, Vessby B, Uusitupa M, Hermansen K, Berglund L, et al. Effects of dietary saturated, monounsaturated and n-3 fatty acids on fasting lipoproteins, LDL size and post-prandial lipid metabolism in healthy subjects. Atherosclerosis 2003;167(1):149-58.

69. Park Y, Harris WS. Omega-3 fatty acid supplementation accelerates chylomicron triglyceride clearance. J Lipid Res 2003;44(3):455-63.

70. Harris WS, Lu G, Rambjor GS, Walen Al, Ontko JA, Cheng Q, et al. Influence of n-3 fatty acid supplementation on the endogenous activities of plasma lipases. Am J Clin Nutr 1997;66(2):254-60.

71. Steinberg GR, Kemp BE, Watt MJ. Adipocyte triglyceride lipase expression in human obesity. Am J Physiol Endocrinol Metab 2007;293(4):E958-64.

72. Ray H, Pinteur C, Frering V, Beylot M, Large V. Depot-specific differences in perilipin and hormonesensitive lipase expression in lean and obese. Lipids Health Dis 2009;8(58.

73. Roberts R, Bickerton AS, Fielding BA, Blaak EE, Wagenmakers AJ, Chong MF, et al. Reduced oxidation of dietary fat after a short term high-carbohydrate diet. Am J Clin Nutr 2008;87(4):82431.

74. Buettner R, Scholmerich J, Bollheimer LC. High-fat diets: modeling the metabolic disorders of human obesity in rodents. Obesity (Silver Spring) 2007;15(4):798-808.

75. Hegarty BD, Cooney GJ, Kraegen EW, Furler SM. Increased efficiency of fatty acid uptake contributes to lipid accumulation in skeletal muscle of high fat-fed insulin-resistant rats. Diabetes 2002;51(5):1477-84.

76. Schrauwen-Hinderling VB, Kooi ME, Hesselink MK, Moonen-Kornips E, Schaart G, Mustard KJ, et al. Intramyocellular lipid content and molecular adaptations in response to a 1-week high-fat diet. Obes Res 2005;13(12):2088-94.

77. Twickler TB, Dallinga-Thie GM, Cohn JS, Chapman MJ. Elevated remnant-like particle cholesterol concentration: a characteristic feature of the atherogenic lipoprotein phenotype. Circulation 2004;109(16):1918-25.

78. Abbasi F, McLaughlin T, Lamendola C, Yeni-Komshian H, Tanaka A, Wang $T$, et al. Fasting remnant lipoprotein cholesterol and triglyceride concentrations are elevated in nondiabetic, insulinresistant, female volunteers. J Clin Endocrinol Metab 1999;84(11):3903-6. 
79. Watanabe N, Taniguchi T, Taketoh H, Kitagawa Y, Namura H, Yoneda N, et al. Elevated remnant-like lipoprotein particles in impaired glucose tolerance and type 2 diabetic patients. Diabetes Care 1999;22(1):152-6.

80. Chan DC, Watts GF, Barrett PH, Mamo JC, Redgrave TG. Markers of triglyceride-rich lipoprotein remnant metabolism in visceral obesity. Clin Chem 2002;48(2):278-83.

81. Williams KJ, Chen K. Recent insights into factors affecting remnant lipoprotein uptake. Curr Opin Lipidol 2010;21(3):218-28.

82. Abbasi F, McLaughlin T, Lamendola C, Kim HS, Tanaka A, Wang T, et al. High carbohydrate diets, triglyceride-rich lipoproteins, and coronary heart disease risk. Am J Cardiol 2000;85(1):45-8. 

Summary 
The metabolic syndrome (MetS) is a heterogeneous condition that is characterised by abdominal obesity, hyperglycaemia, insulin resistance, dyslipidaemia and hypertension, which markedly enhance the risk for the development of cardiovascular diseases and type 2 diabetes mellitus. Disturbances in fatty acid metabolism play an important role in the MetS. During conditions of chronic excessive energy intake (a high-fat, energy dense diet) and a sedentary lifestyle, the adipose tissue expands and its capacity to adequately store dietary lipids becomes limited. As a result, lipids 'flow over' into the circulation and non-adipose tissues such as skeletal muscle, liver, heart and pancreas are exposed to an excessive supply of triacylglycerol (TAG) and free fatty acids (FFA). Both the increased supply of lipids to skeletal muscle and intrinsic disturbances in skeletal muscle fatty acid metabolism may contribute to intramyocellular lipid accumulation and the development of insulin resistance in skeletal muscle. Dietary intervention, aimed at reducing the intake of saturated fat, may improve lipid metabolism and insulin action in the MetS. The research described in this thesis was mainly performed as part of the LIPGENE human dietary intervention study; a 12-week European multicentre study designed to investigate the effects of reducing dietary saturated fat by isoenergetic alteration of fat quantity and quality on insulin sensitivity and various risk factors of the MetS. The effects of the amount and/or type of dietary fatty acids on skeletal muscle and adipose tissue fatty acid metabolism was studied in detail in a subcohort of the LIPGENE study.

A total of 486 men and women with the MetS were included in the LIPGENE study and randomised to four isoenergetic dietary treatments: a control high-fat diet rich in saturated fat (HSFA), a high-fat diet rich in monounsaturated fat (HMUFA) and two low-fat high-complex carbohydrate diets (LFHCC), one supplemented with 1.24 g/d long-chain $n-3$ polyunsaturated fatty acids (LFHCCn-3). Contrary to our hypothesis, 12-week isoenergetic reduction of SFA intake had no effects on insulin sensitivity. Dyslipidaemia, however, was improved in men on the LFHCCn-3 diet as shown by reduced plasma TAG and FFA concentrations. Also, despite the isoenergetic design of the study, small but significant reductions in body weight were observed on both low-fat high-complex carbohydrate diets $(<1 \%)$. In chapter $\mathbf{2}$ we performed post hoc analysis to investigate potential interactions between subjects characteristics, lifestyle, metabolic profile, reduction of saturated fat consumption and insulin resistance. We showed that changes in body weight and fasting plasma TAG were inversely related to changes in insulin sensitivity. Furthermore, the effects of dietary intervention on insulin resistance (HOMA $\left.A_{I R}\right)$ depended on habitual fat intake and gender; insulin resistance decreased in women on the HMUFA diet with a habitual low-fat intake (<36.0 energy\%) and in women on the LFHCCn-3 diet with a habitual high-fat intake (> 36.0 energy\%). These results emphasise a role of background diet and gender, but further research is needed to explore the impact of these factors on the outcome of dietary interventions. 
The contribution of dietary fat (chylomicron-TAG) vs. endogenous fat (FFA and VLDL-TAG) to lipid overflow and in vivo skeletal muscle fatty acid metabolism in insulin resistant men was studied in chapter $\mathbf{3}$ by using a dual stable isotope palmitate tracer technique in combination with arteriovenous measurements across the forearm muscle. Despite similar circulating FFA and TAG concentrations, insulin resistance was associated with increased postprandial (VLDL)-TAG extraction across the forearm muscle. Intramyocellular TAG, diacylglycerol, FFA and phospholipid content, as well as their fractional synthetic rates, were not different between insulin resistant men and controls, whereas saturation of intramyocellular diacylglycerol was increased in the insulin resistant state. These data suggest that increased muscle (hepatically derived) TAG extraction during postprandial conditions and increased saturation of intramuscular DAG are associated with insulin resistance.

Additionally, using similar methodology, the effects of the LIPGENE dietary intervention on fasting and postprandial skeletal muscle fatty acid handling were investigated in a subcohort of men with the metabolic syndrome (chapter 4). We observed a reduced TAG response to a high-fat mixed meal after 12-week consumption of the LFHCCn-3 diet compared to the HSFA diet, which was (partly) explained by a reduction of dietary TAG in the circulation. In this study, however, the intervention had no marked effects on forearm muscle fatty acid metabolism, except for a decrease in fasting TAG clearance across forearm muscle after the HSFA diet. Thus, isoenergetic variation in dietary fat quality and quantity in this study was insufficient to affect forearm muscle fatty acid handling and whole body insulin sensitivity.

Impairments in the regulation of adipose tissue lipolysis may contribute to circulating FFA concentrations and lipid overflow into the circulation, and therefore we examined the impact of dietary intervention on the expression of the two major lipolytic enzymes, adipose triglyceride lipase (ATGL) and hormone-sensitive lipase (HSL), in subcutaneous adipose tissue during fasting (chapter 5). Both ATGL and HSL protein expression levels decreased on the LFHCC diets and increased on the highfat diets, without additional effects of dietary fat quality on these expression levels. Although changes in ATGL and HSL protein expression were positively associated with changes in the rate of appearance of FFA in the circulation $\left(R_{\mathrm{FFA}}\right)$, there were no differences in $\mathrm{Ra}_{\mathrm{FFA}}$ between the different dietary treatment groups.

Finally, determinants of fasting and postprandial remnant-like particle cholesterol concentrations in lean and obese subjects were described in chapter 6 as part of the European NUGENOB study. Remnant-like particles derive from TAG-rich lipoproteins (VLDL and chylomicrons) and especially their cholesterol content is considered to be highly atherogenic. Plasma concentrations of remnant-like particle cholesterol were related to body fat distribution and the degree of insulin resistance, both during fasting and postprandially after a high-fat load, but the strongest relationship was 
found with plasma TAG concentrations. Moreover, we showed that during a 10week weight loss programme, a high-fat diet was more effective in lowering fasting plasma remnant-like particle cholesterol concentrations in obesity than a low-fat diet given an identical weight loss.

To conclude, research described in this thesis showed that not lipid overflow per se but rather a slightly increased muscle TAG extraction and increased saturation of intramuscular DAG are associated with insulin resistance, suggesting that disturbances in skeletal muscle fatty acid handling could play a role in the development of whole body insulin resistance and type 2 diabetes mellitus. Furthermore, isoenergetic modulation of dietary fat quantity and quality was insufficient to affect whole body insulin sensitivity and forearm muscle fatty acid metabolism in men with the metabolic syndrome. Effects of the LFHCC diets on fasting TAG metabolism, in addition to the effects of the LFHCCn-3 diet on postprandial circulating TAG concentrations, however, indicate that an isoenergetic low-fat high-complex carbohydrate diet, supplemented with long-chain $n-3$ polyunsaturated fatty acids, may contribute to an improved TAG-related metabolic risk profile. 
Samenvatting 
Het metabool syndroom is een heterogene aandoening die wordt gekenmerkt door abdominale obesitas, hyperglycemie, insulineresistentie, een verstoorde vetstofwisseling en hypertensie. Deze metabole stoornissen verhogen samen het risico op de ontwikkeling van hart- en vaatziekten en type 2 diabetes mellitus. Verstoringen in het vetzuurmetabolisme spelen een belangrijke rol in het ontstaan van het metabool syndroom. Als gevolg van een vet- en energierijke voeding en een inactieve leefstijl neemt de vetmassa toe en wordt de capaciteit van het vetweefsel om voedingsvetten op te slaan beperkt. Dit resulteert in een stijging van circulerende vetten en een verhoogde blootstelling van andere weefsels en organen, zoals skeletspier, lever, hart en pancreas, aan vetten (triacylglycerol (TAG) en vrije vetzuren). Dit wordt ook wel 'lipiden overflow' genoemd. Zowel een verhoogd aanbod van vetten aan de skeletspier als intrinsieke verstoringen in (de regulering van) het vetzuurmetabolisme in de skeletspier kunnen bijdragen aan de accumulatie van vetten in de spier en de ontwikkeling van skeletspier insulineresistentie. Er wordt verondersteld dat een voedingsinterventie die zich richt op reductie van de inname van verzadigde vetten het vetzuurmetabolisme en de werking van insuline zou kunnen verbeteren. Het onderzoek dat wordt beschreven in dit proefschrift maakt hoofdzakelijk deel uit van de LIPGENE humane voedingsinterventie studie, een onderdeel van het Europese LIPGENE project; een 12-weken durende studie die is uitgevoerd in meerdere onderzoekscentra in Europa om de gevolgen van een verlaging van de inname van verzadigde en de totale hoeveelheid vetten op insulinegevoeligheid en verschillende risicofactoren van het metabool syndroom te onderzoeken. In een subgroep van de LIPGENE studie werd het vetzuurmetabolisme bij mensen met het metabool syndroom nader onderzocht door het gedetailleerd bestuderen van het vetzuurmetabolisme in de skeletspier en het vetweefsel met behulp van stabiele isotopen tracers van vetzuren.

In totaal werden er 486 mannen en vrouwen met het metabool syndroom geïncludeerd in de LIPGENE studie en gerandomiseerd naar vier iso-energetische diëten: een controle voeding met een hoog vetgehalte, rijk in verzadigde vetten (HSFA); een voeding met een hoog vetgehalte, rijk in enkelvoudig onverzadigde vetten (HMUFA); een voeding met een laag vetgehalte en een hoog gehalte aan complexe koolhydraten (LFHCC); en een voeding met een laag vetgehalte en een hoog gehalte aan complexe koolhydraten, aangevuld met een supplement van langketenige $n-3$ meervoudig onverzadigde vetzuren (1.24 g/dag) (LFHCCn-3). In tegenstelling tot onze hypothese resulteerde de iso-energetische reductie van de inname van verzadigd vet gedurende 12 weken niet in verbeteringen van de insulinegevoeligheid. Er werd echter wel een daling in de concentraties van lipiden (zowel TAG als vrije vetzuren) in de circulatie gemeten bij mannen op het LFHCCn-3 dieet. Bovendien werden er, ondanks de iso-energetische opzet van de studie, kleine maar significante dalingen in lichaamsgewicht gemeten $(<1 \%)$ bij personen op de LFHCC diëten. In hoofdstuk 2 voerden we post hoc analyses uit om de 
potentiële interacties tussen proefpersoon karakteristieken, leefstijl, metabool profiel, reductie in de inname van verzadigde vetten en insulineresistentie te onderzoeken. Hiermee toonden we aan dat veranderingen in lichaamsgewicht en concentraties van TAG (vetten) in de circulatie tijdens het vasten negatief gerelateerd zijn aan veranderingen van de insulinegevoeligheid. Daarnaast toonden we aan dat de effecten van de verschillende diëten op insulineresistentie ( $\mathrm{HOMA}_{\mathrm{R}}$ ) afhankelijk waren van de gebruikelijke vetconsumptie bij aanvang van de studie en van sekse; een afname van insulineresistentie werd enkel waargenomen bij vrouwen op het HMUFA dieet die normaal een lage vetinname hebben $\quad<36.0$ energie\%) en bij vrouwen op het LFHCCn-3 dieet die normaal een hoge vetinname hebben (> 36.0 energie\%). Deze resultaten benadrukken het belang van het gebruikelijke voedingspatroon en sekse in dit type onderzoek, maar er zijn meer studies nodig om de invloed van deze factoren op de uitkomst van voedingsinterventies te onderzoeken.

In hoofdstuk 3 onderzochten we de afzonderlijke bijdrage van vetten afkomstig van de voeding (chylomicronen) en vetten reeds aanwezig in het lichaam (endogene vetten; vrije vetzuren en vetten in de vorm van VLDL deeltjes) aan 'lipiden overflow' en de vetopname en opslag in de skeletspier in vivo bij mannen met insulineresistentie. Hiertoe gebruikten we twee verschillende stabiele isotopen van het vetzuur palmitaat, in combinatie met metingen van arterieel-veneuze concentratieverschillen over de onderarmspier. Insulineresistentie was geassocieerd met een verhoogde extractie van (VLDL)-TAG over de skeletspier bij insulineresistentie mannen in vergelijking met een controle groep, ondanks gelijke TAG concentraties in de circulatie. De absolute hoeveelheid en de incorporatie van voedingsvetten in lipidenfracties van de spier (TAG, diacylglycerol, vrije vetzuren en fosfolipiden) was niet verschillend tussen insulineresistentie mannen en de controle groep. Wel toonden we aan dat de spier diacylglycerolfractie van insulineresistente mannen een hoger gehalte aan verzadigde vetzuren bevatte. Deze data suggereren dat verhoogde extractie van (VLDL)-TAG over de skeletspier na een maaltijd en een verhoogde verzadiging van de spier diacylglycerolfractie geassocieerd zijn met insulineresistentie.

Met behulp van dezelfde methodologie bestudeerden we in hoofdstuk 4 de effecten van de LIPGENE humane voedingsinterventie op de vetstofwisseling van de skeletspier tijdens het vasten en na een maaltijd in een subgroep van mannen met het metabool syndroom. De TAG response na een vetrijke, gemengde maaltijd was verlaagd na 12 weken interventie met het LFHCCn-3 dieet ten opzichte van het controle HSFA dieet, en deze bevinding was (deels) toe te schrijven aan een verlaging van voedingsvetten in de circulatie op het LFHCCn-3 dieet. De voedingsinterventie in deze studie had echter geen wezenlijke effecten op het vetzuurmetabolisme in de onderarmspier; er werd alleen een verlaagde klaring van TAG over de onderarmspier geobserveerd bij personen op het controle HSFA dieet. 
Op basis van deze resultaten kan geconcludeerd worden dat de iso-energetische variatie in de hoeveelheid en kwaliteit van voedingsvetten in deze studie ontoereikend was om de vetstofwisseling van de skeletspier en de insulinegevoeligheid van het hele lichaam te beïnvloeden.

Verstoringen in de regulering van de afbraak van vetten (lipolyse) in het vetweefsel kunnen bijdragen aan een verhoogde concentratie van vrije vetzuren en 'lipiden overflow' in de circulatie. Daarom onderzochten we in hoofdstuk $\mathbf{5}$ de invloed van de voedingsinterventie op de expressie van twee belangrijke lipolytische enzymen, 'adipose triglyceride lipase' (ATGL) en hormoon-gevoelig lipase (HSL), in het subcutaan (onderhuids) vetweefsel na een nacht vasten. De eiwitexpressie van zowel ATGL als HSL was verlaagd bij personen op de LFHCC diëten en verhoogd bij personen op de diëten met het hoge vetgehalte, waarbij de kwaliteit van de vetten geen additioneel effect op de expressieniveaus had. Hoewel deze veranderingen in de eiwitexpressie van ATGL en HSL positief geassocieerd waren met veranderingen in de snelheid waarmee vrije vetzuren in de circulatie verschijnen $\left(R_{\mathrm{FFA}}\right)$, observeerden we uiteindelijk geen verschillen in de $\mathrm{Ra}_{\mathrm{FFA}}$ tussen de verschillende dieetinterventiegroepen.

Tenslotte onderzochten we in het kader van de Europese NUGENOB studie, waar gekeken werd naar de effecten van een energiebeperkt dieet met een hoog of laag vetgehalte, welke factoren van invloed zijn op concentraties van 'remnant-like particle cholesterol' (RLP-C) in de circulatie van slanke en obese personen (hoofdstuk 6). Remnant-like particles zijn de overblijfselen van TAG-rijke deeltjes (VLDL en chylomicronen) in de circulatie en er wordt verondersteld dat met name het cholesterolgehalte van deze deeltjes sterk atherogeen is. We toonden met dit onderzoek aan dat plasma concentraties van RLP-C, zowel tijdens het vasten als na een vetrijke maaltijd ( 95 energie\% vet), geassocieerd zijn met lichaamsvetverdeling en de mate van insulineresistentie, maar de meest sterke associatie werd gevonden met plasma TAG concentraties. Tijdens het gewichtsverlies programma van 10 weken in de NUGENOB studie toonden we bovendien aan dat, bij gelijk gewichtsverlies, een dieet met een hoog vetgehalte gunstigere (verlagende) effecten op plasma RLP-C concentraties tijdens het vasten heeft dan een dieet met een laag vetgehalte.

Op basis van de resultaten van het onderzoek beschreven in dit proefschrift kan geconcludeerd worden dat niet 'lipiden overflow' op zich, maar veeleer een kleine toename in de extractie van TAG over de spier en een verhoogde saturatie van de spier diacylglycerolfractie geassocieerd zijn met insulineresistentie. Dit suggereert dat verstoringen in de vetstofwisseling van de skeletspier een rol kunnen spelen bij de ontwikkeling van insulineresistentie en type 2 diabetes mellitus. Ook toonden we aan dat de iso-energetische verandering van de vetkwaliteit en -kwantiteit van de voeding in deze studie ontoereikend was om insulinegevoeligheid en het 
vetzuurmetabolisme in de onderarmspier van mannen met het metabool syndroom te beïnvloeden. De effecten van de LFHCC diëten op het TAG metabolisme tijdens het vasten en de additionele effecten van het LFHCCn-3 dieet op de TAG response na een maaltijd duiden echter aan dat een iso-energetisch dieet met een laag vetgehalte en een hoog gehalte aan complexe koolhydraten, aangevuld met een supplement van langketenige $n-3$ meervoudig onverzadigde vetzuren, kan bijdragen aan een verbetering van een TAG-gerelateerd metabool risicoprofiel. 

Dankwoord 
Zo.... eindelijk toe aan het dankwoord, wat een heerlijk gevoel na al die jaren! Ja, het heeft even geduurd, maar zoals ik in één van mijn stellingen aangeef: 'It does not matter how slowly you go so long as you do not stop'. Dat is precies wat ik heb gedaan en uiteindelijk is het (sociaal) gewenste resultaat daar. Zoals ieder promotietraject was ook die van mij er één van pieken en dalen. Om in volleybaltermen te spreken: een spannende vijfsetter met matchpoints over en weer, waarbij ik niet altijd op mijn eigen positie kon staan en de verdediging nu eens niet de stabiele factor, maar juist het beoogde eindpunt was. Ik weet dat het niet altijd even leuk was om naar te kijken, maar uiteindelijk heb ik er zelf heel veel van geleerd. $\mathrm{Nu}$ is het eindelijk tijd om iedereen te bedanken die een bijdrage heeft geleverd aan de totstandkoming van dit proefschrift.

Beste Ellen, tijdens mijn afstudeerstage heb ik een goed beeld gekregen van het onderzoek bij Humane Biologie en toen je me een aioplaats aanbood in jouw groep kon en wilde ik dat natuurlijk niet weigeren. Ik wil je graag bedanken voor het vertrouwen dat je me hiermee hebt gegeven. Onze gesprekken gaven me altijd weer energie en motivatie om verder te gaan, zowel in de uitvoerende als schrijvende fase van het onderzoek. Daarnaast kijk ik ook met plezier terug op de LIPGENE uitstapjes die we vaak samen hebben gemaakt; van de luxe treinrit door het zuiden van Spanje en de toeristische fietstaxi in Krakow, tot een biertje op een terras in Athene. Beste Wim, jij was op de juiste manier op de achtergrond aanwezig en dat heb ik als zeer prettig ervaren. Net even dat schouderklopje of een duw in de goede richting, bedankt daarvoor!

I would like to thank the members of the dissertation committee, Patrick Schrauwen, Bas Havekes, Martine Laville, Marco Mensink and Ger van der Vusse, for their time and effort to critically evaluate this thesis.

I would also like to thank Mike Gibney for initiating and coordinating the LIPGENE project and Helen Roche for coordinating the human dietary intervention study. The project gave me a great opportunity to work in an international community and the human dietary intervention study was the perfect base for performing the stable isotope substudy in Maastricht.

Wie ik nooit zal vergeten, zijn de meest belangrijke personen die hebben bijgedragen aan de totstandkoming van dit proefschrift: 'mijn proefpersonen'. Drie maanden lang je eetpatroon aanpassen en meerdere lange meetdagen vol bloedafnames en biopten ondergaan valt zeker niet mee en ik heb daar altijd veel bewondering voor gehad. Niet alleen bedankt voor jullie waardevolle bijdrage aan de wetenschap, maar ook voor de vaak gezellige testdagen en Limburgse (levens)lessen! 
Vele handen maken licht werk:

Gabby, dankzij jou kwam ik in een gespreid LIPGENE bedje terecht en kon ik me direct in het onderzoek storten. Jouw hulp, vooral in het eerste jaar van het onderzoek, was onmisbaar en daar ben ik je erg dankbaar voor. Dat ik af en toe je duim bijna brak tijdens het afdrukken van een arterie doet daar hopelijk geen afbreuk aan...

Marja, Tanja en Dorien, bedankt voor de geweldige begeleiding van de proefpersonen tijdens de dieetperiode, het beheren van alle studieproducten, het bereiden van de shakes en maaltijden, het berekenen van de dagboekjes en nog veel meer. Dankzij jullie had ik geen omkijken naar dit deel van het onderzoek! Renate, Nicole, Petra en Amanda, hartelijk dank voor jullie enorme inzet en hulp bij de lange testdagen! Zonder jullie was ik nu waarschijnlijk nog steeds bezig met het schrijven van cupjes, vullen van spuiten, bloedafnames, pipetteren, meten van de hematocriet, etc etc. Mannen van de spierbiopten (Martijn, Marco, Luc, Sander en Wim) bedankt voor de vele spierbiopten die jullie voor de studie hebben afgenomen. Misschien niet altijd gewaardeerd door de proefpersonen, maar zeker wel door mij. Ook de mensen van anesthesie wil ik bedanken voor het plaatsen van de arteriële lijnen. Wat was ik toch altijd opgelucht als ik een witte jas de gang op zag komen lopen...

$\mathrm{Na} 2$ jaren vol testdagen was het praktische werk nog lang niet gedaan en dan is het erg prettig als er een sterk team op het lab voor je klaar staat. Jos, Wendy, Renate, Hasibe en Annemie, bedankt voor het opwerken en analyseren van de duizenden plasmasamples en spierbiopten. Yvonne, ik vond het fijn om met je samen te werken. Dank voor het analyseren van alle vetbiopten en de gezellige uren op het lab! Samen hebben we heel wat blotjes gesleten...

Ik was vrij honkvast bij HB; na een half jaar verblijf op de stagiairekamer achter in de gang promoveerde ik van 'stagiaire van' tot 'collega van' Johan en Gijs en kwam ik bij jullie op de kamer terecht. Ideaal gezelschap gezien jullie ervaring met alle metingen die ik nog voor de boeg had, jullie inhoudelijke kennis, maar vooral ook jullie Belgische en Brabantse gezelligheid! Dankzij jullie voelde ik me prima op m'n plek in kamer 2.332! Ook de goede samenwerking en sfeer binnen het vetstofteam heb ik enorm gewaardeerd. Dank daarvoor aan Chantalle, Gijs, Johan, Anneke, Ellen K., Judith, Yvonne, Eefje, Cheryl, Annemieke, Marleen, Ellen B., Janneke, Nicole en Hanneke. Daarnaast wil ik Chantalle, Gijs en Anneke in het bijzonder bedanken voor de interesse die jullie ook na m'n tijd bij HB hebben getoond, dat maakt het altijd leuk en fijn om af en toe weer eens terug te keren in Maastricht! Judith bedankt voor de ideale hotelkamergenoot die je was tijdens congressen! Natuurlijk wil ik verder ook alle andere collega's van $\mathrm{HB}$, inclusief de dames van het secretariaat, hartelijk bedanken voor de prettige samenwerking. 
Het is ondertussen alweer 2,5 jaar geleden dat ik voor het eerst bij Danone Research op de stoep stond. Hoewel het de afronding van mijn proefschrift niet echt heeft bevorderd, heb ik er geen moment spijt van gehad dat ik op dat moment de stap naar Wageningen heb gezet. Leden van het 'oude' DTN team (met name Marloes, Wessel, Roel, Barbara, Ardy, Berdine, Niki, Judith, Mirian en Johan) en alle collega's van het CS platform wil ik graag bedanken voor de open ontvangst en fijne werksfeer. Jullie belangstelling en positieve stimulans heb ik erg op prijs gesteld! Ardy en Barbara, bedankt voor de ruimte die jullie me vorig jaar hebben gegeven om dat boekje nu eindelijk eens af te ronden...

De keuze van mijn paranimfen was snel gemaakt. Chantalle, ik kende je natuurlijk al wel een beetje van de studie maar als kamergenoot heb ik je pas echt beter leren kennen. Je bracht lekker veel drukte, chaos en vrolijkheid met je mee, en niet te vergeten veel chocolade, andere zoetigheid en stapels borden... Heerlijk hoe je me altijd weer wist te motiveren als je 's ochtends al 'zingend' binnen kwam: 'En... ik heb toch zo geen...'. Bedankt voor alle leuke gesprekken over van alles en nog wat en je steun tijdens m'n laatste officiële maanden als aio, ik ben blij dat je vandaag als paranimf achter me staat! Ondanks de afschuwelijke klap die je vorig jaar hebt moeten incasseren, blijf je positief en vol doorzettingsvermogen. Ik twijfel er dan ook niet aan dat je me snel gaat volgen!

Lieve Miesje en Joyce, ik ben ontzettend blij met jullie als vriendinnen en ben er trots op dat Mies vandaag als paranimf achter me staat. De laatste jaren is er veel gebeurd en de sterke manier waarop jullie daarmee omgaan heeft me geholpen om mijn eigen leventje af en toe goed te kunnen relativeren. Jullie oprechte aandacht en interesse doen me altijd erg goed en hebben me zeker ook geholpen om de moed erin te houden tijdens de afronding van m'n proefschrift. Dat we nog maar vele dingen samen mee mogen maken!

Al nam ik er niet altijd tijd genoeg voor en ging het niet altijd gepaard zonder schuldgevoel, zonder de nodige ontspanning zou ik het niet volgehouden hebben de laatste jaren. Gelukkig heb ik fijne vrienden om me heen die daarvoor zorgden! Danny, Charlotte, Bart, Yvon, Erwin, Marjolein, bedankt voor de gezellige weekendjes, festivals, Koninginnedagen, beachvolleybaltripjes, stedentripjes, etc. En ja Danny, mijn 'obesithesis' is nu eindelijk af!! De Tukkers (Maarten, Sander, Robbert) in het bijzonder bedankt voor de ontzettend gezellige carnavalsdagen in Mestreech en Kuuk die me altijd enorm veel ontspanning en nieuwe energie geven. En dan natuurlijk niet te vergeten alle (andere) volleybalvriendinnetjes en vrienden, met name van Fyrfad; bedankt voor de vele fijne trainingen, wedstrijden, avondjes aan de bar en leuke uitjes, die een belangrijke uitlaatklep voor me waren en waar ik met héél veel plezier op terug kijk. Tannie, stiekem heb je veel voor me betekend, vooral toen ik in Wageningen woonde en je me trouw iedere week weer belde. 
Lieve familie, bedankt voor jullie begrip en geduld de laatste jaren. Pap, ik ben er trots op dat we nu collega's zijn. Wie had nou gedacht dat ik het ooit van vakantiekracht/fabrieksmedewerkster tot scientist bij Nutricia zou schoppen! Liefste zussie, ik kan me geen betere zus bedenken dan jij. Samen kunnen we de hele wereld aan!! Mamsie, je probeert me vaak bezorgd in te laten zien dat ik toch vooral moet genieten van het leven en ik zal je beloven dat ik dat vanaf nu nog veel meer zal gaan doen! Ook de Eijgelaars bedankt voor alle goede zorgen en interesse, fijn om zo'n warme schoonfamilie te hebben. Voor de omslag heb ik me laten inspireren door de keramiek van Tineke, bedankt!

M'n lieve Wouter, ik zou niet weten hoe ik zonder jou deze klus had moeten klaren. Heerlijk om altijd maar weer terug te kunnen vallen op zo'n stabiele, rustige, relativerende, begripvolle, maar vooral ook hele lieve vent! Twee uit zeven, 't was niet echt een leven, maar wel dat van ons, en we zijn er samen alleen maar sterker van geworden. Op naar de volgende uitdaging! Mwah! 

List of publications 


\section{FULL PAPERS}

Van Hees AMJ, Saris WHM, Dallinga-Thie GM, Hul GB, Martinez JA, Oppert JM, Stich V, Astrup A, Arner A, Sørensen TIA, Blaak EE. Fasting and postprandial remnant-like particle cholesterol concentrations in obese participants are associated with plasma triglycerides, insulin resistance, and body fat distribution. J Nutr 2008;138(12):2399405.

Jocken JWE, Goossens GH, van Hees AMJ, Frayn KN, van Baak M, Stegen J, Pakbiers MT, Saris WHM, Blaak EE. Effect of beta-adrenergic stimulation on whole-body and abdominal subcutaneous adipose tissue lipolysis in lean and obese men. Diabetologia 2008;51(2):320-7.

Van Hees AMJ, Saris WHM, Hul GB, Schaper NC, Timmermans BE, Lovegrove JA, Roche HM, Blaak EE, for the LIPGENE Consortium. Effects of dietary fat modification on skeletal muscle fatty acid handling in the metabolic syndrome. Int J Obes (Lond) 2010;34(5):859-70.

Gulseth HL, Gjelstad IM, Tierney AC, Shaw DI, Helal O, van Hees AMJ, Delgado-Lista J, Leszczynska-Golabek I, Karlström B, Lovegrove J, Defoort C, Blaak EE, LopezMiranda J, Dembinska-Kiec A, Risérus U, Roche HM, Birkeland KI, Drevon CA. Dietary fat modifications and blood pressure in subjects with the metabolic syndrome in the LIPGENE dietary intervention study. Br J Nutr 2010;104(2):160-3.

Van Hees AMJ, Jans A, Hul GB, Roche HM, Saris WHM, Blaak EE. Skeletal muscle fatty acid metabolism in insulin resistant men. Obesity 2011;19(7):1350-9.

Jans A, Sparks LM, van Hees AMJ, Gjelstad IMF, Tierney AC, Risérus U, Drevon CA, Roche HM, Schrauwen P, Blaak EE. Transcriptional metabolic inflexibility in skeletal muscle among individuals with increasing insulin resistance. Obesity 2011; in press.

Van Hees AMJ, Jocken JWE, Essers Y, Roche HM, Saris WHM, Blaak EE. Adipose triglyceride lipase and hormone-sensitive lipase protein expression in subcutaneous adipose tissue are decreased after an isoenergetic low-fat high-complex carbohydrate diet in the metabolic syndrome. Submitted.

Van Hees AMJ, Tierney AC, Shaw DI, Gulseth HL, Paniagua JA, McMonagle J, KiećWilk B, Risérus U, Defoort C, López-Miranda J, Dembińska-Kieć A, Karlström B, Saris WHM, Drevon CA, Roche HM, Lovegrove JA, Blaak EE. Determinants of diet-induced changes in insulin sensitivity among subjects with the metabolic syndrome: the Lipgene study. Submitted. 
Jans A, van Hees AMJ, Gjelstad IMF, Sparks LM, Tierney AC, Risérus U, Drevon CA, Schrauwen $\mathrm{P}$, Roche HM, Blaak EE. Impact of dietary fat quantity and quality on skeletal muscle fatty acid metabolism in subjects with the metabolic syndrome. Submitted.

\section{ABSTRACTS}

Van Hees AMJ, Saris WHM, Hul GB, Blaak EE, and the NUGENOB Consortium. Determinants of remnant like particle metabolism in obesity. Int J Obes (Lond) 2007;31(S1):S148.

Jocken JWE, Goossens GH, van Hees AMJ, Frayn KN, Van Baak M, Pakbiers M, Saris WHM, Blaak EE. Effect of beta-adrenergic stimulation on whole-body and regional abdominal subcutaneous adipose tissue lipolysis in lean and obese men. Diabetologia 2007;50(S1):S86.

Van Hees AMJ, Lovegrove J, Devron CA, Lairon D, López-Miranda J, Dembinska-Kie A, Vessby B, Williams CM, Roche HM, Gibney MJ, Saris WHM, Blaak EE, and the LIPGENE Consortium. Determinants of diet induced changes in insulin sensitivity in subjects with the metabolic syndrome: The Lipgene study. Int J Obes (Lond) 2008;32(S1):S27.

Gulseth HL, Gjelstad IMF, McMonagle J, Tierney A, Shaw D, Defoort C, van Hees AMJ, Marin C, Partyka L, Riserus U, Lovegrove J, Lairon D, Blaak E, Miranda JL, Dembinska-Kiec A, Karlstrom B, Roche HM, Birkeland KI, Drevon CA. The LIPGENE dietary intervention study affects pulse pressure in males. Effects of dietary saturated, monounsaturated and n-3 polyunsaturated fatty acids on blood pressure in subjects with metabolic syndrome. J Hypertens 2008;26(S1):S18.

Van Hees AMJ, Saris WHM, Hul GB, Schaper NC, Timmerman BE, Roche HM, Blaak $E E$, for the LIPGENE Consortium. Effect of dietary fat modification on skeletal muscle fatty acid handling in the metabolic syndrome; a stable isotope approach. Obesity Facts 2009;2(S2);16.

Jans A, van Hees AMJ, Gjelstad IMF, Tierney AC, Riserus U, Drevon CA, Roche HM, Blaak EE. Effect of different dietary fat quantity and quality on skeletal muscle fatty acid handling in subjects with the metabolic syndrome. Diabetologia 2010;53(S1):S103. 

Curriculum Vitae 
Anneke van Hees was born on 6 October 1981 in Boxmeer, the Netherlands, and was raised in Beers. In 2000 she completed secondary school at the Merlet College Land van Cuijk. In the same year, she started her study Health Sciences with specialisation in Biological Health Sciences at the Maastricht University. For her master thesis she performed a 6-month internship at the Department of Human Biology (NUTRIM), Maastricht University, in which she studied the effects of $\beta$ adrenergic stimulation on skeletal muscle and adipose tissue metabolism in obesity. She graduated in 2004.

In December 2004 she started her PhD at the Department of Human Biology (NUTRIM), Maastricht University, under supervision of Prof. dr. Ellen Blaak and Prof. dr. Wim Saris. Her research, described in this thesis, was mainly performed as part of the LIPGENE human dietary intervention study within the European Union $6^{\text {th }}$ Framework Project 'LIPGENE: Interaction of nutrients and genotype in the metabolic syndrome'. In June 2009 she started working as a scientist within the Disease Targeted Nutrition team at Danone Research / Nutricia Advanced Medical Nutrition in Wageningen, the Netherlands. 